\title{
Use of physiologically based kinetic modelling facilitated read-across in risk assessment of botanical food-borne alkenylbenzenes
}

Amer Al-Malahmeh 


\section{Thesis committee}

\section{Promotor}

Prof. Dr I.M.C.M. Rietjens

Professor of Toxicology

Wageningen University \& Research

\section{Co-promotors}

Dr J.J.M. Vervoort

Associate professor, Biochemistry

Wageningen University \& Research

Dr S. Wesseling

Research assistant, Sub-department of Toxicology

Wageningen University \& Research

\section{Other members}

Dr A.A.C.M. Peijnenburg, Wageningen University \& Research

Prof. Dr R.F. Witkamp, Wageningen University \& Research

Dr G. Prinsloo, University of South Africa, Johannesburg, Republic of South Africa

Dr M.J. Martena, Ministry of VWS, The Hague

This research was conducted under the auspices of the Graduate School VLAG (Advanced studies in Food Technology, Agrobiotechnology, Nutrition and Health Sciences). 


\title{
Use of physiologically based kinetic modelling facilitated read-across in risk assessment of botanical food-borne alkenylbenzenes
}

\author{
Amer Al-Malahmeh
}

Thesis

submitted in fulfillment of the requirements for the degree of doctor

at Wageningen University

by the authority of the Rector Magnificus,

Prof. Dr A.P.J. Mol,

in the presence of the

Thesis Committee appointed by the Academic Board

to be defended in public

on Tuesday 5 September 2017

at 4 p.m. in the Aula. 
Amer Al-Malahmeh

Use of physiologically based kinetic modelling facilitated read-across in risk assessment of botanical food-borne alkenylbenzenes, 246 pages.

$\mathrm{PhD}$ thesis, Wageningen University, Wageningen, the Netherlands (2017) With references, with summary in English

ISBN: 978-94-6343-459-1

DOI: $10.18174 / 416932$ 


\section{TABLE OF CONTENTS}

1

Physiologically based kinetic modeling of the bioactivation of myristicin

Mode of action based risk assessment of the botanical food-borne

alkenylbenzene apiol from parsley using physiologically based kinetic (PBK) modelling and read-across from safrole

Determination and risk assessment of naturally occurring genotoxic and carcinogenic alkenylbenzenes in basil-containing sauce of pesto Determination and risk assessment of naturally occurring genotoxic and carcinogenic alkenylbenzenes in nutmeg-based plant food supplements 


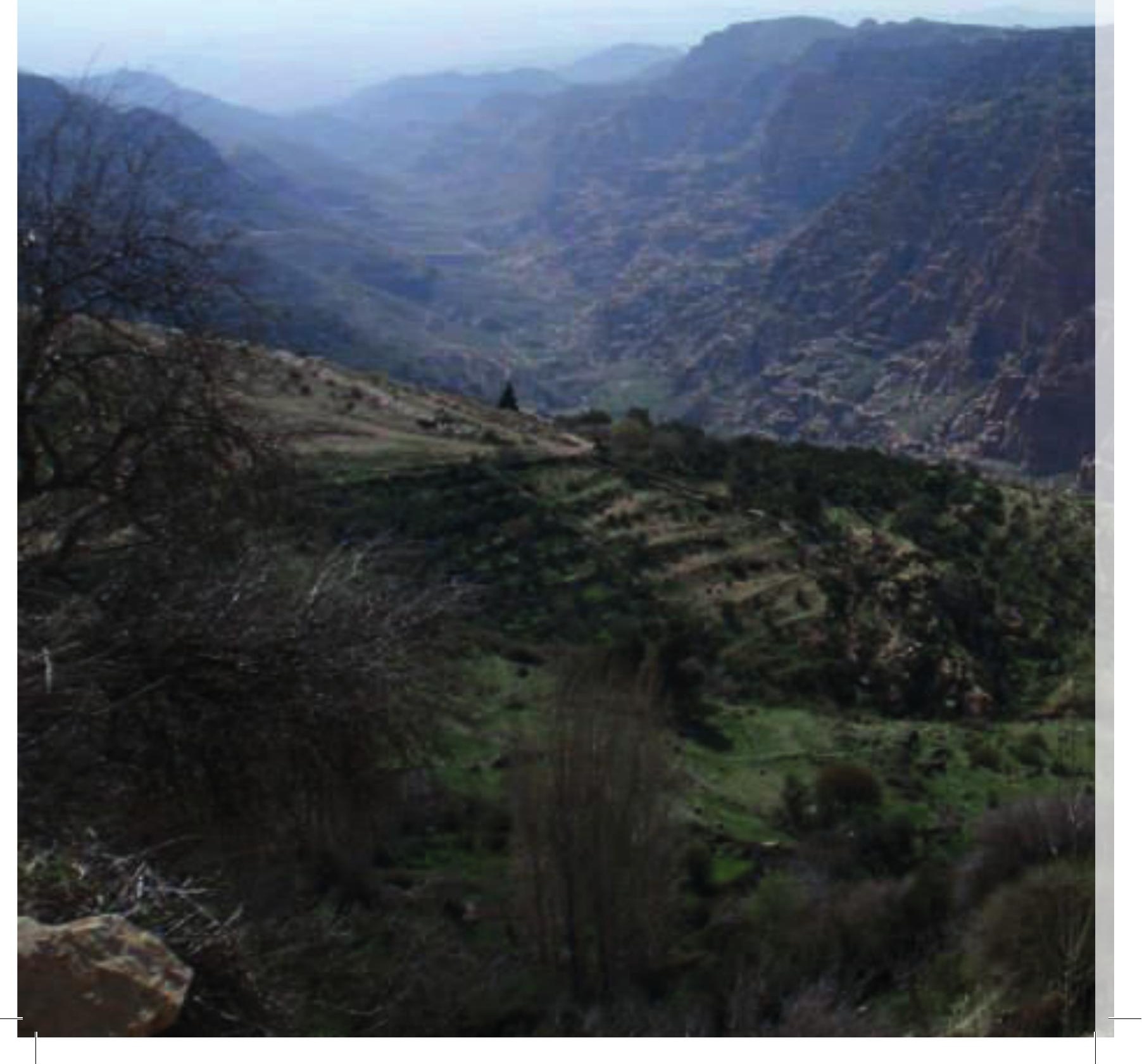




\section{Chapter 1}

General introduction 


\section{Description and aim of the thesis}

Botanicals and botanical preparations have become widely available in the form of food supplements and other food preparations. In Europe the safety of botanicals and their derived food products has to comply with the general requirements set out in regulation (EC) No 178/2002. Risk assessment procedures which consist of hazard identification, hazard characterization, exposure assessment, and risk characterization, evaluating the consequences of exposure to different classes of chemicals in food (e.g. additives, contaminants, pesticide residues, veterinary drug residues and natural toxicants) have been harmonized (Barlow et al. 2006; EFSA 2009a; WHO 2015). So far these regulatory procedures did not focus on botanicals and botanical preparations. In 2009 the European Food Safety Authority (EFSA) published a toolkit to help assess the safety of botanicals and derived preparations. A compendium of botanicals that have been reported to contain substances that may be of health concern when used in food or food supplements was part of that tool (EFSA 2012a). Also guidelines for risk assessment of botanicals and botanical preparations were provided (EFSA 2009a) indicating that a risk assessment should include the definition of the botanical species including the plant and preparation(s) of interest, environmental conditions of growing, part(s) of the botanical used, the manufacturing processes used for making the botanical preparation, evaluation of the compositional, toxicological and exposure data, definition of the biologically active substances and their levels, and the history of use. In spite of these guidelines, at the present state-of-the-art the safety and risks of botanicals and botanical preparations are generally not assessed before they enter the market.

An important aim of the present thesis was to perform risk assessment of selected botanicals and their derived preparations focusing especially on samples likely to contain alkenylbenzenes, 
including myristicin, apiol, safrole, methyleugenol, elemicin, and estragole (Figure 1), to give a better understanding of when risk management actions would be needed for botanicals and derived preparations containing these ingredients. Samples containing alkenylbenzenes may be of concern because these compounds may be genotoxic and carcinogenic displaying similar characteristics regarding mode of action (MOA) and tumor formation (Phillips et al. 1981; Miller et al. 1983; Randerath et al. 1984; Wiseman et al. 1985; NTP 2000; Zhou et al. 2007; Kobets et al. 2016). In the present thesis a MOA based risk assessment of especially two of the alkenylbenzenes, myristicin and apiol, for which tumor data are not available, was performed. This was done using physiologically based kinetic (PBK) modelling and read-across from safrole and the margin of exposure (MOE) approach. Botanical preparations included in the risk assessments performed in the present thesis were basil-containing pesto and nutmeg-based plant food supplements (PFS). Given that several of the preparations analyzed contained several alkenylbenzenes a risk assessment of combined exposure to these alkenylbenzenes was included as well.

\section{Physicochemical properties of the structurally related alkenylbenzenes}

The alkenylbenzenes of interest are allylbenzenes with alkoxy substitution at the para position. The alkenylbenzenes safrole (3,4-methylenedioxyallylbenzene), myristicin (5-methoxy-3,4methylenedioxyallylbenzene) and apiole (2,5-dimethoxy-3,4-methylenedioxyallylbenzene) have a 3,4-methylenedioxy substituent (Figure 1). The other compounds, estragole (4methoxyallylbenzene), methyleugenol (3,4-dimethoxyallylbenzene) and elemicin (3,4,5trimethoxyallylbenzene) do not contain a 3,4-methylenedioxy substituent (Figure 1). All molecules, except safrole, contain one or more methoxy groups. 
The aforementioned alkenylbenzenes are colorless or slightly yellow oily liquids, with the characteristic odor of the plants from which they can be extracted. They are practically insoluble in water with a maximum solubility of $500 \mathrm{mg} / \mathrm{l}$, and have octanol/water partition coefficients ( $\log \mathrm{K}_{\mathrm{ow}}$ values) ranging from 3.0 to 3.5 . They are miscible with most organic solvents, and generally denser than water (EPA 1986b). Because these alkenylbenzenes are structurally related, they may share similar metabolism, MOA and biological effects (JECFA 2009; van den Berg et al. 2012). This similarity provides the basis for the MOA based read-across and risk assessments of the present thesis.

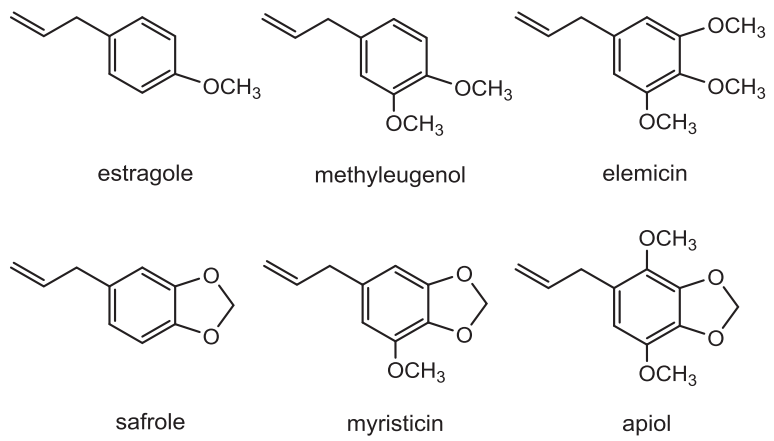

Figure 1. The structural formulas of the alkenylbenzenes estragole, methyleugenol, elemicin, safrole, myristicin and apiol.

\section{Natural occurrence and estimated daily intake (EDI) of alkenylbenzenes from different sources}

The alkenylbenzenes are naturally occurring in a variety of botanicals including anise, star anise, fennel, sweet fennel and parsley that belong to the plant family Umbelliferae, nutmeg and mace that belong to the plant family Myristicaceae, sweet and exotic basil that belong to the family Labiatae, and tarragon that belongs to the plant family Compositeae. The intake of the 
alkenylbenzenes occurs from consumption of spices and herb and spice oils. The levels of alkenylbenzenes in spices vary significantly depending on exact growing region, plant maturity at harvest, harvesting techniques, storage conditions and processing methods (e.g. extraction, drying). Nutmeg is the main source of exposure to myristicin, safrole, and elemicin, with an average content of 5292, 2099, and $1395 \mathrm{mg} / \mathrm{kg}$ respectively, as based on data from a variety of sources, including industry data and published reports (JECFA 2009; van den Berg et al. 2012). Exposure to estragole and methyleugenol occurs mainly by consumption of basil, with an average content of $1162 \mathrm{mg} / \mathrm{kg}$ for estragole and $62.8 \mathrm{mg} / \mathrm{kg}$ for methyleugenol, depending on harvest and storage time, and plant height (maturity) (Miele et al. 2001). Intake of apiole is predominantly from consumption of parsley with an average content of $8.7 \mathrm{mg} / \mathrm{kg}$ (JECFA 2009).

Plant Food Supplements (PFS) are concentrated sources of dietary ingredients derived from various plants and herbal extracts. Exposure to alkenylbenzenes through PFS is dependent on the level of the alkenylbenzenes in the PFS and amount and frequency of PFS intake. PFS made of essential oils were found to contain highly concentrated levels of alkenylbenzenes, and may result in high intakes (Archer 1988; van den Berg et al. 2011). General concerns related to the quality and safety of botanicals and botanical preparations such as PFS are often related to the presence of naturally occurring toxic compounds (EFSA 2004; JECFA 2009). Especially the use of highly concentrated plant material, which is usually marketed in the form of capsules or powder and supposed to supplement the normal diet, raises concerns.

Exposure to myristicin, safrole, estragole, and methyleugenol from food occurs mostly from basil, nutmeg, and parsley. The estimated daily intake (EDI) of these four alkenylbenzenes from the use of spices and spice oils ranges from 0.9 to $166 \mu \mathrm{g} / \mathrm{kg}$ bw per day, with the EDI of safrole 
being the lowest and that for estragole the highest (JECFA 2009). The dietary intakes of elemicin and apiole from all sources, with EDI values of 0.04 and $0.43 \mu \mathrm{g} / \mathrm{kg}$ bw per day, respectively (JECFA 2009), were reported to make a minor contribution to the overall alkenylbenzene intake. With respect to alkenylbenzene exposure, pesto paste eaters are considered the highest exposed group, with $20 \mathrm{mg}$ methyleugenol on average in each meal, making the daily consumption amount to $250 \mu \mathrm{g} / \mathrm{kg}$ bw per day of methyleugenol for a $70 \mathrm{~kg}$ person (Miele et al. 2001). In 2001 The Scientific Committee on Food (SCF) concluded that the structural analogues, methyleugenol, estragole, and safrole are genotoxic and carcinogenic and indicated the need for a reduction in exposure and restrictions in the levels of use (SCF 2001a; SCF 2001b; SCF 2002). However, SCF or EFSA opinions on myristicin, apiole and elemicin are not available.

Further investigation is needed to assess the potential risk to human health from low-level dietary exposure to alkenylbenzenes present in foods and essential oils (JECFA 2009). To this end, the EDI values in the present thesis will be calculated based on alkenylbenzene levels in samples containing alkenylbenzenes purchased from the market, taking into consideration the possible combined exposure to different alkenylbenzenes. Combined exposure can be evaluated by dose addition, which is considered appropriate for mixtures with components acting by a similar MOA, at a similar target organ, and causing a similar adverse effect i.e. liver carcinogenicity (EPA 1986a; EPA 1988; EPA 2000). This implies that the response to the mixture can be predicted by summing up the EDIs of the alkenylbenzenes assuming equal potency, or using their toxic equivalency factors (TEFs) relative to a reference alkenylbenzene. This requires definition of relative potency factors (RPFs) or toxic equivalency factors (TEFs) which were not available at the start of these studies. 


\section{Absorption, Distribution, Metabolism and Excretion (ADME) of alkenylbenzenes}

Many studies on the fate and behavior of alkenylbenzenes were performed in in vitro models and in experimental animals, and results thus obtained were important in the interpretation of toxicity and extrapolation to humans (IPCS 1986a; Lipscomb and Ohanian 2007).

Toxicokinetic and metabolic experiments for alkenylbenzenes indicate that they undergo rapid and complete absorption following oral intake (Kamienski and Casida 1970; Fritsch et al. 1975; Fritsch et al. 1975; Benedetti et al. 1977; Sutton et al. 1985; Anthony et al. 1987; Lee et al. 1998).

The metabolites of elemicin, myristicin, and safrole have been identified in rat urine and the presence of some of them has been demonstrated in human urine of a nutmeg abuser (Beyer et al. 2006) (see also below). Figure 2 shows the proposed metabolic pathways of myristicin, which are similar to those for the structurally related alkenylbenzenes (Punt et al. 2008; JECFA 2009; Al-Subeihi et al. 2011; Martati et al. 2012; van den Berg et al. 2012). The primary biotransformation process of alkenylbenzenes is $O$-demethyl(en)ation that yields a phenolic derivative, that is mostly excreted as the sulfate or glucuronic acid conjugate (Benedetti et al. 1977; Zangouras et al. 1981; Sangster et al. 1983; Anthony et al. 1987; Lee et al. 1998; Beyer et al. 2006). Epoxidation of the double bond in the allyl side-chain is the alternative biotransformation pathway, yielding the 2',3'-epoxide. In vivo, the epoxide is rapidly detoxified by epoxide hydrolase or via glutathione conjugation and this prevents it from forming detectable levels of DNA adducts (Luo et al. 1992; Luo and Guenthner 1995). Hydroxylation of the alkene side-chain to yield the 1'-hydroxy metabolite is considered the primary bioactivation pathway (Drinkwater et al. 1976; Benedetti et al. 1977; Zangouras et al. 1981; Miller et al. 1983). The 1'hydroxymetabolite can be conjugated with either glucuronic acid or sulfate. The sulfate 
conjugate is an unstable sulfate ester, and is considered to be the proximate hepatocarcinogenic agent (Smith et al. 2002) since it hydrolyses to form a reactive electrophilic intermediate, which binds to DNA. Rodent studies have shown that the formation of DNA adducts in the liver of exposed rodents is dose dependent (Drinkwater et al. 1976; Swanson et al. 1981; Miller et al. 1982; Boberg et al. 1983; Miller et al. 1983; Caldwell et al. 1992; Chan and Caldwell 1992; Hasheminejad and Caldwell 1994; Gardner et al. 1995; Daimon et al. 1998). The relative contribution of the different biotransformation routes of the alkenylbenzenes was also shown to be dose dependent and to show species and sex differences (Table 1). From all these data it is concluded that at low doses in humans, mice and rats, significant amounts of alkenylbenzenes are $O$-dealkylated. When dose levels increase, the relative amount of 1 '-hydroxylation increases. In all species bioactivation to 1'-hydroxy occurs, but there may be species differences and/or differences between the alkenylbenzenes: so quantifying it for each congener is essential to obtain insight in relative bioactivation of the different alkenylbenzenes. The overview presented in table 1 also reveals that detection of a 1'-hydroxy alkenylbenzene in urine reflects its glucurondiation and thus its detoxification rather than its bioactivation by sulfation. This implies that relative differences in bioactivation and detoxification for each specific congener in rat and human cannot be derived from urinary metabolite patterns, and remain to be established before you can do read-across for risk assessment. The observation that the 1'-hydroxy metabolites of myristicin, safrole and elemicin are present in the urine of rats administered pure alkenylbenzenes at $100 \mathrm{mg} / \mathrm{kg}$ bw via oral intubation but absent from the urine of rodents or humans consuming nutmeg (50 times lower amount) may be due to dose or matrix effects. 


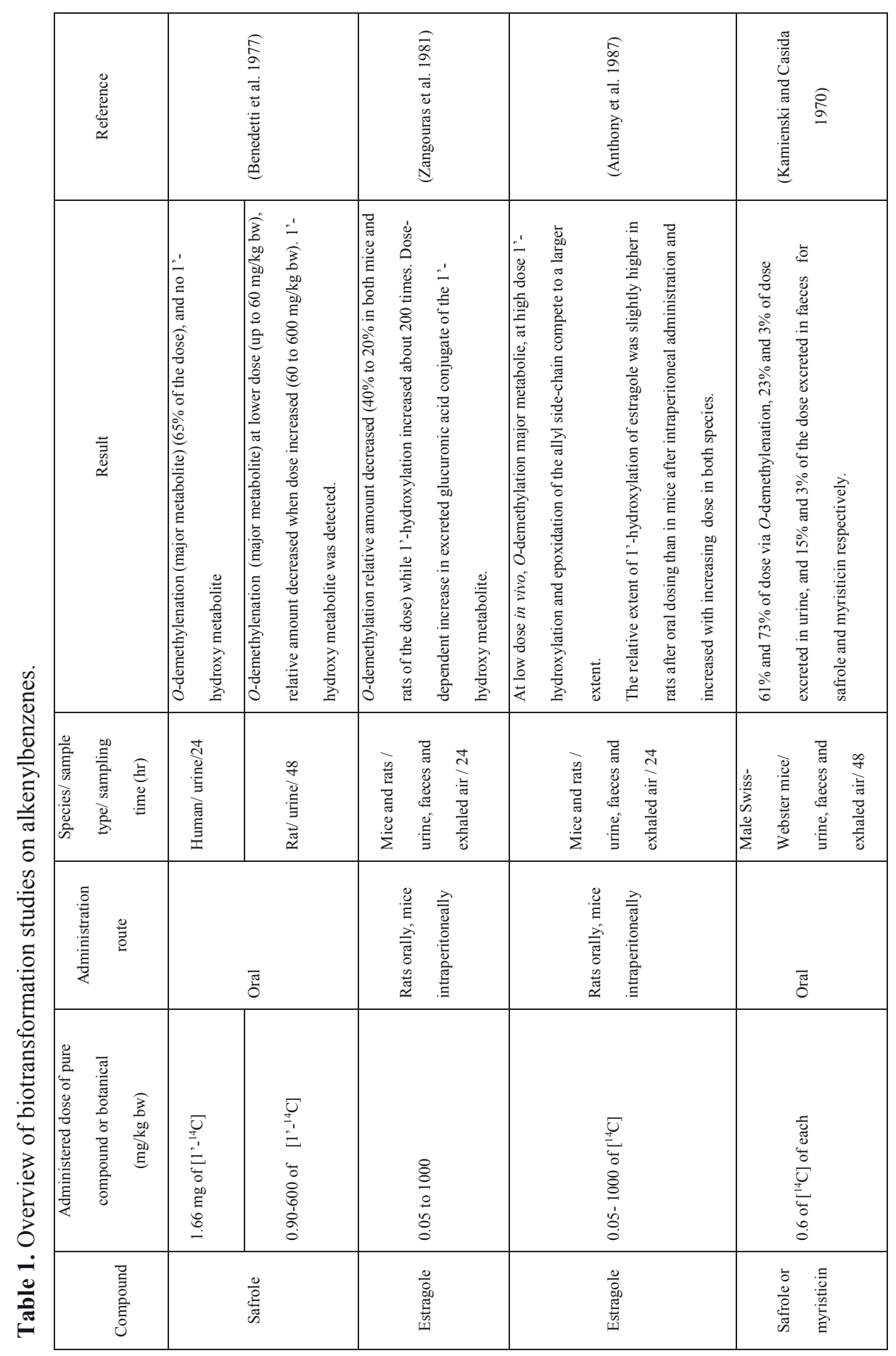




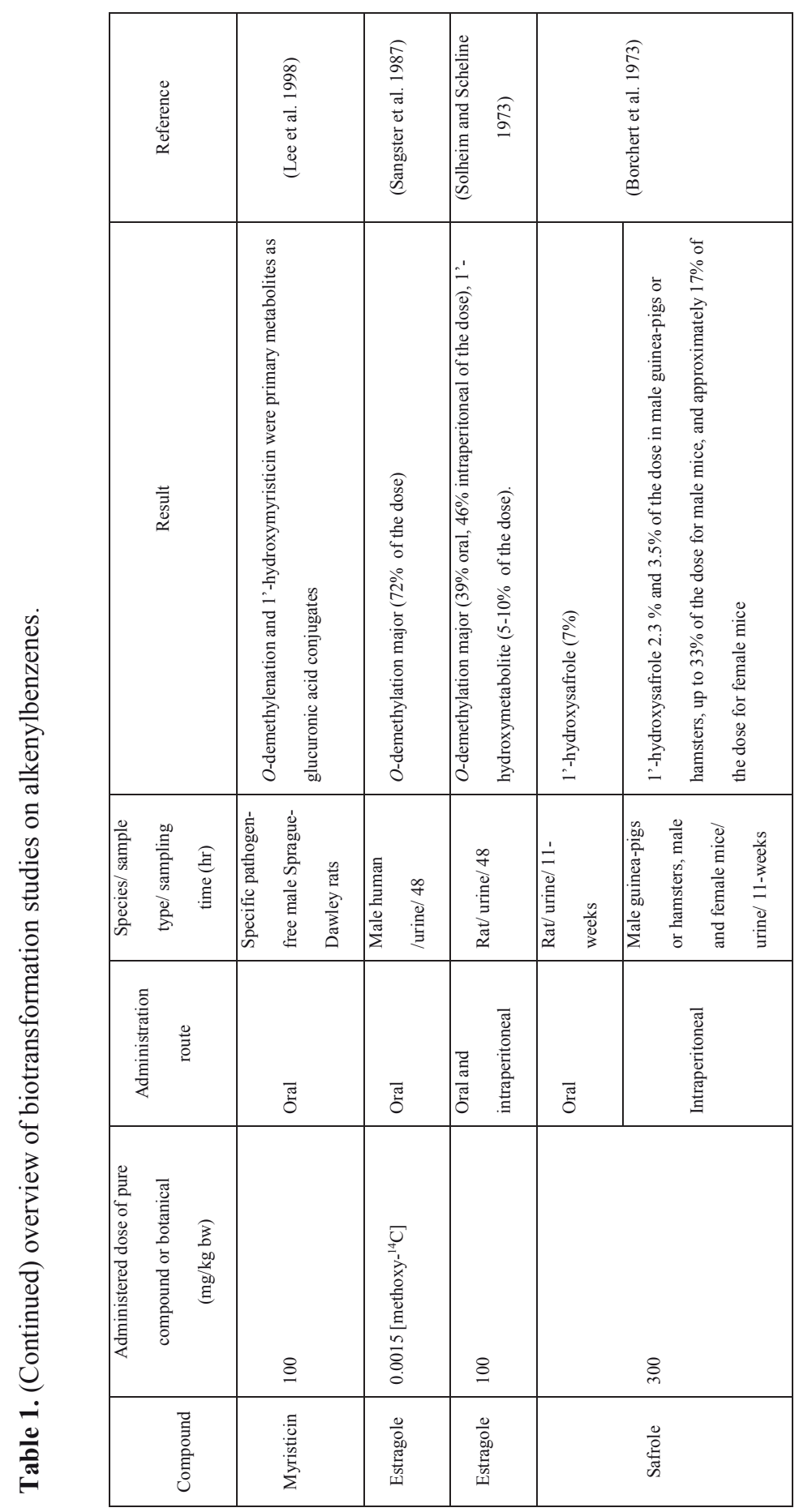




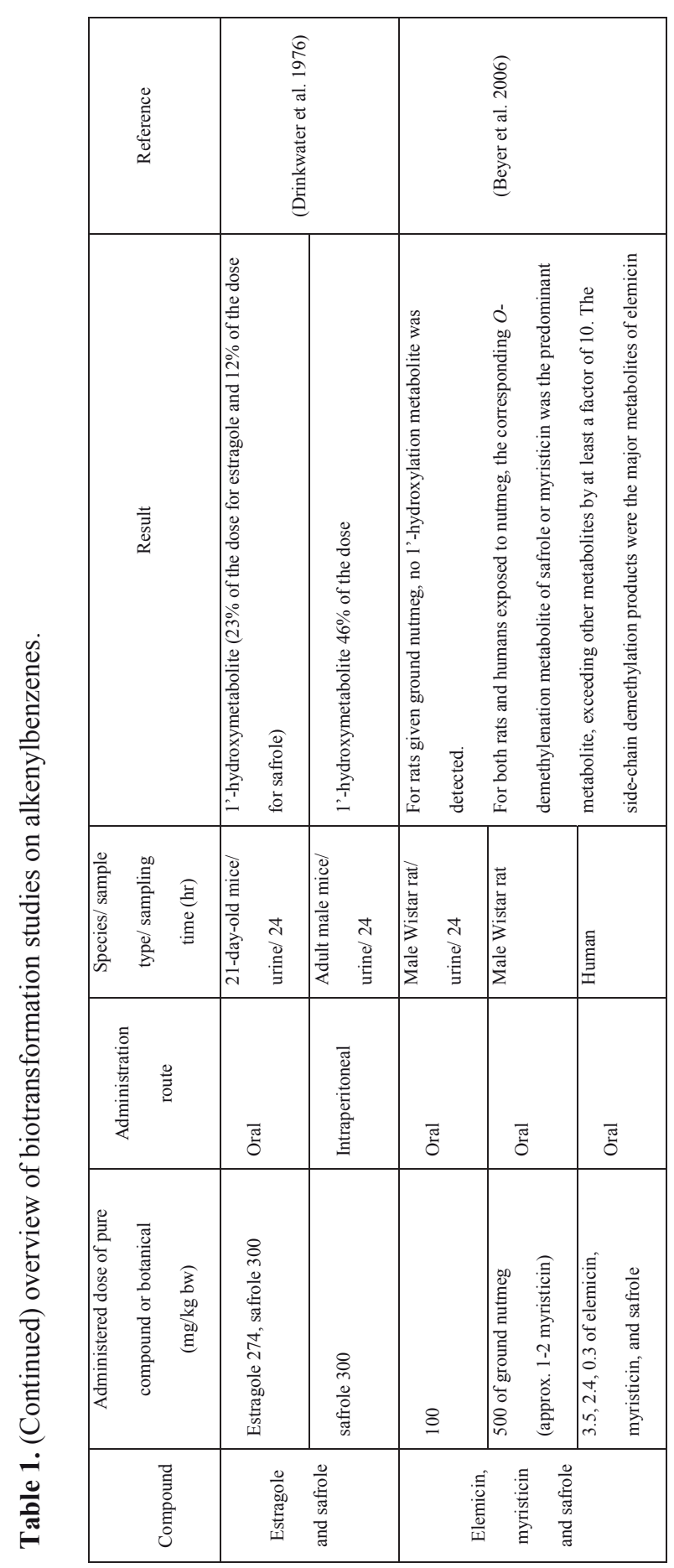



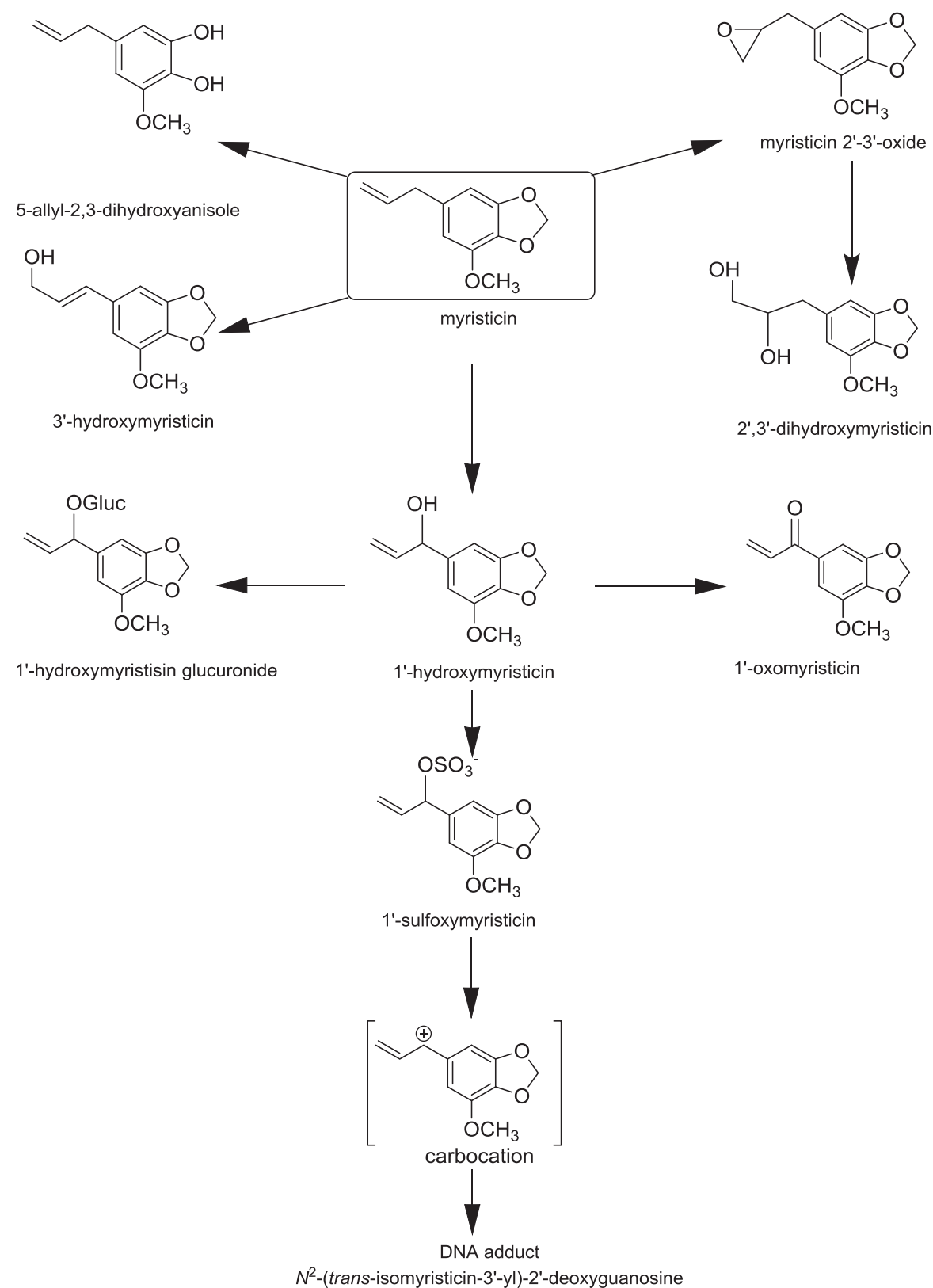

Figure 2. Proposed metabolic pathways of the alkenylbenzene myristicin (Kamienski and Casida 1970; Sangster et al. 1987; Lee et al. 1998; Beyer et al. 2006). 


\section{Carcinogenicity and MOA}

The adverse critical effect of the alkenylbenzenes is the formation of liver tumors, and for some of the alkenylbenzenes long term carcinogenicity studies in rodents are actually available (Hagan et al. 1967; Borchert et al. 1973; Lipsky et al. 1981a; Lipsky et al. 1981b; Lipsky et al. 1981c; Miller et al. 1983; NTP 2000) (Table 2). The purpose of testing chemicals for carcinogenicity in a chronic lifetime exposure scenario with experimental animals is to identify potential cancer hazards for humans. Positive findings require careful interpretation in relation to MOA, possible interspecies differences in background incidence and in response and with respect to high dose to low dose extrapolation (WHO 2009b). Virtually all chemicals associated with cancer in humans have been found to increase the incidence of neoplasms in experimental animals albeit not causing necessarily the same type of tumor (McGregor and Anderson 1999). For alkylating compounds, genetic changes arise from the reactivity of the carcinogen with DNA, because the reactive proximate carcinogen may operate as an electrophilic reactant covalently binding to DNA as a fundamental part of the MOA underlying induction of carcinogenesis. Carcinogens that act through such genotoxic mechanisms are usually multi-organ and trans-species carcinogens that can be active with a single dose and are effective at low exposures (Vaino et al. 1992; Williams 1992).

${ }^{32} \mathrm{P}$-postlabeling indicated that estragole, safrole, methyleugenol, myristicin, elemicin, and apiol have the ability to produce DNA adducts in adult mouse liver upon intraperitoneal injections. Estragole, methyleugenol and safrole showed the highest activity of the alkenylbenzenes tested (Randerath et al. 1984). Similar results were shown by Phillips et al. 1984, who reported that in neonatal mice upon intraperitoneal injections the ability to form DNA adducts was in the following order; methyleugenol $>$ estragole $>$ safrole $>$ myristicin $>$ apiol (Phillips et al. 1984). 
Using human HepG2 cells exposed in vitro, the level of DNA adduct formation by estragole, methyleugenol and safrole was the highest at low concentration $(50 \mu \mathrm{mol} / \mathrm{l})$, while at higher concentration $(450 \mu \mathrm{mol} / \mathrm{l})$, the level of adduct formation of myristicin was as high as that of safrole and methyleugenol (Zhou et al. 2007).

Long-term carcinogenicity data from studies with rodents given high dose levels showed increased incidences of hepatocellular carcinoma especially with safrole, estragole and methyleugenol (Table 2). These studies indicate that the structurally related alkenylbenzenes are compounds that are genotoxic and carcinogenic, with relative difference in potency. Similar long term carcinogenicity studies for myristicin, elemicin and apiole are not available.

\section{Risk assessment approach}

In the present thesis risk assessment of consumption of the alkenylbenzene-containing samples was performed using the MOE approach. The MOE approach is the approach recommended for risk assessment of compounds that are both genotoxic and carcinogenic (EFSA 2005). The MOE is a dimensionless ratio comparing a standardized reference point derived, by mathematical modelling, from the animal data within the observed range of experimental data, with the EDI of the compound of interest resulting from the use of food containing that compound. The EFSA Scientific Committee considered that an MOE of 10000 or more, based on animal cancer bioassay data, "would be of low concern from a public health point of view and might reasonably be considered as a low priority for risk management actions" (EFSA 2005). The EFSA recommends the use of the $\mathrm{BMDL}_{10}$ as a reference point for $\mathrm{MOE}$ calculations, which is the lower confidence limit of the benchmark dose resulting in a $10 \%$ extra cancer incidence above background level (EFSA 2009a; EFSA 2009b). In previous studies, the BMDL 10 values for 
safrole, estragole, and methyleugenol could be derived from in vivo tumor data (van den Berg et al. 2011). Table 3 presents an overview of these $\mathrm{BMDL}_{10}$ values. However, not for all alkenylbenzenes tumor data enabling definition of a $\mathrm{BMDL}_{10}$ for risk assessment are available. Such data are missing for elemicin, myristicin and apiol. Previously, a BMDL 10 value for elemicin was derived by read-across from methyleugenol and estragole (EFSA 2005; van den Berg et al. 2012) (Table 3). In the present thesis a similar approach with read-across form safrole was undertaken for myristicin and apiol.

Van den Berg et al. (2011) investigated the alkenylbenzene content in 28 PFS samples containing botanicals including basil, fennel, sassafras, nutmeg, cinnamon, and calamus (van den Berg et al. 2011), and performed a risk assessment using the MOE aproach. The results obtained revealed that out of 28 PFS samples, 25 samples contained alkenylbenzenes at levels that would result in EDIs that would give rise to MOE values below 10000, indicating a priority for risk management. Among these 25 PFS samples, there were 4 nutmeg-based samples shown to contain methyleugenol and safrole at levels that would result in EDI values that gave rise to MOE values $<10000$ (van den Berg et al. 2011). In addition to safrole and methyleugenol, nutmeg may also contain myristicin and elemicin (JECFA 2009). 


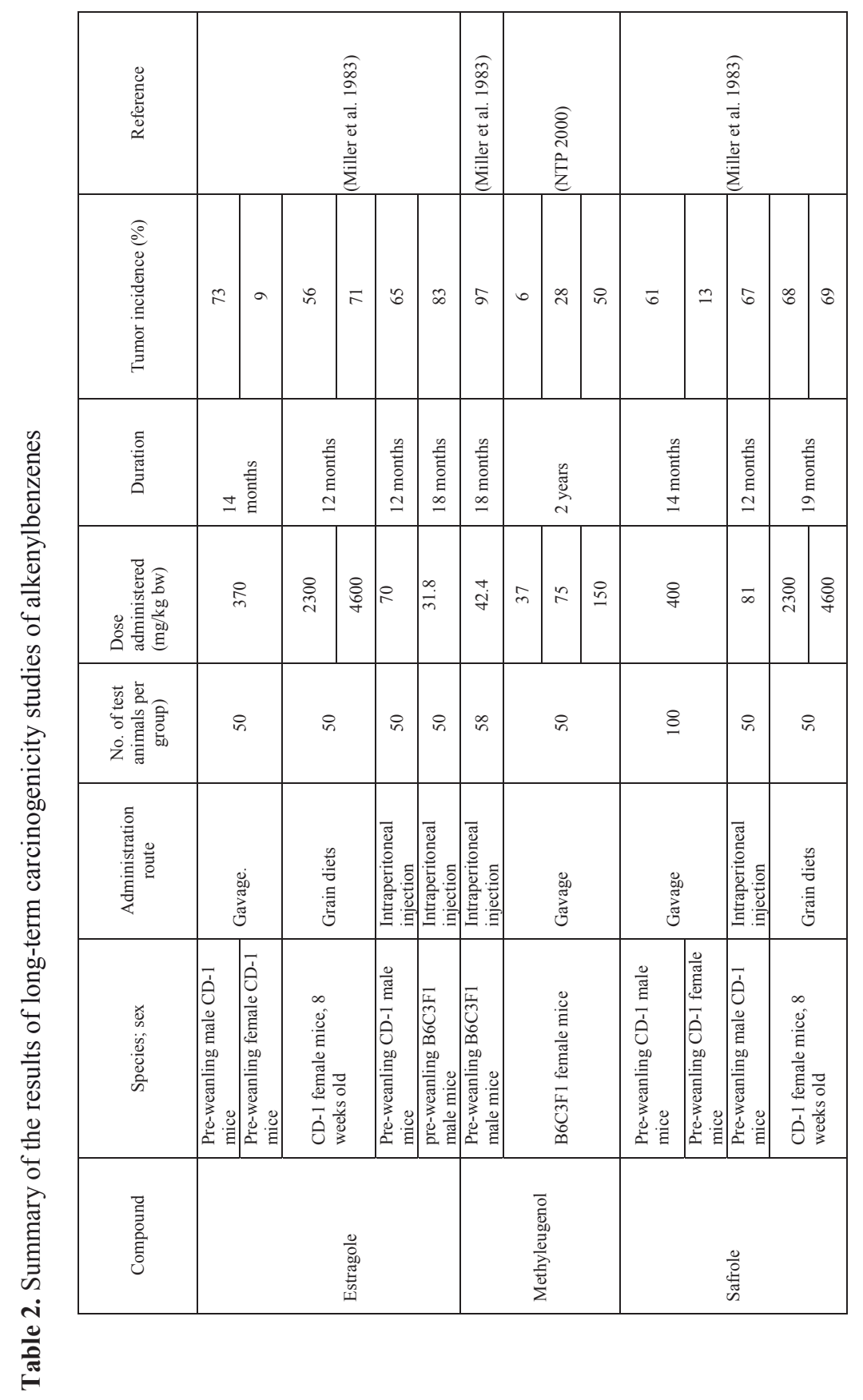


Table 3. BMDL 10 values of alkenylbenzenes as derived from in vivo tumor data for safrole, estragole, and methyleugenol, or obtained by read-across from methyleugenol and estragole for elemicin. NA, Not Available.

\begin{tabular}{|l|c|c|}
\hline \multicolumn{1}{|c|}{ Compound } & $\begin{array}{c}\text { BMDL }_{10} \\
(\mathrm{mg} / \mathrm{kg} \mathrm{bw})\end{array}$ & \multirow{2}{*}{ (veference } \\
\cline { 1 - 2 } Methyleugenol & $15.3-34.0$ & \\
\hline Safrole & $1.9-5.1$ & \\
\hline Estragole & $3.3-6.5$ & (van den Berg et al. 2012) \\
\hline Elemicin & $30.6-68.0$ & NA \\
\hline Myristicin & NA & NA 2011) \\
\hline Apiol & NA & \\
\hline
\end{tabular}

The aim of the present study was to develop a MOA and PBK modeling based approach for read-across in risk assessment from safrole, for which in vivo toxicity studies are available to myristicin and apiol for which tumor data are not reported, thus contributing to alternatives in animal testing, and to use the outcomes for risk assessment for the consumption of PFS and other botanical products containing myristicin and structurally related alkenylbenzenes considering individual and combined exposure. The next section illustrates in some more detail how PBK modeling can be used to estimate $\mathrm{BMDL}_{10}$ values for alkenylbenzenes for which no tumor data are available.

\section{PBK modeling}

PBK models are developed in order to study effects related to interspecies, intraspecies, high to low dose, route to route, and exposure scenario extrapolations using in vitro and in vivo kinetic data. PBK models, in general, are developed to integrate diverse sets of kinetics data, and predict tissue dosimetry for situations relevant to human dietary levels. 
A PBK model is represented by a set of mathematical equations that together describe the process of a substance entering the body (absorption), dispersing throughout the fluids and tissues of the body (distribution), the biotransformation to its metabolites (metabolism), and the elimination from the body (excretion), having all the compartments mutually connected through the systemic circulation. Steps to build a PBK model are as follows (Rietjens et al. 2011); First define the structure of the model including organs and tissues that are of importance for the kinetic processes and the toxicity of the compound of interest. Second, mathematically describe the relevant processes, using equations for absorption, distribution, excretion and metabolism the latter including separate Michaelis-Menten equations for each metabolic conversion, one for each important metabolic route. Third, define the values of the model parameters needed to develop the PBK model for a specific compound. Fourth, using software, e.g. Berkeley Madonna, solve the mass-balance differential equations and predict the levels of the parent compound and its relevant metabolites at certain dose levels in the relevant compartments of the body in time. Fifth, evaluate the model against experimental in vivo data to support the validity of the model and thus its subsequent predictions. In a final step the model can be used to make predictions. The parameters needed for the model are physiological parameters (cardiac output, tissue blood flow rate, tissue volumes), physicochemical parameters (partition coefficients), kinetic and biochemical parameters (describing metabolic processes, rates of absorption, biotransformation). These parameters can be obtained from literature, experimentally (in vitro or in vivo), and/or by using in silico tools such as for example Quantitative Structure Activity Relationships (QSAR). A quantitative evaluation of how input parameters influence the model output of relevance to the risk assessment can be provided via a sensitivity analysis (Iman and Helton 1988; Farrar et al. 1989; Krewski et al. 1995; Campolongo and Saltelli 1997; Nestorov 2001; Gueorguieva et al. 2006; Chiu et al. 2007; Loizou et al. 2008). In a sensitivity analysis one input parameter 
is changed (for example by $5 \%$ ) while the other parameters are kept at their initial value and it is estimated how the prediction is affected by that change. Sensitivity analysis results are presented as high (absolute value of the sensitivity coefficient greater than or equal to 0.5 ), medium (absolute value greater than or equal to 0.2 but less than 0.5 ) or low (absolute value of the sensitivity coefficient greater than or equal to 0.1 but less than 0.2 ); parameters with a sensitivity coefficient less than 0.1 are generally not listed (Kohn 1995; IPCS 2010).

\section{Objectives and outline of the thesis}

The aim of the present PhD project was to develop a MOA and PBK modeling based approach for read-across in risk assessment from safrole for which in vivo toxicity studies are available to myristicin and apiol for which tumor data are not reported, and to use the outcomes for risk assessment for the consumption of PFS and other botanical products containing myristicin and structurally related alkenylbenzenes considering individual and combined exposure.

The introduction chapter (this chapter) starts with a short background and definition of the aim of the thesis, followed by a description of the physicochemical properties, natural occurrence and EDI of the alkenylbenzenes, as well as of their ADME characteristics, carcinogenicity and MOA, the relevant risk assessment approach, and finally PBK modelling. Chapter 2 of the thesis describes the development of a PBK model for myristicin in male rat and human, enabling the prediction of dose-dependent effects in bioactivation and detoxification of myristicin. This allows comparison of the PBK model-based prediction of bioactivation of myristicin to the PBK model-based predictions for bioactivation of the structurally related compound safrole, enabling estimation of a BMDL 10 for myristicin from read-across to the $\mathrm{BMDL}_{10}$ available for safrole, thereby facilitating risk assessment of current dietary exposure to myristicin. 
Chapter 3 describes PBK models for the alkenylbenzene apiol in rat and human, based on the PBK models previously developed for the structurally related alkenylbenzenes safrole. Using the newly developed models, the level of metabolic activation of apiol in rat and human was predicted to obtain insight in species differences in the bioactivation of apiol and read-across to the related alkenylbenzene safrole. The models were also used for read-across from safrole to apiol and definition of a BMDL 10 for apiol.

Chapter 4 evaluates the risk of exposure to methyleugenol and related alkenylbenzenes through consumption of pesto sauce. To this end the levels of methyleugenol and other alkenylbenzenes in basil-containing sauce of pesto were quantified enabling an associated risk assessment based on the MOE approach, taking into consideration the possible combined exposure to different alkenylbenzenes and the $\mathrm{BMDL}_{10}$ values as defined in literature (Table 3 ) and in chapter 2 and 3 of the thesis.

Chapter 5 evaluates the risk of exposure to myristicin and related alkenylbenzenes through human exposure to nutmeg-based PFS based on the MOE approach. Chemical analyses of various PFS samples were performed and the amount of alkenylbenzenes that would be consumed through consumption of these nutmeg-based PFS where quantified. MOE values where calculated for the individual alkenylbenzenes as well as taking into account the presence of more than one alkenylbenzenes within selected PFS samples.

Chapter 6 summarizes the results obtained in the thesis, compiles the overall discussion and presents the future perspectives that follow from the results obtained. 


\section{References}

Al-Subeihi, A. A., Spenkelink, B., Rachmawati, N., Boersma, M. G., Punt, A., Vervoort, J., van Bladeren, P. J. and Rietjens, I. M. C. M. (2011). "Physiologically based biokinetic model of bioactivation and detoxification of the alkenylbenzene methyleugenol in rat." Toxicology in vitro : an international journal published in association with BIBRA 25(1): 267-285. from http://www.ncbi.nlm.nih.gov/pubmed/20828604.

Anthony, A., Caldwell, J., Hutt, A. J. and Smith, R. L. (1987). "Metabolism of estragole in rat and mouse and influence of dose size on excretion of the proximate carcinogen 1'hydroxyestragole." Food and chemical toxicology : an international journal published for the British Industrial Biological Research Association 25(11): 799-806. from http://www.ncbi.nlm.nih.gov/pubmed/3121480.

Archer, A. W. (1988). "Determination of safrole and myristicin in nutmeg and mace by highperformance liquid chromatography." Journal of chromatography 438(1): 117-121. from http://www.ncbi.nlm.nih.gov/pubmed/3379114.

Barlow, S., Renwick, A. G., Kleiner, J., Bridges, J. W., Busk, L., Dybing, E., Edler, L., Eisenbrand, G., Fink-Gremmels, J., Knaap, A., Kroes, R., Liem, D., Muller, D. J., Page, S., Rolland, V., Schlatter, J., Tritscher, A., Tueting, W. and Wurtzen, G. (2006). "Risk assessment of substances that are both genotoxic and carcinogenic report of an International Conference organized by EFSA and WHO with support of ILSI Europe." Food and chemical toxicology : an international journal published for the British Industrial Biological Research Association 44(10): 1636-1650. from http://www.ncbi.nlm.nih.gov/pubmed/16891049.

Benedetti, M. S., Malnoe, A. and Broillet, A. L. (1977). "Absorption, metabolism and excretion of safrole in the rat and man." Toxicology 7(1): 69-83. from http://www.ncbi.nlm.nih.gov/pubmed/14422.

Beyer, J., Ehlers, D. and Maurer, H. H. (2006). "Abuse of nutmeg (Myristica fragrans Houtt.): studies on the metabolism and the toxicologic detection of its ingredients elemicin, myristicin, and safrole in rat and human urine using gas chromatography/mass spectrometry." Therapeutic drug monitoring 28(4): 568-575. from http://www.ncbi.nlm.nih.gov/pubmed/16885726.

Boberg, E. W., Miller, E. C., Miller, J. A., Poland, A. and Liem, A. (1983). "Strong evidence from studies with brachymorphic mice and pentachlorophenol that 1'-sulfooxysafrole is the major ultimate electrophilic and carcinogenic metabolite of 1'-hydroxysafrole in 
mouse liver." Cancer research 43(11): 5163-5173. from

http://www.ncbi.nlm.nih.gov/pubmed/6577945.

Borchert, P., Miller, J. A., Miller, E. C. and Shires, T. K. (1973). "1'-Hydroxysafrole, a proximate carcinogenic metabolite of safrole in the rat and mouse." Cancer research 33(3): 590-600. from http://www.ncbi.nlm.nih.gov/pubmed/4347718.

Caldwell, J., Chan, V. S. W., Marshall, A. D., Hasheminejad, G. and Bounds, S. V. J. (1992). "1'-Hydroxylation is the only metabolic pathway of simple alkenylbenzenes involved in their genotoxicity." Toxicologist 12(1): 56.

Campolongo, F. and Saltelli, A. (1997). " Sensitivity analysis of an environmental model: an application of different analysis methods." Reliability Engineering and System Safety 57(1): 49-69.

Chan, V. S. W. and Caldwell, J. (1992). "Comparative induction of unscheduled DNA synthesis in cultured rat hepatocytes by allylbenzenes and their 1'-hydroxy metabolites." Food Chem. Toxicol. 30: 831-836.

Chiu, W., Barton, H., Dewoskin, R., Schlosser, P., Thompson, C., Sonawane, B., Lipscomb, J. and K., K. (2007). "Evaluation of physiologically based pharmacokinetic models for use in risk assessment." Journal of Applied Toxicology 27: 218-237.

Daimon, H., Sawada, S., Asakura, S. and Sagami, F. (1998). "In vivo genotoxicity and DNA adduct levels in the liver of rats treated with safrole." Carcinogenesis 19(1): 141-146. from http://www.ncbi.nlm.nih.gov/pubmed/9472705.

Drinkwater, N. R., Miller, E. C., Miller, J. A. and Pitot, H. C. (1976). "Hepatocarcinogenicity of estragole (1-allyl-4-methoxybenzene) and 1'-hydroxyestragole in the mouse and mutagenicity of 1'-acetoxyestragole in bacteria." Journal of the National Cancer Institute 57(6): 1323-1331. from http://www.ncbi.nlm.nih.gov/pubmed/187802.

EFSA (2004). "Botanicals and Botanical Preparations widely used as food supplements and related products: Coherent and Comprehensive Risk Assessment and Consumer Information Approaches." European Food Safety Authority: 6. from https://www.efsa.europa.eu/sites/default/files/assets/scdoc_advice03_botanicals_en.pdf

EFSA (2005). "Opinion of the scientific committee on a request from EFSA related to a harmonized approach for risk assessment of substances which are both genotoxic and carcinogenic." European Food Safety Authority 282: 1-31. from http://onlinelibrary.wiley.com/doi/10.2903/j.efsa.2005.282/epdf

EFSA (2009a). "Guidance on safety assessment of botanicals and botanical preparations intended for use as ingredients in food supplements." European Food Safety Authority 
7(1249). from

https://www.pharmamedtechbi.com/ /media/Images/Publications/Archive/The\%20Tan\% 20Sheet/17/037/05170370014_b/090914_efsa_botanicals_guidance.pdf

EFSA (2009b). "Guidance of the Scientific Committee on Use of the benchmark dose approach in risk assessment." European Food Safety Authority 1150 1-72. from http://onlinelibrary.wiley.com/doi/10.2903/j.efsa.2009.1150/epdf

EFSA (2012a). "Compendium of botanicals reported to contain naturally occuring substances of possible concern for human health when used in food and food supplements." European Food Safety Authority 10(5): 60. from fhttps://www.efsa.europa.eu/en/efsajournal/pub/2663.

EPA (1986a). Guidelines for the health risk assessment of chemical mixtures, United states Environmental Protection Agency. Fed Reg 51:34014-34025.

EPA (1986b). Safrole and its alkenylbenzenes congeners Environmental Protection Agency, USA.

EPA (1988). Technical support document on health risk assessment of chemical mixtures. Office of Research and Development. Washington, D.C., United States Environmental Protection Agency. EPA/600/8-90/064.

EPA (2000). Supplementary guidance for conducting health risk assessment of chemical mixtures. R. A. Forum. Washington, DC United States Environmental Protection Agency. EPA/630R-00/002.

Farrar, D., Allen, B., Crump, K. and Shipp, A. (1989). "Evaluation of uncertainty in input parameters to pharmacokinetic models and the resulting uncertainties in output." Toxicology Letters 49: 371-385.

Fritsch, P., de Saint Blanquat, G. and Derache, R. (1975). "[Gastrointestinal absorption in the rat of anisole, trans-anethole, butylhydroxyanisole and safrole]." Food and cosmetics toxicology 13(3): 359-363. from http://www.ncbi.nlm.nih.gov/pubmed/1158324.

Fritsch, P., Lamboeuf, Y. and de Saint Blanquat, G. (1975). "[Effect of anisole, anethole, butylhydroxyanisole and safrole on intestinal absorption in the rat (author's transl)]." Toxicology 4(3): 341-346. from http://www.ncbi.nlm.nih.gov/pubmed/1154431.

Gardner, I., Bergin, P., Stening, P., Kenna, J. G. and Caldwell, J. (1995). "Protein adducts derived from methyleugenol." Meeting report of the 4th International ISSX Meeting. International Society for the Study of Xenobiotics 8: 208. 
Gueorguieva, I., Nestorov, I. and Rowland, M. (2006). "Reducing whole body physiologically based pharmacokinetic models using global sensitivity analysis: diazepam case study." Journal of Pharmacokinetics and Pharmacodynamics 33(1): 1-27.

Hagan, E. C., Hansen, W. H., Fitzhugh, O. G., Jenner, P. M., Jones, W. I., Taylor, J. M., Long, E. L., Nelson, A. M. and Brouwer, J. B. (1967). " Food flavourings and compounds of related structure. II. Subacute and chronic toxicity." Food Cosmet. Toxicol. 5(2): 141157.

Hasheminejad, G. and Caldwell, J. J. (1994). "Genotoxicity of the alkenylbenzenes alpha- and beta-asarone, myristicin and elemicin as determined by the UDS assay in cultured hepatocytes." Food Chem. Toxicol. 3(22): 223-231.

Iman, R. and Helton, J. (1988). "An investigation of uncertainty and sensitivity analysis techniques for computer models." Risk Analysis 8: 71-90.

IPCS (1986a). Principles of toxicokinetic studies. E. H. Criteria. Geneva, World Health Organization, International Programme on Chemical Safety. 57.

IPCS (2010). "Characterization and application of physiologically based pharmacokinetic models in risk assessment." World Health Organization Harmonization Project Document No. 9. from http://www.inchem.org/documents/harmproj/harmproj/harmproj9.pdf.

JECFA (2009). Safety evaluation of certain food additives-Alkoxy-substituted allylbenzenes present in foods and essential oils and used as flavouring agents. I. I. P. o. C. Safety. Geneva, World Health Organization. 60: 351-481.

Kamienski, F. X. and Casida, J. E. (1970). "Importance of demethylenation in the metabolism in vivo and in vitro of methylenedioxyphenyl synergists and related compounds in mammals." Biochem. Pharmacol. 19(1): 91-112.

Kobets, T., Duan, J., Brunnemann, K., Etter, S., Smith, B. and Williams, G. (2016). "Structure activity relationships for DNA damage by alkenylbenzenes in turkey egg fetal liver." Toxicological Sciences 150(2): 301-311.

Kohn, M. (1995). "Achieving credibility in risk assessment models." Toxicology Letters 79: 107-114.

Krewski, D., Wang, Y., Bartlett, S. and Krishnan, K. (1995). "Uncertainty, variability, and sensitivity analysis in physiological pharmacokinetic models." Journal of Biopharmaceutical Statistics 5: 245-271.

Lee, H. S., Jeong, T. C. and Kim, J. H. (1998). "In vitro and in vivo metabolism of myristicin in the rat." Journal of chromatography. B, Biomedical sciences and applications 705(2): 367-372. from http://www.ncbi.nlm.nih.gov/pubmed/9521577. 
Lee, H. S., Jeong, T. C. and Kim, J. H. (1998). "In vitro and in vivo metabolism of myristicin in the rat." J. Chromatogr. B Biomed. Sci. Appl. 705(2): 367-372.

Lipscomb, J. and Ohanian, E. e. (2007). "Toxicokinetics and risk assessment." Informa Healthcare, NY, USA: 361.

Lipsky, M. M., Hinton, D. E., Klaunig, J. E., Goldblatt, P. J. and Trump, B. F. (1981b). "Biology of hepatocellular neoplasia in the mouse. II. Sequential enzyme histochemical analysis of BALB/c mouse liver during safrole-induced carcinogenesis." Journal of the National Cancer Institute 67(2): 377-392. from http://www.ncbi.nlm.nih.gov/pubmed/6943376.

Lipsky, M. M., Hinton, D. E., Klaunig, J. E. and Trump, B. F. (1981a). "Biology of hepatocellular neoplasia in the mouse. I. Histogenesis of safrole-induced hepatocellular carcinoma." Journal of the National Cancer Institute 67(2): 365-376. from http://www.ncbi.nlm.nih.gov/pubmed/6943375.

Lipsky, M. M., Hinton, D. E., Klaunig, J. E. and Trump, B. F. (1981c). "Biology of hepatocellular neoplasia in the mouse. III. Electron microscopy of safrole-induced hepatocellular adenomas and hepatocellular carcinomas." Journal of the National Cancer Institute 67(2): 393-405. from http://www.ncbi.nlm.nih.gov/pubmed/6943377.

Loizou, G., Spendiff, M., Barton, H., Bessems, J., Bois, F., d'Yvoire, M., Buist, H., Clewell, H., Meek, B., Gundert-Remy, U., Goerlitz, G. and Schmitt, W. (2008). "Development of good modeling practice for physiologically based pharmacokinetic models for use in risk assessment: the first steps." Regulatory Toxicology and Pharmacology 50(3): 400-411.

Luo, G. and Guenthner, T. M. (1995). "Metabolism of allylbenzene 2',3'-oxide and estragole 2',3'-oxide in the isolated perfused rat liver." J. Pharmacol. Exp. Ther. 272(2): 588-596.

Luo, G., Qato, M. K. and Guenthner, T. M. (1992). "Hydrolysis of the 2',3'-allylic epoxides of allylbenzene, estragole, eugenol, and safrole by both microsomal and cytosolic epoxide hydrolases." Drug Metab. Dispos. 20: 440-445.

Martati, E., Boersma, M. G., Spenkelink, A., Khadka, D. B., van Bladeren, P. J., Rietjens, I. M. C. M. and Punt, A. (2012). "Physiologically based biokinetic (PBBK) modeling of safrole bioactivation and detoxification in humans as compared with rats." Toxicological sciences : an official journal of the Society of Toxicology 128(2): 301-316. from http://www.ncbi.nlm.nih.gov/pubmed/22588462.

McGregor, D. and Anderson, D. (1999). "DNA damage and repair in mammalian cells in vitro and in vivo as indicators of exposure to carcinogens. The use of short- and mediumterm tests for carcinogens 
and data on genetic effects in carcinogenic hazard evaluation." IARC (International Agency for Research on Cancer Scientific Publications) 146: 309-354.

Miele, M., Dondero, R., Ciarallo, G. and Mazzei, M. (2001). "Methyleugenol in Ocimum basilicum L. Cv. genovese gigante." Journal of agricultural and food chemistry 49(1): 517-521. from http://www.ncbi.nlm.nih.gov/pubmed/11170620.

Miller, E. C., Swanson, A. B., Phillips, D. H., Fletcher, T. L., Liem, A. and Miller, J. A. (1983). "Structure-activity studies of the carcinogenicities in the mouse and rat of some naturally occurring and synthetic alkenylbenzene derivatives related to safrole and estragole." Cancer research 43(3): 1124-1134. from http://www.ncbi.nlm.nih.gov/pubmed/6825084.

Miller, J. A., Miller, E. C. and Phillips, D. H. (1982). "The metabolic activation and carcinogenicity of alkenylbenzenes that occur naturally in many spices." Stich, H.F., ed. Carcinogens and mutagens in the environment. 1(Food products): 83-96.

Nestorov, I. (2001). "Modelling and simulation of variability and uncertainty in toxicokinetics and pharmacokinetics." Toxicology Letters 120: 411-420.

NTP (2000). "Toxicology and Carcinogenesis Studies of Methyleugenol (CAS NO. 93-15-2) in F344/N Rats and B6C3F1 Mice (Gavage Studies)." National Toxicology Program technical report series 491: 1-412. from http://www.ncbi.nlm.nih.gov/pubmed/12563349.

Phillips, D. H., Hanawalt, P. C., Miller, J. A. and Miller, E. C. (1981). "The in vivo formation and repair of DNA adducts from 1'-hydroxysafrole." Journal of supramolecular structure and cellular biochemistry 16(1): 83-90. from http://www.ncbi.nlm.nih.gov/pubmed/7299840.

Phillips, D. H., Reddy, M. V. and Randerath, K. (1984). "32P-post-labelling analysis of DNA adducts formed in the livers of animals treated with safrole, estragole and other naturallyoccurring alkenylbenzenes. II. Newborn male B6C3F1 mice." Carcinogenesis 5(12): 1623-1628. from http://www.ncbi.nlm.nih.gov/pubmed/6499113.

Punt, A., Freidig, A. P., Delatour, T., Scholz, G., Boersma, M. G., Schilter, B., van Bladeren, P. J. and Rietjens, I. M. C. M. (2008). "A physiologically based biokinetic (PBBK) model for estragole bioactivation and detoxification in rat." Toxicology and applied pharmacology 231(2): 248-259. from http://www.ncbi.nlm.nih.gov/pubmed/18539307.

Randerath, K., Haglund, R. E., Phillips, D. H. and Reddy, M. V. (1984). "32P-post-labelling analysis of DNA adducts formed in the livers of animals treated with safrole, estragole and other naturally-occurring alkenylbenzenes. I. Adult female CD-1 mice." Carcinogenesis 5(12): 1613-1622. from http://www.ncbi.nlm.nih.gov/pubmed/6499112. 
Rietjens, I. M. C. M., Louisse, J. and Punt, A. (2011). "Tutorial on physiologically based kinetic modeling in molecular nutrition and food research." Molecular nutrition \& food research 55: 941-956.

Sangster, S. A., Caldwell, J., Anthony, A., Hutt, A. J. and Smith, R. L. (1983). "The dose dependent metabolism of anethole, estragole and p-propylanisole in relation to their safety evaluation." Extrahepatic drug metabolism and chemical carcinogenesis Rystrom, J., Montelius, J. \& Bengtsson, M., eds.: 213-214.

Sangster, S. A., Caldwell, J., Hutt, A. J., Anthony, A. and Smith, R. L. (1987). "The metabolic disposition of [methoxy-14C]-labelled trans-anethole, estragole and p-propylanisole in human volunteers." Xenobiotica; the fate of foreign compounds in biological systems 17(10): 1223-1232. from http://www.ncbi.nlm.nih.gov/pubmed/3424869.

SCF (2001a). "Opinion of the Scientific Committee on Food on Estragole (1-allyl-4methoxybenzene)." European Commission Health \& Consumer Protection DirectorateGeneral. from http://ec.europa.eu/food/fs/sc/scf/out104_en.pdf

SCF (2001b). "Opinion of the Scientific Committee on Food on Methyleugenol (1-allyl-1,2dimethoxybenzene)." European Commission Health \& Consumer Protection DirectorateGeneral. from http://ec.europa.eu/food/fs/sc/scf/out102_en.pdf

SCF (2002). "Opinion of the Scientific Committee on Food on the safety of the presence of safrole (1-allyl-3,4-methylene dioxybenzene) in flavourings and other food ingredients with flavouring properties." European Commission Health \& Consumer Protection Directorate-General. from http://ec.europa.eu/food/fs/sc/scf/out116_en.pdf

Smith, R. L., Adams, T. B., Doull, J., Feron, V. J., Goodman, J. I., Marnett, L. J., Portoghese, P. S., Waddell, W. J., Wagner, B. M., Rogers, A. E., Caldwell, J. and Sipes, I. G. (2002). "Safety assessment of allylalkoxybenzene derivatives used as flavouring substances methyl eugenol and estragole." Food and chemical toxicology : an international journal published for the British Industrial Biological Research Association 40(7): 851-870. from http://www.ncbi.nlm.nih.gov/pubmed/12065208.

Solheim, E. and Scheline, R. R. (1973). "Metabolism of alkenebenzene derivatives in the rat. I. p-Methoxyallylbenzene (Estragole) and p-methoxypropenylbenzene (Anethole)." Xenobiotica; the fate of foreign compounds in biological systems 3(8): 493-510. from http://www.ncbi.nlm.nih.gov/pubmed/4764649.

Sutton, J. D., Sangster, S. A. and Caldwell, J. (1985). "Dose-dependent variation in the disposition of eugenol in rat." Biochem. Pharmacol. 34: 465-466. 
Swanson, A. B., Miller, E. C. and Miller, J. A. (1981). "The side-chain epoxidation and hydroxylation of the hepatocarcinogens safrole and estragole and some related compounds by rat and mouse liver microsomes." Biochimica et biophysica acta 673(4): 504-516. from http://www.ncbi.nlm.nih.gov/pubmed/7225430.

Vaino, H., Magee, P., McGregor, D. and McMichael, A. (1992). "Mechanisms of carcinogenesis in risk identification." IARC Scientific Publications. International Agency for Research on Cancer, Lyon 116: 1-14.

van den Berg, S. J. P. L., Punt, A., Soffers, A. E., Vervoort, J., Ngeleja, S., Spenkelink, B. and Rietjens, I. M. C. M. (2012). "Physiologically based kinetic models for the alkenylbenzene elemicin in rat and human and possible implications for risk assessment." Chemical research in toxicology 25(11): 2352-2367. from http://www.ncbi.nlm.nih.gov/pubmed/22992039.

van den Berg, S. J. P. L., Restani, P., Boersma, M., Delmulle, L. and Rietjens, I. M. C. M. (2011). "Levels of genotoxic and carcinogenic ingredients in plant food supplements and associated risk assessment." Food and Nutrition Sciences 2(9): 989-1010.

WHO (2009b). Principles and Methods for the Risk Assessment of Chemicals in Food.

Chapter 4; Hazard identification and characterization IPCS, international programme on chemical safety.

WHO. (2015). "Harmonization of approaches to the assessment of risk from exposure to chemicals." from http://www.who.int/ipcs/methods/harmonization/en/.

Williams, G. (1992). "DNA reactive and epigenetic carcinogens." Exp Toxicol Pathol 44: 457-464.

Wiseman, R. W., Fennell, T. R., Miller, J. A. and Miller, E. C. (1985). "Further characterization of the DNA adducts formed by electrophilic esters of the hepatocarcinogens 1'-hydroxysafrole and 1'-hydroxyestragole in vitro and in mouse liver in vivo, including new adducts at C-8 and N-7 of guanine residues." Cancer research 45(7): 3096-3105. from http://www.ncbi.nlm.nih.gov/pubmed/4005847.

Zangouras, A., Caldwell, J., Hutt, A. J. and Smith, R. L. (1981). "Dose dependent conversion of estragole in the rat and mouse to the carcinogenic metabolite, 1'-hydroxyestragole." Biochemical pharmacology 30(11): 1383-1386. from http://www.ncbi.nlm.nih.gov/pubmed/7271835.

Zhou, G.-D., Moorthy, B., Bi, J., Donnelly, K. C. and Randerath, K. (2007). "DNA adducts from alkoxyallylbenzene herb and spice constituents in cultured human (HepG2) cells." 
Environmental and Molecular Mutagenesis 48(9): 715-721. from http://dx.doi.org/10.1002/em.20348.

Zhou, G. D., Moorthy, B., Bi, J., Donnelly, K. C. and Randerath, K. (2007). "DNA adducts from alkoxyallylbenzene herb and spice constituents in cultured human (HepG2) cells." Environmental and molecular mutagenesis 48(9): 715-721. from http://www.ncbi.nlm.nih.gov/pubmed/17948277. 


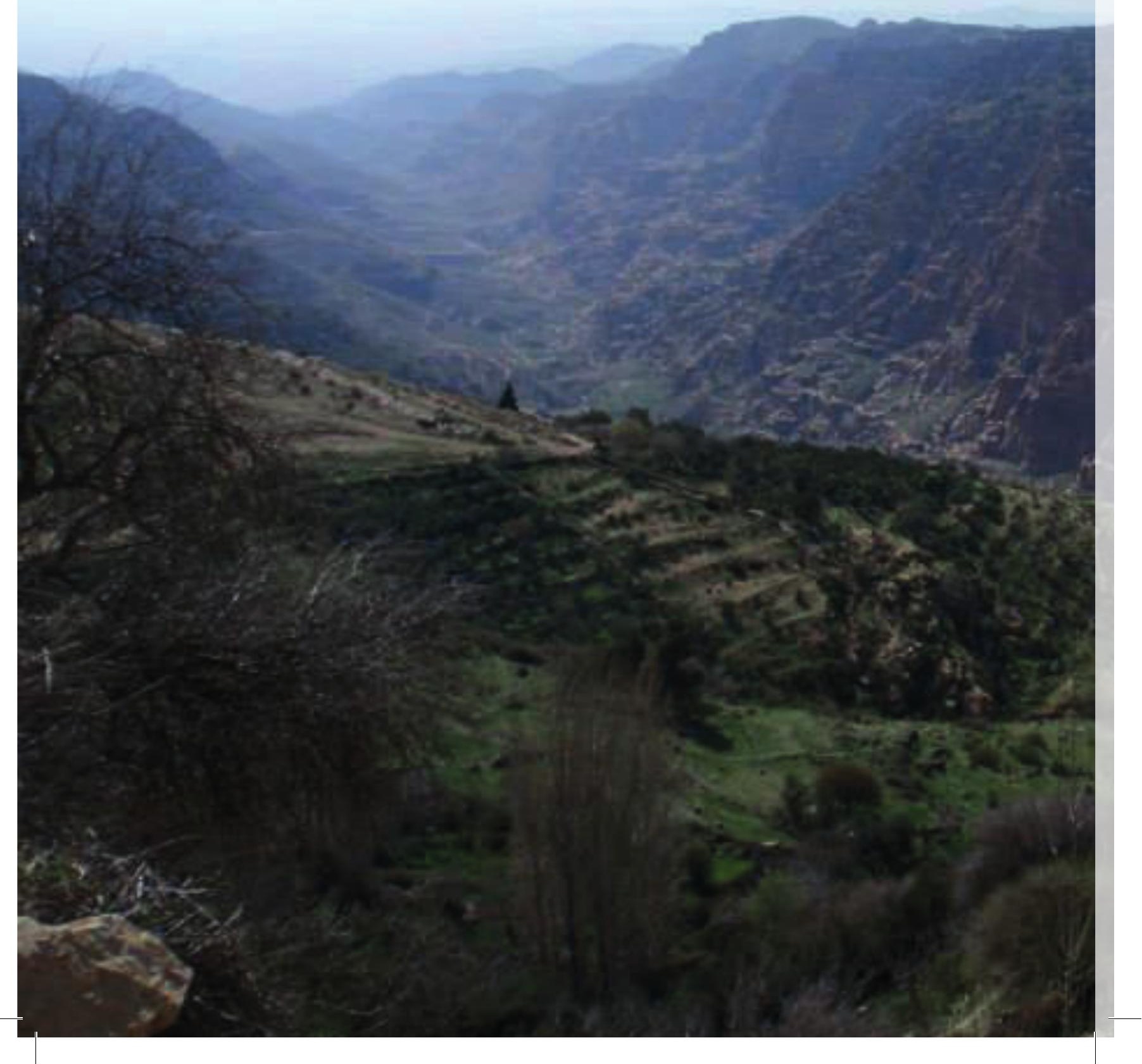




\section{Chapter 2}

\section{Physiologically based kinetic modeling of the bioactivation of myristicin}

Amer J. Al-Malahmeh, Abdelmajeed M. Al-Ajlouni, Sebastiaan Wesseling, Ans E. M. F. Soffers, Ala' Al-Subeihi, Reiko Kiwamoto, Jacques Vervoort, Ivonne M. C. M. Rietjens

Archives of Toxicology (2017), 91(2): 713-734

Doi: 10.1007/s00204-016-1752-5 


\begin{abstract}
The present study describes physiologically based kinetic (PBK) models for the alkenylbenzene myristicin that were developed by extension of the PBK models for the structurally related alkenylbenzene safrole in rat and human. The newly developed myristicin models revealed that the formation of the proximate carcinogenic metabolite 1'hydroxymyristicin in liver is at most 1.8 -fold higher in rat than in human and limited for the ultimate carcinogenic metabolite 1'-sulfoxymyristicin to (2.8-4.0)-fold higher in human. In addition, a comparison was made between the relative importance of bioactivation for myristicin and safrole. Model predictions indicate that for these related compounds, the formation of the 1'-sulfoxy metabolites in rat and human liver is comparable with a difference of $<2.2$-fold over a wide dose range. The results from this PBK analysis support that risk assessment of myristicin may be based on the BMDL 10 derived for safrole of $1.9-5.1 \mathrm{mg} / \mathrm{kg}$ bw per day. Using an estimated daily intake of myristicin of $0.0019 \mathrm{mg} / \mathrm{kg}$ bw per day resulting from the use of herbs and spices, this results in MOE values for myristicin that amount to $1000-2700$, indicating a priority for risk management. The results obtained illustrate that PBK modeling provides insight into possible species differences in the metabolic activation of myristicin. Moreover, they provide and contributing to alternatives in animal testing example of how PBK modeling can facilitate a read-across in risk assessment from a compound for which in vivo toxicity studies are available to a related compound for which tumor data are not reported, thus contributing to alternatives in animal testing.
\end{abstract}




\section{INTRODUCTION}

Myristicin (1-allyl-5-methoxy-3,4 methylene-dioxybenzene or methoxysafrole) is naturally occurring and present in several spices including nutmeg and mace of trees of Myristica species, principally Myristica fragrans Hout, and their essential oils (Forrest and Heacock 1972; Matthews et al. 1974; Sammy and Nawar 1968). There is a potential for human exposure to myristicin through foods, beverages, food supplements, and traditional medicines. Myristicin belongs to the group of alkenylbenzenes that contains structural analogues such as methyleugenol, estragole, elemicin, safrole, and apiol (Figure 1), compounds that are all naturally occurring in herbs and spices such as basil, nutmeg, and their essential oils (Barceloux 2009). Safrole, estragole, and methyleugenol have been shown to induce hepatic tumors in rats or mice upon chronic oral exposure to high doses and upon administration to male CD-1 mice during the preweaning period (Borchert et al. 1973; Drinkwater et al. 1976; Ioannides et al. 1981; Wislocki et al. 1977; Innes 1969; National Toxicology 2000). Tumors were found especially in the liver at frequencies that amounted to, for example, $2 / 50,3 / 50,14 / 50$, and $25 / 50$ at $0,37,75$, and $150 \mathrm{mg}$ methyleugenol/kg bw per day in male rats (National Toxicology 2000). A summary of further incidences of malignant tumor formation in mice and rats after administration of estragole, methyleugenol, or safrole can be found in our previous paper (van den Berg et al. 2011). However, myristicin is less well studied than its structurally related analogues, and only limited toxicological data are available. While in vitro genotoxicity studies indicate that myristicin is mutagenic and capable of inducing the formation of DNA adducts (EFSA 2012; Zhou et al. 2007b), no two-year carcinogenicity studies of myristicin in experimental animals are available hampering its risk assessment. 


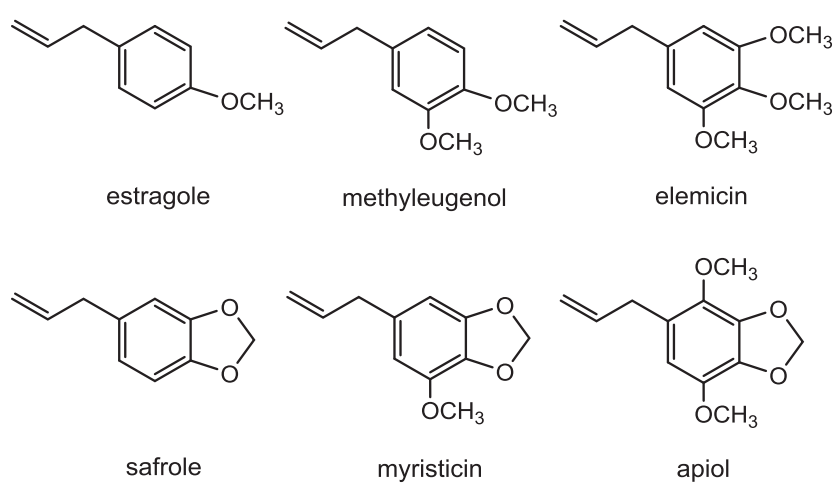

Figure 1. Structural formulas of the alkenylbenzenes, estragole, methyleugenol, elemicin, safrole, myristicin, and apiol.

Some short-term studies were conducted on the induction of hepatic tumors, in which male B6C3F1 mice were given myristicin during the preweaning period in two separate experiments. In the first experiment, myristicin was injected with a total dose of $3.75 \mu$ mol to 33 male B6C3F1 mice over a period of 22 days, and the total duration of the experiment was 12 months. In a second experiment, 45 male $\mathrm{B} 6 \mathrm{C} 3 \mathrm{~F} 1$ mice were each injected with a total dose of $4.75 \mu \mathrm{mol}$ myristicin over a period of 22 days, and the total duration of the experiment was 18 months. In these short-term exposure experiments, myristicin had no detectable activity for the initiation of hepatic tumors (Miller et al. 1983).

In agreement with hepatocarcinogenicity in mice (Miller et al. 1983), DNA adduct formation upon exposure to myristicin was generally lower and less persistent than DNA adduct formation upon exposure to methyleugenol and estragole and appeared to be about 2-fold lower than DNA adduct formation upon exposure to safrole, both in in vitro study (Zhou et al. 2007a) and in in vivo studies (Table 1) (Phillips et al. 1984; Randerath et al. 1984). $\mathrm{N}^{2}$-(trans-isomyristicin-3'-yl)2'-deoxyguanosine was found to be the major myristicin DNA adduct formed when mice were 
given cola drinks instead of water up to 8 weeks. In a parallel experiment, pregnant ICR mice were treated by gastric intubation with a single dose of $6 \mathrm{mg}$ of myristicin, and the level of myristicin adducts in maternal and fetal liver was 68 and $63 \%$ of the total adducts (Randerath et al. 1993). In freshly isolated rat hepatocytes in primary culture, safrole, estragole, and methyleugenol induced unscheduled DNA synthesis (UDS) and cytotoxicity at the concentrations of $10^{-6}$ to $10^{-3} \mathrm{M}$, (Howes et al. 1990) while myristicin showed cytotoxicity. In these studies, concentrations inducing UDS were generally close to or already at concentrations detecting cytotoxicity, hampering interpretation of the data. The data supporting a genotoxic mode of action for the tumor induction by the alkenylbenzenes rather come from studies reporting DNA adduct formation. In these studies, myristicin, as well as estragole, methyleugenol, and safrole, all showed positive results (Zhou et al. 2007a; Kobets et al. 2016; Phillips et al. 1984; Randerath et al. 1984). A schematic overview of the detoxification and bioactivation of myristicin that is similar to that of its structurally related compound safrole (Swanson et al. 1979; Borchert et al. 1973; Drinkwater et al. 1976) is shown in Figure 2. Epoxidation of the double bond in the allyl side chain yields the 2,3-epoxide. In in vitro experiments, the epoxide readily forms DNA adducts, but rapid detoxification by epoxide hydrolase and glutathione S-transferases (GSTs) prevents it from forming detectable levels of DNA adducts in vivo (Luo et al. 1992; Luo and Guenthner 1996). The primary bioactivation pathway of myristicin is 1'-hydroxylation of the alkene side chain to yield the 1'-hydroxy metabolite which can be conjugated with either glucuronic acid representing a detoxification reaction or sulfate representing the ultimate bioactivation to 1'-sulfoxymyristicin (Drinkwater et al. 1976; Benedetti et al. 1977; Zangouras et al. 1981; Miller et al. 1983). The 1'-sulfoxy metabolite represents the ultimate carcinogenic metabolite (Wiseman et al. 1985, 1987; 
Randerath et al. 1984; Phillips et al. 1984). 1'-Sulfoxy metabolites of alkenylbenzenes may react readily with DNA, RNA, and proteins but can also be detoxified through reaction with $\mathrm{H}_{2} \mathrm{O}$ or conjugation with glutathione (Phillips et al. 1984; Miller et al. 1983; Fennell et al. 1984; Ishii et al. 2011). Therefore, only a fraction of the 1'-sulfoxy metabolite is expected to form DNA adducts (Rietjens et al. 2014).

Although myristicin is thus likely to also induce DNA adducts and liver tumors, its risk assessment at low realistic dietary intake levels is hampered by the fact that carcinogenicity studies are lacking (Hallstrom and Thuvander 1997). Therefore, the aim of the present study was to characterize the detoxification and bioactivation of myristicin and to develop a physiologically based kinetic (PBK) model to describe the ultimate formation of the 1'-sulfoxy metabolite in the liver of both rat and human and subsequently perform a read-across-based risk assessment using a similar PBK model previously described for safrole for which tumor data from long-term toxicity testing are available. Previously, using a similar approach and read-across from estragole and methyleugenol, the risk of exposure to elemicin for which also only limited in vivo rodent tumor data were available could be evaluated (van den Berg et al. 2012). Such a PBK modelingbased read-across illustrates a novel approach for animal-free risk assessment of a genotoxic carcinogen without the need for a long-term carcinogenicity study. 


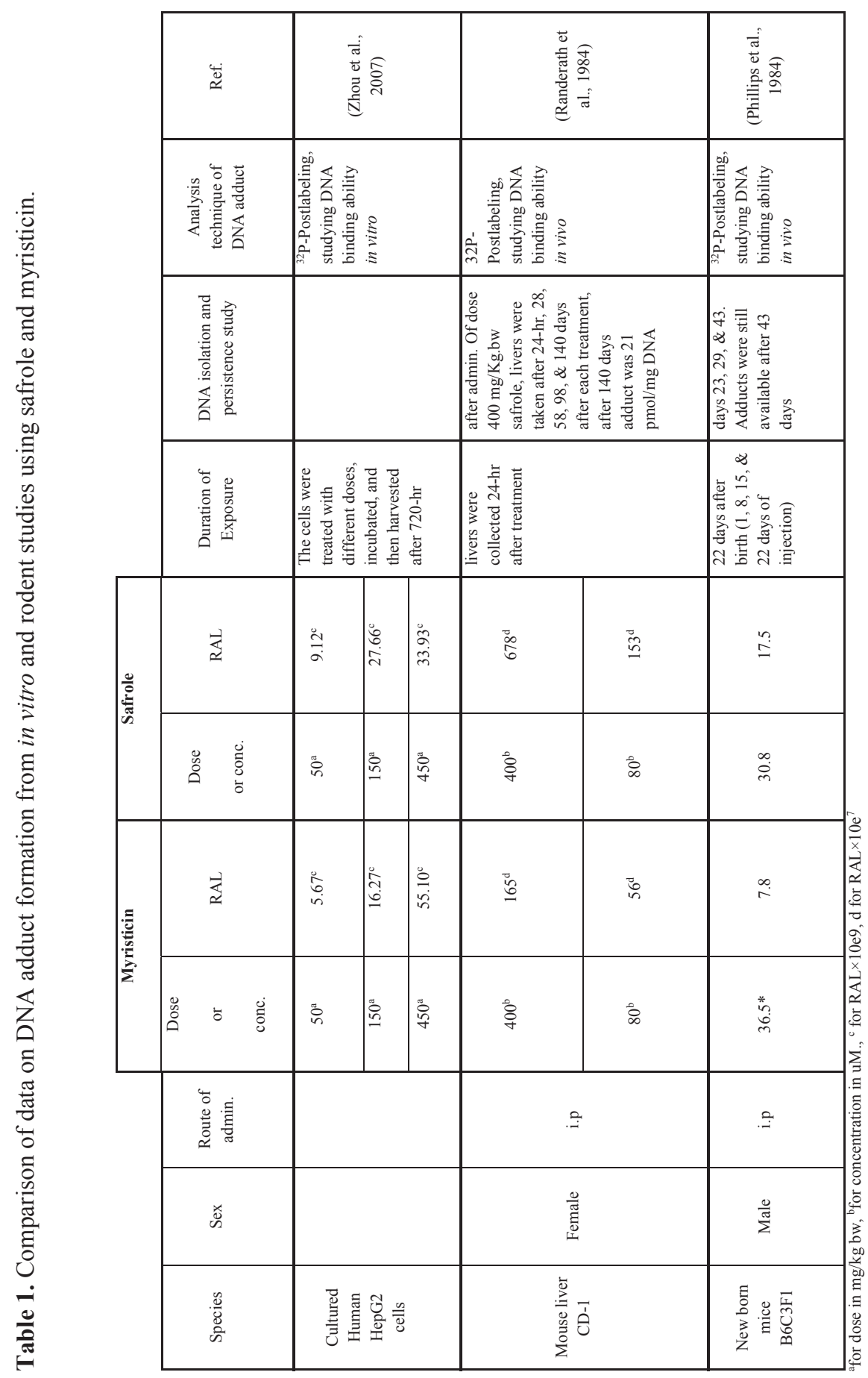




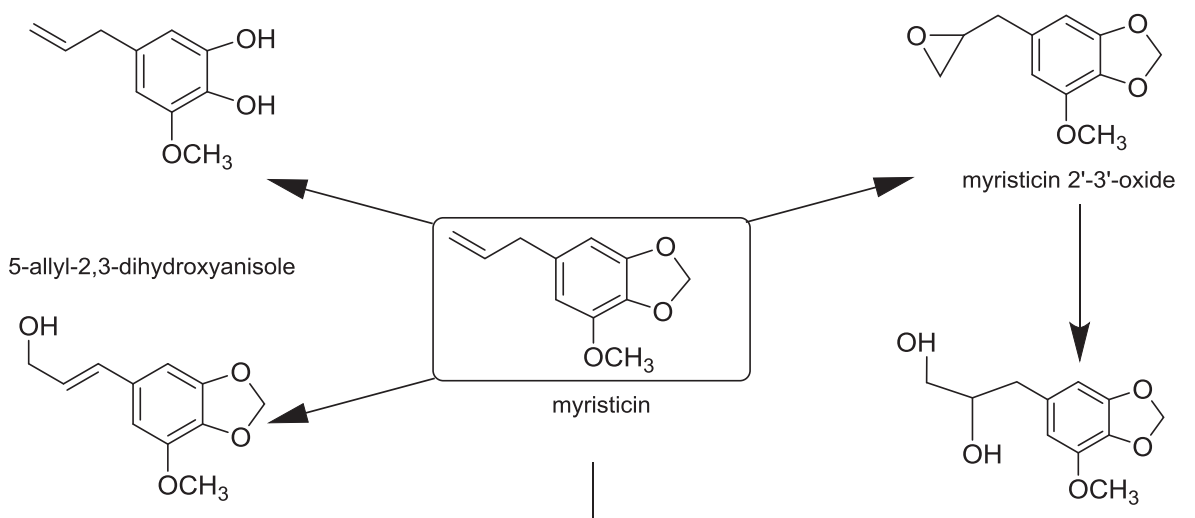

$$
\text { 3'-hydroxymyristicin }
$$

2',3'-dihydroxymyristicin<smiles>C=CC(OC)c1cc(OC)c2c(c1)OCO2</smiles><smiles>C=CC(O)c1cc(OC)c2c(c1)OCO2</smiles><smiles>C=CC(=O)c1cc(OC)c2c(c1)OCO2</smiles>

1'-hydroxymyristisin glucuronide<smiles>C=CC(OS(=O)(=O)[O-])c1cc(OC)c2c(c1)OCO2</smiles>

1 '-oxomyristicin

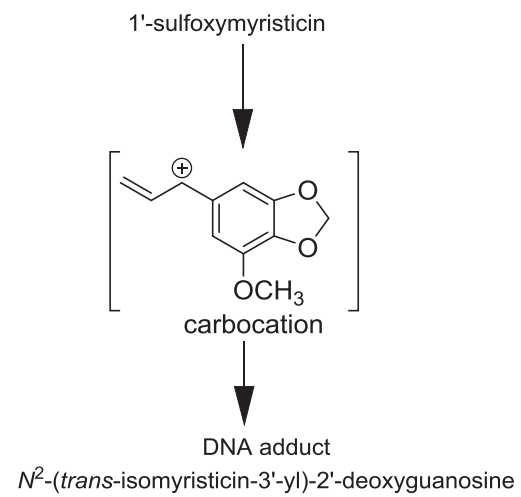

Figure 2. Proposed metabolic pathways of the alkenylbenzene myristicin. 


\section{MATERIAL AND METHODS}

\section{Chemicals}

Myristicin, tris(hydroxymethyl)aminomethane, uridine 5'-diphosphoglucuronide acid (UDPGA), reduced L-glutathione (GSH), alamethicin (from Trichodermaviride), 3'-phosphoadenosine-5' phosphosulfate (PAPS), $\beta$-nicotinamide adenine dinucleotide $(\mathrm{NAD}+)$, and reduced $\beta$ nicotinamide adenine dinucleotide phosphate (NADPH) were obtained from Roche Diagnostics (Mannheim, Germany). Dimethyl sulfoxide (DMSO) was obtained from Acros Organics (Geel, Belgium). Potassium dihydrogen phosphate, dipotassium hydrogen phosphate trihydrate, acetic acid, and magnesium chloride were supplied by VWR International (Darmstadt, Germany). Acetonitrile (ACN) (UPLC/MS grade) was purchased from Biosolve BV (Valkenswaard, The Netherlands). Trifluoroacetic acid TFA was obtained from Merck (Darmstadt, Germany). Pooled male rat liver microsomes and S9 from Sprague-Dawley and mixed gender pooled human liver microsomes and S9 were obtained from BD Gentest (Woburn, USA). Pooled male SpragueDawley rat lung, kidney, and small intestinal microsomes and pooled gender human lung, kidney, and intestinal microsomes were purchased from BioPredic International (Rennes, France).

\section{Synthesis of 1'-hydroxymyristicin and 1'-oxomyristicin}

The synthesis of 1'-hydroxymyristicin from myristicin was done as described previously by Jeurissen et al. (2004), and 1'-oxomyristicin was synthesized from 1'-hydroxymyristicin according to the method used for the synthesis of 1'-oxoestragole from 1'-hydroxyestragole (Wislocki et al. 1976). 


\section{Microsomal metabolism of myristicin}

First, it was determined which organs are involved in the biotransformation of myristicin in rat and human. For this purpose, liver, kidney, lung, and small intestine microsomes from male Sprague-Dawley rat and pooled gender human were used. Incubations were performed by adding myristicin to incubation mixtures containing $1 \mathrm{mg} / \mathrm{mL}$ of the microsomal protein preparations and $3 \mathrm{mM}$ NADPH in $0.2 \mathrm{M}$ Tris- $\mathrm{HCl}(\mathrm{pH}$ 7.4). After $1 \mathrm{~min}$ of pre-incubation at 37 ${ }^{\circ} \mathrm{C}$, myristicin (final concentration, $1000 \mu \mathrm{M}$ ) was added from a 100 times concentrated stock solution in DMSO so that the final DMSO content was $1 \%(\mathrm{v} / \mathrm{v})$. Incubations were carried out for 30 min after which the reactions were terminated by adding $25 \mu 1(0.25$ times the incubation volume) of ice-cold ACN. Samples were centrifuged for $5 \mathrm{~min}$ at $13000 \times \mathrm{g}$, and the supernatant was stored at $-20{ }^{\circ} \mathrm{C}$ until UPLC analysis. As metabolism of myristicin was observed only in incubations with liver microsomes for male rats and pooled gender human, the determination of kinetic constants for the formation of microsomal metabolites was performed only for the liver fractions. Incubations to determine kinetic constants were performed following the conditions described above using final concentrations of myristicin from 25 to $1000 \mu \mathrm{M}$ for rat and human liver. In all incubations, the final concentration of DMSO, in which myristicin was dissolved, was kept at $1 \%(\mathrm{v} / \mathrm{v})$. The formation of different microsomal metabolites was linear with time and microsomal protein concentration under the conditions described. Blank incubations were performed in the absence of the cofactor NADPH. All incubations were performed in triplicate.

\section{Glucuronidation of 1'-hydroxymyristicin to 1'-hydroxymyristicin glucuronide}

The kinetic constants for the metabolic conversion of 1'-hydroxymyristicin to 1'hydroxymyristicin glucuronide (HMG) by both male rat and human liver fractions were 
determined as described previously for the related 1'-hydroxyalkenylbenzenes (Punt et al. 2008; van den Berg et al. 2012; Punt et al. 2009; Martati et al. 2011, 2012; Al-Subeihi et al. 2011, 2012). Briefly, incubations contained (final concentrations) $10 \mathrm{mM}$ of UDPGA and $0.5 \mathrm{mg} / \mathrm{ml}$ of male Sprague-Dawley or pooled gender human $\mathrm{S} 9$ protein in $0.2 \mathrm{M}$ Tris- $\mathrm{HCl}$ ( $\mathrm{pH} 7.4$ ) containing $10 \mathrm{mM}$ of $\mathrm{MgCl}$. To overcome enzyme latency and to obtain maximal glucuronidation activity, incubations containing S9 were pretreated on ice with $0.025 \mathrm{mg} / \mathrm{ml}$ alamethicin added from a 200 times concentrated stock dissolved in methanol (Fisher et al. 2000; Lin and Wong 2002). After $15 \mathrm{~min}$ of alamethicin treatment, samples were pre-incubated at 37 ${ }^{\circ} \mathrm{C}$ for $1 \mathrm{~min}$, and reactions were subsequently started by adding 1 '-hydroxymyristicin at final concentrations of 10 to $1200 \mu \mathrm{M}$. 1'-Hydroxymyristicin was added from 100 times concentrated stock solutions in DMSO. The reaction mixtures were incubated for 30 and $180 \mathrm{~min}$ for rat and human, respectively, and terminated by adding $25 \mu 1$ ( 0.25 times the incubation volume) of icecold ACN. Blank incubations were carried out in the absence of the cofactor UDPGA. Experiments were performed in triplicate. The longer incubation time in human samples was required due to the lower rate of glucuronidation. The formation of 1'-hydroxymyristicin glucuronide was linear with time and the S9 protein concentration under the experimental conditions described. All samples were centrifuged for $5 \mathrm{~min}$ at $16000 \times \mathrm{g}$, and the supernatant was stored at $-20{ }^{\circ} \mathrm{C}$ until ultra-performance liquid chromatography (UPLC) analysis.

\section{Oxidation of 1'-hydroxymyristicin to 1'-oxomyristicin}

The kinetic constants for the enzymatic conversion of 1'-hydroxymyristicin to 1'-oxomyristicin were determined using incubation mixtures containing (final concentrations) $3 \mathrm{mM} \mathrm{NAD+}, 2$ $\mathrm{mM} \mathrm{GSH}$, and $1 \mathrm{mg} / \mathrm{ml}$ rat or human liver microsomes in $0.2 \mathrm{M}$ Tris- $\mathrm{HCl}$ (pH 7.4). GSH was 
added to the incubation mixtures to trap the reactive 1'-oxo metabolite formed after oxidation of 1'-hydroxymyristicin. The level of GSH in the incubations was optimized in a previous study to obtain maximum scavenging of 1'-oxoestragole (Punt et al. 2009). To this end, incubations were performed in the presence of increasing concentrations of GSH, ranging from 2 to $10 \mathrm{mM}$. At a concentration of $2 \mathrm{mM} \mathrm{GSH}$ maximum formation of GS-1'-oxoestragole was reached in the incubations, pointing at maximum scavenging of 1'-oxoestragole at this concentration (Punt et al. 2009). Kinetic constants for this reaction in rat and human liver were derived by performing incubations with $\mathrm{NAD}^{+}$as a cofactor, given that in rat and human liver, $\mathrm{NAD}^{+}$is mainly present in an oxidized form with levels of $\mathrm{NAD}^{+}$being much higher than those of $\mathrm{NADH}$. In a previous study, it was shown that the highest level of 1'-hydroxy alkenylbenzene oxidation occurs in incubations with microsomes in the presence of $\mathrm{NAD}^{+}$as cofactor. In incubations with pooled human liver cytosol in the presence of $\mathrm{NAD}^{+}$or $\mathrm{NADP}^{+}$, lower levels of oxidation were observed, indicating that the reaction is not primarily catalyzed by alcohol dehydrogenases (ADH) or other enzymes present in the cytosol (Punt et al. 2010). The enzyme responsible for the oxidation may be 17ß-hydroxysteroid dehydrogenase type 2 (17ß-HSD2) (Punt et al. 2010). Prior to the addition of 1'-hydroxymyristicin at final concentrations ranging between 10 and $4000 \mu \mathrm{M}$ to the incubation mixture from 100 times concentrated stock solutions in DMSO, samples were pre-incubated for $1 \mathrm{~min}$ at $37{ }^{\circ} \mathrm{C}$. Reactions were terminated after $10 \mathrm{~min}$ of incubation at $37^{\circ} \mathrm{C}$ by adding $25 \mu \mathrm{l}(0.25$ times the incubation volume $)$ of ice-cold ACN. The formation of the GSH conjugate of 1'-oxomyristicin (GS-1'-oxomyristicin) was linear with time and microsomal protein concentration under the experimental conditions used. Blank incubations were performed without the cofactor $\mathrm{NAD}^{+}$. Incubations were performed in triplicate. All 
samples were centrifuged for $5 \mathrm{~min}$ at $13000 \times \mathrm{g}$, and the supernatant was stored at $-20{ }^{\circ} \mathrm{C}$ until UPLC analysis.

\section{Sulfonation of 1'-hydroxymyristicin to 1'-sulfoxymyristicin}

The formation of 1'-sulfoxymyristicin was determined using incubations containing male rat liver Sprague-Dawley or pooled gender human liver S9 proteins, PAPS as a cofactor, and GSH, which acts as a scavenger of the reactive carbocation formed due to the unstable nature of the 1'sulfoxy metabolite in an aqueous environment (van den Berg et al. 2012; Martati et al. 2011; AlSubeihi et al. 2011). Incubation mixtures containing (final concentrations) $10 \mathrm{mM}$ of GSH, 0.2 $\mathrm{mM}$ of PAPS, and $3 \mathrm{mg} / \mathrm{ml}$ of $\mathrm{S} 9$ proteins in $0.1 \mathrm{M}$ potassium phosphate $(\mathrm{pH} 8.2)$ were preincubated for $1 \mathrm{~min}$ at $37^{\circ} \mathrm{C}$. After the pre-incubation, 1'-hydroxymyristicin dissolved in DMSO was added in final concentrations ranging between 10 and $6000 \mu \mathrm{M}$ while keeping the final content of DMSO at $1 \%(\mathrm{v} / \mathrm{v})$. The reaction was terminated after $360 \mathrm{~min}$ of incubation by adding $25 \mu \mathrm{l}$ ( 0.25 times the incubation volume) of ice-cold ACN. The formation of the GSH conjugate of 1'-sulfoxymyristicin was linear with time and S9 protein concentrations under the experimental conditions used. Blank incubations were performed in the absence of PAPS. Incubations were performed in triplicate. All samples were centrifuged for $5 \mathrm{~min}$ at $16000 \times \mathrm{g}$, and the supernatant was stored at $-20{ }^{\circ} \mathrm{C}$ until ultra-performance liquid chromatography (UPLC) analysis. 


\section{Identification and quantification of metabolism of myristicin and 1'-hydroxymyristicin by}

\section{UPLC}

Microsomal incubations with myristicin only detected primary metabolites, and all incubation conditions were chosen such that substrate conversion did not exceed $10 \%$ of the initial substrate concentration, a condition that is also essential to ascertain adequate determination of the kinetic constants. Secondary metabolism of the relevant 1'-hydroxy metabolite of myristicin was taken into account by determining the kinetic constants for its conversion in (a) glucuronidation, (b) sulfation, and (c) oxidation, again under conditions that allowed adequate definition of kinetic constants and with $<10 \%$ substrate conversion. Incubation samples were subjected to UPLC analysis that was performed as described previously (Punt et al. 2008). Identification was achieved by comparing the UV spectra of the formed metabolites to the spectra of the synthesized 1'-hydroxymyristicin and 1'-oxomyristicin reference standards. Quantification of all formed metabolites was done by comparing the peak areas to those of calibration curves of the corresponding reference compounds, determined using UPLC with photodiode array detection (UPLC-PDA). The UPLC system was composed of a Waters (Waters, Milford, MA) Acquity solvent manager, sample manager, and photodiode array detector, equipped with Water Acquity UPLC BEH C18 column.

For 2',3'-dihydroxymyristicin and 5-allyl-2,3-dihydroxyanisole that were found to have the same UV spectrum as 1'-hydroxymyristicin, and for 1'-hydroxymyristicin, estimation was based on the comparison of the peak area of the formed metabolites to the calibration curve of the synthesized 1'-hydroxymyristicin at a wavelength of $210 \mathrm{~nm}$. For 3'-hydroxymyristicin, estimation was based on the comparison of the peak area to the calibration curve of the GSH adduct of synthetised 1'-oxymyristicin at a wavelength of $212 \mathrm{~nm}$, because 3'-hydroxymyristicin 
was found to have the same UV spectrum as the GSH adduct of synthetised 1'-oxymyristicin. The gradient for analysis of microsomal metabolites was performed with $100 \% \mathrm{ACN}$ and ultrapure water containing $0.1 \%(\mathrm{v} / \mathrm{v})$ TFA. The flow rate was $0.6 \mathrm{ml} / \mathrm{min}$. The gradient started at $10 \% \mathrm{ACN}$, increased to $50 \% \mathrm{ACN}$ over $4 \mathrm{~min}$, increased to $80 \%$ over $0.5 \mathrm{~min}$, followed by decrease to $10 \% \mathrm{ACN}$ over $0.5 \mathrm{~min}$, and finally kept at $10 \%$ for $1 \mathrm{~min}$.

1 '-Hydroxymyristicin glucuronide was estimated based on the comparison of the peak area of the formed metabolite to the calibration curve of 1'-hydroxymyristicin at a wavelength of 210 $\mathrm{nm}$. The flow rate was $0.6 \mathrm{ml} / \mathrm{min}$. The gradient was made using a mixture of $\mathrm{ACN}$ and ultrapure water containing $0.1 \%(\mathrm{v} / \mathrm{v})$ TFA. The gradient started at $10 \% \mathrm{ACN}$, increased to $60 \%$ over 3.5 min, after which ACN was increased to $80 \%$ over $0.5 \mathrm{~min}$, and kept at $80 \%$ for $0.5 \mathrm{~min}$, and finally decreased to $10 \%$ over $0.5 \mathrm{~min}$.

Quantification of GS-1'-oxomyristicin was based on a calibration curve of the GSH adduct of the synthesized 1'-oxymyristicin made as previously described (van den Berg et al. 2012; Punt et al. 2009; Martati et al. 2011; Al-Subeihi et al. 2011). In short, a $60 \mu \mathrm{M}$ concentration of the synthetic standard of 1'-oxomyristicin, dissolved in ACN, was incubated with different concentrations of GSH (i.e., $0-20 \mu \mathrm{M})$ in $0.2 \mathrm{M}$ Tris $-\mathrm{HCl}(\mathrm{pH} 7.4)$ for 6 -hr at $37^{\circ} \mathrm{C}$, resulting in full conversion of the GSH to GS-1'-oxymyristicin. Quantification was done by comparing the peak areas of the formed GS-1'-oxo metabolite in the incubation mixtures with peak areas of the GS-1'-oxymyristicin calibration curve thus obtained at a wavelength of $212 \mathrm{~nm}$. The gradient for analysis of the metabolite consisted of a mixture of ACN and ultrapure water containing $0.1 \%$ (v/v) TFA. The flow rate was $0.6 \mathrm{ml} / \mathrm{min}$, The gradient started with $10 \% \mathrm{ACN}$, increased to 30 $\%$ ACN over 2.5 min, after which ACN was increased to $80 \%$ over 0.5 min, kept at $80 \%$ for 0.5 min, followed by a decrease to $10 \%$ over $0.5 \mathrm{~min}$, and finally kept at $10 \%$ for $0.5 \mathrm{~min}$. 
Quantification of 1'-sulfoxymyristicin was done using UPLC analysis as described for the estimation of 1'-sulfoxysafrole (Martati et al. 2011). The UV spectrum of the GSH adduct of 1'sulfoxymyristicin was found to be similar to the UV spectrum of the GSH conjugate of 1'oxomyristicin, and estimation of the GSH adduct of 1'-sulfoxymyristicin was thus accomplished by comparing the peak area of this metabolite to the calibration curve of GS-1'-oxomyristicin at a wavelength $305 \mathrm{~nm}$. The gradient for analysis of the metabolite consisted of a mixture of ACN and ultrapure water containing $0.1 \%(\mathrm{v} / \mathrm{v})$ TFA. The flow rate was $0.6 \mathrm{ml} / \mathrm{min}$, starting at $0 \%$ $\mathrm{ACN}$ and increasing the percentage of $\mathrm{ACN}$ to $20 \%$ over $0.2 \mathrm{~min}$, followed by an increase to 30 $\%$ ACN over $4.3 \mathrm{~min}$, then increasing to $100 \%$ over $0.3 \mathrm{~min}$, and keeping it at $100 \%$ for 0.2 min, and finally decreasing to $0 \%$ over $0.2 \mathrm{~min}$ and keeping it at $0 \%$ for $0.8 \mathrm{~min}$. Separation and purification of the GSH adduct of 1'-sulfoxymyristicin was performed by collecting the peak of the metabolite from the UPLC column. Then, LC-MS analysis of the metabolite was conducted using a micro-TOF MS (Bruker) coupled to an Agilent LC (1200 Series) equipped with Altima C18 column $(150 \times 4.6 \mathrm{~mm}, 3 \mu \mathrm{m})$. The mobile phase used consisted of (A) nanopure water with $0.1 \%$ formic acid and (B) HPLC-grade ACN with $0.1 \%$ formic acid. Elution was at a flow rate of $0.8 \mathrm{ml} / \mathrm{min}$, starting at $22 \% \mathrm{~B}$ with a linear increase to $100 \% \mathrm{~B}$ in $30 \mathrm{~min}$. Subsequently, the gradient returned linearly to the initial conditions in $2 \mathrm{~min}$ and remained $13 \mathrm{~min}$ at this condition prior to the next injection. Mass spectrometric analysis was in the negative electrospray mode using a spray capillary voltage of $4500 \mathrm{~V}$, a capillary temperature of $200{ }^{\circ} \mathrm{C}$, and nitrogen as nebulizer gas at $8.0 \mathrm{~L} / \mathrm{min}$. 


\section{Determination of kinetic constants}

Kinetic constants for the metabolic conversions of myristicin and 1'-hydroxymyristicin were derived by fitting the data to the standard Michaelis-Menten equation,

$$
\mathrm{v}=\mathrm{V}_{\max } \times[\mathrm{S}] / \mathrm{K}_{\mathrm{m}}+[\mathrm{S}]
$$

For conversion of 1'-hydroxymyristicin to 1'-sulfoxymyristicin, a first-order rate linear equation was used:

$$
\mathrm{v}=\mathrm{k}_{\mathrm{HMS}} \times[\mathrm{S}]
$$

In which $[\mathrm{S}]$ represents the substrate concentration, $\mathrm{V}_{\max }$ the maximum velocity, and $\mathrm{K}_{\mathrm{m}}$ the Michaelis-Menten constant for the formation of the different metabolites of myristicin or 1'hydroxymyristicin, $\mathrm{k}_{\mathrm{HMS}}$ the first-order rate constant for sulfonation of 1'-hydroxymyristicin. Data analysis was accomplished using GraphPad Prism, version 5.04 (GraphPad Software, San Diego, CA).

\section{Physiologically based kinetic (PBK) models}

Two PBK models were developed describing the relative importance of bioactivation and detoxification of myristicin in rat and human at different oral dose levels. The models developed in this study were essentially based on the PBK models previously defined for the metabolism of estragole (Punt et al. 2008, 2009), methyleugenol (Al-Subeihi et al. 2011, 2012), elemicin (van den Berg et al. 2012), and safrole (Martati et al. 2011, 2012) in rat and human. A schematic overview of the developed PBK models for myristicin metabolism in rat and human is shown in Figure 3. The models consist of several compartments representing different organs and tissues (i.e., liver, fat tissue, richly perfused tissues, and slowly perfused tissues) that are mutually connected through the systemic circulation. First-order kinetics was used to describe the uptake 
of myristicin from the gastrointestinal (GI) tract assuming a direct uptake by the liver with an absorption rate constant $\left(\mathrm{k}_{\mathrm{a}}\right)$ of $1.0 \mathrm{~h}^{-1}$, which is based on the fast and complete absorption of the structurally related alkenylbenzene safrole from the GI tract (Punt et al. 2008). For rat and human, the liver was the only organ able to convert myristicin to different microsomal metabolites. 2',3'-Dihydroxymyristicin (DHM), 3'-hydroxymyristicin $\quad(3 \mathrm{HM}), \quad$ 1'hydroxymyristicin (HM), and 5-allyl-2,3-dihydroxyanisole (DHA) were formed in incubations with both rat and human liver.

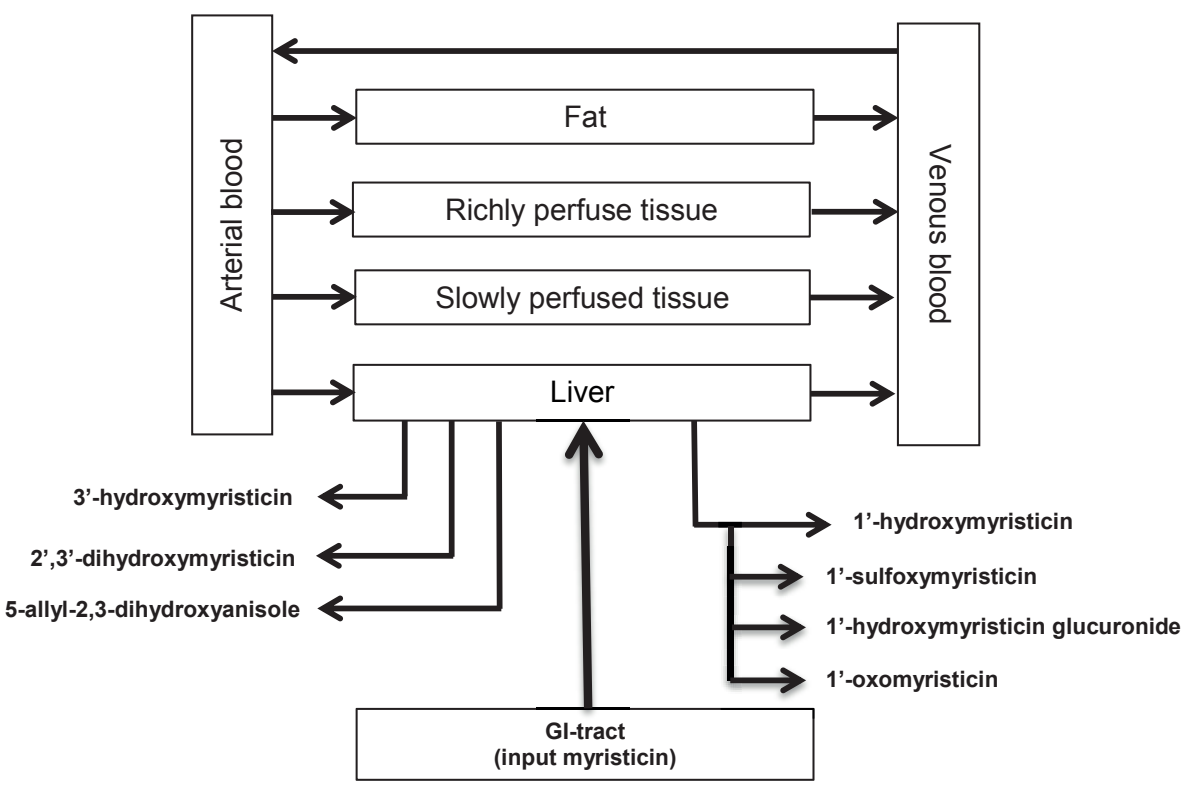

Figure 3. Schematic overview of the PBK model for myristicin in rat and human. 
Accordingly, mass balance equations for myristicin in rat liver and human were as follows:

$$
\begin{aligned}
& \partial A L_{M} / \partial t=\partial \text { Uptake }_{M} / \partial t+Q L \times\left(C A_{M}-C L_{M} / P L_{M}\right) \\
& -V_{\max _{H M}} \times C L_{M} / P L_{M} /\left(K_{m_{H M}}+C L_{M} / P L_{M}\right) \\
& -V_{\max _{3 H M}} \times C L_{M} / P L_{M} /\left(K_{m_{3 H M}}+C L_{M} / P L_{M}\right) \\
& -V_{\max _{D H A}} \times C L_{M} / P L_{M} /\left(K_{m_{D H A}}+C L_{M} / P L_{M}\right) \\
& -V_{\max _{D H M}} \times C L_{M} / P L_{M} /\left(K_{m_{D H M}}+C L_{M} / P L_{M}\right) \\
& \text { DUptake } / \partial t=-\partial A G I_{M} / \partial t=K_{a} \times A G I_{M}, A G I_{M}(0)=\text { oral dose } \\
& C L_{M}=A L_{M} / V L
\end{aligned}
$$

Where Uptake $(\mu \mathrm{mol})$ is the amount of myristicin taken up from the GI tract, $\mathrm{AGI}_{\mathrm{M}}(\mu \mathrm{mol})$ is the amount of myristicin remaining in the GI tract, and $\mathrm{AL}_{\mathrm{M}}(\mu \mathrm{mol})$ is the amount of myristicin in the liver or CLM is the myristicin concentration in the liver $(\mu \mathrm{mol} / \mathrm{L}) . \mathrm{CA}_{\mathrm{M}}$ and $\mathrm{CV}_{\mathrm{M}}$ are the myristicin concentrations in the arterial and venous blood (both in $\mu \mathrm{mol} / \mathrm{L}$ ), QL is the blood flow rate to a tissue $(\mathrm{L} / \mathrm{h}), \mathrm{QC}$ is the cardiac output $(\mathrm{L} / \mathrm{h}), \mathrm{VL}$ is the volume of liver, $\mathrm{PL}_{\mathrm{M}}$ is the tissue/blood partition coefficient of myristicin, and Vmax and $\mathrm{Km}$ are the values representing the maximum rate of formation and Michaelis-Menten constant, respectively, for the formation of 2',3'-dihydroxymyristicin (DHM), 3'-hydroxymyristicin (3HM), 1'-hydroxymyristicin (HM), and 5-allyl-2,3-dihydroxyanisole (DHA).

The mass balance equation for the metabolic conversion of 1'-hydroxymyristicin by glucuronidation, oxidation, and sulfonation in the liver in rat and human liver is as follows:

$$
\begin{gathered}
\partial A L_{H M} / \partial t=V_{\max _{H M}} \times C L_{M} / P L_{M} /\left(K_{m_{H M}}+C L_{M} / P L_{M}\right) \\
-V_{\max _{,} L_{H M G}} \times C L_{H M} / P L_{H M} /\left(K_{m_{H M G}}+C L_{H M} / P L_{H M}\right) \\
-V_{\max _{H M O}} \times C L_{H M} / P L_{H M} /\left(K_{m_{H M O}}+C L_{H M} / P L_{H M}\right) \\
-k_{H M S} \times C L_{H M} / P L_{H M} \\
C L_{M}=A L_{M} / V L
\end{gathered}
$$


where $\mathrm{AL}_{\mathrm{Hm}}$ is the amount of 1'-hydroxymyristicin in the liver ( $\left.\mu \mathrm{mol}\right)$, CLHM is the 1'hydroxymyristicin concentration in the liver $(\mu \mathrm{mol} / \mathrm{L}), \mathrm{PL}_{\mathrm{HM}}$ is the liver/blood partition coefficient of 1'-hydroxymyristicin, and Vmax and $\mathrm{Km}$ are the maximum rate of formation and Michaelis-Menten constant, respectively, for the formation of the different 1'-hydroxymyristicin metabolites in the liver, including 1'-hydroxymyristicin glucuronide, 1'-oxomyristicin, and $k_{\mathrm{HMS}}$ is the first-order rate constant for sulfonation of 1'-hydroxymyristicin that was used instead of $\mathrm{Km}$ and $\mathrm{Vmax}$ as sulfonation showed no saturation. $\mathrm{V}_{\max }$ and $\mathrm{K}_{\mathrm{m}}$ values and first-order rate constants $\mathrm{k}$ in case of the absence of saturation (for sulfonation of 1'-hydroxymyristicin in rat and human) for the different metabolic pathways of myristicin and 1'-hydroxymyristicin were derived from results from in vitro experiments in the present study. $\mathrm{V}_{\max }$ values that were derived in vitro expressed as $\mathrm{nmol} \mathrm{min}^{-1}$ (mg liver microsomal or $\mathrm{S} 9$ protein) ${ }^{-1}$ were scaled to values representing the $\mathrm{V}_{\max }$ per $\mu \mathrm{mol} \mathrm{h}{ }^{-1}$ (g liver) ${ }^{-1}$ using microsomal protein yields of $35 \mathrm{mg} / \mathrm{g}$ for rat and $32 \mathrm{mg} / \mathrm{g}$ for human liver and $\mathrm{S} 9$ protein yields of $143 \mathrm{mg} / \mathrm{g}$ for liver, as defined previously (Punt et al. 2008, 2009), based on Medinsky et al. (1994). First-order rate constant k expressed in $\mathrm{ml} \mathrm{min}^{-1}$ (mg liver S9 protein) $)^{-1}$ was scaled to values expressed in $\mathrm{ml} \mathrm{h}^{-1}$ per $\mathrm{g}$ liver using the same conversion factor for S9 protein yield. Tables 2 and 3 summarize the physiological parameters (i.e., tissue volumes, cardiac output, and tissue blood flows) for rat and human, respectively, which were derived from the literature (Brown et al. 1997). Partition coefficients were derived in silico based on a method described by DeJongh et al. (1997) using the log Kow. $\log \mathrm{K}_{\mathrm{ow}}$ values for myristicin (Clog P 3.1721) and 1'-hydroxymyristicin (Clog P 1.6151) were estimated using Chemdraw professional 15 (ChemOffice ${ }^{\circledR}$ Professional 15.0 by perkin elmer). Mass balance equations were coded and numerically integrated in Berkely Madonna 8.3.18 (Macey and Oster, UC Berkeley, CA) using Rosenbrock's algorithm for stiff systems. PBK 
models in rat and human liver were run for $720-\mathrm{hr}$, because that would be the time for total clearance of myristicin in human tissues after one dose.

Table 2. Parameters used in the physiologically based kinetic model for myristicin in male rat.

\begin{tabular}{|c|c|c|c|}
\hline \multicolumn{2}{|c|}{$\begin{array}{l}\text { Physiological parameters } \\
\text { (Brown, 1997) }\end{array}$} & \multicolumn{2}{|c|}{ Tissue: blood partition coefficient } \\
\hline body weight (kg) & 0.25 & myristicin & \\
\hline \multicolumn{2}{|c|}{ percentage of body weight } & liver & \\
\hline liver & 3.4 & fat & 1.68 \\
\hline fat & 7.0 & rapidly perfused & 37.73 \\
\hline rapidly perfused & 5.1 & slowly perfused & 1.68 \\
\hline slowly perfused & 60.2 & & 0.67 \\
\hline \multirow[t]{2}{*}{ blood } & 7.4 & 1'-hydroxymyristicin & \\
\hline & & liver & 0.94 \\
\hline cardiac output (L/h) & 5.4 & & \\
\hline \multicolumn{2}{|c|}{ percentage of cardiac output } & & \\
\hline liver & 25 & & \\
\hline fat & 7.0 & & \\
\hline rapidly perfused & 51.0 & & \\
\hline slowly perfused & 17.0 & & \\
\hline
\end{tabular}


Table 3. Parameters used in the physiologically based kinetic model for myristicin in human.

\begin{tabular}{|c|c|c|c|}
\hline \multicolumn{2}{|c|}{$\begin{array}{l}\text { Physiological parameters } \\
\text { (Brown, 1997) }\end{array}$} & \multicolumn{2}{|c|}{ Tissue: blood partition coefficients } \\
\hline body weight (Kg) & 60 & \multicolumn{2}{|l|}{ myristicin } \\
\hline \multicolumn{2}{|c|}{ percentage of body weight } & liver & 4.22 \\
\hline liver & 2.6 & fat & 83.45 \\
\hline fat & 21.4 & rapidly perfused & 4.22 \\
\hline rapidly perfused & 5.0 & slowly perfused & 2.81 \\
\hline slowly perfused & 51.7 & & \\
\hline \multirow[t]{2}{*}{ blood } & 7.9 & 1'-hydroxymyristicin & \\
\hline & & liver & 0.93 \\
\hline cardiac output $(\mathrm{L} / \mathrm{h})$ & 310 & & \\
\hline \multicolumn{2}{|c|}{ percentage of cardiac output } & & \\
\hline liver & 22.7 & & \\
\hline fat & 5.2 & & \\
\hline rapidly perfused & 47.3 & & \\
\hline
\end{tabular}

\section{Sensitivity analysis}

To determine which parameters have the greatest influence on model predictions, a sensitivity analysis was performed as described previously (Punt et al. 2008, 2009; van den Berg et al. 2012; Martati et al. 2011, 2012; Al-Subeihi et al. 2011, 2012). For this purpose, normalized sensitivity coefficients (SCs) were determined using the following equation:

$$
\mathrm{SC}=\left(\mathrm{C}^{\prime}-\mathrm{C}\right) /\left(\mathrm{P}^{\prime}-\mathrm{P}\right) \times(\mathrm{P} / \mathrm{C})
$$

where $\mathrm{C}$ is the initial value of the model output, $\mathrm{C}^{\prime}$ is the modified value of the model output resulting from an increase in parameter value, $\mathrm{P}$ is the initial parameter value, and $\mathrm{P}^{\prime}$ represents the modified parameter value. An increase of $5 \%$ in parameter values was used to analyze the effect of a change in parameter on the formation of 1'-hydroxymyristicin and 1'- 
sulfoxymyristicin (expressed as a percentage of the dose). Each parameter was analyzed individually, while the other parameters were kept at their initial value.

\section{Comparison of the PBK model-based prediction of bioactivation of myristicin to the PBK} model-based predictions for bioactivation of the structurally related compound safrole

The predicted model outcomes for the formation of 1'-hydroxymyristicin and 1'sulfoxymyristicin in the liver of rat and human were compared with the predicted dosedependent formation of the 1'-hydroxy- and 1'-sulfoxy metabolite of the structurally related alkenylbenzene safrole. For this purpose, the previously defined PBK models for safrole described by Martati et al. $(2011,2012)$ for rat and human were used (Martati et al. 2011, 2012). For the comparison, the models describing the metabolism of myristicin and safrole were run for a period of $720-\mathrm{hr}$.

\section{RESULTS}

\section{Microsomal conversion of myristicin}

To identify which organs are involved in the metabolism of myristicin in both male rat and human, incubations were performed using microsomal protein preparations from liver, kidney, lung, and small intestine of both species. Chromatographic analysis of these incubations revealed that for rat and human, no detectable metabolism of myristicin occurred in small intestine, lung, or kidney microsomes, and metabolism was only observed for liver microsomes.

An example of a chromatogram of an incubation of myristicin with male rat liver microsomes and NADPH as a cofactor is shown in Figure 4. In incubations with rat liver microsomes, 2', 3'dihydroxymyristicin $(\mathrm{Rt}=1.19 \mathrm{~min})$, 3'-hydroxymyristicin $(\mathrm{Rt}=2.01 \mathrm{~min})$, ''-hydroxymyristicin 
$(\mathrm{Rt}=2.04 \mathrm{~min})$, and 5-allyl-2,3-dihydroxyanisole $(\mathrm{Rt}=2.11 \mathrm{~min})$ were formed. In incubations with human liver microsomes, the same four metabolites were found. Identification was done based on the comparison of the UV spectra and retention times of the formed metabolites with those of the specific synthesized or commercially available reference compounds. However, tentative identification of 2',3'-dihydroxymyrsticin was based on the fact that the epoxidation of the double bond in the allyl side chain of estragole, methyleugenol, and safrole yields the 2',3'epoxide, found to be hydrolyzed by epoxide hydrolase to the 2',3'-dihydroxy metabolite (Luo et al. 1992; Luo and Guenthner 1996; Guenthner and Luo 2001). The hydrolysis product of the epoxide, 2',3'-dihydroxy metabolite of myristicin, safrole, or elemicin, was detected in the urine of rats administered high doses $(100 \mathrm{mg} / \mathrm{kg} \mathrm{bw})$ of each substance individually or a high dose of nutmeg (500 mg/kg bw) (Beyer et al. 2006). Data revealed that 3'-hydroxymyristicin was formed directly from myristicin rather than from isomerization of 1'-hydroxymyristicin since the formation of 3'-hydroxymyristicin was not observed in incubations of 1'-hydroxymyristicin with liver microsomes and NADPH (data not shown). The kinetic constants (i.e., $\mathrm{V}_{\max }$ and $\mathrm{K}_{\mathrm{m}}$ ) were derived from plots of the rates of formation of different microsomal metabolites in incubations with male rat liver microsomes, and human liver microsomes from myristicin at concentrations ranging from 25 to $1000 \mu \mathrm{M}$ (for details, see Figure S1 in the supplementary materials). The values obtained are shown in Table 4, together with the catalytic efficiencies, calculated as $\mathrm{V}_{\max } / \mathrm{K}_{\mathrm{m}}$. Analysis of incubations that were performed with male rat liver microsomal preparations revealed that the metabolite arising from $O$-demethylenation of myristicin, namely 5-allyl-2,3-dihydroxyanisole, was formed with the highest $\mathrm{V}_{\max }$ value. Moreover, the 2',3'dihydroxymyristicin and 5-allyl-2,3-dihydroxyanisole were abundantly formed in incubations with male rat microsomal liver preparations with a high affinity. In incubations performed with 
male rat liver microsomes, 1'-hydroxymyristicin and 3'-hydroxymyristicin were the least important metabolites formed upon conversion of myristicin. In general, the catalytic efficiency for the formation of 5-allyl-2,3-dihydroxyanisole by male rat liver microsomes had the highest value, followed by the catalytic efficiency for the formation of 2',3'-dihydroxymyristicin, 1'hydroxymyristicin, and 3'-hydroxymyristicin, respectively. The catalytic efficiency for the formation of 5-allyl-2,3-dihydroxyanisole was found to be approximately 7-fold higher than that for the formation of 3'-hydroxymyristicin. In incubations with human liver fractions, 5-allyl-2,3dihydroxyanisole was found to be the most abundant metabolite formed followed by 2',3'dihydroxymyristicin, 1'-hydroxymyristicin, and 3'-hydroxymyristicin, respectively. Analysis of the catalytic efficiencies for the formation of the different microsomal metabolites of myristicin, obtained with pooled human liver microsomes, showed that the formations of 2',3'dihydroxymyristicin, 1'-hydroxymyristicin, and 3'-hydroxymyristicin were the least important routes of myristicin metabolism, whereas the formation of 5-allyl-2,3-dihydroxyanisole represents the major pathway for the human liver microsomal conversion of myristicin.

\section{Glucuronidation of 1'-hydroxymyristicin}

Chromatographic analysis of incubations with male rat and mixed gender pooled human liver S9, UDPGA as cofactor and 1'-hydroxymyristicin as substrate, revealed a peak at 1.36 min (chromatogram not shown). Moreover, chromatographic analysis of incubations performed in the absence of the cofactor UDPGA did not show a peak at a retention time of $1.36 \mathrm{~min}$. Together, these data indicate that the compound eluting at $1.36 \mathrm{~min}$ can be assumed to be 1'hydroxymyristicin glucuronide. The rate of the metabolic conversion of 1'-hydroxymyristicin to 1 '-hydroxymyristicin glucuronide in incubations with both male rat and human liver fractions 
with increasing concentrations of 1'-hydroxymyristicin is presented in Figure 5a, d, respectively. The kinetic constants derived from these plots are presented in Table 4.

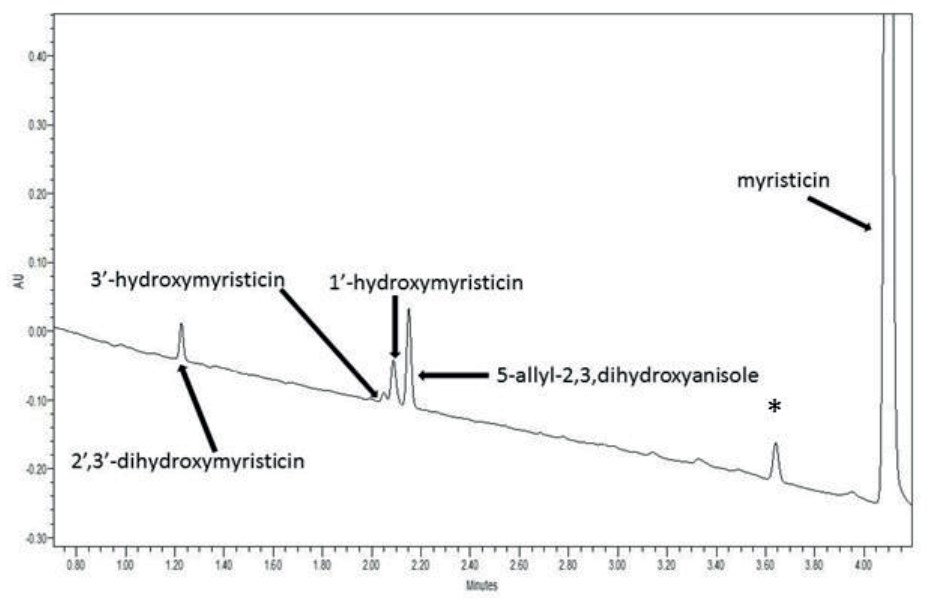

Figure 4. UPLC chromatogram of an incubation of myristicin $(1000 \mu \mathrm{M})$ with male rat liver microsomes. The peak marked with an asterisk $\left(^{*}\right)$ was also found in the blank incubation without NADPH. 


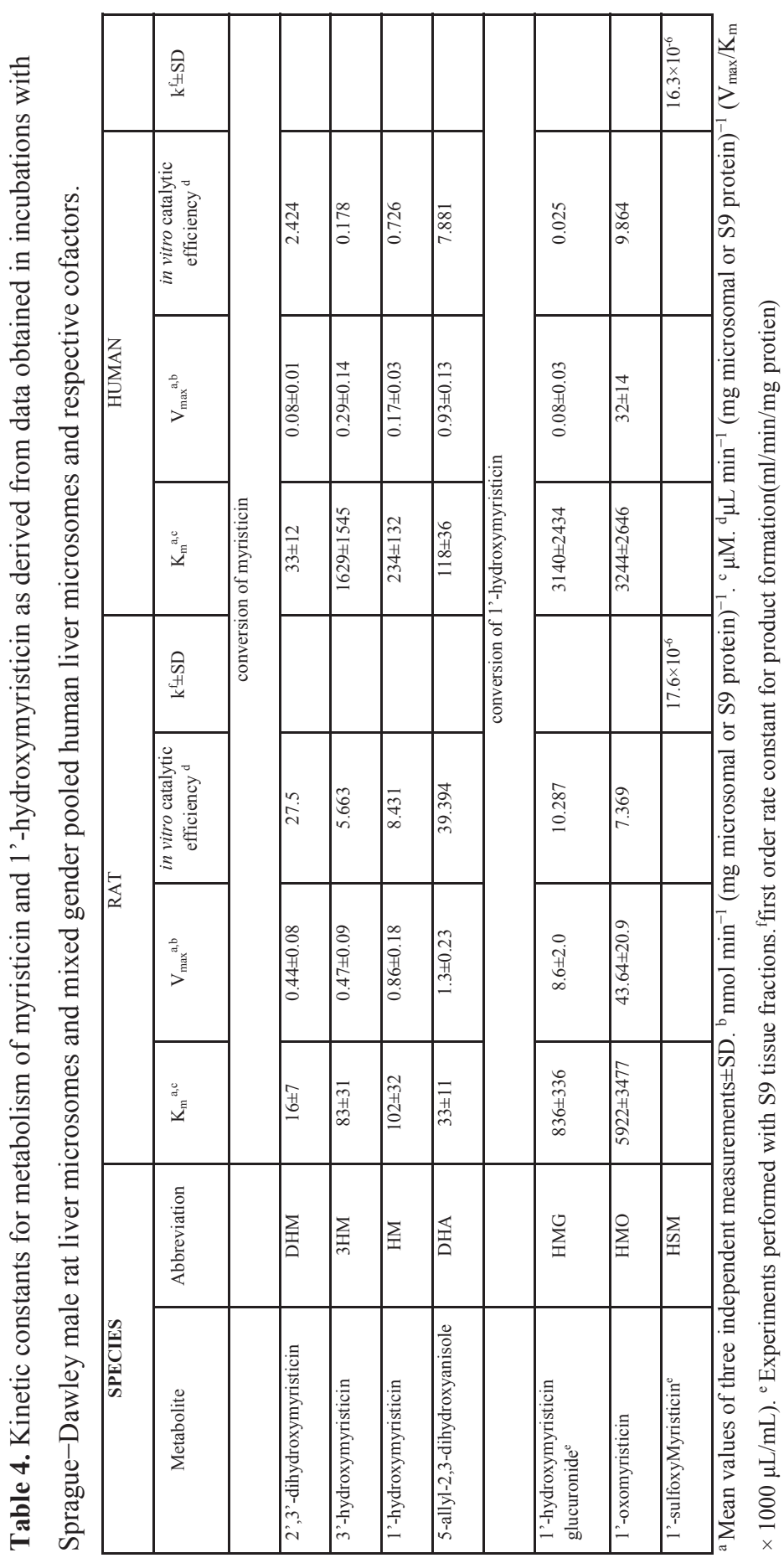


RAT

A

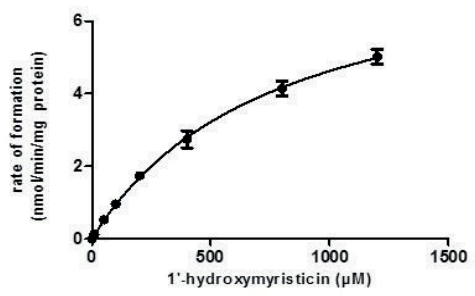

B

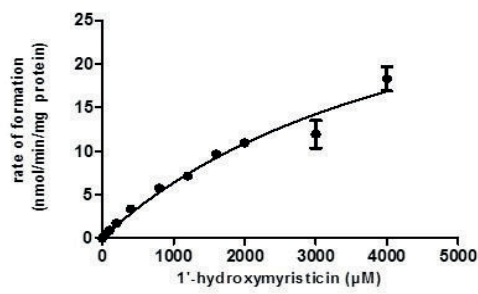

C

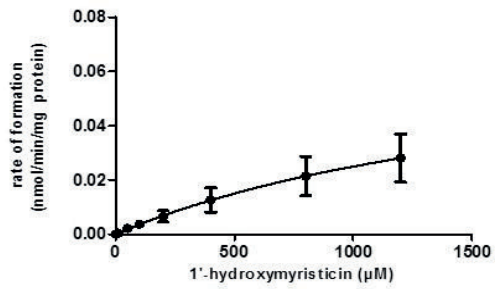

HUMAN

D

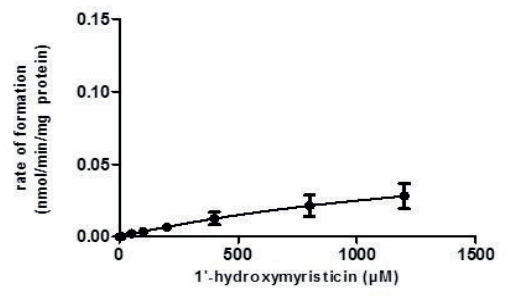

E

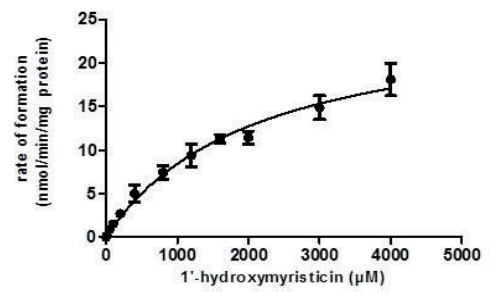

$\mathbf{F}$

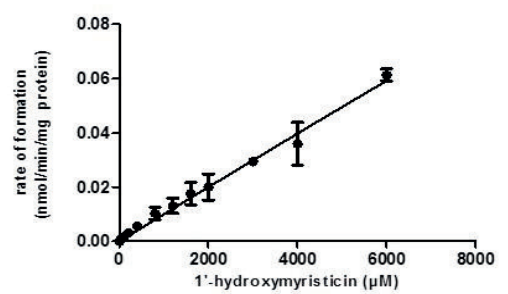

Figure 5. Concentration-dependent rate of (A) glucuronidation of 1'-hydroxymyristicin in incubations with male rat liver S9 or (D) pooled human mixed gender liver S9, (B) oxidation of 1 '-hydroxymyristicin in incubations with pooled male rat liver microsomes or (E) pooled human mixed gender liver S9, and (C) sulfonation of 1'-hydroxymyristicin in pooled male rat liver S9 or (F) pooled human mixed gender liver S9. Data points represent mean values +/- SD of three or four individual experiments. 


\section{Oxidation of 1'-hydroxymyristicin}

The rate of oxidation of 1'-hydroxymyristicin with increasing concentrations of 1'hydroxymyristicin in incubations with male rat and pooled human liver microsomes is shown in Figure $5 \mathrm{~b}$, e, respectively, and the kinetic constants derived from these data are presented in Table 4.

\section{Sulfonation of 1'-hydroxymyristicin}

In the present study, GSH was used to trap the reactive 1'-sulfoxymyristicin formed upon sulfonation of the proximate carcinogenic metabolite of myristicin, 1'-hydroxymyristicin. The scavenging is based on a chemical reaction but can also be catalyzed by the GST present in the S9 incubations in which the sulfonation of 1'-hydroxymyristicin was measured. Chromatographic analysis of incubations with male rat or mixed gender pooled human liver S9, increasing concentration of 1'-hydroxymyristicin, PAPS, and GSH revealed a peak at 1.05 min, which was identified as the GSH adduct of the carbocation of 1'-sulfoxymyristicin. Identification was achieved based on the chromatographic analysis of incubations performed in the absence of GSH and the presence of PAPS and liver S9 proteins since in these incubations; no peak was found at $1.05 \mathrm{~min}$. The identity was verified by LC-MS analysis, which revealed a deprotonated molecule at $\mathrm{m} / \mathrm{z} 496$ that corresponds to the expected $[\mathrm{M}-\mathrm{H}]$ mass of a GSH adduct of 1'sulfoxymyristicin. The rate of formation of 1'-sulfoxymyristicin in incubations with male rat and mixed gender pooled human liver S9 is presented in Figure 5c, f, respectively. The kinetic constants for the conversion of 1'-hydroxymyristicin to 1'-sulfoxymyristicin in rat and human liver are presented in Table 4. 
Comparison of the kinetic constants for conversion of myristicin and 1'-hydroxymyristicin by male rat and mixed gender pooled human tissue fractions

To allow a comparison between the kinetic constants for metabolism of myristicin and 1'hydroxymyristicin by male rat and mixed gender pooled human tissue fractions, $\mathrm{V}_{\max }$ values that

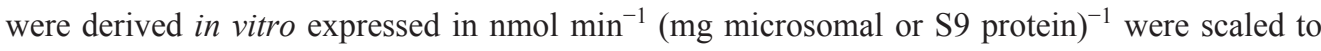
values representing the $\mathrm{V}_{\max }$ per $\mu \mathrm{mol} \mathrm{h}{ }^{-1}$ (g tissue $)^{-1}$ using microsomal and $\mathrm{S} 9$ protein yields as described in the literature (Medinsky et al. 1994) and previously used (Martati et al. 2011, 2012; van den Berg et al. 2012; Punt et al. 2009; Al-Subeihi et al. 2011, 2012). Making the use of the in vivo $\mathrm{V}_{\max }$ values derived accordingly, a scaled catalytic efficiency (scaled $\mathrm{V}_{\max }$ in vivo/ $K_{m}$ ) for the formation of myristicin metabolites could be calculated (Table 5). For sulfonation, the rate constants for product formation ( $\mathrm{ml} / \mathrm{min} / \mathrm{mg}$ protein) were scaled based on $\mathrm{S} 9$ protein yield of $143 \mathrm{mg} / \mathrm{g}$ liver. These values show that the catalytic efficiency for the formation of the proximate carcinogenic metabolite of myristicin, 1'-hydroxymyristicin, was found to be 13-fold higher in male rat liver as compared to human liver. This difference in catalytic efficiency for the formation of 1'-hydroxymyristicin is predominantly caused by the high affinity (expressed as $\mathrm{K}_{\mathrm{m}}$ ) and high activity (expressed as $\mathrm{V}_{\max }$ ) for its formation from myristicin in male rat liver, since the $\mathrm{K}_{\mathrm{m}}$ value in rat liver incubations was 2-fold lower than that in human liver incubations and $\mathrm{V}_{\max }$ in rat liver incubations was 5-fold higher than that in human liver incubations. The detoxification of 1'-hydroxymyristicin by formation of 1'-hydroxymyristicin glucuronide was found to be the main metabolic reaction with 1'-hydroxymyristicin in rat. Glucuronidation of 1'hydroxymyristicin occurs in male rat with higher affinity than in human (i.e., $\mathrm{K}_{\mathrm{m}} 836 \mu \mathrm{M}$ ), whereas in human the $\mathrm{Km}$ was $3140 \mu \mathrm{M}$, and analysis of the data revealed a high $\mathrm{V}_{\max }$ value for 1'-hydroxymyristicin glucuronidation resulting in a catalytic efficiency that was 400 -fold higher 
in male rats as compared to human. Oxidation of 1'-hydroxymyristicin was found to be 1.2 times more efficient in human liver as compared to male rat liver resulting from a 1.8 -fold lower affinity in rat. Sulfonation was found to be the least efficient metabolic pathway for 1'hydroxymyristicin in both rats and human. For rat, the in vivo scaled $\mathrm{k}$ was $0.15 \mathrm{ml} \mathrm{h}^{-1}$ (g tissue $)^{-1}$, and for human, it was $0.14 \mathrm{ml} \mathrm{h}^{-1}$ (g tissue $)^{-1}$, indicating that sulfonation of 1 'hydroxymyristicin is equally efficient in male rat liver and human liver. Altogether, it can be concluded that glucuronidation of 1'-hydroxymyristicin, representing a detoxification pathway, is the most important pathway in rat, and the oxidation is the most important pathway for conversion of 1'-hydroxymyristicin in human. Moreover, on the basis of the kinetic data obtained, bioactivation of 1'-hydroxymyristicin following sulfonation was found to represent only a minor pathway in both rat and human.

\section{Evaluation of PBK model performance}

The performance of the newly developed PBK models for myristicin could not be evaluated against in vivo data because quantitative data on the formation or excretion of the different metabolites in rat or humans exposed to myristicin are not available. However, Beyer et al. (2006) reported that in rats and humans, myristicin and safrole were $O$-demethylenated. In the urine of the human nutmeg abuser, who had taken 5 nutmegs, the acetylated metabolites of 5allyl-2,3-dihydroxyanisole and 2',3'-dihydroxymyristicin could be identified. In the same study, $O$-demethylenation of myristicin to generate 5-allyl-2,3-dihydroxyanisole seems to result in the main metabolite of myristicin detected in rat urine samples collected over a 24 -hr period after administration of a single oral dose of $100 \mathrm{mg} / \mathrm{kg}$ bw myristicin, with a percentage of $67 \%$ of 


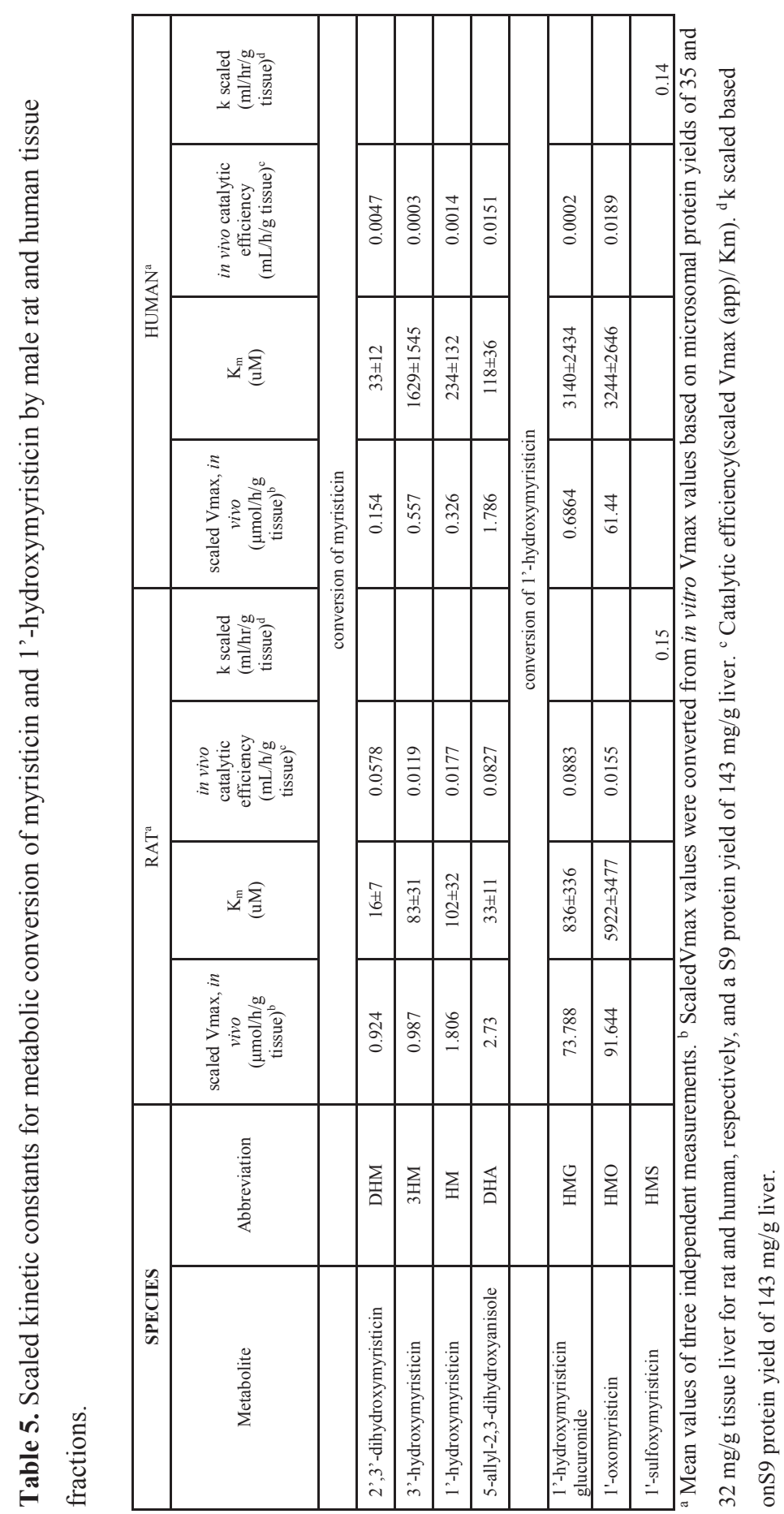


the total dose (Beyer et al. 2006). In line with these results, the developed PBK model predicted 5-allyl-2,3-dihydroxyanisole to be the major metabolite formed at a dose of 100 $\mathrm{mg} / \mathrm{kg}$ bw myristicin in rat after $24-\mathrm{hr}$, with a percentage of $73 \%$ of the total dose. This predicted value of $73 \%$ of the dose matches well with the $67 \%$ observed in the in vivo rat study.

Important to note is that the PBK models for myristicin were based on the proposed biotransformation in Figure 2 and comparable with the PBK models for estragole, methyleugenol, and safrole, for which more data allowing the evaluation of the models were available. The performance of the rat PBK models developed for estragole, methyleugenol, and safrole was reported before (Punt et al. 2008; Martati et al. 2011; Al-Subeihi et al. 2011). Evaluation was done by comparing the predicted levels of a variety of metabolites in plasma or excreted in the urine of rats. Data revealed that the predicted PBK model values and the levels of these metabolites derived from in vivo studies adequately matched (Punt et al. 2008; Martati et al. 2011; Al-Subeihi et al. 2011). Furthermore, also for the developed human PBK models for estragole (Punt et al. 2009), methyleugenol (Al-Subeihi et al. 2012), and safrole (Martati et al. 2012), a comparison could be made between the model predictions and the reported in vivo data for blood concentrations or the urinary excretion of some of the metabolites, thereby further supporting the validity of the models. Considering these data, it was concluded that the developed PBK models for myristicin will also adequately describe the in vivo levels of metabolites formed in rat and human after conversion of myristicin and 1'-hydroxymyristicin at different oral dose levels of myristicin.

\section{PBK model predictions}

PBK modeling was performed at dose levels of 0.05 and $300 \mathrm{mg} / \mathrm{kg}$ bw to allow comparison with the PBK model outcomes previously reported for safrole (Martati et al. 2011, 2012). 
Following an exposure to $0.05 \mathrm{mg} / \mathrm{kg}$ bw myristicin, both myristicin and its proximate carcinogenic metabolite 1'-hydroxymyristicin were predicted and observed to be almost completely metabolized within a 720-hr period in rat and human. At a higher oral dose level of $300 \mathrm{mg} / \mathrm{kg}$ bw myristicin, both myristicin and 1'-hydroxymyristicin were also predicted to be fully metabolized within 720-hr. Therefore, for all further modelings, values were calculated at 720 -hr after dosing. Figure 6 a shows the PBK model-based predictions for the dose-dependent formation of the different microsomal metabolites of myristicin in rat. The percentage of the dose converted to 1'-hydroxymyristicin is predicted to increase in a dosedependent manner. Concurrent with the increased percentage of the dose that undergoes 1 'hydroxylation of the alkene side chain, a 1.6-fold dose-dependent decrease in the percentage of the dose that underwent epoxidation to give 2',3'-dihydroxymyristicin was observed comparing the levels at 0.05 and $300 \mathrm{mg} / \mathrm{kg}$ bw. At the same time, a $<1.6$-fold increase in the formation of 3'-hydroxymyristicin was observed. The formation of 5-allyl-2,3dihydroxyanisole did not change with increasing dose levels and was equal to $48 \%$ of the administered dose. Figure $6 \mathrm{~b}$ shows the dose-dependent increase in the formation of the metabolites of 1'-hydroxymyristicin in rat. This reveals a 1.8-fold increase in the percentage of the dose ultimately converted into 1'-hydroxymyristicin glucuronide, 1'-oxomyristicin, and 1'-sulfoxymyristicin, going from a dose of 0.05 to $300 \mathrm{mg} / \mathrm{kg} \mathrm{bw}$. This dose-dependent increase in the formation of the different 1'-hydroxymyristicin metabolites can be explained by the 1.8 -fold increase in the formation of 1'-hydroxymyristicin with increasing dose levels. Figure 7 a reveals that in human, the percentage of the dose converted to 1 '-hydroxymyristicin equal $6.5 \%$ at a dose of $0.05 \mathrm{mg} / \mathrm{kg}$ bw and increased to $8.0 \%$ at a dose of $300 \mathrm{mg} / \mathrm{kg} \mathrm{bw}$. Accompanying the increase in the formation of 1'-hydroxymyristicin, there were a 1.4-fold decrease in the formation of 2',3'-dihydroxymyristicin and a steady formation of 5-allyl-2,3dihydroxyanisole. Formation of 3'-hydroxymyristicin was predicted to increase 1.8 -fold with 
increasing dose from of 0.05 to $300 \mathrm{mg} / \mathrm{kg}$ bw. Figure $7 \mathrm{~b}$ shows a 1.25 -fold dose-dependent increase in the percentage formation of 1'-hydroxymyristicin glucuronide, 1'sulfoxymyristicin, and 1'-oxomyristicin, in human liver with increasing dose from of 0.05 to $300 \mathrm{mg} / \mathrm{kg}$ bw. Comparison of the relative extent of bioactivation of myristicin by rat and human liver revealed that formation of 1'-hydroxymyristicin (expressed as nmol/g liver) is comparable in rat and human liver at the low dose of $0.05 \mathrm{mg} / \mathrm{kg}$ bw and 1.8 -fold higher in rat liver than in human liver at a dose of $300 \mathrm{mg} / \mathrm{kg}$ bw (Figure 8a). Formation of 1'sulfoxymyristicin (expressed as nmol/g liver) is 4-fold higher in human liver than in rat liver at a low dose of $0.05 \mathrm{mg} / \mathrm{kg}$ bw and 2.8-fold lower in rat liver than in human liver at a dose of $300 \mathrm{mg} / \mathrm{kg}$ bw (Figure $8 b)$.
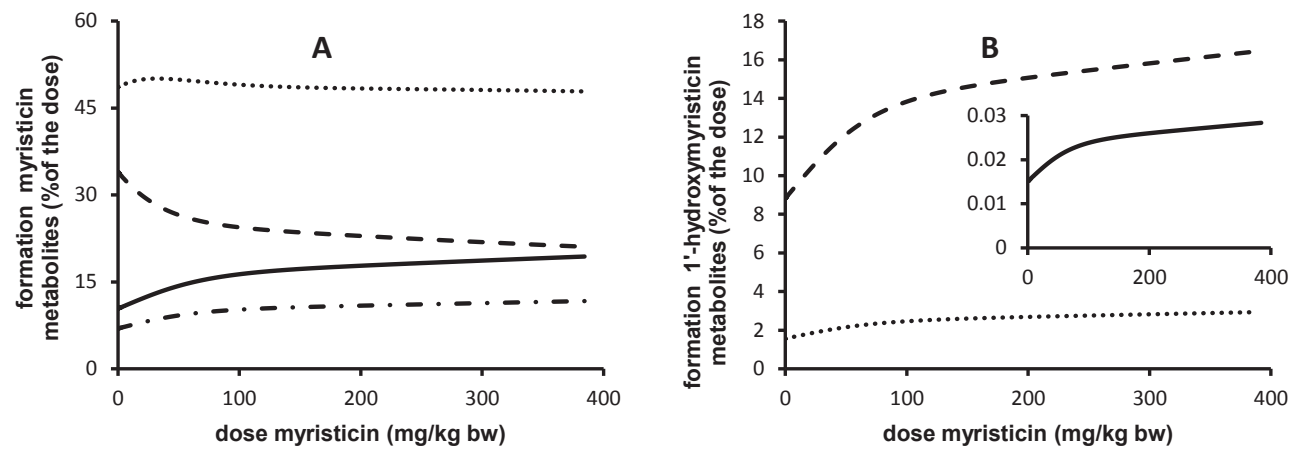

Figure 6. PBK-predicted dose-dependent changes in overall formation of (A) microsomal metabolites of myristicin in rat liver and (B) metabolites of 1'-hydroxymyristicin in rat liver. The lines correspond to (A) 5-allyl-2,3-dihydroxyanisole (•••), 3'-hydroxymyristicin (-•-), 1'-hydroxymyristicin (-), and 2',3'-dihydroxymyristicin (- -), and (B) 1'-hydroxymyristicin glucuronide (- -), 1'-sulfoxymyristicin (-), and 1'-oxomyristicin (••••) 

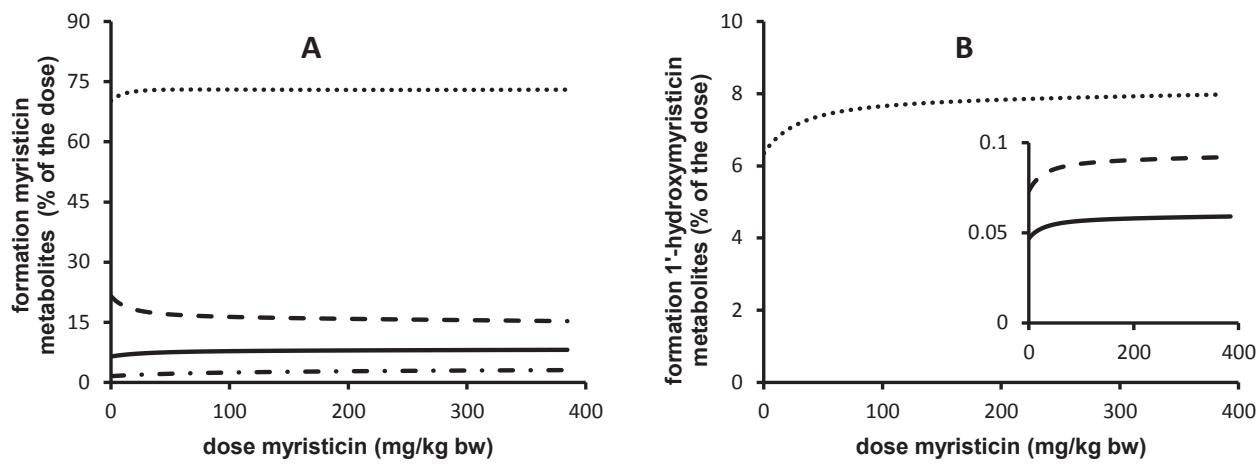

$\tan$

Fig. 7 PBK-predicted dose-dependent changes in overall formation of (A) microsomal metabolites of myristicin in human liver and (B) metabolites of 1'-hydroxymyristicin in human liver. The lines correspond to (A) 5-allyl-2,3-dihydroxyanisole (•••), 3'hydroxymyristicin (-•-), 1'-hydroxymyristicin (-), and 2',3'-dihydroxymyristicin (- -), and (B) 1'-hydroxymyristicin glucuronide (- - ), 1'-sulfoxymyristicin (-), and 1'-

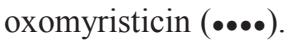
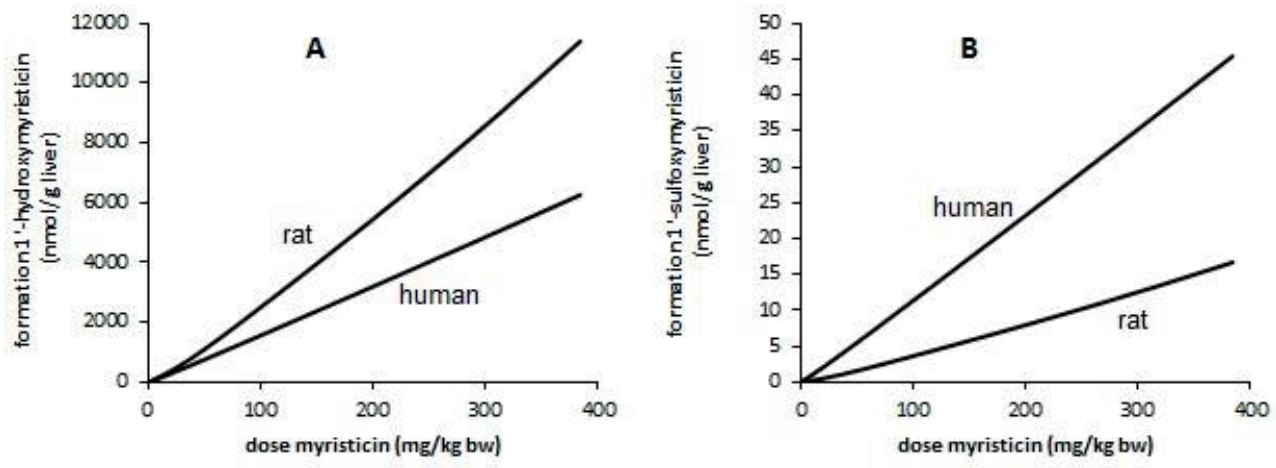

Figure 8. PBK-predicted dose-dependent formation $(\mathrm{mg} / \mathrm{kg} \mathrm{bw})$ of (A) 1'-hydroxymyristicin and (B) 1'-sulfoxymyristicin in rat and human liver. 


\section{Sensitivity analysis}

A sensitivity analysis was performed to define model parameters that are capable of influencing the formation of 1'-hydroxymyristicin and 1'-sulfoxymyristicin in rat and human liver. For this purpose, normalized sensitivity coefficients (SCs) were calculated for all parameters at a dose of $0.05 \mathrm{mg} / \mathrm{kg}$ bw myristicin. This sensitivity analysis reveals to what extent small variation in the respective parameters influences the results. The sensitivity analysis also reveals to which parameters the predicted outcomes are most sensitive. The results of this analysis are presented in Figure 9. Figure 9 especially presents the parameters affecting the formation of 1'-hydroxymyristicin (black) and 1'-sulfoxymyristicin (gray) that have a normalized $\mathrm{SC}>|0.1|$. In rat liver, the formation of the ultimate carcinogenic metabolite 1'-sulfoxymyristicin is primarily influenced by the kinetic constants of 1'hydroxymyristicin formation from myristicin $\left(\mathrm{V}_{\max } \mathrm{HM}, \mathrm{K}_{\mathrm{m}} \mathrm{HM}\right)$. The kinetic constants for the formation of 5-allyl-2,3-dihydroxyanisole and 2',3'-dihydroxymyristicin ( $\mathrm{V}_{\max }$ DHA, $\mathrm{K}_{\mathrm{m} \text { DHA, }}$ $\mathrm{V}_{\max }$ DHM, $\mathrm{K}_{\mathrm{m}}$ DHM) were also found to highly influence the formation of 1'-hydroxymyristicin in rat and human liver. In rat liver, the formation of the ultimate carcinogenic metabolite 1'sulfoxymyristicin is primarily influenced by the kinetic constants of 1'-hydroxymyristicin formation from myristicin $\left(\mathrm{V}_{\max } \mathrm{HM}, \mathrm{K}_{\mathrm{m}} \mathrm{HM}\right)$, and the kinetic constants for the formation of 1'hydroxymyristicin glucuronide $\left(\mathrm{V}_{\max } \mathrm{HMG}_{\mathrm{M}}, \mathrm{K}_{\mathrm{m} H \mathrm{HG}}\right)$, $\mathrm{k}$, the first-order rate constant for the sulfonation of 1'-hydroxymyristicin ( $\mathrm{k}_{\mathrm{HMS}}$ ), and the kinetic constants for the formation of 5allyl-2,3-dihydroxyanisole and 2',3'-dihydroxymyristicin $\left(\mathrm{V}_{\max }\right.$ DHA, $\mathrm{K}_{\mathrm{m} \text { DHA }}, \mathrm{V}_{\max }$ DHM, $\mathrm{K}_{\mathrm{m}}$ DHM) were also found to highly influence the formation of 1'-sulfoxymyristicin in rat liver. In human liver, the formation of the ultimate carcinogenic metabolite 1'-sulfoxymyristicin is primarily influenced by the kinetic constants of 1'-hydroxymyristicin formation from myristicin ( $\left.\mathrm{V}_{\max } \mathrm{HM}, \mathrm{K}_{\mathrm{m} H \mathrm{HM}}\right)$, the kinetic constants for the formation of 1'-oxomyristicin $\left(\mathrm{V}_{\max }\right.$

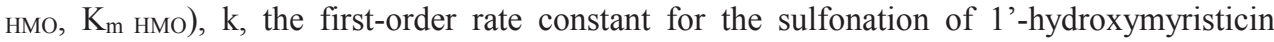


( $\left.\mathrm{k}_{\mathrm{HMS}}\right)$ and liver microsomal protein yield (MP), and the kinetic constants for the formation of 5-allyl-2,3-dihydroxyanisole and 2',3'-dihydroxymyristicin $\left(\mathrm{V}_{\max } \mathrm{DHA}, \mathrm{K}_{\mathrm{m}}\right.$ DHA $)$ were also found to highly influence the formation of 1'-sulfoxymyristicin in human liver. The kinetic constants for the formation of 1'-hydroxymyristicin glucuronide were found to highly influence the formation of 1'-sulfoxymyristicin in rat liver, and the kinetic constants for formation of 1'-oxomyristicin were predicted to affect the formation of 1'-sulfoxymyristicin in human liver to a high extent. These results reflect the fact that glucuronidation of 1'hydroxymyristicin in rat and oxidation of 1'-hydroxymyristicin in human are considered as the most important competitive metabolic pathways to sulfonation.

RAT

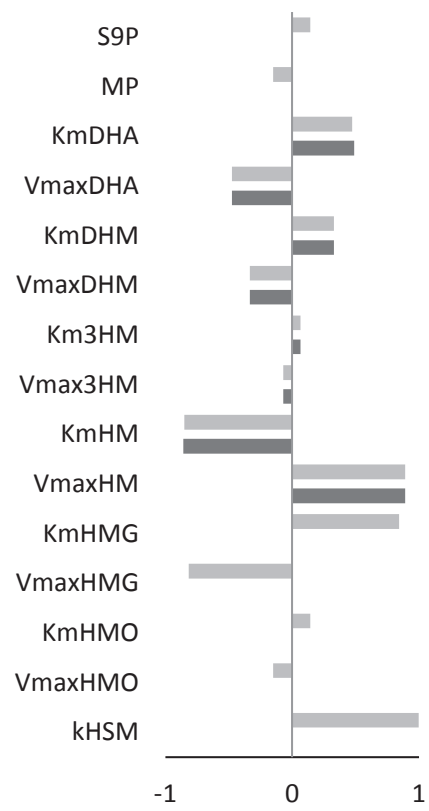

\section{HUMAN}

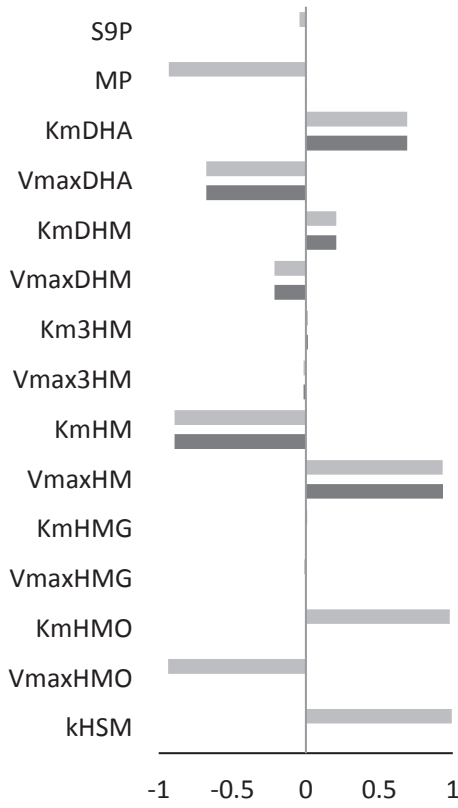

Figure 9. Normalized sensitivity coefficients for the formation from 1'-hydroxymyriticin (black) and l'sulfoxymyristicin (grey) in the liver of rat or human. 
Comparison of the PBK model-based prediction of bioactivation of myristicin by rat and human to that of its structurally related compound safrole

In a next step, the mode of action-based PBK models for myristicin metabolism in rat and human were used to facilitate a read-across from data on safrole (Martati et al. 2011, 2012). On the basis of the PBK models, a comparison was made for the dose-dependent formation of the proximate carcinogenic 1'-hydroxy metabolite and of the ultimate carcinogenic 1'sulfoxy metabolite of myristicin and safrole in the liver of rats. Figure 10 shows the dosedependent formation of these metabolites in rat liver as predicted by the respective PBK models. The PBK model-based predicted formation of the proximate carcinogenic 1'hydroxy metabolites shows that the formation of the 1'-hydroxy metabolites of myristicin and safrole was predicted to be the same at low dose $0.05 \mathrm{mg} / \mathrm{kg}$ bw and 1.4-fold higher for myristicin than that of safrole at dose level $100 \mathrm{mg} / \mathrm{kg}$ bw (Figure 10a). The predicted model outcomes for the formation of the ultimate carcinogenic 1'-sulfoxy metabolites of safrole and myristicin are shown in Figure 10b. The PBK models for rat predict the formation of 1'sulfoxymyristicin to be 1.5 -fold higher for myristicin than safrole at low dose of $0.05 \mathrm{mg} / \mathrm{kg}$ bw and 2.2-fold higher for myristicin than for safrole at dose level of $100 \mathrm{mg} / \mathrm{kg}$ bw. Figure 11 shows the predicted dose-dependent formation of 1'-hydroxy metabolites and 1'-sulfoxy metabolites of safrole and myristicin in human liver. In human liver, the predicted formation of 1'-hydroxymyristicin is 7-fold lower than the formation of 1'-hydroxysafrole at a dose level of $0.05 \mathrm{mg} / \mathrm{kg}$ bw and 4.5 -fold lower for myristicin than for safrole at high dose of 100 $\mathrm{mg} / \mathrm{kg}$ bw (Figure 11a). The data also reveal that in human liver, the formation of the DNAreactive 1'-sulfoxy metabolite is comparable, 1.35-fold higher for safrole at low-dose level $0.05 \mathrm{mg} / \mathrm{kg} \mathrm{bw}$, and 1.1-fold higher for myristicin at high-dose level $100 \mathrm{mg} / \mathrm{kg}$ bw (Figure $11 b)$. 

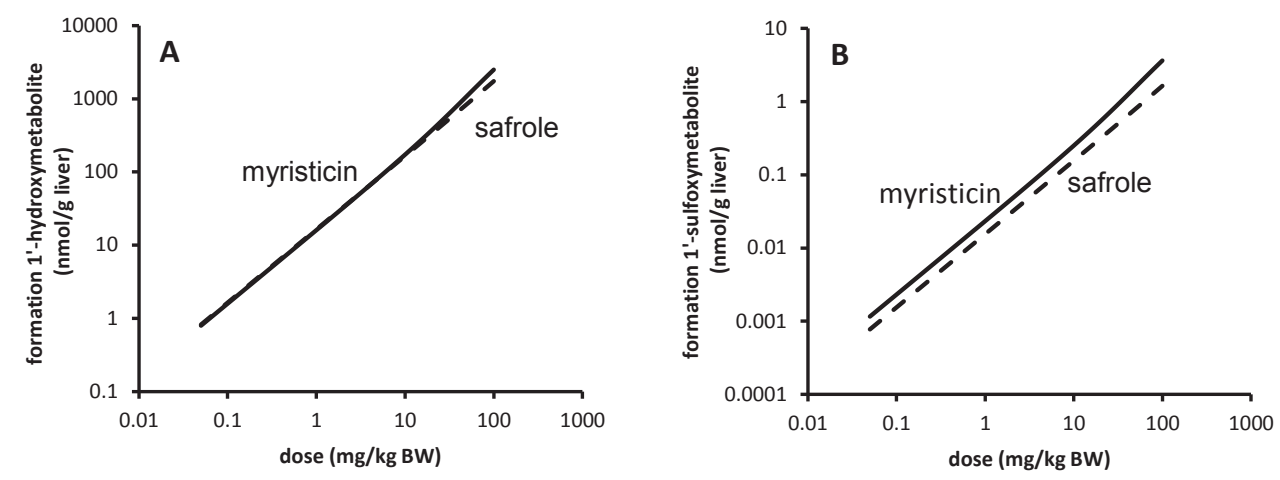

Figure 10. PBK-predicted dose-dependent formation (nmol / g liver) of (A) 1'hydroxymetabolites and (B) 1'-sulfoxymetabolites of myristicin (-) and safrole (- - ) in male rat liver.
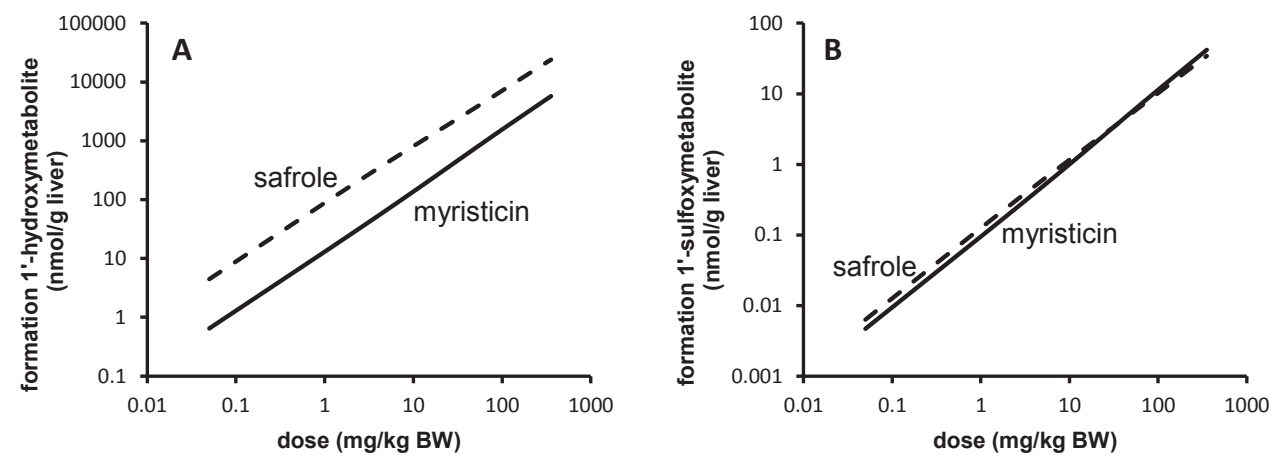

Figure 11. PBK-predicted dose-dependent formation (nmol /g liver) of (A) 1'hydroxymetabolites and (B) 1'-sulfoxymetabolites of myristicin (-), and safrole (- - ) in human liver.

\section{Implications for risk assessment}

The margin-of-exposure (MOE) concept was applied to assess the possible risks for human health resulting from the daily exposure to myristicin (JECFA 2005; EFSA 2005; Barlow et al. 2006; O'Brien et al. 2006). The MOE is a dimensionless ratio based on a reference point 
representing a dose causing a low but measurable cancer incidence in experimental animals (e.g., a BMDL 10 ), which is divided by the estimated daily intake in humans (EFSA 2005). When the MOE is lower than 10000 , the compound of interest is considered to be a priority for risk management actions and a concern for human health (EFSA 2005). To date, tumor data for myristicin, from which a $\mathrm{BMDL}_{10}$ can be derived, are absent in the available literature, hampering the application of the MOE approach in the risk assessment of myristicin. Nevertheless, the results of the PBK model predictions presented above indicate that at dose levels in the range of the $\mathrm{BMDL}_{10}$ values, the formation of 1 '-sulfoxy metabolites of myristicin in human liver is comparable (1.1-fold higher) to that of the structurally related safrole. On the basis of these considerations, and the limited difference in 1'-sulfoxy metabolite formation for myristicin and safrole in rat and human liver, it was concluded that the $\mathrm{BMDL}_{10}$ values of safrole could be used to perform an initial MOE-based risk assessment for myristicin. Using the BMDL 10 for safrole of $1.9-5.1 \mathrm{mg} / \mathrm{kg}$ bw per day (van den Berg et al. 2011) and an estimated daily intake of myristicin of $0.0019 \mathrm{mg} / \mathrm{kg}$ bw per day (WHO 2009) from use of herbs and spices, the MOE for myristicin would amount to 1000-2684. The estimated daily intake of safrole from spice and spice oil in the USA amounts to 0.001 $\mathrm{mg} / \mathrm{kg}$ bw per day (WHO 2009). These data result in an MOE for safrole of 1900-5100, indicating a priority for risk management that is somewhat lower than for myristicin.

\section{DISCUSSION}

In the presented paper, the recently developed mode of action-based PBK models for detoxification and bioactivation of the alkenylbenzene safrole (Martati et al. 2011, 2012) in male rat and human were extended to the structurally related alkenylbenzene myristicin. The newly developed PBK models combine biochemical and physicochemical information on myristicin and on the physiology of the organism of interest (i.e., rat and human), enabling 
the quantification of detoxification and bioactivation in rat and human at realistic low exposure levels. The development of these models facilitates a risk assessment based on readacross from data on safrole, for which in vivo chronic toxicity studies are available, to myristicin, a compound for which toxicity data are limited.

The PBK models for myristicin defined in the present paper were able to predict the overall formation of the reactive 1'-sulfoxymyristicin metabolite in the liver of rat and human, thus enabling comparison to the overall formation of the 1'-sulfoxy metabolites of the corresponding alkenylbenzene safrole. Comparison of the rat and human PBK model predictions indicated an only limited species-dependent difference in the overall metabolic activation of myristicin. The difference observed was within the default factor of 4 , which is generally used to describe kinetic differences between species (IPCS 2010). The newly developed PBK model for myristicin was also used to compare the levels of metabolic activation of myristicin to those predicted previously for safrole in male rat and human liver (Martati et al. 2011, 2012). Results reveal that the formation of the proximate and ultimate carcinogenic metabolites of myristicin and safrole in rat liver appears to be comparable varying about 1.4-fold and 2.2-fold, respectively, with rat liver bioactivation of myristicin predicted to be somewhat higher than that of safrole for both metabolites. In humans, the formation of especially the 1'-sulfoxy metabolites of the two alkenylbenzenes is predicted to be comparable (1.1-fold difference). The PBK model outcomes obtained for the formation of reactive 1'-sulfoxy metabolites of myristicin and safrole can be compared to the relative bioactivation of these two alkenylbenzenes observed in other studies. In an in vitro study with cultured human cells, the ability of myristicin to form DNA adducts upon exposure of the cells to myristicin appeared to be almost the same as upon exposure to safrole (Zhou et al. 2007b) which is in line with the relative differences predicted by the PBK models. Data derived from another study in which mice were exposed to the alkenylbenzenes via 
intraperitoneal (i.p) injection (Table 1) suggest that the DNA adduct formation of safrole and myristicin is also not much different with DNA adduct formation in the liver of safrole being 2.7 times higher than that of myristicin (Randerath et al. 1984). In a parallel study, Phillips et al. (Table 1) reported that in neonatal mice, both safrole and myristicin were able to form DNA adducts in liver, and the DNA binding levels of safrole and myristicin were 17.5 and $7.8 \mathrm{pmol} / \mathrm{mg}$ DNA, respectively (Phillips et al. 1984). It is important to note that in these mice studies, DNA adduct levels were quantified by ${ }^{32} \mathrm{P}$ post-labeling which is known to be less accurate than, for example, LC-MS in the quantification of DNA adduct levels (Randerath et al. 1984). On the basis of the results now available, it can be concluded that using data on safrole for a read-across to myristicin is a reasonable approach for an initial risk assessment on myristicin. Such a risk assessment for myristicin can be based on the MOE approach. Because data on tumor formation are currently not available for myristicin, risk assessment for myristicin was performed using the $\mathrm{BMDL}_{10}$ values for tumor formation by safrole, given the comparable bioactivation in human liver predicted by the newly developed PBK models, where the difference in the bioactivation of myristicin and safrole was predicted to be only 1.1 -fold.

Using the BMDL 10 for safrole of $1.9-5.1 \mathrm{mg} / \mathrm{kg}$ bw per day (van den Berg et al. 2011) and an estimated daily intake of myristicin of $0.0019 \mathrm{mg} / \mathrm{kg}$ bw per day (WHO 2009) from use of herbs and spices, the MOE for myristicin would amount to 1000-2684. For comparison, the MOE values of safrole can be given, obtained at the estimated daily intake of safrole from spice and spice oil in the USA that amounts to $0.001 \mathrm{mg} / \mathrm{kg}$ bw per day (WHO 2009) and a BMDL $_{10}$ of safrole of 1.9-5.1 mg/kg bw per day (van den Berg et al. 2011). These data result in an MOE for safrole of 1900-5100, indicating a priority for risk management that is lower than for myristicin. 
Altogether, the results obtained indicate that PBK modeling provides an important insight into the limited species differences between male rat and human in the metabolic activation of myristicin, and that in human liver, formation of the ultimate carcinogenic 1'-sulfoxy metabolites is almost the same for myristicin and safrole supporting a possibility for the risk assessment for myristicin based on the $\mathrm{MOE}$ approach using the $\mathrm{BMDL}_{10}$ for tumor formation of safrole as a reasonable but careful approximation. The present study provides an example of how PBK modeling can facilitate a read-across in risk assessment from compounds for which in vivo toxicity studies are available to a compound for which only limited toxicity data have been described, thus contributing to the development of alternatives for animal testing.

\section{ACKNOWLEDGMENTS}

The authors would like to thank Dr. Yiannis Fiamegos for the synthesis of 1'hydroxymyristicin, and Bert Spenkelink and Suzanne van den Berg for the synthesis of 1'oxymyristicin. AMA and AJAM acknowledge financial support from the SOIT foundation (The foundation for Stimulation of Innovation in Toxicology).

\section{FUNDING}

This publication has been produced with the financial assistance of the European Union under the ENPI CBC Mediterranean Sea Basin Programme. The contents of this document are the sole responsibility of ASEZA and can under no circumstances be regarded as reflecting the position of the European Union or of the programme's management structures. BRAMA (Botanicals Risk Assessment Training in the Mediterranean Area) project I.B/4.1/257. 


\section{CONFLICT OF INTEREST}

Prof. IMCM Rietjens declares she is a member of the Expert Panel of the Flavour and Extract Manufacturers Association (FEMA). Other authors declare that no conflict of interest exists.

\section{REFERENCES}

Al-Subeihi AA, Spenkelink B, Rachmawati N, Boersma MG, Punt A, Vervoort J, van Bladeren PJ, Rietjens IMCM (2011) Physiologically based biokinetic model of bioactivation and detoxification of the alkenylbenzene methyleugenol in rat. Toxicol In Vitro 25:267-285. doi:10.1016/j.tiv.2010.08.019

Al-Subeihi AA, Spenkelink B, Punt A, Boersma MG, van Bladeren PJ, Rietjens IMCM (2012) Physiologically based kinetic modeling of bioactivation and detoxification of the alkenylbenzene methyleugenol in human as compared with rat. Toxicol Appl Pharmacol 260:271-284. doi:10.1016/j.taap.2012.03.005

Barceloux DG (2009) Nutmeg (Myristica fragrans Houtt.). Dis Month: DM 55:373-379. doi:10.1016/j.disamonth.2009.03.007

Barlow S, Renwick AG, Kleiner J, Bridges JW, Busk L, Dybing E, Edler L, Eisenbrand G, Fink-Gremmels J, Knaap A, Kroes R, Liem D, Muller DJ, Page S, Rolland V, Schlatter J, Tritscher A, Tueting W, Wurtzen G (2006) Risk assessment of substances that are both genotoxic and carcinogenic report of an International Conference organized by EFSA andWHOwith support of ILSI Europe. Food Chem Toxicol 44:1636-1650

Benedetti MS, Malnoe A, Broillet AL (1977) Absorption, metabolism and excretion of safrole in the rat and man. Toxicology 7:69-83

Beyer J, Ehlers D, Maurer HH (2006) Abuse of nutmeg (Myristica fragrans Houtt.): studies on the metabolism and the toxicologic detection of its ingredients elemicin, myristicin, and safrole in rat and human urine using gas chromatography/mass spectrometry. Ther Drug Monit 28:568-575

Borchert P, Miller JA, Miller EC, Shires TK (1973) 1'-Hydroxysafrole, a proximate carcinogenic metabolite of safrole in the rat and mouse. Cancer Res 33:590-600

Brown RP, Delp MD, Lindstedt SL, Rhomberg LR, Beliles RP (1997) Physiological parameter values for physiologically based pharmacokinetic models. Toxicol Ind Health 13:407-484 
DeJongh J, Verhaar HJ, Hermens JL (1997) A quantitative property-property relationship (QPPR) approach to estimate in vitro tissue-blood partition coefficients of organic chemicals in rats and humans. Arch Toxicol 72:17-25

Drinkwater NR, Miller EC, Miller JA, Pitot HC (1976) Hepatocarcinogenicity of estragole (1-allyl-4-methoxybenzene) and 1'-hydroxyestragole in the mouse and mutagenicity of 1'-acetoxyestragole in bacteria. J Natl Cancer Inst 57:1323-1331

EFSA (2005) Opinion of the Scientific Committee on a request from EFSA related to a harmonised approach for risk assessment of substances which are both genotoxic and carcinogenic. EFSA J 282:1-31

EFSA (2012) Compendium of botanicals reported to contain naturally occurring substances of possible concern for human health when used in food and food supplements. EFSA J 10(5):2663

Fennell TR, Miller JA, Miller EC (1984) Characterization of the biliary and urinary glutathione and N-acetylcysteine metabolites of the hepatic carcinogen 1'hydroxysafrole and its 1'-oxo metabolite in rats and mice. Cancer Res 44:3231-3240

Fisher MB, Campanale K, Ackermann BL, VandenBranden M, Wrighton SA (2000) In vitro glucuronidation using human liver microsomes and the pore-forming peptide alamethicin. Drug Metab Dispos 28:560-566

Forrest JE, Heacock RA (1972) Nutmeg and mace, the psychotropic spices from Myristica fragrans. Lloydia 35:440-449

Guenthner TM, Luo G (2001) Investigation of the role of the 2',3'-epoxidation pathway in the bioactivation and genotoxicity of dietary allylbenzene analogs. Toxicology $160: 47-58$

Hallstrom H, Thuvander A (1997) Toxicological evaluation of myristicin. Nat Toxins 5:186192. doi:10.1002/nt.3

Howes AJ, Chan VS, Caldwell J (1990) Structure-specificity of the genotoxicity of some naturally occurring alkenylbenzenes determined by the unscheduled DNA synthesis assay in rat hepatocytes. Food Chem Toxicol 28:537-542

Innes J (1969) Bioassay of pesticides and industrial chemicals for tumorigenicity in mice. Natl Cancer Inst 42:1101-1114

Ioannides C, Delaforge M, Parke DV (1981) Safrole: its metabolism, carcinogenicity and interactions with cytochrome P-450. Food Cosmet Toxicol 19:657-666 
International Programme on Chemical Safety (IPCS) (2010) Characterization and application of physiologically based pharmacokinetic models in risk assessment. World Health Organization, International Programme on Chemical Safety, Geneva, Switzerland

Ishii Y, Suzuki Y, Hibi D, Jin M, Fukuhara K, Umemura T, Nishikawa A (2011) Detection and quantification of specific DNA adducts by liquid chromatography-tandem mass spectrometry in the livers of rats given estragole at the carcinogenic dose. Chem Res Toxicol 24:532-541. doi:10.1021/tx100410y

JECFA (2005) Sixty-fourth meeting. FAO/WHO publication under WHO Food Additives 55 paper 83

Jeurissen SM, Bogaards JJ, Awad HM, Boersma MG, Brand W, Fiamegos YC, van Beek TA, Alink GM, Sudhölter EJ, Cnubben NH, Rietjens IMCM (2004) Human cytochrome P450 enzyme specificity for bioactivation of safrole to the proximate carcinogen 1'hydroxysafrole. Chem Res Toxicol 17:1245-1250. doi:10.1021/tx040001v

Kobets T, Duan JD, Brunnemann KD, Etter S, Smith B, Williams GM (2016) Structureactivity relationships for DNA damage by alkenylbenzenes in turkey egg fetal liver. Toxicol Sci: Off J Soc Toxicol 150:301-311. doi:10.1093/toxsci/kfv322

Lin JH, Wong BK (2002) Complexities of glucuronidation affecting in vitro in vivo extrapolation. Curr Drug Metab 3:623-646

Luo G, Guenthner TM (1996) Covalent binding to DNA in vitro of 2',3'-oxides derived from allylbenzene analogs. Drug Metab Dispos 24:1020-1027

Luo G, Qato MK, Guenthner TM (1992) Hydrolysis of the 2',3'-allylic epoxides of allylbenzene, estragole, eugenol, and safrole by both microsomal and cytosolic epoxide hydrolases. Drug Metab Dispos 20:440-445

Martati E, Boersma MG, Spenkelink A, Khadka DB, Punt A, Vervoort J, van Bladeren PJ, Rietjens IMCM (2011) Physiologically based biokinetic (PBBK) model for safrole bioactivation and detoxification in rats. Chem Res Toxicol 24:818-834. doi:10.1021/tx200032m

Martati E, Boersma MG, Spenkelink A, Khadka DB, van Bladeren PJ, Rietjens IMCM, Punt A (2012) Physiologically based biokinetic (PBBK) modeling of safrole bioactivation and detoxification in humans as compared with rats. Toxicol Sci 128:301-316. doi:10.1093/toxsci/kfs174

Matthews WSA, Pickering GR, Robinson FU (1974) The distillation and composition of nutmeg oils. Proceedings International Congress Essential Oils, San Franciso 
Medinsky MA, Leavens TL, Csanady GA, Gargas ML, Bond JA (1994) In vivo metabolism of butadiene by mice and rats: a comparison of physiological model predictions and experimental data. Carcinogenesis 15:1329-1340

Miller EC, Swanson AB, Phillips DH, Fletcher TL, Liem A, Miller JA (1983) Structureactivity studies of the carcinogenicities in the mouse and rat of some naturally occurring and synthetic alkenylbenzene derivatives related to safrole and estragole. Cancer Res 43:1124-1134

National Toxicology P (2000) NTP toxicology and carcinogenesis studies of methyleugenol (CAS NO. 93-15-2) in F344/N Rats and B6C3F1 Mice (Gavage Studies). Natl Toxicol Prog Tech Rep Ser 491:1-412

O’Brien J, Renwick AG, Constable A, Dybing E, Muller DJ, Schlatter J, Slob W, Tueting W, van Benthem J, Williams GM, Wolfreys A (2006) Approaches to the risk assessment of genotoxic carcinogens in food: a critical appraisal. Food Chem Toxicol 44:16131635

Phillips DH, Reddy MV, Randerath K (1984) 32P-post-labelling analysis of DNA adducts formed in the livers of animals treated with safrole, estragole and other naturallyoccurring alkenylbenzenes. II. Newborn male B6C3F1 mice. Carcinogenesis 5:16231628

Punt A, Freidig AP, Delatour T, Scholz G, Boersma MG, Schilter B, van Bladeren PJ, Rietjens IMCM (2008) A physiologically based biokinetic (PBBK) model for estragole bioactivation and detoxification in rat. Toxicol Appl Pharmacol 231:248259. doi:10.1016/j.taap.2008.04.011

Punt A, Paini A, Boersma MG, Freidig AP, Delatour T, Scholz G, Schilter B, van Bladeren PJ, Rietjens IMCM (2009) Use of physiologically based biokinetic (PBBK) modeling to study estragole bioactivation and detoxification in humans as compared with male rats. Toxicol Sci 110:255-269. doi:10.1093/toxsci/kfp102

Punt A, Jeurissen SM, Boersma MG, Delatour T, Scholz G, Schilter B, van Bladeren PJ, Rietjens IMCM (2010) Evaluation of human interindividual variation in bioactivation of estragole using physiologically based biokinetic modeling. Toxicological Sci 113:337-348. doi:10.1093/toxsci/kfp272

Randerath K, Haglund RE, Phillips DH, Reddy MV (1984) 32P-post-labelling analysis of DNA adducts formed in the livers of animals treated with safrole, estragole and other naturally-occurring alkenylbenzenes. I. Adult female CD-1 mice. Carcinogenesis $5: 1613-1622$ 
Randerath K, Putman K, Randerath E (1993) Flavor constituents in cola drinks induce hepatic DNA adducts in adult and fetal mice. Biochem Biophys Res Commun 192:61-68

Rietjens IMCM, Cohen SM, Fukushima S, Gooderham NJ, Hecht S, Marnett LJ, Smith RL, Adams TB, Bastaki M, Harman CG, Taylor SV (2014) Impact of structural and metabolic variations on the toxicity and carcinogenicity of hydroxy- and alkoxysubstituted allyl- and propenylbenzenes. Chem Res Toxicol 27:1092-1103. doi:10.1021/tx500109s

Sammy GM, Nawar WW (1968) Identification of the major components of nutmeg oil by gas chromatography and mass spectrometry. Chem Ind 38:1279-1280

Swanson AB, Chambliss DD, Blomquist JC, Miller EC, Miller JA (1979) The mutagenicities of safrole, estragole, eugenol, trans-anethole, and some of their known or possible metabolites for Salmonella typhimurium mutants. Mut Res 60:143-153

van den Berg SJ, Restani P, Boersma MG, Delmulle L, Rietjens IMCM (2011) Levels of genotoxic and carcinogenic compounds in plant food supplements and associated risk assessment. Food Nutr Sci 2:989-1010

van den Berg SJ, Punt A, Soffers AE, Vervoort J, Ngeleja S, Spenkelink B, Rietjens IMCM (2012) Physiologically based kinetic models for the alkenylbenzene elemicin in rat and human and possible implications for risk assessment. Chem Res Toxicol 25:2352-2367. doi:10.1021/tx300239z

WHO (2009) Safety evaluation of certain additives, prepared by the Sixty-ninth meeting of the Joint FAO/WHO Expert Committee on Food Additivies, pp 103-164. http://whqlibdoc.who.int/publications/2009/9789241660600_eng.pdf

Wiseman RW, Fennell TR, Miller JA, Miller EC (1985) Further characterization of the DNA adducts formed by electrophilic esters of the hepatocarcinogens 1'-hydroxysafrole and 1'-hydroxyestragole in vitro and in mouse liver in vivo, including new adducts at C-8 and N-7 of guanine residues. Cancer Res 45:3096-3105

Wiseman RW, Miller EC, Miller JA, Liem A (1987) Structure-activity studies of the hepatocarcinogenicities of alkenylbenzene derivatives related to estragole and safrole on administration to preweanling male $\mathrm{C} 57 \mathrm{BL} / 6 \mathrm{~J}$ x C3H/HeJ F1 mice. Cancer Res $47: 2275-2283$

Wislocki PG, Borchert P, Miller JA, Miller EC (1976) The metabolic activation of the carcinogen 1'-hydroxysafrole in vivo and in vitro and the electrophilic reactivities of possible ultimate carcinogens. Cancer Res 36:1686-1695 
Wislocki PG, Miller EC, Miller JA, McCoy EC, Rosenkranz HS (1977) Carcinogenic and mutagenic activities of safrole, 1'-hydroxysafrole, and some known or possible metabolites. Cancer Res 37:1883-1891

Zangouras A, Caldwell J, Hutt AJ, Smith RL (1981) Dose dependent conversion of estragole in the rat and mouse to the carcinogenic metabolite, 1'-hydroxyestragole. Biochem Pharmacol 30:1383-1386

Zhou GD, Moorthy B, Bi J, Donnelly KC, Randerath K (2007a) DNA adducts from alkoxyallylbenzene herb and spice constituents in cultured human (HepG2) cells. Environ Mol Mutagen 48:715-721. doi:10.1002/em.20348

Zhou SF, Xue CC, Yu XQ et al (2007b) Metabolic activation of herbal and dietary constituents and its clinical and toxicological implications: an update. Curr Drug Metab 8:526-553 

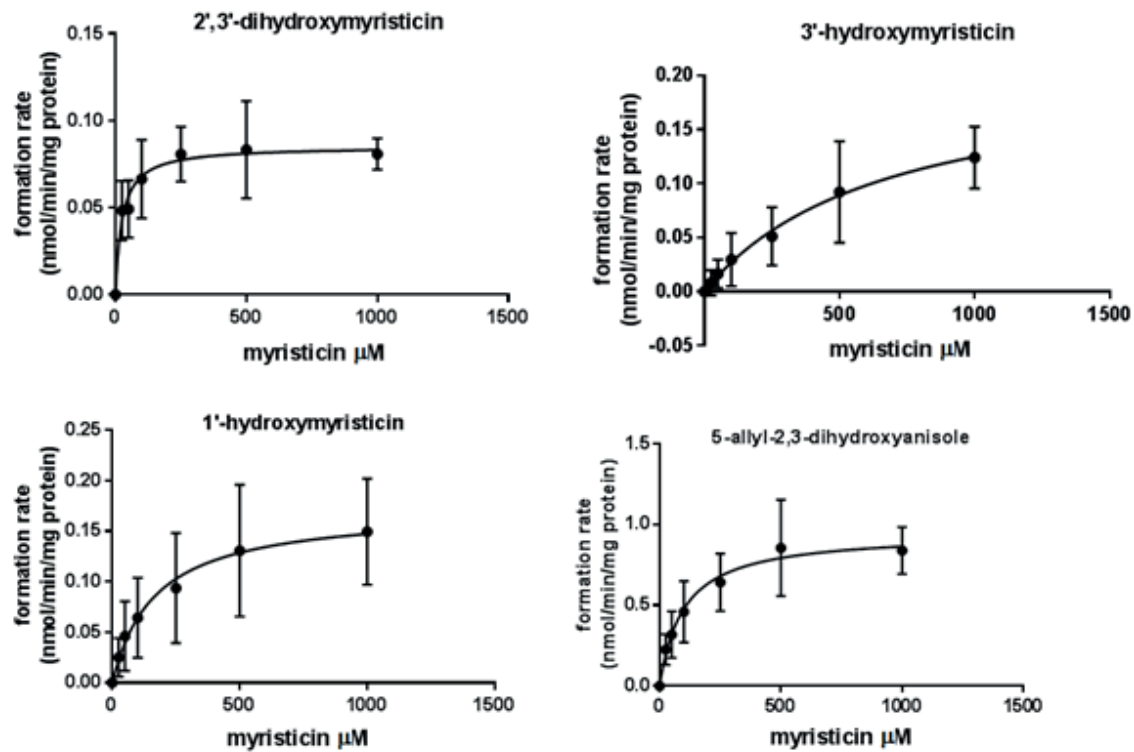

Figure S1. Concentration-dependent rate of myristicin metabolite formation in incubations with pooled human mixed gender liver microsomes. Curves for formation of four different phase I metabolites (2',3'-dihydroxymyristicin, 3'-hydroxymyristicin, 1'-hydroxymyristicin and 5-allyl-2,3-dihydroxyanisole) are presented. 


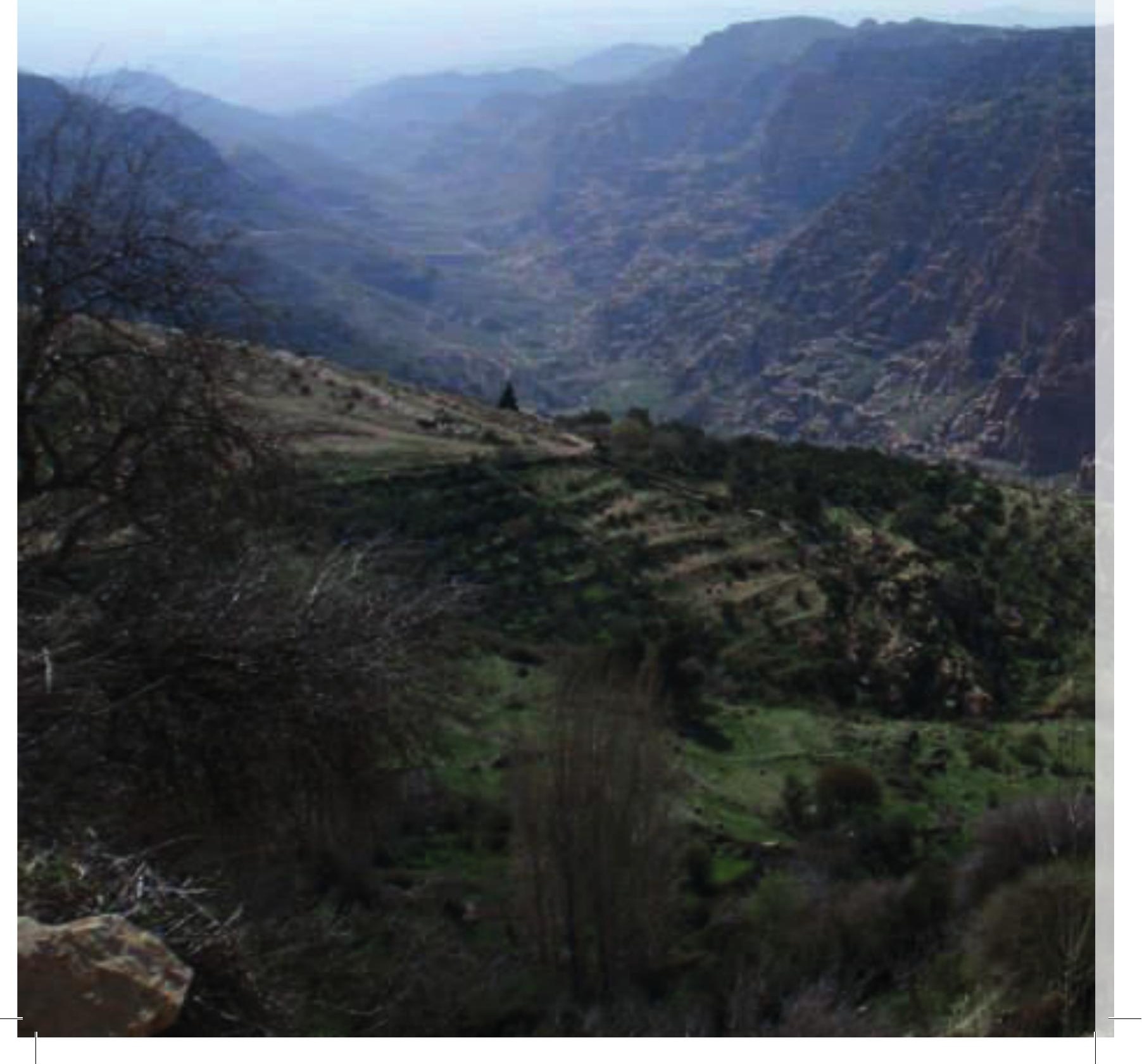




\section{Chapter 3}

\section{Mode of action based risk assessment of the botanical food-borne alkenylbenzenes apiol from parsley using physiologically based kinetic (PBK) modelling and read-across from safrole}

Abdelmajeed M. Al-Ajlouni, Amer J. Al-Malahmeh, Sebastiaan Wesseling, Ans E. M. F. Soffers, Ala' Al-Subeihi, Reiko Kiwamoto, Jacques Vervoort, Ivonne M. C. M. Rietjens

Food and Chemical Toxicology (2016), 89:138-50. Doi: 10.1016/j.fct.2016.01.018 


\begin{abstract}
The present study developed physiologically-based kinetic (PBK) models for the alkenylbenzene apiol in order to facilitate risk assessment based on read-across from the related alkenylbenzene safrole. Model predictions indicate that in rat liver the formation of the 1'-sulfoxy metabolite is about 3 times lower for apiol than for safrole. These data support that the lower confidence limit of the benchmark dose resulting in a $10 \%$ extra cancer incidence $\left(\mathrm{BMDL}_{10}\right)$ that would be obtained in a rodent carcinogenicity study with apiol may be 3-fold higher for apiol than for safrole. These results enable a preliminary risk assessment for apiol, for which tumor data are not available, using a BMDL 10 value of 3 times the $\mathrm{BMDL}_{10}$ for safrole. Based on an estimated $\mathrm{BMDL}_{10}$ for apiol of $5.7-15.3 \mathrm{mg} / \mathrm{kg}$ body wt per day and an estimated daily intake of $4 \times 10^{-5} \mathrm{mg} / \mathrm{kg}$ body wt per day, the margin of exposure (MOE) would amount to $140000-385000$. This indicates a low priority for risk management. The present study shows how PBK modelling can contribute to the development of alternatives for animal testing, facilitating read-across from compounds for which in vivo toxicity studies on tumor formation are available to compounds for which these data are unavailable.
\end{abstract}




\section{INTRODUCTION}

Apiol (1-allyl-2,5-dimethoxy-3,4-methylenedioxybenzene) is one of alkenylbenzene compounds found in herbs and other botanicals like parsley, fennel, nutmeg and elemi tree. High levels of apiol are especially present in parsley and apiol gives parsley its characteristics odour (Miller et al., 1983, Parthasarathy, 2008, Tunali et al., 1999). Parsley parts (leaves, stems, roots and seeds) are used as food flavouring agent in many food types such as sauces, soups, stuffing, rissoles, and minces, and are also sprinkled over vegetables or salads. Beside the use of parsley in food, medicinal uses of apiol extracted from the Triple Moss curled variety of parsley have been reported (Parthasarathy, 2008). The structure of apiol is closely related to that of safrole, myristicin, estragole, methyleugenol, and elemicin (Figure 1).<smiles>C=CCc1ccc(OC)cc1</smiles>

estragole<smiles>C=CCc1ccc2c(c1)OCO2</smiles>

safrole<smiles>C=CCc1ccc(OC)c(OC)c1</smiles>

methyleugenol<smiles>C=CCc1cc(OC)c2c(c1)OCO2</smiles>

myristicin<smiles>C=CCc1cc(OC)c(OC)c(OC)c1</smiles>

elemicin<smiles>C=CCc1cc(OC)c2c(c1OC)OCO2</smiles>

apiol

Figure 1. The structural formulas of the alkenylbenzenes estragole, methyleugenol, elemicin, safrole, myristicin and apiol.

These alkenylbenzenes are of concern because they can be converted to DNA reactive 1'sulfoxy metabolites that readily form DNA adducts that may contribute to the formation of hepatomas in rodent bioassays upon exposure to these alkenylbenzenes at high dose levels (Miller et al., 1983, Randerath et al., 1984, SCF, 2001b, SCF, 2001a, SCF, 2002, Wiseman et al., 1987). DNA adduct formation results from bioactivation of apiol following the 
metabolic pathways presented in Figure 2 (WHO, 2009). Apiol however is less well studied than its related alkenylbenzene safrole and rodent carcinogenicity studies on apiol are not available hampering its risk assessment.
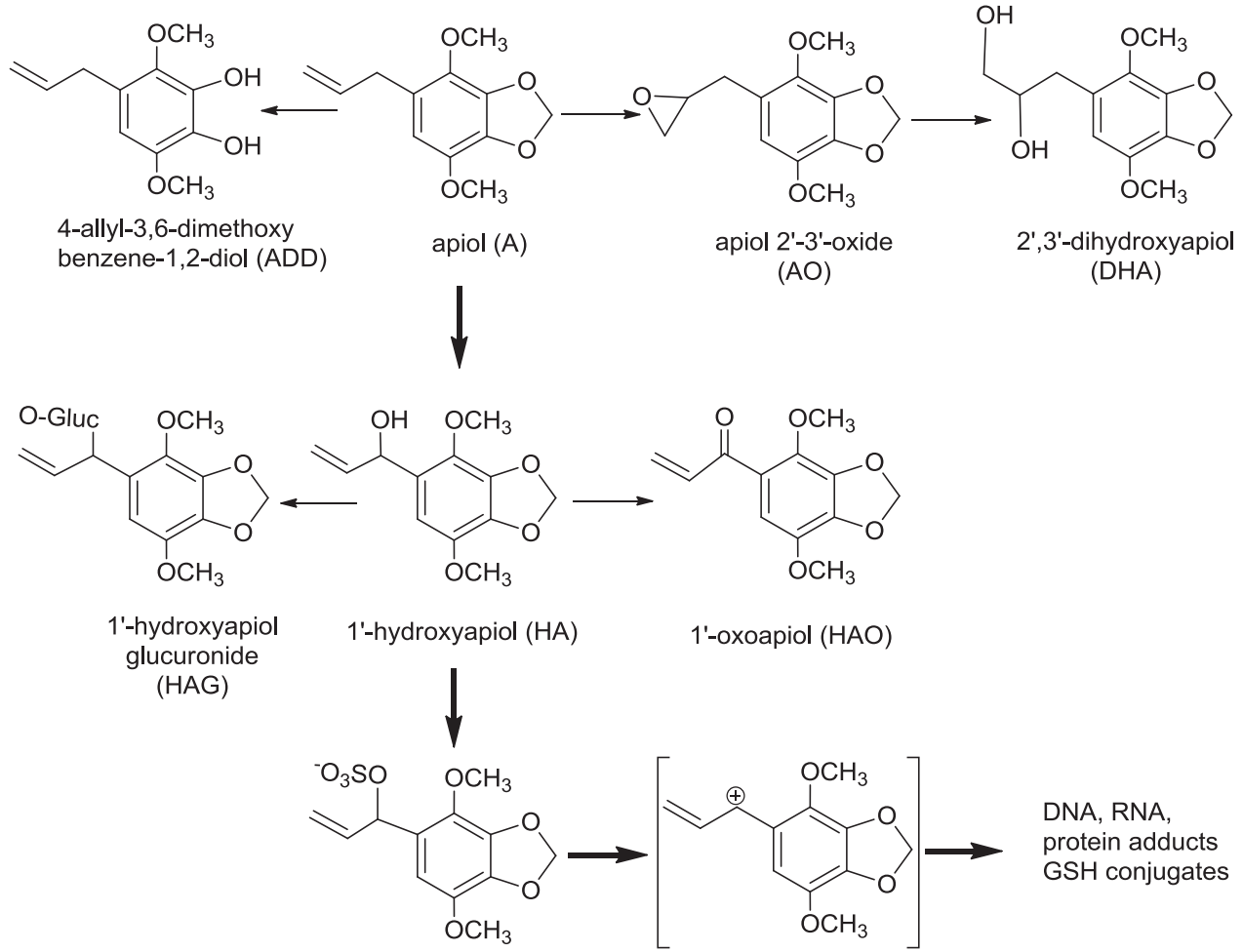
1 '-sulfoxyapiol (HAS)

Figure 2. Suggested metabolic pathways of apiol.

The structural similarity of apiol to safrole raises a concern and provides a rationale for an updated risk assessment of exposure to apiol via food including food supplements. Several studies have reported on the DNA adduct formation by apiol in animal in vivo studies or in human in vitro models as compared to the related alkenylbenzenes and found apiol to be less potent than its structural analogues (Miller et al., 1983, Phillips et al., 1984, Randerath et al., 1984, Zhou et al., 2007). 
The safety of human exposure to apiol has been assessed by the WHO in 2009 concluding that the structural similarities to safrole with available experimental data give evidence that apiol may cause toxicity and carcinogenicity in rodents exposed to high dose levels (WHO, 2009). Because rodent bioassays characterizing the possible carcinogenicity of apiol are not available, the aim of the present study was to perform a risk assessment for apiol based on PBK-modelling based read-across from safrole for which rodent tumor data are available (Miller et al., 1983, Phillips et al., 1984, Randerath et al., 1984).

\section{MATERIALS AND METHODS}

\section{Chemicals and Reagents:}

Caution: Apiol and 1'-hydroxyapiol are possible carcinogens and should be handled with care.

Apiol, uridine 5'-diphosphoglucuronic acid trisodium salt (UDPGA), reduced L-glutathione (GSH), alamethicin (from Trichoderma viride), and 3'-phosphoadenosine-5'-phosphosulfate (PAPS) were obtained from Sigma Aldrich (Zwijndrecht, Netherlands). Reduced $\beta$ nicotinamide adenine dinucleotide phosphate (NADPH) and nicotinamide adenine dinucleotide $\left(\mathrm{NAD}^{+}\right)$were from Roche Diagnostic (Mannheim, Germany), and dimethyl sulfoxide (DMSO) was obtained from Acros Organics (Geel, Belgium). Chromatographic grade trifluoroacetic acid (TFA) was obtained from Merck (Darmstadt, Germany). Potassium dihydrogen phosphate, dipotassium hydrogen phosphate trihydrate, acetic acid, and magnesium chloride were provided by VWR International (Darmstadt, Germany). Acetonitrile (ACN) (ULC/MS grade) was purchased from Biosolve BV (Valkenswaard, The Netherlands).

Pooled male rat liver microsomes and S9 from Sprague-Dawley and mixed gender pooled human liver microsomes and S9 were from BD Gentest (Woburn, United States). Pooled 
male Sprague-Dawley rat lung, kidney, and small intestinal microsomes and pooled gender human lung, kidney, and intestinal microsomes were purchased from BioPredic International (Rennes, France).

\section{Synthesis of 1'-hydroxyapiol and 1'-oxoapiol}

The synthesis of 1'-hydroxyapiol from apiol was done as described previously for the synthesis of 1'-hydroxysafrole from safrole by Jeurissen et al. (Jeurissen et al., 2004) and 1'oxoapiol was synthesized from 1'-hydroxyapiol according to the method used for synthesis of 1'-oxoestragole from 1'-hydroxyestragole (Wislocki et al., 1976).

\section{In vitro incubations}

\section{Microsomal metabolism of apiol by rat and human microsomes}

Liver, kidney, lung and small intestine microsomes from male Sprague Dawley rat and from human were used to determine tissue-specificity of the microsomal biotransformation of apiol in rat and human. Incubations were performed by adding $1 \mathrm{mg} / \mathrm{ml}$ of the microsomal protein preparation to an incubation mixture containing (final concentrations) $3 \mathrm{mM}$ NADPH in 0.2 $\mathrm{M}$ Tris- $\mathrm{HCl}\left(\mathrm{pH}\right.$ 7.4). After a 1 minute pre-incubation at $37^{\circ} \mathrm{C}$, apiol (final concentration 1000 $\mu \mathrm{M})$ was added from a 100 times concentrated stock solution in DMSO so that the final DMSO content was $1 \%(\mathrm{v} / \mathrm{v})$. After 120 minutes incubation at $37^{\circ} \mathrm{C}$ for rat and human microsomes the reactions were terminated by adding $25 \mu 1$ ice-cold acetonitrile. All samples were centrifuged for 5 minutes at $16000 \times \mathrm{g}$ and the supernatant was stored at $-20^{\circ} \mathrm{C}$ until Ultra Performance Liquid Chromatography (UPLC) analysis.

For both male rat and human, metabolism of apiol was only observed in incubations with liver microsomes (See the results section) and hence kinetic constants for the formation of microsomal metabolites were determined only for liver microsomes. To determine the kinetic 
constants incubations following the conditions described above were done using final concentrations of apiol from 25 to $1000 \mu \mathrm{M}$ for rat and human liver while keeping the DMSO content at $1 \%(\mathrm{v} / \mathrm{v})$. Blank incubations were performed in the absence of the cofactor NADPH. All incubations were performed in triplicate.

Glucuronidation of 1'-hydroxyapiol to 1'-hydroxyapiol glucuronide by rat and human liver S9

The kinetic constants for the metabolic conversion of 1'-hydroxyapiol to 1'-hydroxyapiol glucuronide in incubations with both male rat and human liver fractions were determined as described previously for related 1'-hydroxyalkenylbenzenes (Al-Subeihi et al., 2012, AlSubeihi et al., 2011, Martati et al., 2011b, Martati et al., 2012b, Punt et al., 2008, Punt et al., 2009, Van den Berg et al., 2012). In short, incubations were performed using (final concentrations) $10 \mathrm{mM}$ UDPGA and $0.5 \mathrm{mg} / \mathrm{mL}$ male Sprague-Dawley rat or pooled gender human $\mathrm{S} 9$ protein in $0.2 \mathrm{M}$ Tris- $\mathrm{HCl}(\mathrm{pH} 7.4)$ containing $10 \mathrm{mM} \mathrm{MgCl}_{2}$. First the incubations were pre-treated on ice for 15 minutes with $0.025 \mathrm{mg} / \mathrm{mL}$ alamethicin added from a 200 times concentrated stock solution in methanol to overcome enzyme latency and to obtain maximal glucuronidation activity. After the pre-treatment on ice and pre-incubation at $37^{\circ} \mathrm{C}$ for 1 minute, the reactions were subsequently started by adding 1'-hydroxyapiol in final concentrations of 10 to $2000 \mu \mathrm{M}$. 1'-Hydroxyapiol was added from 100 times concentrated stock solutions dissolved in DMSO. The reaction was incubated for 30 and 120 minutes for rat and human S9, respectively, and terminated by adding $25 \mu \mathrm{L}$ of ice-cold acetonitrile. Blank incubations were carried out in the absence of the cofactor UDPGA. Experiments were performed in triplicate. All samples were centrifuged for 5 minutes at $16000 \times \mathrm{g}$, and the supernatant was stored at $-20^{\circ} \mathrm{C}$ until UPLC analysis. 


\section{Oxidation of 1'-hydroxyapiol to 1'-oxoapiol by rat and human liver microsomes}

The kinetic constants for the enzymatic conversion of 1'-hydroxyapiol to 1'-oxoapiol were determined using incubation mixtures containing (final concentrations) $3 \mathrm{mM} \mathrm{NAD}+2 \mathrm{mM}$ $\mathrm{GSH}$, and $1 \mathrm{mg} / \mathrm{mL}$ rat or human liver microsomes in $0.2 \mathrm{M}$ Tris- $\mathrm{HCl}(\mathrm{pH}$ 7.4). GSH was added to the incubation mixtures to trap the reactive 1'-oxometabolite formed after oxidation of 1'-hydroxyapiol. To determine the kinetic constants incubations following the conditions described above were done using final concentrations of 1'-hydroxyapiol from 50 to 2000 $\mu \mathrm{M}$ added to the incubation mixture from 100 times concentrated stock solutions in DMSO. After pre-incubation for 1 minute at $37^{\circ} \mathrm{C}$ the reactions were started by adding the 1 'hydroxyapiol and were terminated after 60 minutes of incubation at $37^{\circ} \mathrm{C}$ by adding $25 \mu \mathrm{L}$ of ice-cold acetonitrile. The formation of the GSH conjugate of 1'-oxoapiol, GS-1'-oxoapiol, was linear with time and microsomal protein under the experimental conditions used. Blank incubations were performed without the cofactor $\mathrm{NAD}^{+}$. Incubations were performed in triplicate. All samples were centrifuged for 5 minutes at $16000 \times \mathrm{g}$, and the supernatant was stored at $-20^{\circ} \mathrm{C}$ until UPLC analysis.

\section{Sulfonation of 1'-hydroxyapiol to 1'-sulfoxyapiol by rat and human liver S9}

The kinetic constants for the enzymatic conversion of 1'-hydroxyapiol to 1'-sulfoxyapiol were determined using incubation mixtures containing (final concentrations) $10 \mathrm{mM} \mathrm{GSH}$, $0.2 \mathrm{mM}$ PAPS, and $3 \mathrm{mg} / \mathrm{mL}$ Sprague-Dawley rat or mixed gender pooled human liver S9 proteins in $0.1 \mathrm{M}$ potassium phosphate buffer ( $\mathrm{pH} 8.0)$. GSH was used as a scavenger of the reactive carbocation formed due to the unstable nature of the 1'-sulfoxymetabolite in an aqueous environment. After pre-incubation for 1 minute at $37^{\circ} \mathrm{C} 1^{\prime}$-hydroxyapiol dissolved in DMSO was added in final concentrations ranging between 50 and $2000 \mu \mathrm{M}$, while keeping the final DMSO content at $1 \%(\mathrm{v} / \mathrm{v})$. The reaction was terminated after 360 minutes by 
adding $25 \mu \mathrm{L}$ of ice-cold acetonitrile. The formation of the GSH conjugate of 1'-sulfoxyapiol was linear with time and S9 protein concentration under the experimental conditions used. The scavenging may either be chemically or catalysed by the glutathione S-transferases present in the S9 incubations in which the sulfonation of 1'-hydroxyapiol was measured. Blank incubations were performed in the absence of PAPS. Incubations were performed in triplicate. All samples were centrifuged for 5 minutes at $16000 \times \mathrm{g}$, and the supernatant was stored at $-20^{\circ} \mathrm{C}$ until UPLC analysis.

\section{Identification and quantification of apiol metabolites}

Apiol metabolites formed in microsomal incubations were identified using a photodiode array detection (UPLC-PDA) composed of a Waters (Waters, Milford, MA) Acquity solvent manager, sample manager, and diode array detector, equipped with a Water Acquity UPLC BEH C18 column. The gradient was made with a mixture of ACN and ultrapure water containing $0.1 \%(\mathrm{v} / \mathrm{v})$ TFA. The flow rate was $0.6 \mathrm{ml} / \mathrm{min}$. After equilibrating the column at the starting condition of $10 \% \mathrm{ACN}, \mathrm{ACN}$ increased to $50 \%$ over $4 \mathrm{~min}$, was further increased to $80 \%$ over $0.5 \mathrm{~min}$, decreased to $10 \%$ over $0.5 \mathrm{~min}$ and was finally kept at $10 \%$ for $1 \mathrm{~min}$. Metabolites were identified as described in the Result section. Quantification of microsomal apiol metabolites was done by comparison of the peak areas obtained at a wavelength of $208 \mathrm{~nm}$ to the calibration curve of synthesized 1'-hydroxyapiol because UV spectra of all metabolites were similar.

The concentration of 1'-hydroxyapiol glucuronide was determined using the same UPLCPDA system as described above. The gradient was made with acetonitrile and ultrapure water containing $0.1 \%(\mathrm{v} / \mathrm{v})$ TFA. The flow rate was $0.6 \mathrm{ml} / \mathrm{min}$. In a mixture of $\mathrm{ACN}$ and ultrapure water containing $0.1 \%(\mathrm{v} / \mathrm{v}) \mathrm{TFA}$, the gradient started at $10 \% \mathrm{ACN}$, increased to $60 \% \mathrm{ACN}$ over 3.5 minutes, further increased to $80 \%$ over $0.5 \mathrm{~min}$, kept at $80 \% \mathrm{ACN}$ for 0.5 
min and then decreased to $10 \% \mathrm{ACN}$ over $0.5 \mathrm{~min}$. 1'-hydroxyapiol glucuronide was identified as described in the results section. Quantification of 1'-hydroxyapiol glucuronide was done by comparison of the peak areas obtained at a wavelength of $208 \mathrm{~nm}$ to the calibration curve of synthesized 1'-hydroxyapiol.

The concentration of the glutathione conjugate of 1'-oxoapiol was determined using the same UPLC-PDA system as described above. The gradient was made with acetonitrile and ultrapure water containing $0.1 \%(\mathrm{v} / \mathrm{v})$ TFA. The flow rate was $0.6 \mathrm{ml} / \mathrm{min}$. In a mixture of $\mathrm{ACN}$ and ultrapure water containing $0.1 \%(\mathrm{v} / \mathrm{v}) \mathrm{TFA}$, the gradient started at $10 \% \mathrm{ACN}$, increased to $30 \% \mathrm{ACN}$ over 2.5 minutes, was further increased to $80 \% \mathrm{ACN}$ over $0.5 \mathrm{~min}$, kept at $80 \% \mathrm{ACN}$ for $0.5 \mathrm{~min}$ and finally decreased to $10 \% \mathrm{ACN}$ over $0.5 \mathrm{~min}$, and kept at $10 \% \mathrm{ACN}$ for $0.5 \mathrm{~min}$. Quantification of the GSH adduct of the metabolite was done by comparison of the peak areas obtained at a wavelength of $280 \mathrm{~nm}$ to the calibration curve of the GSH adduct of the synthesized 1'-oxoapiol.

The concentration of the glutathione conjugate of 1'-sulfoxyapiol was determined using the same UPLC-PDA system described above. The flow rate was $0.6 \mathrm{ml} / \mathrm{min}$. In a mixture of ACN and ultrapure water containing $0.1 \%(\mathrm{v} / \mathrm{v}) \mathrm{TFA}$, the gradient started at $0 \% \mathrm{ACN}$, increased to $20 \% \mathrm{ACN}$ over 0.2 minutes, further increased to $30 \% \mathrm{ACN}$ over $4.3 \mathrm{~min}$, and again increased to $100 \% \mathrm{ACN}$ over $0.3 \mathrm{~min}$, kept at $100 \% \mathrm{ACN}$ for $0.2 \mathrm{~min}$, and finally decreased to $0 \% \mathrm{ACN}$ over $0.2 \mathrm{~min}$ and kept at $0 \% \mathrm{ACN}$ for $0.8 \mathrm{~min}$. The $\mathrm{GSH}$ adduct of 1'-sulfoxyapiol formed was identified by LC-MS using a microTOF MS (Bruker) coupled to an Agilent LC (1200 Series) equipped with an Altima C18 column $(150$ x $4.6 \mathrm{~mm}, 3 \mu \mathrm{m})$. The mobile phase used consisted of nanopure water with $0.1 \%$ formic acid and ACN with $0.1 \%$ formic acid. Elution was at a flow rate of $0.8 \mathrm{ml} / \mathrm{min}$, starting at $22 \%$ ACN with a linear increase to $100 \% \mathrm{ACN}$ in $30 \mathrm{~min}$. Subsequently, the gradient returned linearly to the initial condition in 2 min and remained 13 min at this condition prior to the next injection. 
Quantification of the GSH adduct of 1'-sulfoxyapiol was done by comparison of the peak areas obtained at a wavelength of $280 \mathrm{~nm}$ to the calibration curve of the GSH adduct of synthesized 1'-oxoapiol since their UV spectra are comparable. Mass spectrometric analysis was in the negative electrospray mode using a spray capillary voltage of $4500 \mathrm{~V}$, a capillary temperature of $200^{\circ} \mathrm{C}$ and nitrogen as nebulizer gas at $8.0 \mathrm{~L} / \mathrm{min}$.

\section{Determination of kinetic constants of apiol and 1'-hydroxyapiol metabolic conversions}

Kinetic constants for the metabolic conversions of apiol and 1'-hydroxyapiol were calculated by two equations depending on the dose-dependency of the kinetics of the conversion. If the reaction reached saturation with increasing substrate concentration, the kinetic constants were derived by fitting the data to the standard Michaelis-Menten equation; $\mathrm{v}=\mathrm{V}_{\max } \times[\mathrm{S}] /\left(\mathrm{K}_{\mathrm{m}}+\right.$ $[S])$, in which $[S]$ represents the substrate concentration, $V_{\max }$ the maximum velocity and $K_{m}$ the Michaelis-Menten constant for the formation of the different metabolites of apiol or 1'hydroxyapiol. Data analysis was accomplished using GraphPad Prism, version 5.04 (GraphPad Software, San Diego, California, USA). When the reaction did not reach saturation and rather displayed a linear increase in the rate of conversion with increasing substrate concentration, the kinetic rate constant for a first order reaction was derived by using the following equation; $\mathrm{v}=\mathrm{k} \cdot[\mathrm{S}]$, with $\mathrm{k}$ being the first order rate constant and $[\mathrm{S}]$ representing the substrate concentration.

\section{Apiol PBK models in rat and human}

PBK models were developed describing the dose-dependent bioactivation and detoxification of apiol in respectively rat and human. The apiol models were based on the PBK models previously defined for the metabolism of estragole, methyleugenol, elemicin and safrole in rat and human (Al-Subeihi et al., 2011, Al-Subeihi et al., 2012, Martati et al., 2011, Martati et 
al., 2012, Punt et al., 2008, Punt et al., 2009). Figure 3 presents an overview of the developed PBK models for apiol metabolism in rat and human.

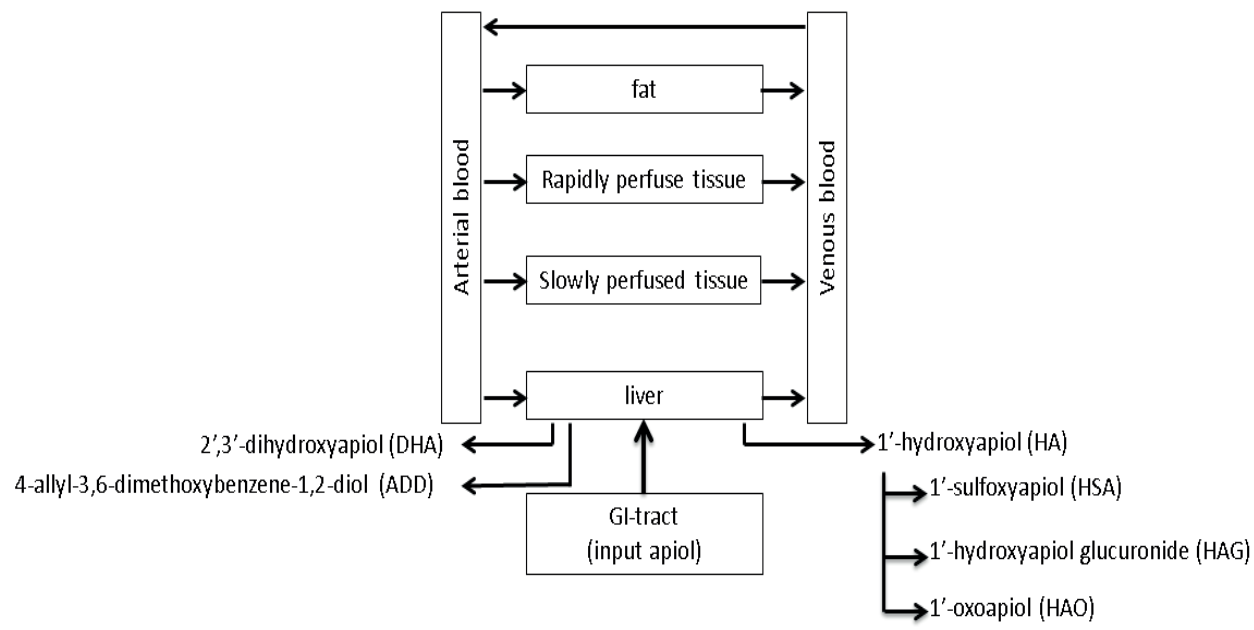

Figure 3. Overview of the PBK model for apiol.

The models consist of several compartments representing different organs and tissues (i.e. liver, fat tissue, rapidly perfused tissues and slowly perfused tissues) which are connected through the systemic circulation. First order kinetics was used to describe the uptake of apiol from the gastrointestinal tract assuming a direct and complete uptake by the liver with an absorption rate constant $\left(\mathrm{k}_{\mathrm{a}}\right)$ of $1.0 \mathrm{~h}^{-1}$ which is based on the fast and complete absorption of the structurally related alkenylbenzene estragole from the gastrointestinal tract (WHO, 2009). For both rat and human, only the liver microsomes were able to convert apiol to different microsomal metabolites (see results section) and this is why no other tissue compartments were described as separate compartments in the model. In liver microsomal incubations 2',3'dihydroxyapiol (DHA), 1'-hydroxyapiol (HA), and 4-allyl-3,6-dimethoxybenzene-1,2-diol (ADD) were formed and their formation was included. Since 2',3'-dihydroxyapiol is formed after hydrolysis of apiol-2',3'-oxide, data for both metabolites that result from epoxidation of 
apiol were combined and referred to as 2',3'-dihydroxyapiol. Accordingly, a mass balance equation for apiol in rat and human liver is as follows:

$$
\begin{gathered}
\partial A L_{A} / \partial t=\text { dUptake }_{A} / \partial t+Q L \times\left(C A_{A}-C L_{A} / P L_{A}\right) \\
-V_{\text {max }{ }_{H A}} \times C L_{A} / P L_{A} /\left(K_{m, H A}+C L_{A} / P L_{A}\right) \\
-V_{\text {max }, D H A} \times C L_{A} / P L_{A} /\left(K_{m, D H A}+C L_{A} / P L_{A}\right) \\
-V_{\text {max }, A D D} \times C L_{A} / P L_{A} /\left(K_{m, A D D}+C L_{A} / P L_{A}\right) \\
\text { dUptake } / \partial t=-\partial A G I_{A} / \partial t=K_{a} \times A G I_{A}, \\
A G I_{A}(0)=\text { oral dose } \\
C L_{A}=A L_{A} / V L
\end{gathered}
$$

Where uptake $(\mu \mathrm{mol})$ is the amount of apiol taken up from the gastrointestinal tract, $\mathrm{AGI}_{\mathrm{A}}$ ( $\mu \mathrm{mol})$ is the amount of apiol remaining in the gastrointestinal tract, $\mathrm{AL}_{\mathrm{A}}(\mu \mathrm{mol})$ is the amount of apiol in liver. $\mathrm{CL}_{\mathrm{A}}$ is the apiol concentration in the liver $(\mu \mathrm{mol} / \mathrm{L}) . \mathrm{CA}_{\mathrm{A}}$ is the apiol concentrations in the arterial blood (in $\mu \mathrm{mol} / \mathrm{L}$ ), QL is the blood flow rate to liver $(\mathrm{L} / \mathrm{h}), \mathrm{VL}$ is the volume of the liver (L), $\mathrm{PL}_{\mathrm{A}}$ is the liver/blood partition coefficient of apiol, and $\mathrm{V}_{\max }$, and $\mathrm{K}_{\mathrm{m}}$, are the values representing the maximum rate of formation and Michaelis-Menten constant, respectively, for the formation of 1'-hydroxyapiol (HA), 2',3'-dihydroxyapiol (DHA), and 4-allyl-3,6-dimethoxybenzene-1,2-diol (ADD).

In both models, the conversion of apiol to 2',3'-dihydroxyapiol and 4-allyl-3,6dimethoxybenzene-1,2-diol are described, but further reactions with these metabolites were not included in the model. It was assumed that these metabolites and/or their possible conjugates were completely excreted into the urine. Since the liver is the major target organ for alkenylbenzene-induced carcinogenicity in rats and mice, the present study focused primarily on metabolic conversion of 1'-hydroxyapiol by glucuronidation, oxidation and sulfonation in the liver only. The mass balance equation for 1'-hydroxyapiol in rat and human liver is as follows: 
Rat:

$$
\begin{gathered}
\partial A L_{H A} / \partial t=V_{\max _{H A}} \times C L_{A} / P L_{A} /\left(K_{m, H A}+C L_{A} / P L_{A}\right) \\
-V_{\text {max }_{H A G}} \times C L_{H A} / P L_{H A} /\left(K_{m, H A}+C L_{H A} / P L_{H A}\right) \\
-k_{H A O} \times C L_{H A} / P L_{H A} \\
-k_{H A S} \times C L_{H A} / P L_{H A} \\
C L_{H A}=A L_{H A} / V L
\end{gathered}
$$

Human:

$$
\begin{gathered}
\partial A L_{H A} / \partial t=V_{\text {max }_{H A}} \times C L_{A} / P L_{A} /\left(K_{m, H A}+C L_{A} / P L_{A}\right) \\
-V_{\text {max }_{H A G}} \times C L_{H A} / P L_{H A} /\left(K_{m, H A}+C L_{H A} / P L_{H A}\right) \\
-V_{\text {max }_{H A O}} \times C L_{H A} / P L_{H A} /\left(K_{m, H A O}+C L_{H A} / P L_{H A}\right) \\
-k_{H A S} \times C L_{H A} / P L_{H A} \\
C L_{H A}=A L_{H A} / V L
\end{gathered}
$$

where ALHA is the amount of 1'-hydroxyapiol in the liver $(\mu \mathrm{mol}), \mathrm{CL}_{\mathrm{HA}}$ is the 1'hydroxyapiol concentration in the liver $(\mu \mathrm{mol} / \mathrm{L}), \mathrm{PL}_{\mathrm{HA}}$ is the liver/blood partition coefficient of 1'-hydroxyapiol, $\mathrm{V}_{\max }$, and $\mathrm{K}_{\mathrm{m}}$, are the maximum rate of formation and Michaelis-Menten constant, respectively, for the formation of the different apiol metabolites, including 1'hydroxyapiol glucuronide (HAG) in the rat and human liver and 1'-oxoapiol (HAO) in human, and $\mathrm{k}$ is the first order rate constant for formation of 1'-oxoapiol in rat, and 1'sulfoxyapiol (HAS) in rat and human liver.

$\mathrm{V}_{\max }$ and $\mathrm{K}_{\mathrm{m}}$ values and first order rate constants $\mathrm{k}$ in case of absence of saturation (for oxidation in rat and sulfonation of 1'-hydroxyapiol) for the different metabolic pathways of apiol and 1'-hydroxyapiol were derived in vitro in the present study. $\mathrm{V}_{\max }$ values that were derived in vitro expressed as $\mathrm{nmol} \mathrm{min}^{-1}$ (mg liver microsomal or S9 protein) $)^{-1}$ were scaled to values representing the $\mathrm{V}_{\max }$ per $\mu \mathrm{mol} \mathrm{h}^{-1}$ (g liver) $^{-1}$ using microsomal yields of $35 \mathrm{mg} / \mathrm{g}$ liver in rat and $32 \mathrm{mg} / \mathrm{g}$ liver in human and S9 protein yields of $143 \mathrm{mg} / \mathrm{g}$ liver as defined by Punt 
et al. (Punt et al., 2008, Punt et al., 2009) based on Medinsky et al. (Medinsky et al., 1994). First order rate constants $\mathrm{k}$ expressed in $\mathrm{ml} \mathrm{min}^{-1}$ (mg liver microsomal or $\mathrm{S} 9$ protein) ${ }^{-1}$ were scaled to values expressed in $\mathrm{ml} \mathrm{h}^{-1}$ per g liver using the same conversion factor for microsomal and S9 protein yield.

Tables 1 and 2 summarize the physiological parameters (i.e. tissue volumes, cardiac output and tissue blood flows) for rat and human respectively which were derived from literature (Brown et al., 1997). Partition coefficients were derived in silico based on a method described by DeJongh et al.(DeJongh et al., 1997) using the $\log \mathrm{K}_{\mathrm{ow}}$. Log $\mathrm{K}_{\mathrm{ow}}$ values for apiol (ClogP 3.12) and 1'-hydroxyapiol (ClogP 1.56) were estimated using ChemBio3D 2010 (CambrigeSoft, USA). Mass balance equations were coded and numerically integrated in Berkeley Madonna 8.3.18 (Macey and Oster, UC Berkeley, CA, USA) using the Rosenbrock's algorithm for stiff systems. The PBK models were run during 720-hr after the dosing to allow full conversion of the parent compound. 
Table 1. Parameters used in the physiologically based biokinetic model for apiol in male rat.

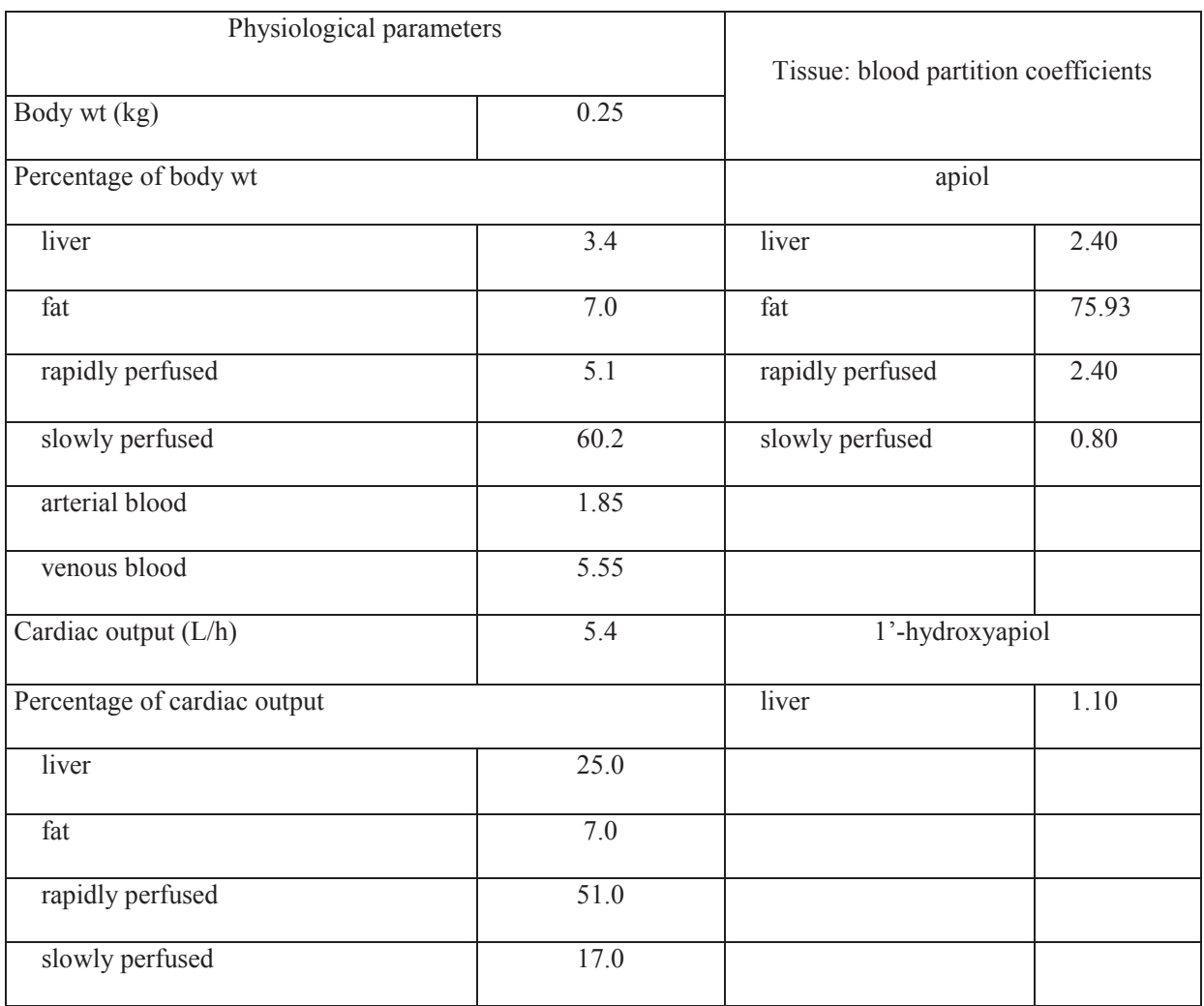


Table 2. Parameters used in the physiologically based biokinetic model for apiol in human.

\begin{tabular}{|c|c|c|c|}
\hline Phys & & \multirow{2}{*}{\multicolumn{2}{|c|}{ Tissue: blood partition coefficients }} \\
\hline Body wt (kg) & 60 & & \\
\hline \multicolumn{2}{|l|}{ Percentage of body wt } & \multicolumn{2}{|c|}{ apiol } \\
\hline liver & 2.6 & liver & 6.45 \\
\hline fat & 21.4 & fat & 104.74 \\
\hline rapidly perfused & 5.0 & rapidly perfused & 6.45 \\
\hline slowly perfused & 51.7 & slowly perfused & 4.08 \\
\hline \multirow[t]{2}{*}{ blood } & 7.9 & & \\
\hline & & \multicolumn{2}{|c|}{ 1'-hydroxyapiol } \\
\hline Cardiac output (L/h) & 310 & liver & 1.55 \\
\hline \multicolumn{2}{|c|}{ Percentage of cardiac output } & & \\
\hline liver & 22.7 & & \\
\hline fat & 5.2 & & \\
\hline rapidly perfused & 47.3 & & \\
\hline slowly perfused & 24.8 & & \\
\hline
\end{tabular}

\section{Model sensitivity analysis using normalized sensitivity coefficients}

A sensitivity analysis was used to determine which parameters have the greatest influence on model predictions, and performed as described previously(Al-Subeihi et al., 2012, Al-Subeihi et al., 2011, Martati et al., 2011, Martati et al., 2012, Punt et al., 2008, Punt et al., 2009, Van den Berg et al., 2012). For this purpose normalized sensitivity coefficients (SC) were determined using the following equation: $\mathrm{SC}=\left(\mathrm{C}^{\prime}-\mathrm{C}\right) /\left(\mathrm{P}^{\prime}-\mathrm{P}\right) \cdot(\mathrm{P} / \mathrm{C})$, with $\mathrm{C}$ being the initial value of model output, $\mathrm{C}^{\prime}$ the modified value of the model output resulting from an increase in parameter value, $\mathrm{P}$ being the initial parameter value and $\mathrm{P}^{\prime}$ representing the modified parameter value. An increase of $5 \%$ in parameter values was used to analyse the effect of a change in parameter on the formation of 1'-hydroxyapiol and 1'-sulfoxyapiol 
(expressed as a percentage of the dose over 720-hr). Each parameter was analysed individually while the other parameters were kept at their initial value.

\section{Comparison of the newly developed apiol PBK models based predictions with PBK model predictions for the structurally related compound safrole}

The PBK model-based predictions for the formation of 1'-hydroxyapiol and 1'-sulfoxyapiol were compared to the PBK model-based predictions for the dose-dependent formation of the 1'-hydroxy and 1'-sulfoxymetabolites of the structurally related alkenylbenzene safrole. For this purpose the previously defined PBK models for safrole in rat and human described by Martati et al. (Martati et al., 2011, Martati et al., 2012) were used. For comparison with apiol, the models describing the metabolism of safrole were also run for $720-\mathrm{hr}$.

\section{RESULTS}

To identify the organs involved in the metabolism of apiol in both male rat and human, incubations were performed using microsomal protein preparations from liver, kidney, lung and small intestine. UPLC analysis of these incubations revealed that for both rat and human conversion of apiol was detected only in incubations with liver microsomes. An example of a chromatogram of an incubation of apiol with male rat liver microsomes and NADPH as the cofactor was shown in Figure 4.

The metabolites formed in incubations with both rat and human liver microsomes were 2',3'dihydroxyapiol (RT 1.5 minutes), 1'-hydroxyapiol (RT 2.4 minutes), and 4-allyl-3,6dimethoxybenzene-1,2-diol (RT 2.2 minutes). Identification of 1'-hydroxyapiol was done based on comparison of the UV-spectrum and retention time of the formed 1'-hydroxyapiol with those of the specific synthesized reference compound. 


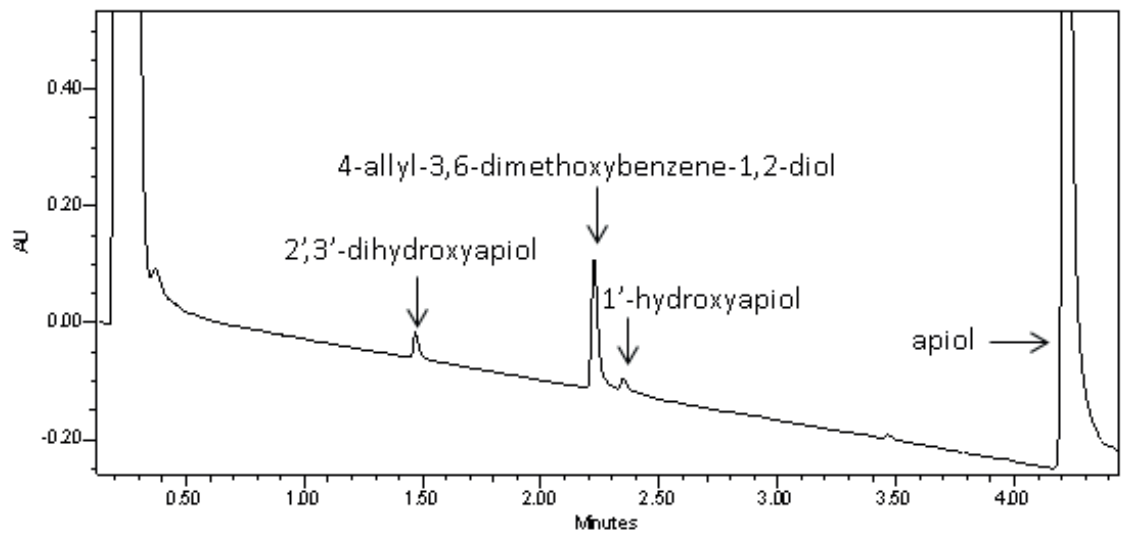

Figure 4. Chromatogram showing the different metabolites of apiol formed in incubations with male rat liver microsomes.

Tentative identification of 4-allyl-3,6-dimethoxybenzene-1,2-diol, resulting from the $O$ demethylenation of apiol (Benedetti et al., 1977, Beyer et al., 2006, Lee et al., 1998), and 2',3'-dihydroxyapiol was based on analogy to UPLC chromatograms of metabolic conversions of safrole and the fact that apiol-2',3'-oxide, formed following incubation of apiol with liver microsomes and NADPH, would be hydrolysed by epoxide hydrolase to 2',3'-dihydroxyapiol as was previously demonstrated for the structurally related alkenylbenzenes (Al-Subeihi et al., 2011, Martati et al., 2011, Punt et al., 2008, Luo et al., 1992, Luo and Guenthner, 1996, Guenthner and Luo, 2001). Furthermore the formation of these three major metabolites is in line with the overview presented by JECFA of the three primary biotransformation pathways for methylenedioxy-substituted alkenylbenzenes including safrole, myristicin and apiol (WHO, 2009). Safrole, myristicin and apiol were reported to be converted primarily by 1,2 ring- $O$-demethenylation yielding diphenolic derivatives (Benedetti et al., 1977, Beyer et al., 2006, Lee et al., 1998), by epoxidation of the double bond in the allyl side-chain yielding the 2',3'-epoxide (Luo and Guenthner, 1996, Luo et al., 1992), and by hydroxylation of the alkene side-chain to yield the 1'-hydroxy 
metabolite (Benedetti et al., 1977, Miller et al., 1983, Zangouras et al., 1981). Apiol concentration-dependent formation of the various microsomal metabolites was also characterised and the kinetic constants derived from these data on the concentrationdependent microsomal metabolite formation of apiol in incubations with both male rat and human liver samples are presented in Table 3.

\section{Glucuronidation of 1'-hydroxyapiol to 1'-hydroxyapiol glucuronide by rat and human}

\section{liver S9}

UPLC analysis of incubations with male rat liver S9 or mixed gender pooled human liver S9, UDPGA as cofactor and 1'-hydroxyapiol as substrate revealed a peak at 1.5 minutes, representing 1'-hydroxyapiol glucuronide since this peak was increased with increasing apiol concentration. Chromatographic analysis of blank incubations performed in the absence of the cofactor UDPGA did not show this peak at a retention time of 1.50 minutes, and the formation and elution behaviour of the metabolite was in analogous to results from similar incubations with safrole (Martati et al., 2011, Martati et al., 2012).

The 1'-hydroxyapiol concentration-dependent increase in glucuronidation of 1'-hydroxyapiol to 1'-hydroxyapiol glucuronide in incubations with both male rat and human liver fractions is presented in figures 5A and 5D respectively. The kinetic constants derived from these data are presented in Table 3. 


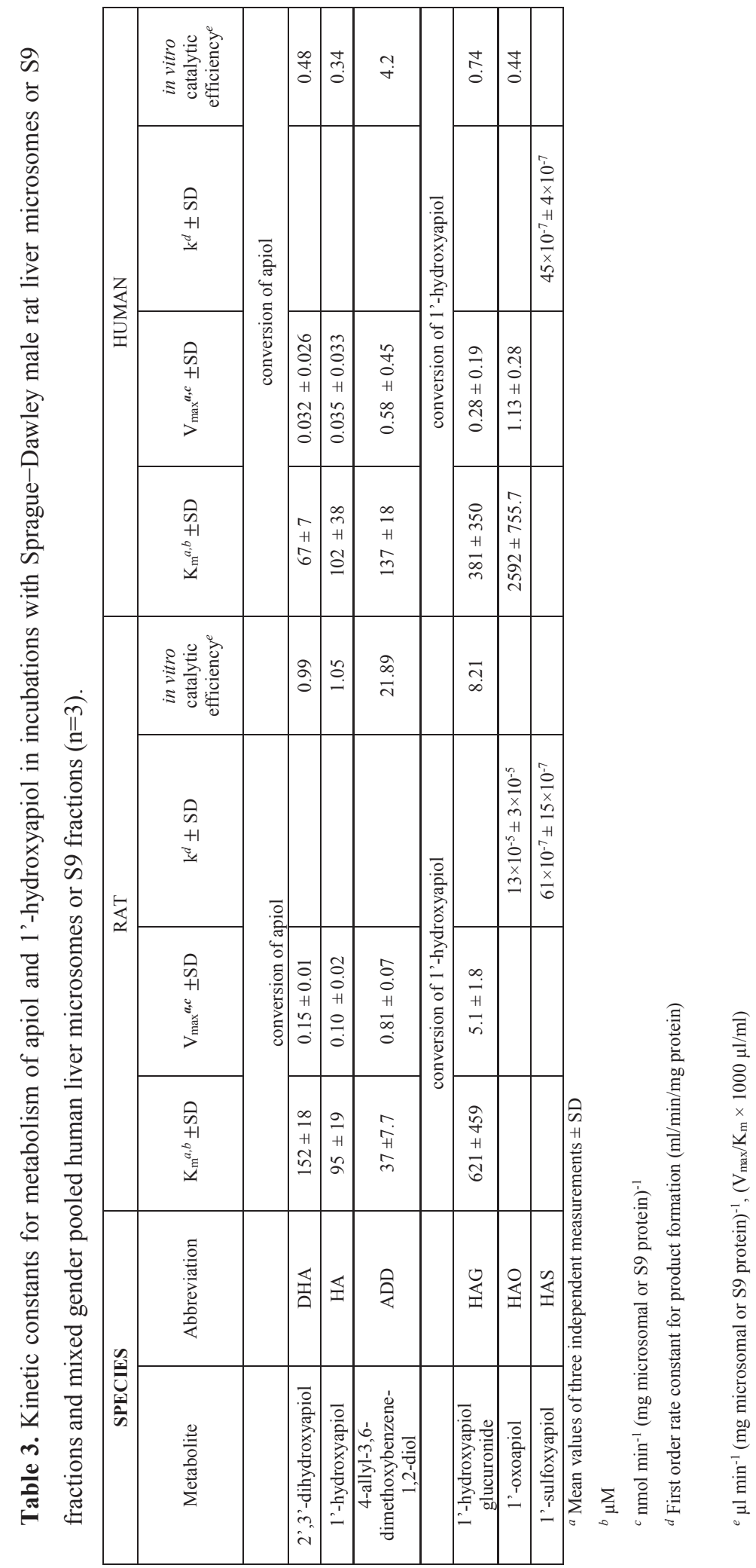


RAT

A

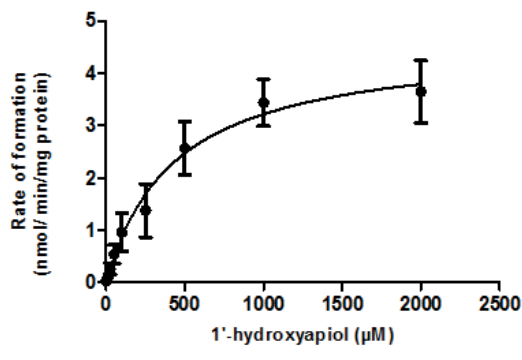

B

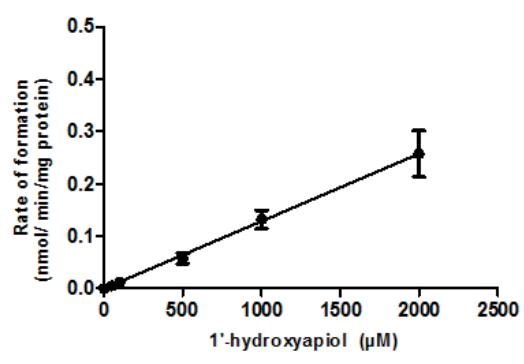

C

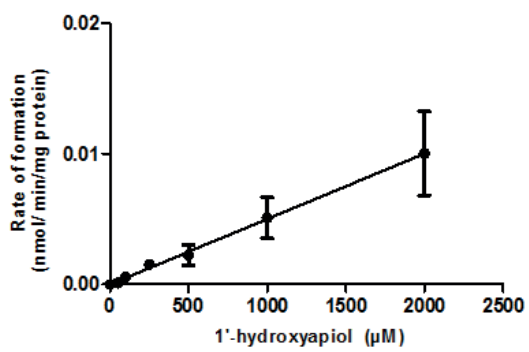

HUMAN

D

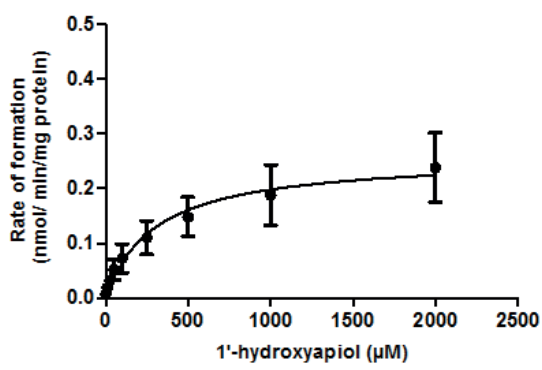

E

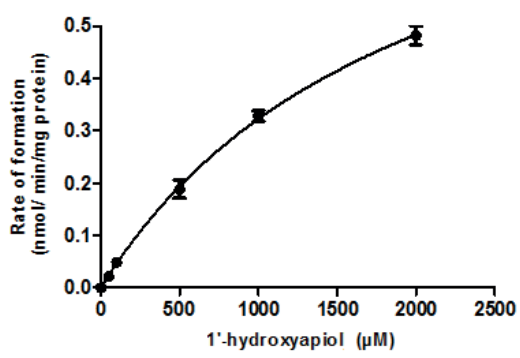

$\mathbf{F}$

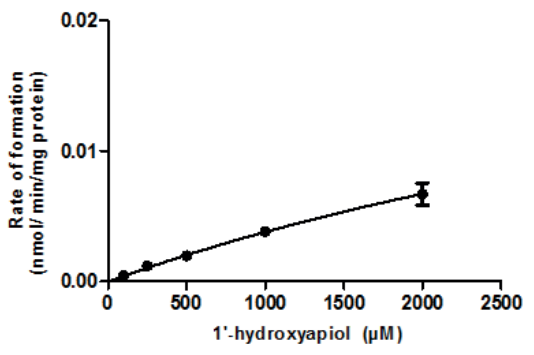

Figure 5. Concentration-dependent rate of (A) glucuronidation of 1'-hydroxyapiol in incubations with pooled male rat liver S9 or (D) pooled human mixed gender liver S9, (B) oxidation of 1'-hydroxyapiol in incubations with pooled male rat liver microsomes or (E) pooled human mixed gender liver S9, and (C) sulfonation of 1'-hydroxyapiol in pooled male rat liver S9 or (F) pooled human mixed gender liver S9. Data points represent mean values +/- SD of three or four individual experiments. 


\section{Oxidation of 1'-hydroxyapiol to 1'-oxoapiol by rat and human liver microsomes}

UPLC analysis of incubations with male rat liver microsomes or mixed gender pooled human liver microsomes, $\mathrm{NAD}^{+}$as cofactor and 1'-hydroxyapiol as substrate revealed a peak at 2.0 minutes. In this incubation GSH was also added to trap the reactive oxidation metabolite 1'oxoapiol. The peak at 2.0 minutes was identified as the GSH conjugate of 1'-oxoapiol, GS1'-oxoapiol. Identification of GS-1'-oxoapiol was done based on comparison of the UVspectrum and retention time of the formed GS-1'-oxoapiol with those of the synthesized reference compound.

The rate of oxidation of 1'-hydroxyapiol in male rat liver microsomes and pooled human liver microsomes with increasing concentrations of 1'-hydroxyapiol is presented in figures 5B and 5E respectively. Table 3 presents the kinetic constants derived from these data.

\section{Sulfonation of 1'-hydroxyapiol to 1'-sulfoxyapiol by rat and human liver S9}

The reactive 1'-sulfoxyapiol formed upon sulfonation of the proximate carcinogenic metabolite 1'-hydroxyapiol was trapped by using GSH. The scavenging may be either chemically or catalysed by the glutathione S-transferases present in the S9 incubations in which the sulfonation of 1'-hydroxyapiol was measured.

UPLC analysis of incubations with male rat liver S9 or mixed gender pooled human liver S9, 1'-hydroxyapiol, PAPS and GSH revealed a peak at 1.3 minutes. The LC-MS analysis showed increased signal of $\mathrm{m} / \mathrm{z} 526$ with negative ion mode. The ion at $\mathrm{m} / \mathrm{z} 526$ corresponds to the theoretically expected $[\mathrm{M}-\mathrm{H}]^{-}$mass of a GSH adduct of $1^{\prime}$-sulfoxyapiol. Figures $5 \mathrm{C}$ and $5 \mathrm{~F}$ present the 1'-hydroxyapiol concentration dependent rate of formation of 1'sulfoxyapiol in incubations with male rat liver S9 or mixed gender pooled human liver S9. The kinetic constants for the conversion of 1'-hydroxyapiol to 1'-sulfoxyapiol in rat and human liver derived from these data are presented in Table 3. 


\section{Comparison of the kinetic constants for conversion of apiol and 1'-hydroxyapiol by} male rat and mixed gender pooled human tissue fractions

In order to allow a comparison between the kinetic constants for metabolism of apiol and 1'hydroxyapiol by male rat and mixed gender pooled human tissue fractions, $\mathrm{V}_{\max }$ values that were derived in vitro expressed as $\mathrm{nmol} \mathrm{min}^{-1}$ (mg microsomal or S9 protein) ${ }^{-1}$ were scaled to values representing the $\mathrm{V}_{\max }$ per $\mu \mathrm{mol} \mathrm{h}{ }^{-1}$ (g tissue) $)^{-1}$ using microsomal and S9 protein yields as described in literature (Medinsky et al., 1994) and previously used by Punt et al., (Punt et al., 2009, Punt et al., 2008), Al-Subeihi et al. (Al-Subeihi et al., 2012, Al-Subeihi et al., 2011) and Martati et al. (Martati et al., 2012, Martati et al., 2011). The in vivo $\mathrm{V}_{\max }$ values derived accordingly, were used to calculate a scaled catalytic efficiency (scaled $\mathrm{V}_{\max }$ in vivo/ $\mathrm{K}_{\mathrm{m}}$ ) for the formation of apiol metabolites (Table 4). These values revealed that the catalytic efficiency for formation of the proximate carcinogenic metabolite of apiol, 1'-hydroxyapiol, is 3.3 times higher in male rat liver than in human liver. The difference in the formation rate is mainly due to the 3 -fold difference in the maximum velocity $\left(\mathrm{V}_{\max }\right)$ for the conversion of apiol to 1'-hydroxyapiol (see Table 3).

The formation of 1'-hydroxyapiol glucuronide was found to represent the main metabolic reaction for detoxification of 1'-hydroxyapiol in rat and human liver while in rat liver the catalytic efficiency for this conjugation was found to be 11.2-fold higher than in human.

For 1'-hydroxyapiol oxidation, the scaled $\mathrm{k}$ for rat liver was found to be 3.1 times lower than the scaled in vivo catalytic efficiency for human liver. While for sulfonation the scaled $\mathrm{k}$ was 1.3-fold higher in rat liver than in human liver.

Altogether, the results revealed that glucuronidation of 1'-hydroxyapiol, representing a detoxification pathway, is the most important pathway in rat and in human for conversion of 1'-hydroxyapiol, and bioactivation of 1'-hydroxyapiol by sulfonation was found to represent only a minor pathway in both rat and human. 


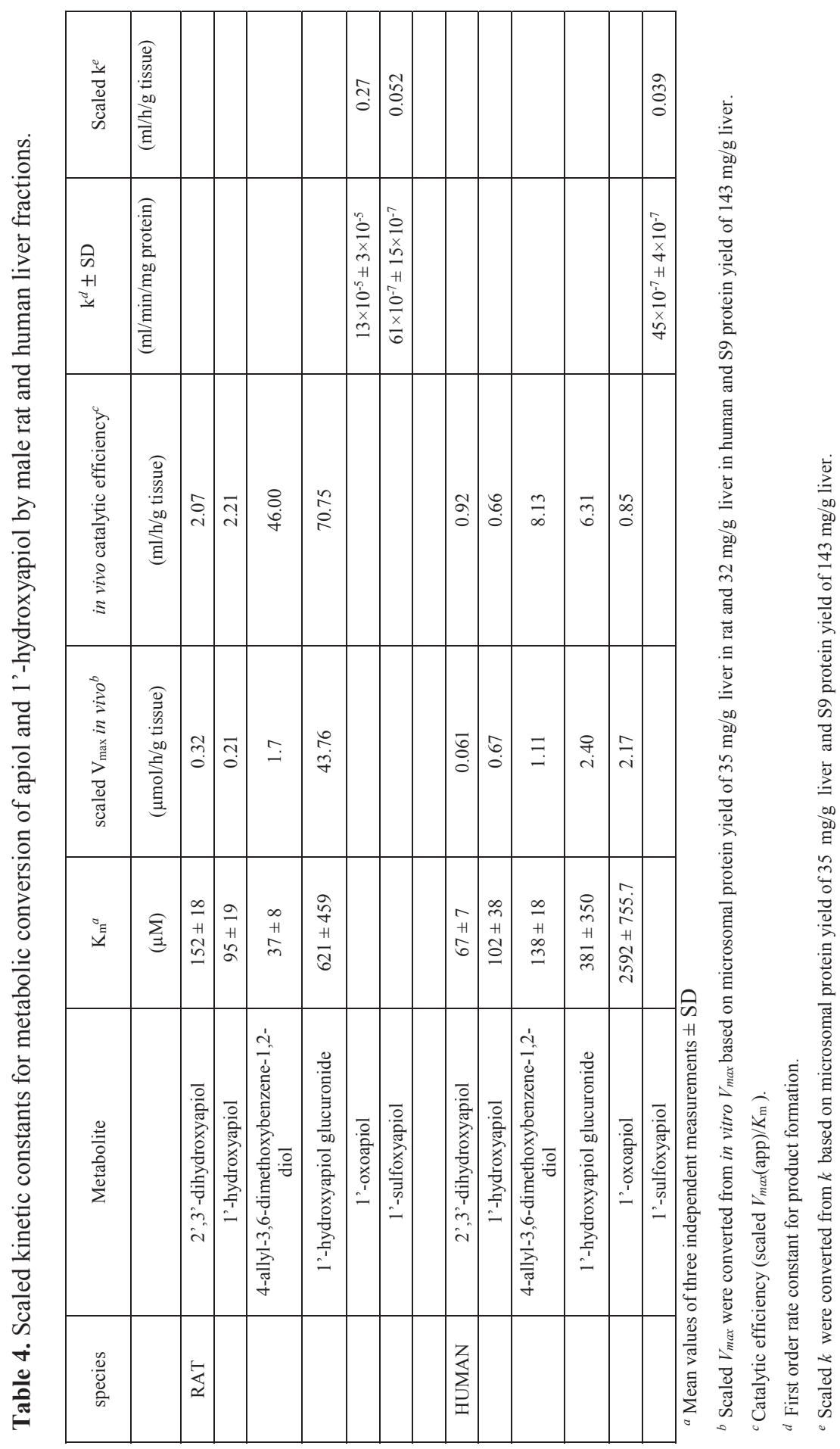




\section{Evaluation of apiol PBK model performance}

Since there are no available quantitative experimental data on the excretion of the apiol metabolites formed after metabolism in both rat and human exposed to apiol, the performance of the newly developed PBK models for apiol could not be evaluated against in vivo data. Therefore the evaluation of the PBK models for apiol was based on the evaluation of the similar PBK models for safrole and the other alkenylbenzenes, for which more in vivo data allowing evaluation of the models were available. The performance of the rat PBK model developed for safrole was evaluated by Martati et al. (Martati et al., 2011b) where the predicted and observed levels of a variety of safrole metabolites in plasma or the urine of rats were compared. The predicted and observed safrole metabolite levels were found to be similar(Martati et al., 2011). Besides that, a comparison could be made between the predictions of the developed human PBK model for safrole (Martati et al., 2012) and the known in vivo data for human plasma concentrations or the urinary excretion of selected safrole metabolites. Furthermore a comparison of the predictions of the developed PBK models for other alkenylbenzenes (estragole and methyleugenol) (Al-Subeihi et al., 2012, AlSubeihi et al., 2011, Punt et al., 2008, Punt et al., 2009) and the reported plasma and urine levels of their metabolites could be done to support the validity of developed PBK models for the alkenylbenzenes, thus indirectly supporting the validity of the apiol models. Based on the above considerations showing the validity of developed PBK models for all other alkenylbenzenes, it was concluded that it is a reasonable assumption that these models also adequately describe the metabolite levels formed in vivo in both rat and human after ingestion of different oral doses of apiol. 


\section{Apiol PBK model predictions for rat and human}

Figure 6A shows the PBK model-based predictions for the dose-dependent formation of the different microsomal metabolites of apiol in rat liver. 4-Allyl-3,6-dimethoxybenzene-1,2-diol appears to be the major metabolite formed amounting to $91.5-85 \%$ of the dose with the percentage somewhat decreasing with increasing dose. The percentage of the dose converted to 1 '-hydroxyapiol was predicted to increase in a dose-dependent manner from $4 \%$ to about 7 $\%$ of the dose at low and high dose levels respectively. Concurrent with the increase in the percentage of the dose that undergoes 1'-hydroxylation of the alkene side chain, a dosedependent increase from about $4 \%$ to $8 \%$ of the dose converted by epoxidation was observed. Figure 6B shows the PBK model-based predictions for the dose-dependent increase in the formation of the metabolites of 1'-hydroxyapiol in rat liver. The percentage of the dose of apiol converted to 1 '-sulfoxyapiol varies with the dose amounting to $0.0032 \%$ at a low dose of $0.05 \mathrm{mg} / \mathrm{kg}$ bw to $0.0050 \%$ of the dose at a relatively high dose of $300 \mathrm{mg} / \mathrm{kg}$ bw, while these percentages amount to $0.017 \%$ at low dose and $0.026 \%$ at high dose for 1 'oxoapiol. Glucuronidation appears to be the major metabolic route for 1'-hydroxyapiol at all dose levels as 1'-hydroxyapiol glucuronide amounts to about $4.38 \%$ of the dose at low dose levels and to $6.80 \%$ of the dose at high dose levels. 

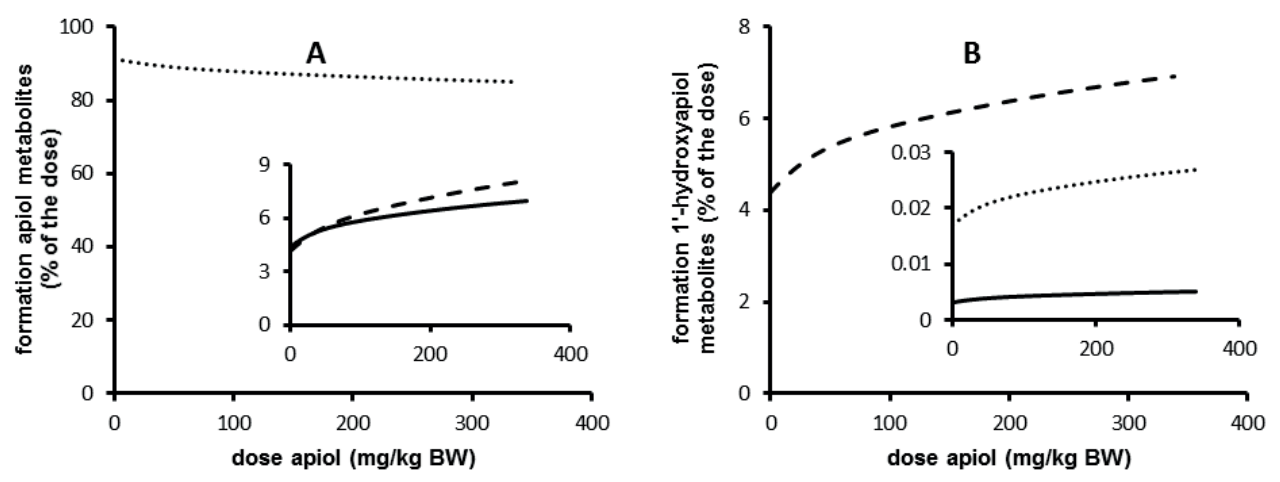

Figure 6. PBK-predicted dose-dependent changes in overall formation of (A) microsomal metabolites of apiol in rat liver and (B) metabolites of 1'-hydoxyapiol in rat liver. The lines correspond to (A) 4-allyl-3,6-dimethoxybenzene-1,2-diol (••••), 1'-hydroxyapiol (-), and 2',3'-dihydroxyapiol (- - ), and (B) 1'-hydroxyapiol glucuronide (- -), 1'-sulfoxyapiol

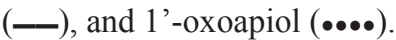

Figure 7A shows the PBK model-based predictions for the dose-dependent formation of the different microsomal metabolites of apiol in human liver. In human liver 4-allyl-3,6dimethoxybenzene-1,2-diol was predicted to be the major microsomal metabolite amounting to about $82.6-83.5 \%$ of the dose. In human liver the percentage of the dose converted to 1 'hydroxyapiol was only slightly decreased with the dose amounting to $6.7-6.3 \%$ of the dose. The decrease in the formation of 1'-hydroxyapiol with increasing dose, is predicted to be accompanied by a decrease in the formation of apiol-2',3'-oxide. Figure 7B shows the dosedependent decrease in the relative formation of 1'-hydroxyapiol glucuronide and 1'-oxoapiol and the dose-dependent decrease of the relative formation of 1'-sulfoxyapiol in human liver. There were only limited changes in the relative percentage of the different metabolites with the dose. 1'-Hydroxyapiol glucuronide appears to be the major 1'-hydroxyapiol metabolite amounting to about $5.9-5.5 \%$ of the dose, while 1'-oxoapiol amounts to about $0.75 \%$ of the dose and 1 'sulfoxyapiol to $0.035 \%$ of the dose. 

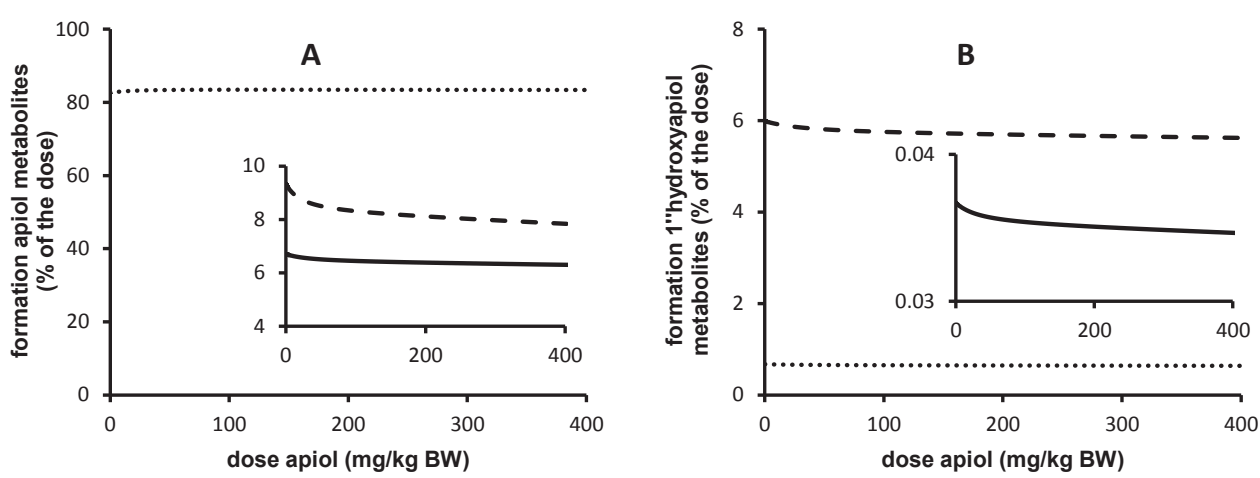

Figure 7. PBK-predicted dose-dependent changes in overall formation of (A) microsomal metabolites of apiol in human liver and (B) metabolites of 1'-hydoxyapiol in human liver. The lines correspond to (A) 4-allyl-3,6-dimethoxybenzene-1,2diol (•••), 1'-hydroxyapiol (-), and 2',3'-dihydroxyapiol (- - ), and (B) 1'-hydroxyapiol glucoronide (- - ), 1'sulfoxyapiol (-), and 1'-oxoapiol (••••).

Figure 8 shows a comparison of the relative extent of bioactivation of apiol by rat and human liver. There are species differences in the formation of 1'-hydroxyapiol (Figure 8A) and 1'sulfoxyapiol (Figure 8B) (expressed as $\mathrm{nmol} / \mathrm{g}$ liver). In rat liver the formation of 1 'hydroxyapiol at low dose was almost 2 times lower than in human liver and gradually increased with increasing the dose to reach almost the same relative level as in human at high dose. Human liver was predicted to be more efficient in formation of 1'-sulfoxyapiol being 15-fold higher at low dose and 8-fold higher at high dose than 1'-sulfoxyapiol formation by rat liver (Figure 8B). This higher relative formation of 1'-sulfoxyapiol in human than rat liver in spite of the almost equal rate of formation of its metabolic precursor 1'-hydroxyapiol in rat and human liver is due to the fact that the glucuronidation of 1'-hydroxyapiol in rat liver is around 10 times more efficient than that in human liver providing increased opportunity for the competing sulfonation. The difference in overall formation of the 1'-sulfoxyapiol formation between rat and human is not due to a marked difference in the kinetics for 
sulfonation of the 1'-hydroxyapiol since this difference appeared limited with an only 1.35fold higher first order rate constant for sulfonation in rat than human liver (see Table 3).
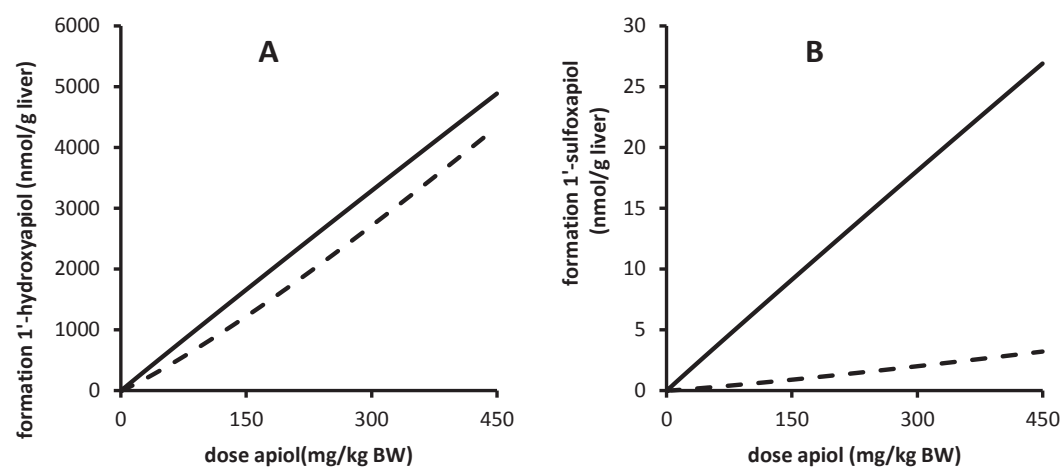

Figure 8. PBK-predicted dose-dependent formation of (A) 1'-hydroxyapiol and (B) 1'sulfoxyapiol in rat and human liver.

\section{Sensitivity analysis}

In order to know the model parameters that have the highest impact on the formation of 1'hydroxyapiol and 1'-sulfoxyapiol in rat and human liver, a sensitivity analysis was performed. The analysis was done at an apiol dose of $0.05 \mathrm{mg} / \mathrm{kg}$ body wt per day to calculate the normalized sensitivity coefficients for all model parameters. Normalized sensitivity coefficient values higher than 0.1 , affecting the formation of 1'-hydroxyapiol and 1'sulfoxyapiol in rat and human liver, are shown in figures 9A and 9B. Figure 9 shows that in both rat and human the parameters that influence the formation of both metabolites to the highest extent are the same. 1'-Hydroxyapiol formation is mainly influenced by the kinetic constants for formation of 1'-hydroxyapiol $\left(\mathrm{V}_{\max , \mathrm{HA}}, \mathrm{k}_{\mathrm{m}, \mathrm{HA}}\right)$ and the kinetic constants for formation of 4-allyl-3,6-dimethoxybenzene-1,2-diol ( $\left.\mathrm{V}_{\max , \mathrm{ADD}}, \mathrm{k}_{\mathrm{m}, \mathrm{ADD}}\right)$. Besides the above 
parameters, 1'-sulfoxyapiol formation was influenced by kinetic constants for formation of 1'-hydroxyapiol glucuronide ( $\left.\mathrm{V}_{\text {max,HAG}}, \mathrm{k}_{\mathrm{m}, \mathrm{HAG}}\right)$ and of 1'-sulfoxyapiol (k,HAS).
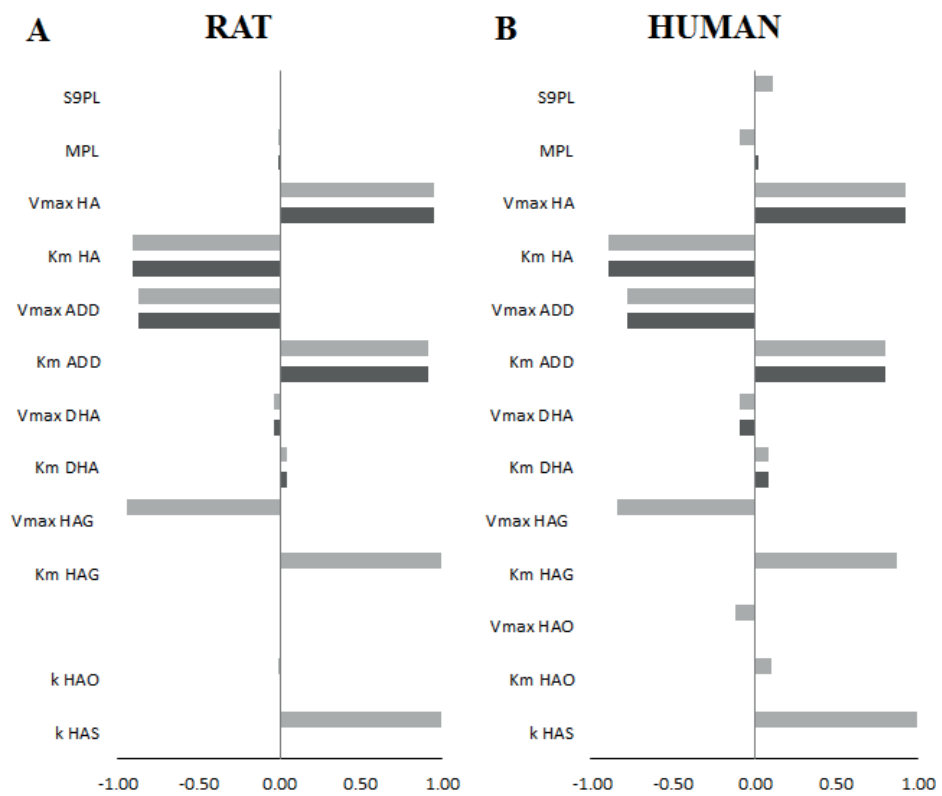

Figure 9. Normalized sensitivity coefficients for the formation of 1'-hydroxy apiol (black) and 1'-sulfoxyapiol (grey ) in the liver of rat and human. S9PL $=$ S9 protein yield of the liver, $\mathrm{MPL}=$ microsomal protein yield of the liver, $\mathrm{Vmax}$ the maximum velocity and $\mathrm{Km}$ the Michaelis-Menten constant for the formation of the different metabolites, $\mathrm{k}=$ the kinetic rate constant for a first order reaction, $\mathrm{ADD}=4$-allyl-3,6-dimethoxybenzene-1,2-diol, $\mathrm{DHA}=$ 2',3'-di hydroxyapiol, HA = 1'-hydroxyapiol, HAG = 1'-hydroxyapiol glucuronide, HAO $=1$ '-oxoapiol, HES = 1'-sulfoxyapiol

\section{Comparison of the PBK model-based prediction of bioactivation of apiol by rat and human to the PBK model predictions for bioactivation of the structurally related compound safrole.}

The PBK model-based predictions for bioactivation of apiol in rat and human, were compared to the PBK model-based predictions for bioactivation of safrole to facilitate a read-acrossbased risk assessment. Figure 10 shows the dose-dependent formation of the 1'-hydroxy and 
1'-sulfoxy metabolites in rat liver as predicted by the respective PBK models from dose levels representing estimated human daily intakes up to dose levels causing liver tumors in rodent bioassays with safrole. In rat liver the PBK model-based predicted formation of the proximate carcinogenic 1'-hydroxy metabolite was found to be 2.8 -fold lower for apiol than for safrole at low dose and 2.0-fold lower at the highest dose (Figure 10A). Figure 10B shows the predicted model outcomes for the formation of the ultimate carcinogenic 1'sulfooxy metabolites of apiol and safrole. In rat liver the formation of the 1'-sulfoxymetabolite is predicted to be about 3-fold lower for apiol than for safrole. For both alkenylbenzenes the formation of their 1'-sulfoxymetabolite increases linearly with increase of the dose.
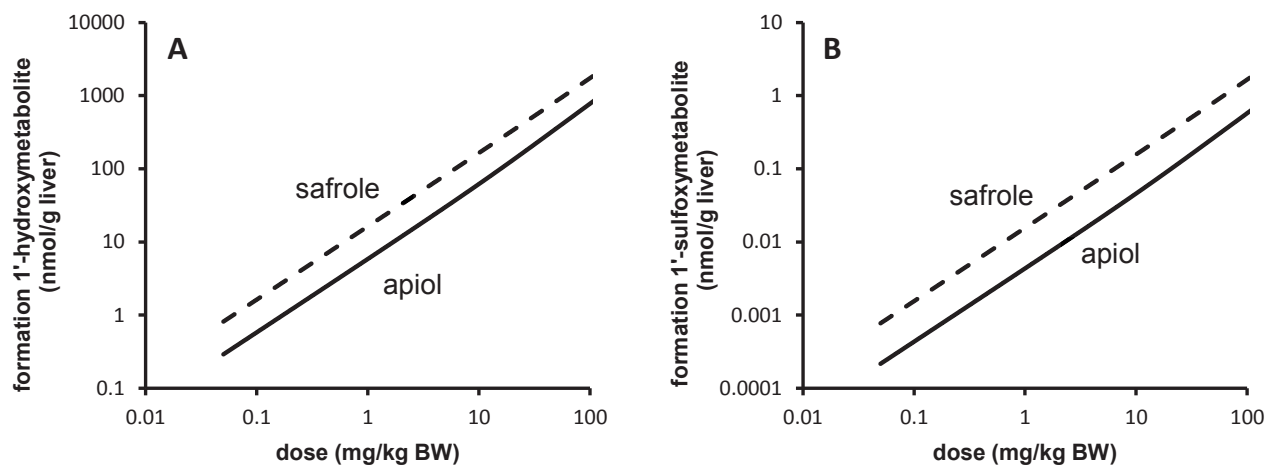

Figure 10. PBK-predicted dose-dependent formation (nmol/g liver) of (A) 1'hydroxymetabolites and (B) 1'-sulfoxymetabolites of apiol (-) and safrole (--) in male rat liver.

Figure 11 shows the predicted dose-dependent formation of the 1'-hydroxymetabolites and 1'-sulfoxymetabolites of apiol and safrole in human liver. The predicted formation of the 1'hydroxy metabolite is predicted to be about 8-fold lower for apiol than for safrole at low dose and about 6-fold lower at high dose levels. In human liver the formation of the 1'sulfoxymetabolites of apiol is predicted to be 2 times lower for apiol than for safrole. 

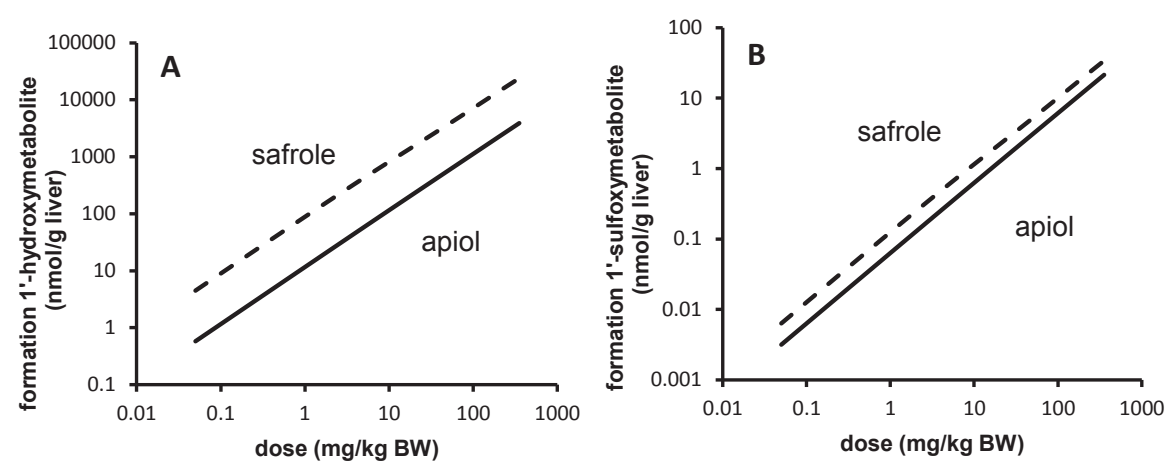

Figure 11. PBK-predicted dose-dependent formation (nmol/g liver) of (A) 1'hydroxymetabolites and (B) 1'-sulfoxymetabolites of apiol (-) and safrole (- -) in human liver.

\section{Implications for risk assessment}

In order to evaluate the possible human health hazards due to daily consumption of apiol, the margin of exposure (MOE) approach can be used. The MOE is the preferred approach to assess the safety of a compound that is carcinogenic and genotoxic(EFSA, 2005).

Carcinogenicity data for apiol from which a $\mathrm{BMDL}_{10}$ can be derived are absent, hampering the application of the MOE approach in the risk assessment of apiol. On the other hand, the results of the PBK model predictions presented above indicate that at dose levels in the range at which safrole exposed rodents develop tumors (10-100 $\mathrm{mg} / \mathrm{kg}$ body wt per day)(Long et al., 1963), the formation of 1'-sulfoxymetabolites of apiol in rat liver is about 3 -fold lower than that of safrole. Based on this result it can be assumed that the PBK modelling supports use of the $\mathrm{BMDL}_{10}$ for tumor formation by safrole for risk assessment of the related compound apiol making a correction for the expected 3-fold lower formation of the ultimate carcinogenic 1'sulfoxymetabolite assuming the same mode of action for these two analogues. Depending on the differences of formation of ultimate carcinogen of apiol and safrole in rat liver at dose 
levels that induce liver tumor formation in rodents exposed to safrole, the $\mathrm{BMDL}_{10}$ of safrole which amounts to $1.9-5.1 \mathrm{mg} / \mathrm{kg}$ body wt per day (van den Berg et al., 2011) was multiplied by factor of 3 resulting in a $\mathrm{BMDL}_{10}$ of $5.7-15.3 \mathrm{mg} / \mathrm{kg}$ body wt per day. The estimated mean daily intake of apiol from spice and spice oil in the USA was reported to amount to $4 \times 10^{-5}$ $\mathrm{mg} / \mathrm{kg}$ body wt per day(WHO, 2009). Using a $\mathrm{BMDL}_{10}$ of $5.7-15.3 \mathrm{mg} / \mathrm{kg}$ body wt per day and an estimated daily intake of apiol of $4 \times 10^{-5} \mathrm{mg} / \mathrm{kg}$ body wt per day the MOE for apiol would amount to $140000-385000$. This indicates that there would be a low concern and a low priority for risk management of the current levels of exposure to apiol. For comparison the MOE values of safrole can be given, obtained at the estimated daily intake of safrole from spice and spice oil in USA that amounts to $1 \times 10^{-3} \mathrm{mg} / \mathrm{kg}$ body wt per day (WHO, 2009), and using a BMDL 10 of safrole of $1.9-5.1 \mathrm{mg} / \mathrm{kg}$ body wt per day. These data result in an MOE for safrole of 1900-5100 indicating a priority for risk management that is higher than for apiol.

\section{DISCUSSION}

The present paper describes the definition of mode of action-based PBK models for detoxification and bioactivation of the alkenylbenzene apiol in rat and human and the use of predictions made by these models to facilitate a read-across-based risk assessment to the structurally related alkenylbenzene safrole (Martati et al., 2011, Martati et al., 2012), for which in vivo carcinogenicity data are available. Previously, using a similar approach and read-across to estragole and methyleugenol, the risks of exposure to elemicin for which also no in vivo rodent tumor data were available could be evaluated (Van den Berg et al., 2012). The approach enables a preliminary risk assessment of apiol for which in vivo toxicity data are limited without the need for additional animal studies. The physiological parameters for rat and human and the biochemical and physiochemical parameters for apiol were defined to 
develop the apiol PBK models. The newly developed PBK models for apiol provide insight into the species-differences in the relative extent of bioactivation and detoxification, and could also be used to compare the level of metabolic activation of apiol to that of safrole in male rat and human liver(Martati et al., 2011b, Martati et al., 2012b). Comparing the apiol and safrole model-based predictions showed that the formation of the proximate and ultimate carcinogenic metabolites of the two alkenylbenzenes in rat is predicted to be comparable within an order of magnitude. The PBK models predict the formation of the ultimate carcinogenic 1'-sulfoxymetabolite at a dose level of $100 \mathrm{mg} / \mathrm{kg}$ body wt, at which safrole is causing liver tumors in rodent animal(Long et al., 1963, WHO, 2009), to be 3-fold lower for apiol than for safrole in rat liver. In line with these differences, Randerath et al. (Randerath et al., 1984), using ${ }^{32} \mathrm{P}$-postlabeling reported that the number of DNA adducts formed by apiol in adult mouse liver was lower than for safrole. In a parallel study, Phillips et al. (Phillips et al., 1984) reported that in preweaning male mice the level of DNA adducts formed after neonatal apiol exposure was about 12-fold lower than after neonatal safrole exposure (Phillips et al., 1984). In addition, the ability of apiol to form DNA adducts in cultured human (HepG2) cells was reported to be 3-5 times lower than that of safrole (Zhou et al., 2007).

It is important to note that the PBK model-based predictions quantify the amount of the ultimate carcinogenic metabolite formed and not the ability of these compounds to bind to DNA or other macromolecules. One could argue that this reactivity may differ between the different alkenylbenzene compounds and that an increasing number of methoxy groups may reduce the electrophilicity of the 1'-sulfoxymetabolite or its carbocation decreasing its ability to bind to DNA (Miller et al., 1983, Randerath et al., 1984). However, given that the PBK model-based predicted differences are in line with the currently available data from in vivo and cellular in vitro studies on DNA adduct formation by apiol and safrole it is concluded that 
these possible differences in electrophilicity of the two 1'-sulfoxymetabolites does not affect the predictions to an extent that it would modify the conclusions of the current MOE based preliminary risk assessment.

Based on the rat PBK model predictions for formation of the related 1'-sulfoxymetabolite, being 3-fold lower for apiol than for safrole at dose levels that are known to induce tumors in safrole-exposed rodent models, it was concluded that the BMDL 10 that would be expected in a rodent animal bioassay for apiol could be 3 -fold higher than that of safrole. Based on these considerations a preliminary risk assessment was performed for apiol using the MOE approach and an estimated $\mathrm{BMDL}_{10}$ for apiol, of 3 times the $\mathrm{BMDL}_{10}$ for safrole (1.9-5.1 $\mathrm{mg} / \mathrm{kg}$ body wt per day) (Suzanne J. P. L. van den Berg et al., 2011) and the MOE for apiol was calculated to amount to $140000-385000$. It is of interest to note that the PBK model of the present study predicted that the formation of the ultimate carcinogenic 1'sulfoxymetabolite of apiol in human liver would be about 10 times higher than its formation in rat liver. This difference is included in the MOE of 10000 which was defined to include a factor of 10 for interspecies differences (EFSA, 2005). Given that the MOE values actually obtained for apiole are 14-38-fold higher than 10000 they could accommodate an even larger species difference than the 10-fold difference now included in the MOE of 10000 without leading to a different conclusion. Furthermore, comparison of the MOE values obtained in the present study for apiol and safrole, indicate a priority for risk management of safrole that is higher than for apiol, due to its 3 times lower $\mathrm{BMDL}_{10}$ and its 25 -fold higher estimated daily intake.

In conclusion, the present study reports the development of apiol PBK models for rat and human providing insight into the occurrence of species differences in the metabolic activation of this food-borne compound that is genotoxic and carcinogenic. In addition the PBK model predictions were applied to support read-across from safrole for which tumor data are 
available facilitating a preliminary risk assessment for apiol for which limited in vivo data are available. This example illustrates how PBK modelling can be used to contribute to risk assessment eliminating the need for animal bioassays thereby contributing to the $3 \mathrm{Rs}$ of animal testing in human safety assessments.

\section{FUNDING}

Part of this work has been supported by financial assistance of the European Union under the ENPI CBC Mediterranean Sea Basin Programme under project I.B/4.1/257, BRAMA (Botanicals Risk Assessment Training in the Mediterranean Area).

The contents of this document are the sole responsibility of the authors and can under no circumstances be regarded as reflecting the position of the European Union or of the Programme's management structures.

\section{ACKNOWLEDGEMENTS}

The authors would like to thank Dr. Yiannis Fiamegos for the synthesis of 1'-hydroxyapiol and Mr. Bert Spenkelink for the synthesis of 1'-oxoapiol. AMA and AJAM acknowledge financial support from the SOIT foundation (the Foundation for Stimulation Of Innovation in Toxicology). 


\section{REFERENCES}

Al-Subeihi, A. A., Spenkelink, B., Punt, A., Boersma, M. G., van Bladeren, P. J. \& Rietjens, I. M. C. M. 2012. Physiologically based kinetic modeling of bioactivation and detoxification of the alkenylbenzene methyleugenol in human as compared with rat. Toxicology and applied pharmacology, 260, 271-84.

Al-Subeihi, A. A., Spenkelink, B., Rachmawati, N., Boersma, M. G., Punt, A., Vervoort, J., van Bladeren, P. J. \& Rietjens, I. M. C. M. 2011. Physiologically based biokinetic model of bioactivation and detoxification of the alkenylbenzene methyleugenol in rat. Toxicology in vitro : an international journal published in association with BIBRA, $25,267-85$.

Benedetti, M. S., Malnoe, A. \& Broillet, A. L. 1977. Absorption, metabolism and excretion of safrole in the rat and man. Toxicology, 7, 69-83.

Beyer, J., Ehlers, D. \& Maurer, H. H. 2006. Abuse of nutmeg (Myristica fragrans Houtt.): studies on the metabolism and the toxicologic detection of its ingredients elemicin, myristicin, and safrole in rat and human urine using gas chromatography/mass spectrometry. Therapeutic drug monitoring, 28, 568-75.

Brown, R. P., Delp, M. D., Lindstedt, S. L., Rhomberg, L. R. \& Beliles, R. P. 1997. Physiological parameter values for physiologically based pharmacokinetic models. Toxicol Ind Health, 13, 407-84.

DeJongh, J., Verhaar, H. J. \& Hermens, J. L. 1997. A quantitative property-property relationship (QPPR) approach to estimate in vitro tissue-blood partition coefficients of organic chemicals in rats and humans. Arch Toxicol, 72, 17-25.

EFSA 2005. Opinion of the Scientific Committee on a request from EFSA related to A Harmonised Approach for Risk Assessment of Substances Which are both Genotoxic and Carcinogenic. . EFSA J, 282, 1-31.

Guenthner, T. M. \& Luo, G. 2001. Investigation of the role of the 2',3'-epoxidation pathway in the bioactivation and genotoxicity of dietary allylbenzene analogs. Toxicology, 160, 47-58.

Jeurissen, S. M., Bogaards, J. J., Awad, H. M., Boersma, M. G., Brand, W., Fiamegos, Y. C., van Beek, T. A., Alink, G. M., Sudholter, E. J., Cnubben, N. H. \& Rietjens, I. M. 2004. Human cytochrome p450 enzyme specificity for bioactivation of safrole to the proximate carcinogen 1'-hydroxysafrole. Chemical research in toxicology, 17, 124550. 
Lee, H. S., Jeong, T. C. \& Kim, J. H. 1998. In vitro and in vivo metabolism of myristicin in the rat. Journal of chromatography. B, Biomedical sciences and applications, 705, $367-72$.

Long, E. L., Nelson, A. A., Fitzhugh, O. G. \& Hansen, W. H. 1963. Liver tumors produced in rats by feeding safrole. Archives of Pathology, 76, 595-604.

Luo, G. \& Guenthner, T. M. 1996. Covalent binding to DNA in vitro of 2',3'-oxides derived from allylbenzene analogs. Drug metabolism and disposition: the biological fate of chemicals, 24, 1020-7.

Luo, G., Qato, M. K. \& Guenthner, T. M. 1992. Hydrolysis of the 2',3'-allylic epoxides of allylbenzene, estragole, eugenol, and safrole by both microsomal and cytosolic epoxide hydrolases. Drug metabolism and disposition: the biological fate of chemicals, 20, 440-5.

Martati, E., Boersma, M. G., Spenkelink, A., Khadka, D. B., Punt, A., Vervoort, J., van Bladeren, P. J. \& Rietjens, I. M. 2011. Physiologically based biokinetic (PBBK) model for safrole bioactivation and detoxification in rats. Chem Res Toxicol, 24, 81834.

Martati, E., Boersma, M. G., Spenkelink, A., Khadka, D. B., van Bladeren, P. J., Rietjens, I. M. \& Punt, A. 2012. Physiologically based biokinetic (PBBK) modeling of safrole bioactivation and detoxification in humans as compared with rats. Toxicol Sci, 128, $301-16$

Medinsky, M. A., Leavens, T. L., Csanady, G. A., Gargas, M. L. \& Bond, J. A. 1994. In vivo metabolism of butadiene by mice and rats: a comparison of physiological model predictions and experimental data. Carcinogenesis, 15, 1329-40.

Miller, E. C., Swanson, A. B., Phillips, D. H., Fletcher, T. L., Liem, A. \& Miller, J. A. 1983. Structure-activity studies of the carcinogenicities in the mouse and rat of some naturally occurring and synthetic alkenylbenzene derivatives related to safrole and estragole. Cancer research, 43, 1124-34.

Parthasarathy, V. A., chembackam, B.T., Zachariah, T. 2008. Chemistry of Spices. Kerala: CABI.

Phillips, D. H., Reddy, M. V. \& Randerath, K. 1984. 32P-post-labelling analysis of DNA adducts formed in the livers of animals treated with safrole, estragole and other naturally-occurring alkenylbenzenes. II. Newborn male B6C3F1 mice. Carcinogenesis, 5, 1623-8. 
Punt, A., Freidig, A. P., Delatour, T., Scholz, G., Boersma, M. G., Schilter, B., van Bladeren, P. J. \& Rietjens, I. M. 2008. A physiologically based biokinetic (PBBK) model for estragole bioactivation and detoxification in rat. Toxicology and applied pharmacology, 231, 248-59.

Punt, A., Paini, A., Boersma, M. G., Freidig, A. P., Delatour, T., Scholz, G., Schilter, B., van Bladeren, P. J. \& Rietjens, I. M. C. M. 2009. Use of physiologically based biokinetic (PBBK) modeling to study estragole bioactivation and detoxification in humans as compared with male rats. Toxicological sciences : an official journal of the Society of Toxicology, 110, 255-69.

Randerath, K., Haglund, R. E., Phillips, D. H. \& Reddy, M. V. 1984. 32P-post-labelling analysis of DNA adducts formed in the livers of animals treated with safrole, estragole and other naturally-occurring alkenylbenzenes. I. Adult female CD-1 mice. Carcinogenesis, 5, 1613-22.

SCF 2001a. Opinion of the Scientific Committee of Food on Estragole (1-allyl-4methoxybenzenen)

SCF 2001b. Opinion of the Scientific Committee of Food on Methyleugenol (1-allyl-1,2dimethoxybenzenen).

SCF 2002. Opinion of the Scientific Committee of Food on Safrole (1-allyl-3,4-methylene dioxybenzenen)

Suzanne J. P. L. van den Berg, Patrizia Restani, Marelle G. Boersma, Luc Delmulle \& Rietjens, I. M. C. M. 2011. Levels of Genotoxic and Carcinogenic Compounds in Plant Food Supplements and Associated Risk Assessment. Food and Nutrition Sciences, 989-1010.

Tunali, T., Yarat, A., Yanardag, R., Ozcelik, F., Ozsoy, O., Ergenekon, G. \& Emekli, N. 1999. Effect of parsley (Petroselinum crispum) on the skin of STZ induced diabetic rats. Phytotherapy research : PTR, 13, 138-41.

Van den Berg, S. J., Punt, A., Soffers, A. E., Vervoort, J., Ngeleja, S., Spenkelink, B. \& Rietjens, I. M. C. M. 2012. Physiologically based kinetic models for the alkenylbenzene elemicin in rat and human and possible implications for risk assessment. Chemical research in toxicology, 25, 2352-67.

WHO 2009. Safety evaluation of certain additives, prepared by the Sixty-ninth meeting of the Joint FAO/WHO Expert Committee on Food Additivies. World Health Organization http://whqlibdoc.who.int/publications/2009/9789241660600_eng.pdf. 
Wiseman, R. W., Miller, E. C., Miller, J. A. \& Liem, A. 1987. Structure-activity studies of the hepatocarcinogenicities of alkenylbenzene derivatives related to estragole and safrole on administration to preweanling male $\mathrm{C} 57 \mathrm{BL} / 6 \mathrm{~J} \times \mathrm{C} 3 \mathrm{H} / \mathrm{HeJ} \mathrm{F} 1$ mice. Cancer research, 47, 2275-83.

Wislocki, P. G., Borchert, P., Miller, J. A. \& Miller, E. C. 1976. The metabolic activation of the carcinogen 1'-hydroxysafrole in vivo and in vitro and the electrophilic reactivities of possible ultimate carcinogens. Cancer research, 36, 1686-95.

Zangouras, A., Caldwell, J., Hutt, A. J. \& Smith, R. L. 1981. Dose dependent conversion of estragole in the rat and mouse to the carcinogenic metabolite, 1'-hydroxyestragole. Biochemical pharmacology, 30, 1383-6.

Zhou, G. D., Moorthy, B., Bi, J., Donnelly, K. C. \& Randerath, K. 2007. DNA adducts from alkoxyallylbenzene herb and spice constituents in cultured human (HepG2) cells. Environmental and molecular mutagenesis, 48, 715-21. 


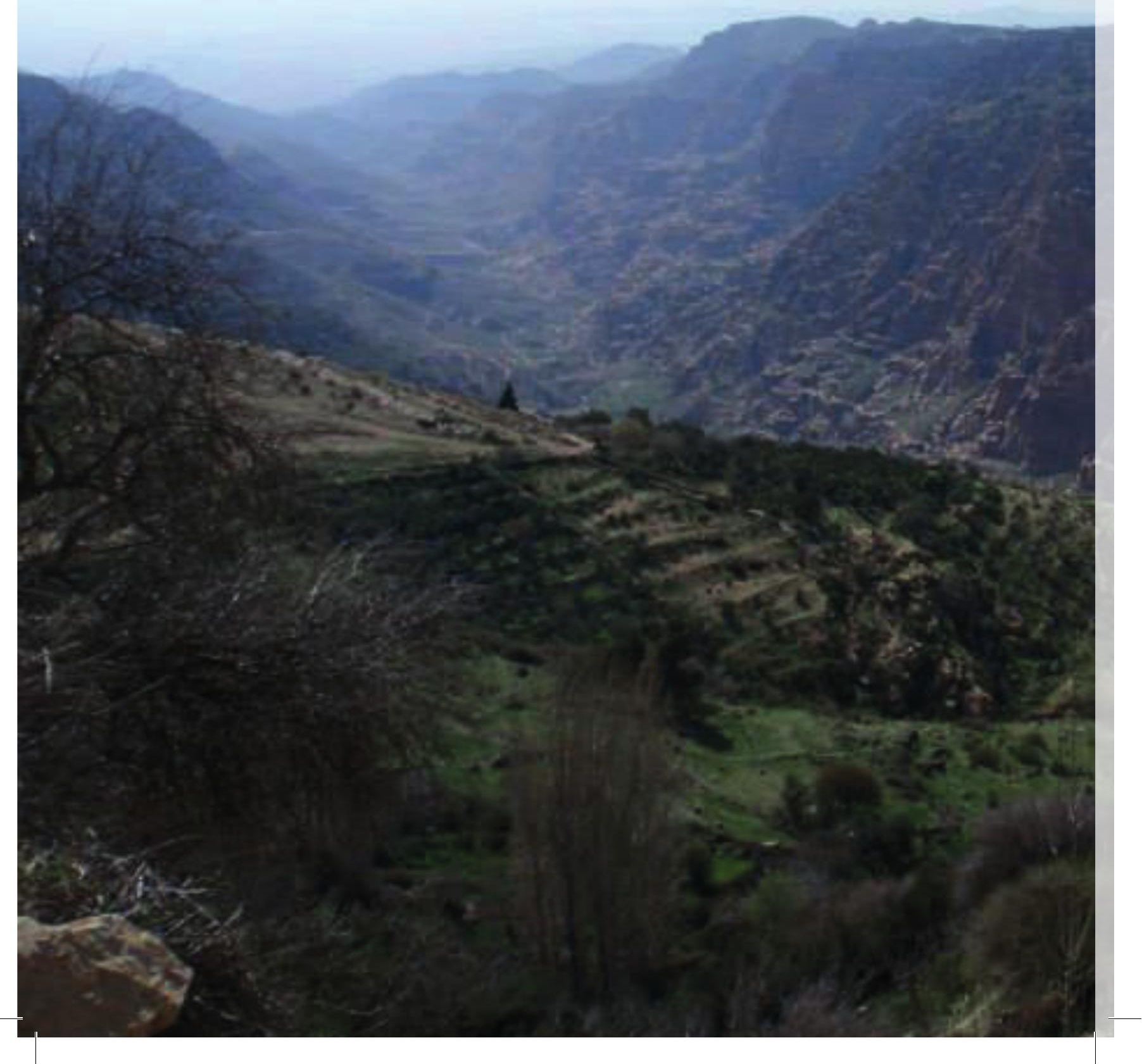




\section{Chapter 4}

\section{Determination and risk assessment of naturally occurring genotoxic and carcinogenic alkenylbenzenes in basil-containing sauce of pesto}

Amer J. Al-Malahmeha, Abdalmajeed M. Al-ajlouni, Sebastiaan Wesseling, Jacques Vervoort, Ivonne M.C.M. Rietjens

Toxicology Reports (2017), 4: 1-8 Doi: 10.1016/j.toxrep.2016.11.002 


\begin{abstract}
A risk assessment of basil-based pesto sauces containing methyleugenol and related alkenylbenzenes was performed based on their levels detected in a series of pesto sauces available on the Dutch market. The estimated daily intake (EDI) values of alkenylbenzenes as a result of consumption of the different pesto sauces amounted to $1.2-44.3 \mu \mathrm{g} / \mathrm{kg}$ bw for individual alkenylbenzenes, $14.3-43.5 \mu \mathrm{g} / \mathrm{kg}$ bw when adding up the alkenylbenzene levels assuming equal potency, and 17.3-62.9 $\mu \mathrm{g} / \mathrm{kg}$ bw when expressed in methyleugenol equivalents using alkenylbenzenes defined toxic equivalency factors (TEF). The margin of exposure approach (MOE), used to evaluate the potential risks, resulted in MOE values that were generally lower than 10000 indicating a priority for risk management when assuming daily consumption. The levels of methyleugenol detected in the pesto sauces would allow consumption of $1.1-29.8,7.5-208,15.1-416.5$, and $32.4-892.5 \mathrm{~g}$ of pesto sauce on a daily basis, once a week, once every two weeks, and once a month, respectively, to achieve MOE values above the 10000 limit indicating low priority for risk management. It is concluded that consumption of pesto sauces would only be of concern if consumed on a daily basis over longer periods of time.
\end{abstract}

\begin{abstract}
Abbreviations
EDI, estimated daily intake; $\mathrm{BMDL}_{10}$, lower confidence limit of the benchmark dose resulting in a $10 \%$ extra cancer incidence; EFSA, European Food Safety Authority; ESCO, scientific cooperation projects between EFSA and its counterparts in the Member States; MOE, margin of exposure; UPLC, Ultra Performance Liquid Chromatography; TEF, toxic equivalency factor; TEQ, toxic equivalency
\end{abstract}

\title{
Keywords
}

Margin Of Exposure (MOE); Basil-based pesto; combined risk assessment; Toxic Equivalency Factors (TEFs) 


\section{INTRODUCTION}

The genus ocimum, collectively called basil, belongs to the Lamiaceae family (the mint family), a family that contains 236 genera (Harley et al. 2004) and 7534 species (Kew). The plants are aromatic and cultivated for culinary purposes. Basil adds a distinctive flavor to many foods, and is consumed fresh, dried, as essential oil, or processed. In its processed form, basil, especially Ocimum basilicum cv. Genovese gigante cultivar, is employed in the production of pesto, a typical Italian sauce. The worldwide consumption of pesto has increased due to recent interest in Mediterranean cuisine, which is considered to be healthy and valuable. The complex matrix of pesto (e.g. cheese, extra-virgin olive oil, pine nuts and/or walnuts, and garlic) significantly affects its taste and flavor (Salvadeo et al. 2007). Previously, the aromatic composition of basil was determined from different areas of north western Italy and showed methyleugenol (1,2-dimethoxy-4-prop-2-en-1-yl-benzene) and eugenol as main components (Miele et al. 2001), while estragole was shown to be present in pesto sauces made of basil cultivars different from the Genovese gigante cultivar (Marotti et al. 1996; Siano et al. 2003). In 1999, the Committee of Experts on Flavoring Substances of the Council of Europe concluded that methyleugenol is a naturally-occurring genotoxic carcinogenic compound with a DNA-binding potency similar to that of safrole (EC 2001). In 2001, the Scientific Committee on Food (SCF) of the European Union concluded that methyleugenol, and its structural analogues estragole and safrole (Figure 1) are genotoxic and carcinogenic and that reductions in exposure and restrictions in use levels are indicated (SCF 2001a; SCF 2001b; SCF 2002). Rodent studies performed at high dose levels provided sufficient evidence of the hepatocarcinogenicity of methyleugenol, estragole and safrole, displaying similar characteristics regarding mode of action and tumor formation (Phillips et al. 1981; Miller et al. 1983; Randerath et al. 1984; NTP 2000; Zhou et al. 2007; Kobets et al. 2016). EC Regulation 1334/2008, which became effective in January 2011, prohibits the 
addition of methyleugenol, estragole and safrole to foods and restricts their concentration in compound foods of dairy products, meat preparations and meat products (including poultry and game), fish preparations and fish products, ready to eat savouries, non-alcoholic beverages, processed fruit and vegetables, and soups and sauces including pesto. For soups and sauces including pesto that have been prepared with flavorings or food ingredients with flavoring properties maximum allowed limits of $60 \mathrm{mg} / \mathrm{kg}$ for methyleugenol and $25 \mathrm{mg} / \mathrm{kg}$ for safrole have been defined while a limit for estragole has not been presented (EC 2008). However, if the only food ingredients with flavoring properties that have been added are only the fresh, dried or frozen herbs, the maximum limit for methyleugenol does not apply. This implies that pesto sauce made with basil is permitted in food preparations, regardless of its genotoxic carcinogenic compounds content.

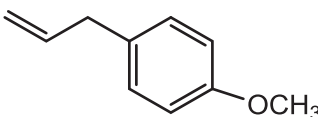

estragole

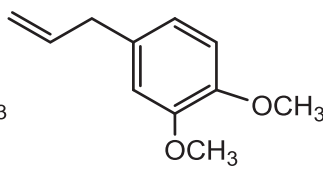

methyleugenol<smiles>C=CCc1ccc2c(c1)OCO2</smiles>

safrole

Figure 1. Structural formula of methyleugenol and its structural analogues.

A major issue in the safety assessment of alkenylbenzene-containing food items is how to provide guidance on the potential risks for human health resulting from the exposure to low levels of these genotoxic and carcinogenic compounds (EFSA 2005). The European Food Safety Authority (EFSA) recommended the Margin of Exposure (MOE) approach (EFSA 2005) to evaluate the priority for risk management actions for compounds that are both genotoxic and carcinogenic and present in a botanical or botanical preparation of interest (EFSA 2009a; EFSA 2009b). The MOE compares the exposure levels causing 
malignant tumors in experimental animals with dietary intake estimates in humans (EDI), taking into account differences in consumption patterns. The Scientific Committee of the European Food Safety Authority recommends the use of the benchmark dose (the BMDL 10 ; the lower confidence limit of the benchmark dose resulting in a $10 \%$ extra cancer incidence) to obtain the MOE (EFSA 2005). The benchmark dose is a standardized reference point derived from the animal data by mathematical modelling within the observed range of experimental data (EFSA 2009b). Pesto eaters could be exposed to some of the highest levels of methyleugenol, because fresh pesto is prepared from a large quantity of fresh basil, reflected by basil amounts in pesto sauce products on the market that amounted on average to $36 \%$ (an average from different products in the market). It has been estimated that the theoretical dietary exposure to methyleugenol could reach $\sim 250 \mu \mathrm{g} / \mathrm{kg}$ bw per meal for adults and $500 \mu \mathrm{g} / \mathrm{kg}$ bw per meal for children, based on the assumptions that the percentage of methyleugenol in the essential oil is generally $>40 \%$, the amount of essential oil in $O$. basilicum cv. Genovese gigante corresponds $0.5 \%$ and that one portion of pesto contains $\sim 10 \mathrm{~g}$ of basil (Miele et al. 2001). The French food control administration analysed methyleugenol in a limited number of well-defined food products and reported that the methyleugenol concentration for one sample of pesto sauce was $6.02 \mu \mathrm{g} / \mathrm{g}$ and for one sample of pasta with pesto was $1.53 \mu \mathrm{g} / \mathrm{g}$ (Smith et al. 2010). Ávila et al. reported methyleugenol concentrations in a pesto sample amounting to $48 \mu \mathrm{g} / \mathrm{g}$ (Avila et al. 2009), and Siano et al. reported methyleugenol concentrations of $0.01-0.52 \mu \mathrm{g} / \mathrm{g}$ and estragole concentrations that amounted to $0.05-19.30 \mu \mathrm{g} / \mathrm{g}$ (Siano et al. 2003). It appears that the current values reported on levels of the alkenylbenzenes in sauces of pesto are limited with values that vary orders of magnitude. The aim of the present study was to make a more detailed analysis of the presence of methyleugenol and possible other alkenylbenzenes in basil-containing sauce of pesto and perform an associated risk assessment based on the MOE approach, taking into consideration 
the possible combined exposure to different alkenylbenzenes. Given that the alkenylbenzenes are known to act by a similar mode of action, at a similar target organ causing the same adverse effect, being liver carcinogenicity caused by a genotoxic mode of action, combined exposure can be evaluated by dose addition. This implies that the response to the mixture can be predicted by summing the doses of the components if needed after adjusting for the differences in potencies. Dose addition is considered most appropriate for mixtures with components that affect the same endpoint by the same mode of action (EPA 1986a; EPA 1988; EPA 2000). Dose addition is the underlying assumption of the toxic equivalency factor (TEF) approach (ATSDR 2004).

\section{MATERIALS AND METHODS}

\section{Pesto sauce samples and chemicals}

Basil containing pesto sauce samples were purchased from local Dutch markets. Table 1 presents an overview of the collected samples and their major characteristics as indicated on the label of each product. Methyleugenol, myristicin, estragole and apiol (purity, $>97 \%$ ), methanol (HPLC gradient) and acetonitrile (LC/MS gradient) were supplied by Sigma Aldrich (Steinheim, Germany). Nano pure water was obtained from a Barnstead Nanopure Type I ultrapure water system. Dimethyl sulfoxide (DMSO) was obtained from Acros organics (Geel, Belgium). Acetonitrile (ACN) (LC/MS grade) was purchased from Biosolve BV (Valkenswaard, The Netherlands). Trifluoroacetic acid TFA was obtained from Merck (Darmstadt, Germany). 
Table1. Basil-containing pesto sauce samples used in the present study and their major characteristics. Information provided was derived from the product labels unless stated otherwise.

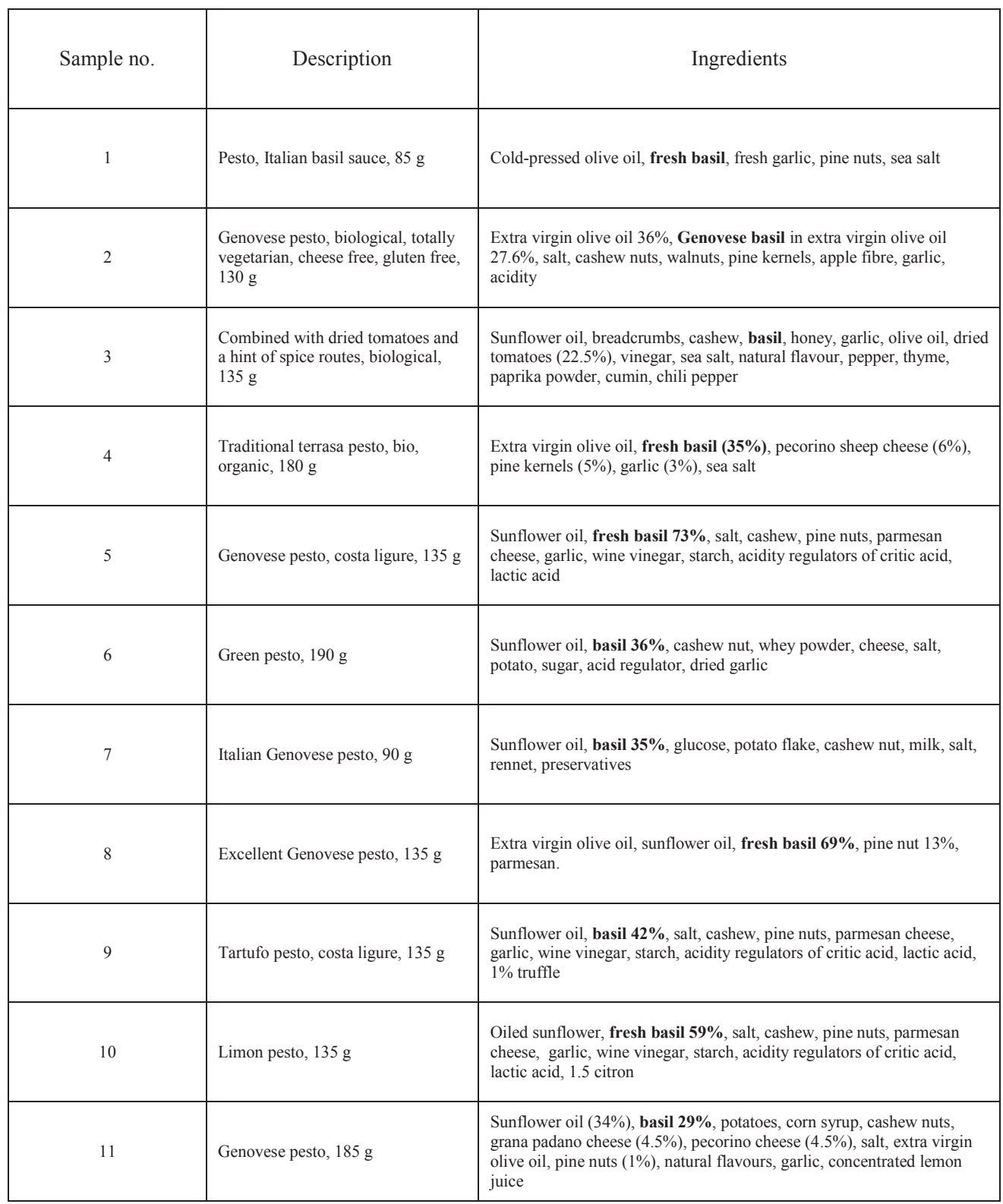


Table1. (Continued) Basil-containing pesto sauce samples used in the present study and their major characteristics. Information provided was derived from the product labels unless stated otherwise.

\begin{tabular}{|c|c|c|}
\hline 12 & Italian arugula pesto, $190 \mathrm{~g}$ & $\begin{array}{l}\text { Sunflower oil, arugula } 30 \% \text {, basil } \mathbf{8 \%} \text {, pecorino romano cheese, sea } \\
\text { salt, garlic, vegetable fibres, pine nuts, extra virgin olive oil, acidity } \\
\text { regulator: lactic acid }\end{array}$ \\
\hline 13 & Biological green pesto, $135 \mathrm{~g}$ & $\begin{array}{l}\text { Sunflower oil, fresh basil } 79 \% \text {, salt } 1 \% \text {, pine nuts, garlic, white wine } \\
\text { vinegar, acid regulator (lactic acid, citric acid) }\end{array}$ \\
\hline 14 & $\begin{array}{l}\text { The real Italian seasoning, green } \\
\text { pesto, } 190 \mathrm{~g}\end{array}$ & $\begin{array}{l}\text { Basil } 42 \% \text {, sunflower oil, cashew nut } 6.5 \% \text {, water, parmigiano reggiano } \\
\text { cheese } 2.5 \% \text {, salt, garlic, yogurt powder, olive oil } 0.5 \% \text {, pine } 0.5 \% \text {, } \\
\text { acidity regulator: lactic acid, natural basil flavor, natural white pepper } \\
\text { flavor, whey protein, antioxidant: E300 }\end{array}$ \\
\hline 15 & $\begin{array}{l}\text { Green pesto, classic basil pesto, } \\
\text { garlic and parmesan cheese, } 125 \mathrm{~g}\end{array}$ & $\begin{array}{l}\text { Basil } 42 \% \text {, sunflower oil } 32.2 \% \text {, cashew nuts, parmesan } 4 \% \text { (milk, salt, } \\
\text { rennet), salt, pecorino cheese } 2 \% \text {, garlic } 1.5 \% \text {, glucose syrup, milk } \\
\text { protein, acidity regulator: lactic acid, extra virgin olive oil, pine } 0.5 \% \text {, } \\
\text { natural flavor }\end{array}$ \\
\hline 16 & Green pesto, with more basil, $185 \mathrm{~g}$ & $\begin{array}{l}\text { Basil } 46 \% \text {, sunflower oil, Italian cheese } 7 \% \text { (grana padano, pecorino } \\
\text { romano), cashews, salt, extra virgin olive oil with virgin olive oil } 2 \% \text {, } \\
\text { glucose syrup, sugar, potato flakes, flavor, garlic } 0.5 \% \text {, pine nut } 0.5 \% \text {, } \\
\text { lactic acid }\end{array}$ \\
\hline 17 & $\begin{array}{l}\text { Green vegan pesto with extra virgin } \\
\text { oil, bio, organic, } 180 \mathrm{~g}\end{array}$ & Extra virgin oil, basil $\mathbf{3 0} \%$, walnuts, cashew nuts, pine kernels, sea salt \\
\hline 19 & $\begin{array}{l}\text { Fresh green pesto, in-house made } \\
\text { (supermarket), } 100 \mathrm{~g}\end{array}$ & $\begin{array}{l}\text { Sunflower oil, basil } \mathbf{2 3 . 7} \%, 9.5 \% \text { cheese powder, walnuts, parsley, salt, } \\
\text { vinegar, garlic } 2 \%, 1.9 \% \text {, pine nuts, sugar water, white pepper, food } \\
\text { acids: lactic acid and citric acid, thickening agent, E415 and E415, } \\
\text { preservative E202 }\end{array}$ \\
\hline 20 & $\begin{array}{l}\text { Artisan and full of flavor green } \\
\text { pesto, } 100 \mathrm{~g}\end{array}$ & $\begin{array}{l}\text { Sunflower oil, basil } \mathbf{3 0} \% \text {, } 8.5 \% \text { grana padano cheese, cashews, olive } \\
\text { oil, salt, pecorino cheese, fructose, pine, bamboo fiber, garlic, } \\
\text { antioxidant E300 }\end{array}$ \\
\hline 21 & $\begin{array}{l}\text { Creamy green pesto with basil, } \\
\text { cheese and pine nuts, } 125 \mathrm{~g}\end{array}$ & $\begin{array}{l}\text { Vegetable oil ( } 27 \% \text { olive, rapeseed), basil } 22 \%, 11 \% \text { cheese powder, } \\
7 \% \text { pine nuts, parsley, } 2.5 \% \text { garlic puree, white wine vinegar, salt, sugar, } \\
\text { vinegar, natural flavoring, preservative (E200, E210), black pepper, } \\
\text { thickening agent (guar gum, xanthan gum) }\end{array}$ \\
\hline
\end{tabular}


Table1. (Continued) Basil-containing pesto sauce samples used in the present study and their major characteristics. Information provided was derived from the product labels unless stated otherwise.

\begin{tabular}{|c|c|c|}
\hline Sample no. & Description & Ingredients \\
\hline 22 & $\begin{array}{l}\text { Creamy red pesto with tomato, } \\
\text { cheese and pine nuts, } 125 \mathrm{~g}\end{array}$ & $\begin{array}{l}\text { Vegetable oil ( } 13 \% \text { olive, rapeseed), } 16 \text { tomatoes, basil } 14 \%, 12 \% \text { cheese } \\
\text { powder, } 8 \% \text { pine nuts, parsley, } 3 \% \text { garlic puree, white wine vinegar, salt, } \\
\text { sugar, vinegar, natural flavoring, preservative (E200, E210), thickener (guar } \\
\text { gum, xanthan gum), } 1.5 \% \text { sundried tomatoes, red peppers }\end{array}$ \\
\hline 23 & $\begin{array}{l}\text { Pesto with Sicilian pistachio nuts, } \\
130 \mathrm{~g}\end{array}$ & Olive oil, Genovese basil $22 \%$, pistachio nut (18\%), cashew nuts, sea salt \\
\hline 24 & Pesto with lemon zest, $135 \mathrm{~g}$ & $\begin{array}{l}\text { Olive oil, fresh basil } \mathbf{5 9} \% \text {, cashew nuts, salt, cheese mix ( } 2 \%) \text {, limon rinds } \\
(1.5 \%) \text {, fructose, pine nuts, wine vinegar, garlic, natural lemon flavoring, } \\
\text { acidity regulator citric acid, lactic acid }\end{array}$ \\
\hline 25 & Pesto with basil \& truffle, $130 \mathrm{~g}$ & $\begin{array}{l}\text { Olive oil, Genovese basil } 22 \% \text {, cashew nuts, sea salt, pine nuts, white } \\
\text { truffle }\end{array}$ \\
\hline 26 & $\begin{array}{l}\text { Rosso pesto with sun dried tomato } \\
\text { and basil, } 130 \mathrm{~g}\end{array}$ & $\begin{array}{l}\text { Olive oil, sun dried tomato } 25 \% \text {, Genovese basil } 25 \% \text {, cashew nuts, sea } \\
\text { salt, pine nuts, acidity regulator citric acid, lactic acid }\end{array}$ \\
\hline 27 & $\begin{array}{l}\text { Freshly made pesto, from Italian food } \\
\text { products shop }\end{array}$ & Private recipe \\
\hline 28 & $\begin{array}{l}\text { Freshly made pesto, from cheese } \\
\text { shop }\end{array}$ & Private recipe \\
\hline 29 & Pesto spread, $90 \mathrm{~g}$ & $\begin{array}{l}\text { Sunflower oil, } 15 \% \text { pine nuts, low-fat cream cheese, basil } 9 \% \text {, spinach, } \\
\text { white wine vinegar, } 2.5 \text { pecorino, garlic, salt, emulsifier (E472), bovine } \\
\text { gelatin, preservative (E202, E224) }\end{array}$ \\
\hline 30 & Special basil pesto, $100 \mathrm{~g}$ & $\begin{array}{l}\text { Sunflower oil, pine nut } 15 \%, 12 \% \text { old cheese, basil } 11 \%, 10 \% \text { spinach, } \\
\text { white wine vinegar, dried garlic, sea salt, preservative (E202, E224) }\end{array}$ \\
\hline 31 & Bio basil pesto, $100 \mathrm{~g}$ & $\begin{array}{l}\text { Basil 32\%, sunflower oil, cheese, olive oil } 55,4 \% \text { pine nuts, vinegar, } \\
\text { garlic, lemon juice, sea salt, spices, coconut blossom sugar }\end{array}$ \\
\hline
\end{tabular}




\section{Methanol extracts}

All basil-containing pesto sauces were extracted using methanol based on the method described by Ávila et al. (Avila et al. 2009), with minor modifications. In short, $5 \mathrm{~g}$ of each sauce sample were sonicated in an ultrasonic bath for $10 \mathrm{~min}$ and macerated for $12-\mathrm{hr}$ at $50^{\circ} \mathrm{C}$ with $80 \mathrm{ml}$ of methanol in a closed glass vessel. Finally, an aliquot of the extract solution was centrifuged at $13000 \times \mathrm{g}$ for $5 \mathrm{~min}$, and stored at $-20^{\circ} \mathrm{C}$ until Ultra Performance Liquid Chromatography (UPLC) analysis. Samples were extracted and then analyzed on UPLC in triplicate. The accuracy of the developed method was assessed by means of a recovery study and standard deviations of the replicates. For recovery, pure standards of commercially available alkenylbenzenes were added in two different quantities (final concentration of 5 and $10 \mu \mathrm{M}$ ) to $5 \mathrm{~g}$ of two pesto sauce samples (sample 16 and 21) which covers the whole range of analysis in a final volume of methanol of $80 \mathrm{ml}$. Samples were prepared and analyzed as described above to quantify the alkenylbenzene levels enabling determination of the recovery. The extraction capacity linearity was demonstrated to applying a range of weight of sample to final volume of the solution ratio of $1.5 \%$ up to $10 \%$.

\section{UPLC analysis}

For quantification of alkenylbenzenes in the extracts, $3.5 \mu \mathrm{l}$ of each sample was subjected to UPLC analysis. The UPLC system consisted of a Waters (Waters, Milford, MA) Acquity solvent manager, sample manager, and photodiode array detector. Chromatographic separation was achieved using an ACQUITY UPLC BEH C18 $1.7 \mu \mathrm{m}$ column, $2.1 \times 50 \mathrm{~mm}$. The column was thermostated at $35^{\circ} \mathrm{C}$ and the sample manager was set at $10^{\circ} \mathrm{C}$. An isocratic gradient was made for the separation using a mixture of acetonitrile (ACN) and ultrapure water containing $0.1 \%(\mathrm{v} / \mathrm{v})$ trifluoroacetic acid (TFA). The mobile phase consisted of $40 \%$ acetonitrile for $4 \mathrm{~min}$, which was the time needed to separate alkenylbenzenes of interest. 
During the whole run, the flow rate was $0.6 \mathrm{ml} / \mathrm{min}$. Under these conditions, the retention times for methyleugenol, estragole, myristicin, and apiol were 1.5, 2.2, 2.4, and $2.8 \mathrm{~min}$, respectively. Identification of the alkenylbenzenes was achieved by comparing the UV spectrum and retention time of the peak to the UV spectrum and retention time of the peaks of commercially available reference compounds. Quantification was done by comparing the area of the alkenylbenzene peak to that of the calibration curve of the reference compounds determined using UPLC with photodiode array detection (UPLC/PDA) at a wavelength 201 $\mathrm{nm}$ for methyleugenol and estragole, and a wavelength $210 \mathrm{~nm}$ for myristicin and apiol.

\section{Determination of estimated daily intake (EDI) of alkenylbenzenes resulting from the use of pesto sauce}

The estimate daily intake (EDI) of alkenylbenzenes resulting from the use of pesto sauce was determined based on the alkenylbenzene content in the pesto sauce as determined in the present study (see results) and a body weight of $70 \mathrm{~kg}$, the default value for adult body weight proposed by EFSA (EFSA 2012b). Daily consumption of pesto sauce was based on the reported use of about $10 \mathrm{~g}$ basil for a meal (Miele et al. 2001), and on the basil content of the samples as mentioned on the label (Table 1). If there was no information on the basil content in the pesto sauce on the label the average content of basil in pesto sauce of $36.0 \pm 19.6 \%$ $(\mathrm{n}=27)($ Table 1) was used. Firstly, the EDI was calculated for individual compounds for all of the samples. And since several alkenylbenzenes were found in some of the pesto samples, and the different alkenylbenzenes show similarity in structure, target organ, type of adverse effects and mode of action through formation of a DNA reactive 1'-sulfoxymetabolite contributing to formation of liver tumors, a combined exposure assessment and subsequent risk assessment were also performed for those samples. To this end two approaches were used; summing up the EDIs of the alkenylbenzenes assuming equal potency, and a so-called 
toxic equivalency (TEQ) approach calculating the estimated daily intake (EDI) values of the alkenylbenzenes using their toxic equivalency factor (TEF) relative to methyleugenol. Methyleugenol was taken as the reference compound $(\mathrm{TEF}=1.0)$, expressing the concentrations of the other alkenylbenzenes in methyleugenol equivalents. TEF values for the different alkenylbenzenes for the TEQ approach need to be defined, which was done by calculating an average of three endpoints. The first one was the slope of the dose-response curve for DNA-adduct formation in female CD-1 mice liver upon exposure to different alkenylbenzenes (Randerath et al. 1984). The second one, was the in vivo level of formation of the hepatocarcinogenic 1'-sulfoxymetabolites of the different alkenylbenzenes predicted using human physiologically based kinetic (PBK) models at a dose level of $0.01 \mathrm{mg} / \mathrm{kg}$ bw (Punt et al. 2009; Al-Subeihi et al. 2012; Alajlouni et al. 2016a; Al-Malahmeh et al. 2017). And finally, the $\mathrm{BMDL}_{10}$ values derived from in vivo tumor data for safrole, estragole, and methyleugenol (Miller et al. 1983), or by read-across from safrole for myristicin and apiol (Alajlouni et al. 2016a; Al-Malahmeh et al. 2017) (Table 2). The TEF values for the different alkenylbenzenes defined by the three approaches relative to methyleugenol were subsequently averaged to define the final TEF values. Using these TEF values the EDI of alkenylbenzenes in the pesto sauces expressed in ( $\mu \mathrm{g}$ methyleugenol equivalents/kg bw per day) was calculated using the formula:

$E D I(\mu g$ methyleugenol equivalents $) /(k g$ bw day $)=\sum(E D I \times T E F)_{i}$, $i$; differnt alkenybenzenes 
Table 2. Data used for estimation of the TEF values for the different alkenylbenzenes as derived from data reported for i) the dose-dependent level of DNA adduct formation in the liver of alkenylbenzene exposed female CD-1 mice (Randerath et al. 1984) ii) the formation of the proximate carcinogenic 1'-sulfoxy metabolites in liver in $\mu \mathrm{mol} / \mathrm{kg}$ bw as predicted by available PBK models at a dose level of $0.01 \mathrm{mg} / \mathrm{kg}$ bw (Punt et al. 2009; Al-Subeihi et al. 2012; Alajlouni et al. 2016a; Al-Malahmeh et al. 2017), and iii) BMDL 10 values reported in the literature (van den Berg et al. 2011; Alajlouni et al. 2016a; Al-Malahmeh et al. 2017). The TEF values were calculated relative to methyleugenol as the reference compound, expressing the concentrations of the other alkenylbenzenes in methyleugenol equivalents.

\begin{tabular}{|c|c|c|c|c|c|c|c|}
\hline \multirow{2}{*}{ Compound } & \multicolumn{2}{|c|}{$\begin{array}{l}\text { Formation of DNA } \\
\text { adduct in } 10^{7} \\
\text { nucleotides versus } \\
\text { dose in } \mathrm{mg} / \mathrm{kg} \mathrm{bw}\end{array}$} & \multicolumn{2}{|c|}{$\begin{array}{l}\text { Formation of the } \\
\text { proximate carcinogenic } \\
\text { 1'-sulfoxy metabolite }\end{array}$} & \multicolumn{2}{|c|}{ In vivo tumor data } & \multirow{2}{*}{$\begin{array}{l}\text { Average } \\
\text { TEF value } \\
\pm \mathrm{SD}\end{array}$} \\
\hline & $\begin{array}{l}\text { slope of } \\
\text { the curve }\end{array}$ & TEF & $\begin{array}{c}\text { formation level } \\
(\mu \mathrm{mol} / \mathrm{kg} \mathrm{bw}) \text { at } \\
0.01 \mathrm{mg} / \mathrm{kg} \mathrm{bw} \\
\text { dose }\end{array}$ & TEF & $\begin{array}{c}\mathrm{BMDL}_{10} \\
\text { (mg/kg bw per } \\
\text { day) }\end{array}$ & TEF & \\
\hline Safrole & 1.68 & 1.05 & $3.28 \mathrm{E}-05$ & 1.08 & 1.9 & 8.05 & $3.39 \pm 4.04$ \\
\hline myristicin & 0.39 & 0.24 & $2.44 \mathrm{E}-05$ & 0.8 & 1.9 & 8.05 & $3.03 \pm 4.36$ \\
\hline apiol & 0.11 & 0.07 & $1.62 \mathrm{E}-05$ & 0.53 & 5.7 & 2.68 & $1.09 \pm 1.40$ \\
\hline estragole & 2.48 & 1.55 & 14.1E-05 & 4.62 & 3.3 & 4.64 & $3.60 \pm 1.78$ \\
\hline methyleugenol & 1.60 & 1.00 & $3.05 \mathrm{E}-05$ & 1.00 & 15.3 & 1.00 & 1.00 \\
\hline
\end{tabular}

\section{Calculation of the margin of exposure}

Risk assessment of consumption of the pesto sauce samples was performed using the Margin of Exposure (MOE) approach (EFSA 2005). For the individual alkenylbenzene approach, the BMDL $_{10}$ values of each compound were used (van den Berg et al. 2011; Alajlouni et al. 2016a; Al-Malahmeh et al. 2017) and then compared with the EDIs of the alkenylbenzenes resulting from the use of pesto sauce. For the equal potency assumption approach, the $\mathrm{BMDL}_{10}$ value of the predominating alkenylbenzene in the samples was used and compared to the sum of the EDIs. And finally, for the TEQ approach, the BMDL 10 of the reference compound methyleugenol was compared to the EDI expressed in methyleugenol equivalents. 


\section{RESULTS}

Determination of methyleugenol content in the basil-containing pesto sauce samples, EDI, and resulting MOEs

Table 3 presents the levels of methyleugenol detected in the various pesto sauces. The results obtained revealed that methyleugenol was detected in all the samples analyzed. The level of methyleugenol in the different samples varied about 28-fold ranging between 3.6 and $99.3 \mu \mathrm{g} / \mathrm{g}$ pesto sauce. Estimated daily intakes (EDIs) of methyleugenol from basil containing pesto sauce were calculated using the methyleugenol content in the samples, a daily consumption of pesto calculated based on the reported use of about $10 \mathrm{~g}$ basil for a meal (Miele et al. 2001), and the basil content of the samples as mentioned on the label (Table 1) or the assumption that the basil content in pesto sauce was on average $36.0 \pm 19.6 \%$ $(\mathrm{n}=27)($ Table 1$)$ in case this $\%$ of basil in the pesto sauce was not mentioned on the label, and an adult body weight of $70 \mathrm{~kg}$. The EDI values thus obtained for methyleugenol vary in the range of $3.2-44.3 \mu \mathrm{g} / \mathrm{kg}$ bw per day. The MOE values were calculated using the $\mathrm{BMDL}_{10}$ value reported in the literature for methyleugenol of $15.3 \mathrm{mg} / \mathrm{kg}$ bw per day (van den Berg et al. 2011) (Table 3). The MOE values obtained vary from 345 to 4781 and were all lower than 10000, the value suggested by EFSA to judge if there is a priority for risk management (EFSA 2005). 
Table 3. Level of methyleugenol detected in the pesto sauce samples, EDI for methyleugenol upon consumption of these pesto samples, and the resulting MOE.

\begin{tabular}{|c|c|c|c|}
\hline Sample no. & $\begin{array}{c}\text { Methyleugenol } \\
\text { concentration in the pesto } \\
\text { sample Average } \pm \mathrm{SD}(\mu \mathrm{g} / \mathrm{g})\end{array}$ & $\begin{array}{c}\text { EDI } \\
(\mu \mathrm{g} / \mathrm{kg} \text { bw per } \\
\text { day })\end{array}$ & MOE \\
\hline 1 & $17.9 \pm 2.4$ & 7.1 & 2154 \\
\hline 2 & $11.4 \pm 1.5$ & 5.9 & 2593 \\
\hline 3 & $11.1 \pm 1.5$ & 4.4 & 3474 \\
\hline 4 & $35.6 \pm 4.8$ & 14.5 & 1053 \\
\hline 5 & $32.3 \pm 4.3$ & 6.3 & 2421 \\
\hline 6 & $41.2 \pm 5.5$ & 16.4 & 936 \\
\hline 7 & $29.6 \pm 4$ & 12.1 & 1266 \\
\hline 8 & $27.6 \pm 3.7$ & 5.0 & 3066 \\
\hline 9 & $25.3 \pm 3.4$ & 8.6 & 1778 \\
\hline 10 & $38.1 \pm 5.1$ & 9.2 & 1659 \\
\hline
\end{tabular}


Table 3. (Continued) level of methyleugenol detected in the pesto sauce samples, EDI for methyleugenol upon consumption of these pesto samples, and the resulting MOE

\begin{tabular}{|c|c|c|c|}
\hline Sample no. & $\begin{array}{c}\text { Methyleugenol } \\
\text { concentration in the pesto } \\
\text { sample Average } \pm \text { SD } \\
(\mu \mathrm{g} / \mathrm{g})\end{array}$ & $\begin{array}{c}\text { EDI } \\
(\mu \mathrm{g} / \mathrm{kg} \text { bw per day })\end{array}$ & MOE \\
\hline 29 & $3.6 \pm 0.5$ & 5.7 & 2678 \\
\hline 30 & $3.8 \pm 0.5$ & 4.9 & 3100 \\
\hline 31 & $99.3 \pm 13.3$ & 44.3 & 345 \\
\hline
\end{tabular}

Determination of other alkenylbenzenes in the pesto sauce samples, EDI for the combined exposure, and resulting MOEs

In four samples $(16,18,19$, and 21$)$ other alkenylbenzenes were detected in addition to methyleugenol, including estragole, myristicin, and/or apiol (Table 4). The levels of methyleugenol, detected in these samples, were already presented in Table 3. Estragole that is known to be present in some basil cultivars in addition to methyleugenol, was detected in two samples $(16,18)$, with one of these samples indeed containing another cultivar than the Genovese cultivar as mentioned on the label (Table 1). The estragole level varied 10-fold between the two samples in which it was detected. Myristicin and apiol were detected in two samples of green pesto (Table 4), which may be due to the fact that these samples contain other herbs in addition to basil (e.g. parsley) (Table 1). For samples 16, 18, 19 and 21 the EDI for the individual alkenylbenzenes varied between $6.4-34.0 \mu \mathrm{g} / \mathrm{kg}$ bw per day for methyleugenol, $1.2-10.6 \mu \mathrm{g} / \mathrm{kg}$ bw per day for estragole, $8.6-9.6 \mu \mathrm{g} / \mathrm{kg}$ bw per day for myristicin, and $2.2 \mu \mathrm{g} / \mathrm{kg}$ bw per day for apiol the latter being detected in only one sample (Table 4). 
Table 4. Level of alkenylbenzenes methyleugenol, estragole, myristicin, and apiol in the four pesto sauce samples that contained other alkenylbenzenes in addition to methyleugenol and EDI values for the individual alkenylbenzenes, as well as combined EDI values calculated either by assuming equal potency, or in methyleugenol equivalents using the TEF values presented in Table 2 .

\begin{tabular}{|c|c|c|c|c|c|c|c|c|c|c|}
\hline \multirow[b]{3}{*}{$\begin{array}{l}\text { Sample } \\
\text { no. }\end{array}$} & \multirow{2}{*}{\multicolumn{4}{|c|}{$\begin{array}{l}\text { Alkenylbenzenes level in the pesto } \\
\text { sample average } \pm \mathrm{SD}(\mu \mathrm{g} / \mathrm{g})\end{array}$}} & \multicolumn{6}{|c|}{ EDI ( $\mu \mathrm{g} / \mathrm{kg}$ bw per day) } \\
\hline & & & & & \multicolumn{4}{|c|}{ individual } & \multicolumn{2}{|c|}{ combined exposure } \\
\hline & 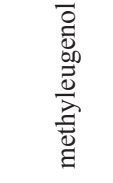 & $\begin{array}{l}\frac{0}{0} \\
0 \\
\mathbb{E} \\
\mathbb{E} \\
0\end{array}$ & .气 & . & 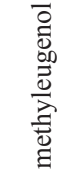 & 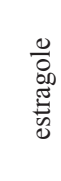 & .气 & 을 & $\begin{array}{l}\text { assuming } \\
\text { equal } \\
\text { potency }\end{array}$ & $\begin{array}{c}\text { based on } \\
\text { TEF } \\
\text { methyleugenol } \\
\text { equivalents }\end{array}$ \\
\hline 16 & $39.0 \pm 5.2$ & $\begin{array}{c}34.1 \pm \\
2.8 \\
\end{array}$ & & & 12.1 & 10.6 & & & 22.7 & 50.3 \\
\hline 18 & $35.8 \pm 4.8$ & $3.2 \pm 1.5$ & & & 13.1 & 1.2 & & & 14.3 & 17.3 \\
\hline 19 & $56.4 \pm 7.5$ & & $\begin{array}{c}15.8 \pm \\
0.01 \\
\end{array}$ & & 34 & & 9.6 & & 43.5 & 62.9 \\
\hline 21 & $22.9 \pm 3.1$ & & $13.2 \pm 1.2$ & $\begin{array}{c}3.4 \\
\pm \\
0.2\end{array}$ & 6.4 & & 8.6 & 2.2 & 17.2 & 34.8 \\
\hline
\end{tabular}

Since several alkenylbenzenes were found in some pesto samples, and because these alkenylbenzenes are known to display similarity in structure, target organ, type of adverse effects and mode of action through formation of a DNA reactive 1'-sulfoxymetabolite contributing to formation of liver tumors, a combined exposure and risk assessment was also performed. To this end the combined exposure was estimated in two ways, assuming either equal potency or using a so-called toxic equivalency (TEQ) approach. When assuming equal potency of the different alkenylbenzenes the combined EDI can be calculated by adding up the EDIs of the different alkenylbenzenes. Table 4 presents the combined EDI values obtained for the four pesto sauce samples in which more than one alkenylbenzene were detected. The values obtained varied from 14.3 to $43.5 \mathrm{mg} / \mathrm{kg}$ bw per day with methyleugenol being the major alkenylbenzene making up 53.3-91.6\% of these values except for sample 22 where methyleugenol makes up $37.2 \%$ of the alkenylbenzenes and myristicin appeared to be the major one at $50.0 \%$. In a second approach the combined exposure was calculated in methyleugenol equivalents taking the relative potency of the different alkenylbenzenes into 
account. For this TEQ approach the required toxic equivalency factor (TEF) relative to methyleugenol were estimated as summarized in Table 2. TEF values for the different alkenylbenzenes were defined by calculating the average of the relative potency as available for three end points, including (i) the slope of the dose-response curve for DNA-adduct formation in female CD-1 mice liver upon exposure to different alkenylbenzenes (Randerath et al. 1984), (ii) the in vivo level of formation of the hepatocarcinogenic 1'-sulfoxymetabolites of the different alkenylbenzenes predicted using human physiologically based kinetic models at a dose level of $0.01 \mathrm{mg} / \mathrm{kg}$ bw (Punt et al. 2009; Al-Subeihi et al. 2012; Alajlouni et al. 2016a; Al-Malahmeh et al. 2017), and (iii) the BMDL $_{10}$ values derived from in vivo tumor data for safrole, estragole, and methyleugenol (Miller et al. 1983), or by read-across from safrole for myristicin and apiol (Alajlouni et al. 2016a; Al-Malahmeh et al. 2017). Methyleugenol was taken as the reference compound $(\mathrm{TEF}=1.0)$, expressing the concentrations of the other alkenylbenzenes in methyleugenol equivalents (Table 2).

Using these TEF values and the toxic equivalency approach (TEQ) the combined EDI values obtained vary in the range of 17.3-62.9 $\mu \mathrm{g}$ methyleugenol equivalents/kg bw per day (Table 4).

Using the EDI values thus obtained MOE values were calculated. To this end different $\mathrm{BMDL}_{10}$ values were used for different approaches to obtain the MOE values. The $\mathrm{BMDL}_{10}$ values for the individual alkenylbenzenes were taken from literature (van den Berg et al. 2011; Alajlouni et al. 2016a; Al-Malahmeh et al. 2017), and were used to calculate MOE values for intakes of each individual alkenylbenzene (Table 5). MOE values thus obtained were all below 10000. Assuming equal potency, the $\mathrm{BMDL}_{10}$ of methyleugenol of $15.3 \mathrm{mg} / \mathrm{kg}$ bw per day (van den Berg et al. 2011), being a dominant alkenylbenzenes in the samples was compared with the combined EDI. The MOE values thus obtained varies between 351 and 1071 (Table 5). For the TEQ approach, the BMDL 10 of methyleugenol of 
$15.3 \mathrm{mg} / \mathrm{kg}$ bw per day (van den Berg et al. 2011) was compared to the EDI expressed in methyleugenol equivalents to calculate the MOE. When using the TEQ approach, MOE values ranged from 243 to 883 .

Table 5. The MOE values obtained for samples containing several alkenylbezenes. MOE values were calculated for each individual alkenylbenzenes, and based on combined exposure estimates either assuming equal potency, or based on a TEQ approach.

\begin{tabular}{|c|c|c|c|c|c|c|}
\hline \multirow[b]{2}{*}{$\begin{array}{c}\text { Sample } \\
\text { no. }\end{array}$} & \multicolumn{4}{|c|}{ MOE individual alkenylbenzenes } & \multirow{2}{*}{$\begin{array}{l}\text { MOE based on equal } \\
\text { potency and BMDL } \\
\text { of the highest level } \\
\text { alkenylbenzene in the } \\
\text { sample }\end{array}$} & \multirow[b]{2}{*}{$\begin{array}{c}\text { MOE based on } \\
\text { TEF }\end{array}$} \\
\hline & methyleugenol & estragole & myristicin & apiol & & \\
\hline 16 & 1263 & 3209 & & & 674 & 304 \\
\hline 18 & 1166 & 355 & & & 1071 & 883 \\
\hline 19 & 450 & & 199 & & 351 & 243 \\
\hline 21 & 1028 & & 221 & 2582 & 892 & 353 \\
\hline
\end{tabular}

From the data thus obtained it is clear that the estimated daily consumption of the pesto sauces at $10 \mathrm{~g}$ basil per meal per day (based on wet weight) would result in MOE values that indicate a priority for risk management for all pesto sauces. It is of interest to evaluate what level of methyleugenol, amount of pesto sauce consumed and/or what exposure frequency would result in an MOE of 10000 . To evaluate how these parameters could be modified to result in MOE values that would be of low priority for risk management, Figure 2 shows the relation between the level of methyleugenol detected in a pesto sauce sample and the amount of pesto sauce consumed that would result in MOE values of 10000 at a certain frequency of intake. For these calculations, it was assumed that Haber's rule would apply so the daily dose would be linearly dependent on the frequency of intake. The results presented indicate that daily intake of for example $30 \mathrm{~g}$ pesto sauce would be of low priority for risk management at a methyleugenol level of $3.6 \mu \mathrm{g} / \mathrm{g}$, while weekly intake of $30 \mathrm{~g}$ would be of low concern at a methyleugenol value of $25.0 \mu \mathrm{g} / \mathrm{g}$. The curves can also be used to derive that for the pesto 
sauce samples of the present study with methyleugenol levels that vary from 99.3 to $3.6 \mu \mathrm{g} / \mathrm{g}$ pesto sauce, the consumption of $1.1-29.8,7.5-208,15.1-416.5$, and $32.4-892.5 \mathrm{~g}$ of pesto sauce on a daily basis, once a week, once every two weeks, and once a month, respectively, could be considered of low concern.

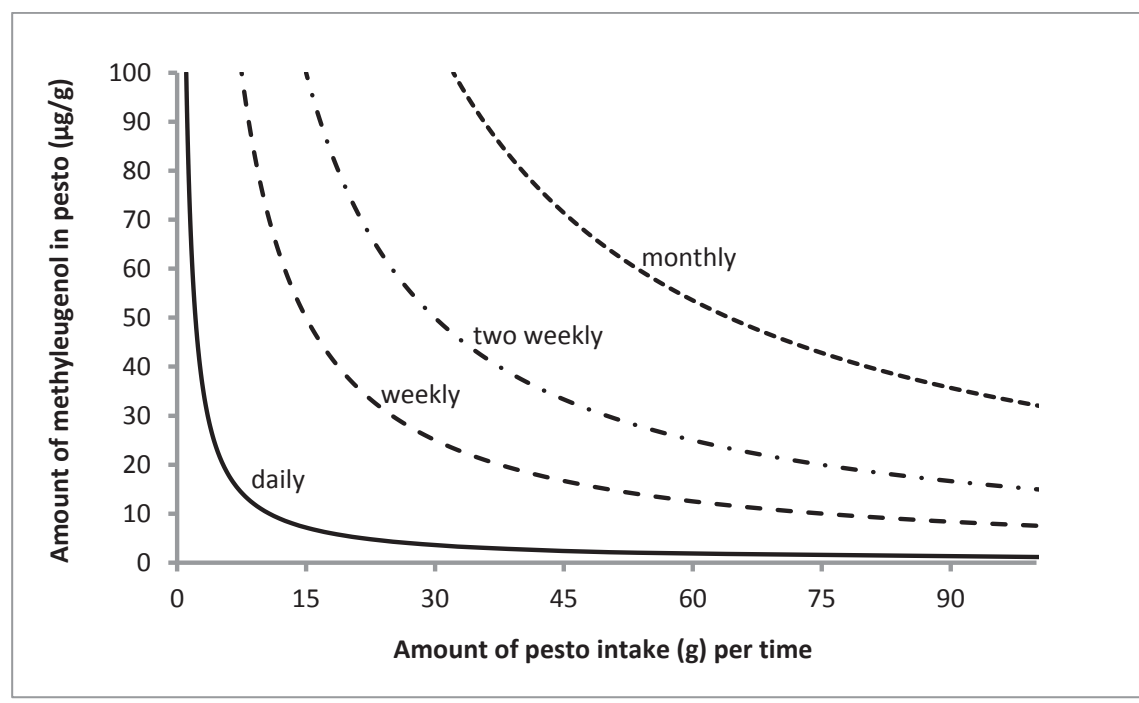

Figure 2. Relation between the methyleugenol content $(\mu \mathrm{g} / \mathrm{g})$ and daily pesto sauce consumption that would result in an MOE of 10000 upon daily (-), weekly (- - ), two weekly (-•-), or monthly (•••) consumption. Combinations of methyleugenol levels and pesto sauce intake that result in values below the respective curves result in MOE values above 10000 and would be of low priority for risk management.

\section{DISCUSSION}

The aim of the present study was to make a more detailed analysis of the presence of methyleugenol and possible other alkenylbenzenes in basil-containing sauce of pesto and perform an associated risk assessment based on the MOE approach, taking into consideration the combined exposure to different alkenylbenzenes.

It is important to consider the variance in aromatic composition of basil at different growth stages from different areas. The methyleugenol content of the volatile oil from commercial 
samples of sweet basil, and in the leaf, flower and stem for the same cultivar of sweet basil were in the range of 0-2.4\% (Tsai and Sheen 1987; Sheen et al. 1991; Lawrence et al. 1993). It was also reported that the content of methyleugenol in the essential oil of basil plants decreases from $100 \%$ to $10 \%$ as plant height and maturity increase (Miele et al. 2001). Different studies revealed different levels of estragole and methyleugenol in basil for different genotypes and as a function of region and harvesting. The concentrations in fresh basil amount $10.2-2029 \mu \mathrm{g} / \mathrm{g}$ for estragole and $0.07-560 \mu \mathrm{g} / \mathrm{g}$ for methyleugenol (Siano et al. 2003; Lee et al. 2005; Avila et al. 2009). For pesto sauce, studies showed different concentrations of estragole that varied between 0.05 and $19.3 \mu \mathrm{g} / \mathrm{g}$, and of methyleugenol at values that varied between 0.01 and $52 \mu \mathrm{g} / \mathrm{g}$ (Siano et al. 2003; Avila et al. 2009). The levels of methyleugenol determined in the pesto sauces of the present study amounted to $3.6-99.3 \mu \mathrm{g} / \mathrm{g}$ pesto sauce, and of estragole, being present in only two out of the 32 pesto sauce samples analyzed, to 3.2 and $34.1 \mu \mathrm{g} / \mathrm{g}$ pesto sauces. Based on these levels and taking the basil content (\%) as indicated on the label of the pesto sauces into account, the level of methyleugenol in basil used to prepare the pesto sauce was estimated to vary between $22.4-310.3 \mu \mathrm{g} / \mathrm{g}$. The determination of the levels of alkenylbenzenes in basil-containing sauce of pesto revealed that all the samples analyzed contained methyleugenol. In addition to methyleugenol, two of the samples contained estragole, while two other samples contained myristicin, and one sample contained both myristicin and apiol in addition to methyleugenol. Based on chemical analysis the EDI values could be determined assuming a body weight of $70 \mathrm{~kg}$ and intake of $10 \mathrm{~g}$ of basil (based on wet weight) per meal (Miele et al. 2001), provided by an amount of pesto sauce that could be calculated taking into account the basil content (\%) in the pesto sauce as indicated on the label (Table 1). For samples containing only methyleugenol, the EDI values ranged from 3.2-44.3 $\mu \mathrm{g} / \mathrm{kg}$ bw per day. These EDI values resulted in MOE values of $345-$ 4781. Since several alkenylbenzenes were found in four of the pesto samples, and these 
alkenylbenzenes show high similarity in structure, target organ, type of adverse effects and mode of action through formation of a DNA reactive 1'-sulfoxymetabolite contributing to formation of liver tumors, for these four samples a combined exposure assessment and subsequent risk assessment were performed. EDI values based on individual compounds amounted to $1.2-34.0 \mu \mathrm{g} / \mathrm{kg}$ bw per day. These EDI values resulted in MOE values of 199 3209 for the individual levels of estragole, myristicin and apiole, indicating that these alkenylbenzenes add to the possible health risks. Assuming equal potency of the alkenylbenzenes, combined EDI values obtained ranged from $14.3-43.5 \mu \mathrm{g} / \mathrm{kg}$ bw per day resulting in MOE values ranging from 351 to 1071. Estimation of the TEF values used in this study was based on in vitro and in vivo data. It is of interest to note that in an ideal situation TEF values would be derived from in vivo data. However in practice in vitro endpoints are also frequently used, for example in the case of TEF values derived for dioxins (Van den Berg et al. 2006 ) and, more recently, in the case of interim TEF values defined for pyrrolizidine alkaloids (Merz and Schrenk 2016). Using a TEF concept combined EDI values ranged from 17.5-59.7 $\mu$ g methyleugenol equivalents $/ \mathrm{kg}$ bw leading to MOE values ranging from 243 to 883. MOE values resulting from this combined exposure assessment were 1.5-5-fold lower than the MOE values obtained when considering the presence of only methyleugenol in these four samples, and are all below 10000. Combined risk assessment based on equal potency did not vary much from results obtained using the TEQ approach. This can be ascribed to the minor variation in potencies of the different alkenylbenzenes detected in the pesto samples.

It is of interest to note that these MOE values refer to regular daily consumption of pesto which may be an overestimation of realistic human consumption. Levels of methyleugenol in pesto sauce samples and consumption frequency of pesto sauce directly impact the EDI and the resulting MOE values. The levels of methyleugenol detected in the pesto sauces of the present study vary between 99.3 and $3.6 \mu \mathrm{g} / \mathrm{g}$ and would allow consumption of 1.1-29.8, 7.5- 
$208,15.1-416.5$, and $32.4-892.5 \mathrm{~g}$ of pesto sauce on a daily basis, once a week, once every two weeks, and once a month, respectively, to achieve MOE values above the 10000 safety limit for low priority for risk management. It is concluded that consumption of pesto sauces would only be of concern if consumed on a daily basis over longer periods of time. The results of the present paper reveal that pesto consumption does not always represent a cancer risk and provide insight into when this might be the case and under which level and frequency of consumption pesto consumption would not raise a concern.

\section{ACKNOWLEDGMENT}

for Stimulation of Innovation in Toxicology). 


\section{REFERENCES}

Al-Malahmeh, A. J., Alajlouni, A. M., Wesseling, S., Soffers, A. E., Al-Subeihi, A., Kiwamoto, R., Vervoort, J. and Rietjens, I. M. C. M. (2017a). "Physiologically based kinetic modeling of the bioactivation of myristicin." Archives of toxicology 91(2): 713-734. from http://www.ncbi.nlm.nih.gov/pubmed/27334372.

Al-Subeihi, A. A., Spenkelink, B., Punt, A., Boersma, M. G., van Bladeren, P. J. and Rietjens, I. M. C. M. (2012). "Physiologically based kinetic modeling of bioactivation and detoxification of the alkenylbenzene methyleugenol in human as compared with rat." Toxicology and applied pharmacology 260(3): 271-284. from

http://www.ncbi.nlm.nih.gov/pubmed/22445790.

Alajlouni, A. M., Al Malahmeh, A. J., Kiwamoto, R., Wesseling, S., Soffers, A. E., AlSubeihi, A. A., Vervoort, J. and Rietjens, I. M. C. M. (2016a). "Mode of action based risk assessment of the botanical food-borne alkenylbenzene apiol from parsley using physiologically based kinetic (PBK) modelling and read-across from safrole." Food and chemical toxicology : an international journal published for the British Industrial Biological Research Association 89: 138-150. from

http://www.ncbi.nlm.nih.gov/pubmed/26826679.

ATSDR (2004). Guidance manual for the assessment of joint toxic actions of chemical mixtures. Agency_for_Toxic_Substances_and_Disease_Registry. Atlanta, GA, U.S. Department of Health and Human Services. Public Health Service.

Avila, M., Zougagh, M., Escarpa, A. and Rios, A. (2009). "Determination of alkenylbenzenes and related flavour compounds in food samples by on-column preconcentrationcapillary liquid chromatography." Journal of chromatography. A 1216(43): 71797185. from http://www.ncbi.nlm.nih.gov/pubmed/19735919.

EC (2001). "Opinion of the Scientific Committee on Food on Methyleugenol (4-Allyl-1,2dimethoxybenzene)." Committee of Experts on Flavouring Substances. from http://ec.europa.eu/food/fs/sc/scf/out102_en.pdf.

EC (2008). Regulation (EC) No 1334/2008 of the European Parliament and of the Council of 16 December 2008 on flavourings and certain food ingredients with flavouring properties for use in and on foods and amending Council Regulation, Off J Eur. (EEC) No 1601/91, Regulations (EC) No 2232/96 and (EC) No 110/2008 and Directive 2000/13/EC. 
EFSA (2005). "Opinion of the scientific committee on a request from EFSA related to a harmonized approach for risk assessment of substances which are both genotoxic and carcinogenic." European Food Safety Authority 282: 1-31. from

http://onlinelibrary.wiley.com/doi/10.2903/j.efsa.2005.282/epdf

EFSA (2009a). "Guidance on safety assessment of botanicals and botanical preparations intended for use as ingredients in food supplements." European Food Safety Authority 7(1249). $\quad$ from https://www.pharmamedtechbi.com/ /media/Images/Publications/Archive/The\%20Ta n\%20Sheet/17/037/05170370014_b/090914_efsa_botanicals_guidance.pdf

EFSA (2009b). "Guidance of the Scientific Committee on Use of the benchmark dose approach in risk assessment." European Food Safety Authority 1150 1-72. from http://onlinelibrary.wiley.com/doi/10.2903/j.efsa.2009.1150/epdf

EFSA (2012b). "Guidance on selected default values to be used by the EFSA Scientific Committee, Scientific Panels and Units in the absence of actual measured data." European Food Safety Authority 10(3): 2579. from

http://www.efsa.europa.eu/en/efsajournal/doc/2579.pdf.

EPA (1986a). Guidelines for the health risk assessment of chemical mixtures, United states Environmental Protection Agency. Fed Reg 51:34014-34025.

EPA (1988). Technical support document on health risk assessment of chemical mixtures. Office_of_Research_and_Development. Washington, D.C., United States Environmental Protection Agency. EPA/600/8-90/064.

EPA (2000). Supplementary guidance for conducting health risk assessment of chemical mixtures. R. A. Forum. Washington, DC United States Environmental Protection Agency. EPA/630R-00/002.

Harley, R. M., Atkins, S., Budantsev, A. L., Cantino, P. D., Conn, B. J., Grayer, R. J., Harley, M. M., de Kok, R. P. J., Krestovskaja, T. V., Morales, R., Paton, A. J., Ryding, P. O. and (2004). "The Families and Genera of Vascular Plants volume VII. J.W. Kadereit (ED.) " SpringerVerlag: Berlin; Heidelberg, Germany. ISBN 9783540405931: 22752283.

Kew "Royal Botanic Gardens. World Checklist of Selected Plant Families." from http://apps.kew.org/wcsp/incfamilies.do.

Kobets, T., Duan, J., Brunnemann, K., Etter, S., Smith, B. and Williams, G. (2016). "Structure activity relationships for DNA damage by alkenylbenzenes in turkey egg fetal liver." Toxicological Sciences 150(2): 301-311. 
Lawrence, M., Shu, C. K., Ho, C. T. and Manley, C. M. (1993). "Essential oils as components of mixtures: their method of analysis and differentiation." Flavor Measurement, Marcel Dekker, New York.

Lee, S. J., Umano, K., Shibamoto, T. and Lee, K. (2005). "Identification of volatile components in basil (Ocimum basilicum L.). and thyme leaves (Thymus vulgaris L.) and their antioxidant properties." Food Chem. Toxicol. 91: 131-137.

Marotti, M., Piccaglia, R. and Giovanelli, E. (1996). "Differences in essential oil composition of basil (Ocimum basilicum L.) italian cultivars related to morphological characteristics." J. Agric. Food Chem. 44: 3926-3929.

Merz, K. H. and Schrenk, D. (2016). "Interim relative potency factors for the toxicological risk assessment of pyrrolizidine alkaloids in food and herbal medicines." Toxicol. Lett. 263: 44-57. from http://dx.doi.org/10.1016/j.toxlet.2016.05.002.

Miele, M., Dondero, R., Ciarallo, G. and Mazzei, M. (2001). "Methyleugenol in Ocimum basilicum L. Cv. genovese gigante." Journal of agricultural and food chemistry 49(1): 517-521. from http://www.ncbi.nlm.nih.gov/pubmed/11170620.

Miller, E. C., Swanson, A. B., Phillips, D. H., Fletcher, T. L., Liem, A. and Miller, J. A. (1983). "Structure-activity studies of the carcinogenicities in the mouse and rat of some naturally occurring and synthetic alkenylbenzene derivatives related to safrole and estragole." Cancer research 43(3): 1124-1134. from

http://www.ncbi.nlm.nih.gov/pubmed/6825084.

NTP (2000). "Toxicology and Carcinogenesis Studies of Methyleugenol (CAS NO. 93-15-2) in F344/N Rats and B6C3F1 Mice (Gavage Studies)." National Toxicology Program technical report $\quad$ series 491: 1-412. from http://www.ncbi.nlm.nih.gov/pubmed/12563349.

Phillips, D. H., Miller, J. A., Miller, E. C. and Adams, B. (1981). "Structures of the DNA adducts formed in mouse liver after administration of the proximate hepatocarcinogen 1'-hydroxyestragole." Cancer Res. 41: 176-186.

Punt, A., Paini, A., Boersma, M. G., Freidig, A. P., Delatour, T., Scholz, G., Schilter, B., van Bladeren, P. J. and Rietjens, I. M. C. M. (2009). "Use of physiologically based biokinetic (PBBK) modeling to study estragole bioactivation and detoxification in humans as compared with male rats." Toxicological sciences : an official journal of the Society of Toxicology 110(2): 255-269. from http://www.ncbi.nlm.nih.gov/pubmed/19447879. 
Randerath, K., Haglund, R. E., Phillips, D. H. and Reddy, M. V. (1984). "32P-post-labelling analysis of DNA adducts formed in the livers of animals treated with safrole, estragole and other naturally-occurring alkenylbenzenes. I. Adult female CD-1 mice." Carcinogenesis 5(12): 1613-1622. from http://www.ncbi.nlm.nih.gov/pubmed/6499112.

Salvadeo, P., Boggia, R., Evangelisti, F. and Zunin, P. (2007). "Analysis of the volatile fraction of Pesto Genovese by headspace sorptive extraction (HSSE)." Food Chem. J. 105(3): 1228-1235.

SCF (2001a). "Opinion of the Scientific Committee on Food on Estragole (1-allyl-4methoxybenzene)." European Commission Health \& Consumer Protection Directorate-General. from http://ec.europa.eu/food/fs/sc/scf/out104_en.pdf

SCF (2001b). "Opinion of the Scientific Committee on Food on Methyleugenol (1-allyl-1,2dimethoxybenzene)." European Commission Health \& Consumer Protection Directorate-General. from http://ec.europa.eu/food/fs/sc/scf/out102_en.pdf

SCF (2002). "Opinion of the Scientific Committee on Food on the safety of the presence of safrole (1-allyl-3,4-methylene dioxybenzene) in flavourings and other food ingredients with flavouring properties." European Commission Health \& Consumer Protection Directorate-General. from http://ec.europa.eu/food/fs/sc/scf/out116_en.pdf

Sheen, L. Y., Tsai Ou, Y. H. and Tsai, S. J. (1991). "Flavor characteristic compounds found in the essential oil of Ocimum basilicum L: with sensory evaluation and statistical analysis." J. Agric. Food Chem. 39 939-943.

Siano, F., Ghizzoni, C., Gionfriddo, F., Colombo, E., Servillo, L. and Castaldo, D. (2003). "Determination of estragole, safrole and eugenol methyl ether in food products." Food Chem. J. 81: 469-475.

Smith, B., Cadby, P., Leblanc, J. C. and Setzer, R. W. (2010). "Application of the margin of exposure (MoE) approach to substances in food that are genotoxic and carcinogenic: example: methyleugenol, CASRN: 93-15-2." Food and chemical toxicology : an international journal published for the British Industrial Biological Research

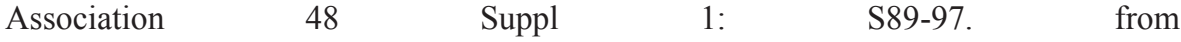
http://www.ncbi.nlm.nih.gov/pubmed/20113858.

Tsai, S. J. and Sheen, L. Y. (1987). "Essential Oil of Ocimum Basilicum L. Cultivated in Taiwan." W. Sze, F.C. Woo (Eds.), Trends in food science. Proceedings of the 7th World Congress of Food Science and Technology, Singapore Institute of Food Science and Technology, Singapore: 66-70. 
Van den Berg, M., Birnbaum, L. S., Denison, M., De Vito, M., Farland, W., Feeley, M., Fiedler, H., Hakansson, H., Hanberg, A., Haws, L., Rose, M., Safe, S., Schrenk, D., Tohyama, C., Tritscher, A., Tuomisto, J., Tysklind, M., Walker, N. and Peterson, R. E. (2006 ). "The 2005 World Health Organization reevaluation of human and Mammalian toxic equivalency factors for dioxins and dioxin-like compounds." Toxicol. Sci. 93 223-241.

van den Berg, S. J. P. L., Restani, P., Boersma, M., Delmulle, L. and Rietjens, I. M. C. M. (2011). "Levels of genotoxic and carcinogenic ingredients in plant food supplements and associated risk assessment." Food and Nutrition Sciences 2(9): 989-1010.

Zhou, G. D., Moorthy, B., Bi, J., Donnelly, K. C. and Randerath, K. (2007). "DNA adducts from alkoxyallylbenzene herb and spice constituents in cultured human (HepG2) cells." Environmental and molecular mutagenesis 48(9): 715-721. from http://www.ncbi.nlm.nih.gov/pubmed/17948277. 


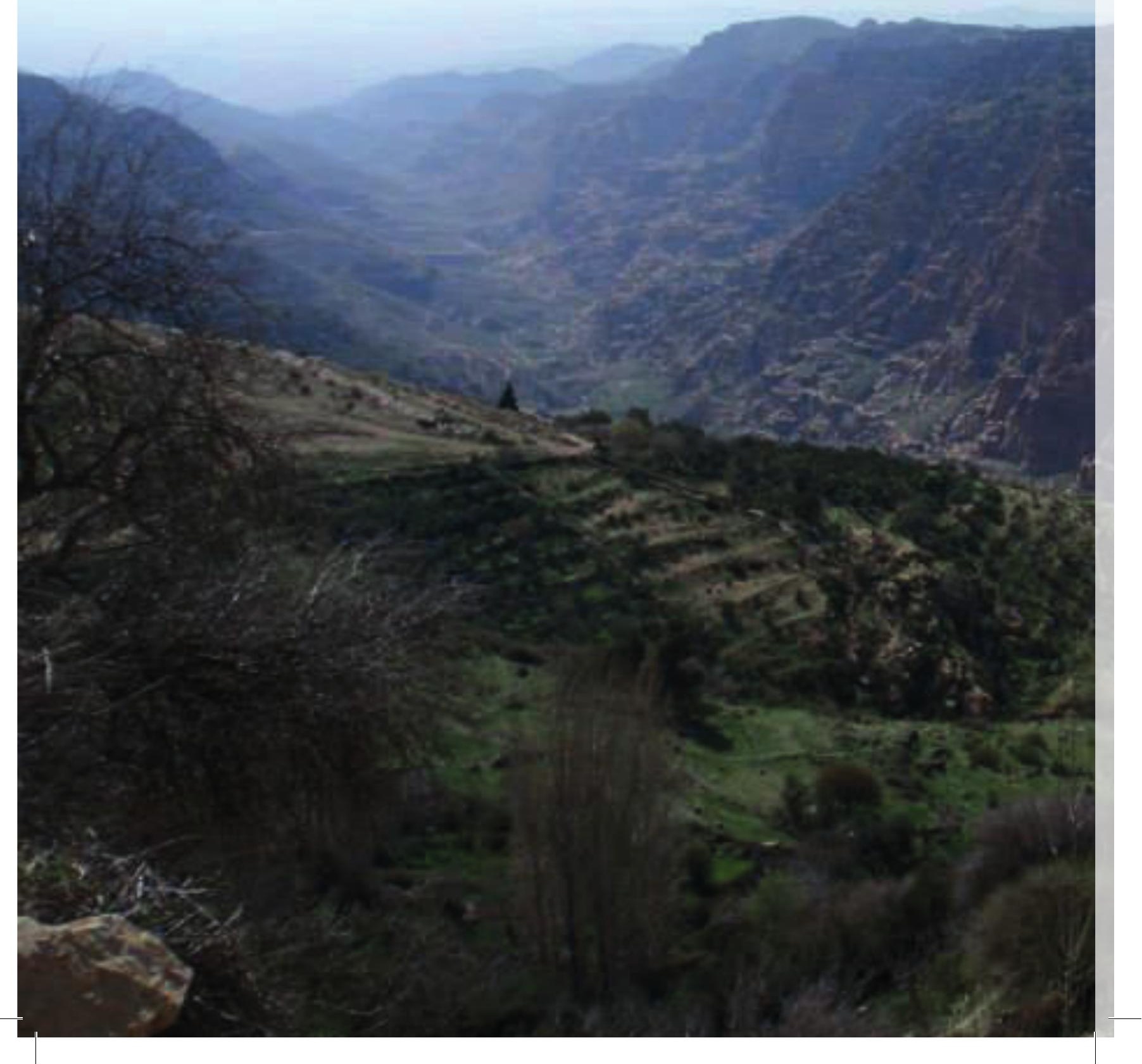




\section{Chapter 5}

\section{Determination and risk assessment of naturally occurring genotoxic and carcinogenic alkenylbenzenes in nutmeg-based plant food supplements}

Amer J. Al-Malahmeh, Abdalmajeed M. Alajlouni, Jia Ning, Sebastiaan Wesseling, Jacques Vervoort, Ivonne M.C.M. Rietjens

Journal of Applied Toxicology (2017)

Doi:10.1002/jat.3491 


\begin{abstract}
A risk assessment of nutmeg-based plant food supplements (PFS) containing different alkenylbenzenes was performed based on the alkenylbenzene levels quantified in a series of PFS collected via the online market. The estimated daily intake (EDI) of the alkenylbenzenes amounted to 0.3 to $312 \mu \mathrm{g} \mathrm{kg}-1$ body weight (bw) for individual alkenylbenzenes, to 1.5 to 631 $\mu \mathrm{gg}^{-1}$ bw when adding up the alkenylbenzene levels assuming equal potency, and to 0.4 to 295 $\mu \mathrm{gg}^{-1}$ bw when expressed in safrole equivalents using toxic equivalency factors (TEFs). The margin of exposure approach (MOE) was used to evaluate the potential risks. Independent of the method used for the intake estimate, the MOE values obtained were generally lower than 10000 indicating a priority for risk management. When taking into account that PFS may be used for shorter periods of time and using Haber's rule to correct for shorter than lifetime exposure it was shown that limiting exposure to only 1 or 2 weeks would result in MOE values that would be, with the presently determined levels of alkenylbenzenes and proposed uses of the PFS, of low priority for risk management $(\mathrm{MOE}>10000)$. It is concluded that the results of the present paper reveal that nutmeg-based PFS consumption following recommendations for daily intake especially for longer periods of time raise a concern.
\end{abstract}

Keywords: margin of exposure (MOE); plant food supplement (PFS); nutmeg-based PFS; alkenylbenzenes; combined risk assessment; toxic equivalency factors (TEFs) 


\section{INTRODUCTION}

Plant food supplements (PFS) are concentrated sources of dietary ingredients derived from various plants and herbal extracts. PFS are usually marketed in the form of capsules or powder and are supposed to supplement the normal diet. Regional regulations, consumer awareness, product availability and acceptance all affect the market for herbal supplements. The global herbal supplement market witnessed fast growth over the last decade and is expected to reach US\$112 billion by the end of the year 2020 (Strategyr, 2015), with Europe accounting for the largest share of the world market (Vargas-Murga et al., 2011). In the US, the supplement industry is approximately $\$ 36.7$ billion (Bradley, 2015). Online marketing of PFS has been increasing, and the sale online is expected to be of growing interest (Vargas-Murga et al., 2011). The need for stricter control and safety testing of PFS products is becoming more vital to protect consumers against adverse health effects. Some PFS may consist (in part) of botanicals and/or botanical preparations that contain compounds that are of concern for human health. Previously, some general concerns related to the quality and safety of botanical preparations such as PFS were expressed by the European Food Safety Authority (EFSA), and a compendium listing botanicals known to contain naturally occurring substances of possible concern for human health when used in food and food supplements was published (EFSA, 2012a). Specific concerns were expressed over the presence of naturally occurring toxic compounds (EFSA, 2004). The group of alkenylbenzenes, for example, contains compounds such as estragole, methyleugenol,

safrole, elemicin, myristicin and apiol (Figure 1), that are genotoxic and carcinogenic, and may be present in botanicals like basil, nutmeg, tarragon and fennel (SCF, 2001a, b, 2002; Rietjens et al., 2008). Nutmeg is derived from several species of trees in the genus Myristica, mostly from Myristica fragrans, and known to contain, in addition to methyleugenol and safrole, especially 
another alkenylbenzene, namely myristicin (van den Berg et al., 2011; Britannica, 2016). In 2001, The Scientific Committee on Food (SCF) concluded that the structural analogues, methyleugenol, estragole, and safrole are genotoxic and carcinogenic and indicated the need for a reduction in exposure and restrictions in the levels of use (SCF, 2001a, b, 2002). Rodent studies performed at high dose levels provided sufficient evidence of the hepatocarcinogenicity of methyleugenol, estragole and safrole, displaying similar characteristics regarding mode of action and tumor formation (Phillips et al., 1981; Miller et al., 1983; Randerath et al., 1984; Wiseman et al., 1985; NTP, 2000; Zhou et al., 2007; Kobets et al., 2016). EC Regulation 1334/2008, which became effective in January 2011, prohibits the addition of methyleugenol, estragole and safrole to foods and restricts their concentration in certain compound food as consumed to which flavorings and/or food ingredients with flavoring properties have been added (European Commission, 2008).<smiles>C=CCc1ccc(OC)cc1</smiles>
estragole<smiles>C=CCc1ccc2c(c1)OCO2</smiles>

safrole methyleugenol<smiles>C=CCc1cc(OC)c2c(c1)OCO2</smiles>

myristicin<smiles>C=CCc1cc(OC)c(OC)c(OC)c1</smiles>

elemicin<smiles>C=CCc1cc(OC)c2c(c1OC)OCO2</smiles>

apiol

Figure 1. The structural formulas of the alkenylbenzenes estragole, methyleugenol, elemicin, safrole, myristicin and apiol 
A major issue in the assessment of the potential risks of human exposure to these genotoxic and carcinogenic compounds via the use of alkenylbenzene-containing PFS is how to perform this assessment (EFSA, 2005). For compounds that are both genotoxic and carcinogenic, the EFSA recommended the Margin of Exposure (MOE) approach to evaluate the priority for risk management actions (EFSA, 2005, 2009a). The MOE compares the exposure levels causing malignant tumors in experimental animals with dietary intake estimates (EDI) in humans, considering differences in consumption patterns. To obtain the MOE, EFSA recommends the use of the $\mathrm{BMDL}_{10}$ (the lower confidence limit of the benchmark dose resulting in $10 \%$ extra cancer incidence) (EFSA, 2009b). The BMDL $_{10}$ is a standardized reference point derived, by mathematical modelling, from the animal data within the observed range of experimental data (EFSA, 2009a). Using the MOE approach, van den Berg et al. (2011) revealed that 25 out of 28 PFS samples containing botanicals including basil, fennel, sassafras, nutmeg, cinnamon, and calamus had alkenylbenzenes at levels that would result in estimated daily intakes that would give rise to MOE values below 10000, indicating a priority for risk management. The aim of the present study was to make a more detailed and extended analysis of the presence of different alkenylbenzenes in nutmeg-based PFS and perform an associated risk assessment based on the MOE approach, taking into consideration the possible combined exposure to different alkenylbenzenes. To this end, the level of alkenylbenzenes in various nutmeg-containing PFS was quantified providing the basis for the risk assessment. In this risk assessment, combined exposure to different alkenylbenzenes was also taken into account. For this group of botanical ingredients combined exposure can be evaluated by dose addition, which is considered appropriate for mixtures with components acting by a similar mode of action, at a similar target organ, i.e. causing liver carcinogenicity (EPA, 1986a, 1988, 2000). This implies that the response 
to the mixture can be predicted by summing the doses of the components, if needed, after adjusting for the differences in potencies using toxic equivalency factors (TEFs) (ATSDR, 2004).

\section{MATERIALS AND METHODS}

\section{Nutmeg-based PFS samples and chemicals}

Nutmeg-based PFS samples were purchased online. Table 1 presents an overview of the collected samples and their major characteristics as indicated on the label of each product. Methyleugenol, myristicin, and safrole (purity, > 97\%), methanol (HPLC grade) and acetonitrile (LC/MS grade) were supplied by Sigma-Aldrich (Zwijndrecht, Netherland). Elemicin was obtained from Synchem OHG (Felsberg, Germany). Nano pure water was obtained from a Barnstead Nanopure Type I ultrapure water system. Dimethyl sulfoxide (DMSO) was obtained from Acros Organics (Geel, Belgium). Acetonitrile (ACN) (LC/MS grade) was purchased from Biosolve BV (Valkenswaard, The Netherlands). Trifluoroacetic acid (TFA) was obtained from Merck (Darmstadt, Germany).

\section{Methanol extracts}

All nutmeg-based PFS samples were extracted using methanol based on the method described by Gursale et al. (2010) with minor modifications. In short, $0.5 \mathrm{~g}$ of each PFS sample was sonicated in an ultrasonic bath for 10 min followed by maceration for $12-\mathrm{hr}$ at $50^{\circ} \mathrm{C}$ with $80 \mathrm{ml}$ of methanol in a closed glass vessel. Finally, an aliquot of the extract solution was centrifuged at $13000 \times \mathrm{g}$ for $5 \mathrm{~min}$, and stored at $20^{\circ} \mathrm{C}$ until Ultra Performance Liquid Chromatography (UPLC) analysis. Samples were extracted and analysed on UPLC in three independent experiments. The 
accuracy of the developed method was assessed using a recovery study and standard deviations of the replicates. For recovery studies, pure standards of commercially available alkenylbenzenes were added in two different quantities (final concentration of 5 and $10 \mu \mathrm{M}$ ) to $0.5 \mathrm{~g}$ of two PFS samples (sample 5 and 8) which covers the whole range of analyses. Samples were prepared and analyzed as described above to quantify the alkenylbenzene levels enabling determination of the recovery. The extraction capacity linearity was demonstrated by analysing a range of weight of the sample to a final volume of the solution ratio of $0.3 \%$ up to $1 \%(\mathrm{w} / \mathrm{v})$.

\section{UPLC analysis}

For the determination of the alkenylbenzene level in the extracts, $3.5 \mu$ of each sample was subjected to UPLC analysis. The UPLC system consisted of a Waters (Milford, MA, USA) Acquity solvent manager, sample manager and photodiode array detector. Chromatographic conditions for compound separation were achieved using an ACQUITY UPLC BEH C18

$1.7 \mu \mathrm{m}$ column, $2.1 \times 50 \mathrm{~mm}$. The column oven was set at $35^{\circ} \mathrm{C}$ and the sample compartment was set at $10^{\circ} \mathrm{C}$. An isocratic gradient was maintained for the separation using a mixture of acetonitrile $(\mathrm{ACN})$ and ultrapure water containing $0.1 \%(\mathrm{v} / \mathrm{v})$ trifluoroacetic acid (TFA). The mobile phase consisted of $40 \%$ acetonitrile for $4 \mathrm{~min}$, which was the time needed to separate the alkenylbenzenes of interest. During the whole run, the flow rate was $0.6 \mathrm{ml} \mathrm{min}{ }^{-1}$. Under these conditions, the retention times for elemicin, methyleugenol, safrole, and myristicin were 1.4, 2.1, 2.2 and 2.4 min, respectively. Identification of the alkenylbenzenes was achieved by comparing the UV spectrum and retention time of the peak to the UV spectrum and the peak retention time of commercially available reference compounds. Quantification was done by comparison of the area of the alkenylbenzene peak to that of the calibration curve of the reference compound 
Chapter 5 | Risk assessment of alkenylbenzenes in nutmeg-based plant food supplements

Table 1. Nutmeg-based PFS samples used in the present study and their major characteristics. Information provided was derived from the product labels unless stated otherwise

\begin{tabular}{|c|c|c|c|}
\hline PFS sample & Description & Ingredients & Recommendation for daily intake \\
\hline 1 & $\begin{array}{l}\text { Ayurvedic nutmeg herbal } \\
\text { supplement "complementary } \\
\text { or alternative medicine" }\end{array}$ & $\begin{array}{l}\text { Nutmeg powder (Myristica fragrans). Capsule } \\
\text { content: } 330 \mathrm{mg}\end{array}$ & 2 capsules $(660 \mathrm{mg})$ \\
\hline 2 & Dietary supplement & $\begin{array}{l}\text { Nutmeg powder (Myristica fragrans). Capsule } \\
\text { content: } 750 \mathrm{mg}\end{array}$ & $1-5$ capsules $(3750 \mathrm{mg})$ \\
\hline 3 & Dietary supplement & $\begin{array}{l}\text { Nutmeg powder (Myristica fragrans). Capsule } \\
\text { content: } 600 \mathrm{mg}\end{array}$ & $\begin{array}{l}2 \text { capsules, }(1200 \mathrm{mg}) \text { with water } \\
\text { at meal time }\end{array}$ \\
\hline 4 & $\begin{array}{l}\text { Nutmeg herbal supplement } \\
\text { "complementary or alternative } \\
\text { medicine" }\end{array}$ & $\begin{array}{l}\text { Nutmeg powder (Myristica fragrans). Capsule } \\
\text { content: } 360 \mathrm{mg}\end{array}$ & $1-3$ capsules $(360 \mathrm{mg})$ \\
\hline 5 & $\begin{array}{l}100 \% \text { pure nutmeg } \\
\text { Therapeutic grade essential oil } \\
\text { supplement }\end{array}$ & $\begin{array}{l}\text { Essential oil of nutmeg. Every drop is around } \\
72 \mathrm{mg}\end{array}$ & $\begin{array}{l}\text { Dilute } 1 \text { drop with } 1 \text { drop of } \mathrm{V}-6^{\mathrm{TM}} \\
\text { or olive oil. Put in a capsule and } \\
\text { takes up to three times daily or as } \\
\text { needed }(216 \mathrm{mg})\end{array}$ \\
\hline 6 & $\begin{array}{l}\text { Ayurvedic invigorates male } \\
\text { sexual vitality herbal } \\
\text { supplement }\end{array}$ & $\begin{array}{l}\text { Blend of cinnamon camphora, nutmeg } \\
\text { (Myristica fragrans), hygrophila auriculata, } \\
\text { tribulus terrestris, withania somnifera, asparagus } \\
\text { recemosus, cardamom, dioscorea sativa, shilajit, } \\
\text { processed silica. Capsule content: } 350 \mathrm{mg}\end{array}$ & $\begin{array}{l}4 \text { capsules, } 15-30 \text { minutes after } \\
\text { meals, daily over a period of at } \\
\text { least } 2-3 \text { months }(1400 \mathrm{mg})\end{array}$ \\
\hline 7 & $\begin{array}{l}\text { Weight loss formula and clean } \\
\text { sensory experience, dietry } \\
\text { supplement. }\end{array}$ & $\begin{array}{l}\text { Super xtreme supergenic complex of: green } \\
\text { coffee bean extract (52.6\%), caffeine anhydrous } \\
(17.8 \%) \text {, nutmeg seed extract (Myristica } \\
\text { fragrans) }(13.2 \%) \text {, sage leaf powder (salvia } \\
\text { officinalis) }(6.5 \%) \text {, alpha lipoic acid }(3.3 \%), \\
\text { cocoa seed extract (theobroma cacao) }(3.3 \%), \\
\text { green tea leaf and shoot extract (camellia } \\
\text { sinensis) }(3.3 \%) \text {. Capsule content: } 760 \mathrm{mg}\end{array}$ & 3 capsules $(2280 \mathrm{mg})$ \\
\hline 8 & Nutmeg herbal supplement & $\begin{array}{l}\text { Nutmeg powder (Myristica fragrans). Capsule } \\
\text { content: } 100 \mathrm{mg}\end{array}$ & 6 capsules $(600 \mathrm{mg})$ \\
\hline 9 & Nutmeg herbal supplement & $\begin{array}{l}\text { Nutmeg powder (Myristica fragrans). Capsule } \\
\text { content: } 900 \mathrm{mg}\end{array}$ & 2 capsules $(1800 \mathrm{mg})$ \\
\hline 10 & $\begin{array}{l}\text { Organic nutmeg herbal } \\
\text { supplement seed capsules }\end{array}$ & $\begin{array}{l}\text { Nutmeg powder (Myristica fragrans). Capsule } \\
\text { content: } 465 \mathrm{mg}\end{array}$ & 2 capsules $(930 \mathrm{mg})$ \\
\hline 11 & $\begin{array}{l}\text { Herbal supplement, Vigor care } \\
\text { for woman, for female libido } \\
\text { support, help maintain normal } \\
\text { sexual desire }\end{array}$ & $\begin{array}{l}\text { Mix of: ashwagandha (root), nutmeg (aril), } \\
\text { lodh tree (bark), cyperus (tuber), spanish } \\
\text { pellitory (root), ginger (rhizome). Capsule } \\
\text { content: } 820 \mathrm{mg}\end{array}$ & 2 capsules $(1640 \mathrm{mg})$ \\
\hline 12 & $\begin{array}{l}\text { Organic nutmeg seed capsules, } \\
\text { herbal dietry supplement }\end{array}$ & $\begin{array}{l}\text { Organic nutmeg seed, pure herb (Myristica } \\
\text { fragrans). Capsule content: } 470 \mathrm{mg}\end{array}$ & 1-2 capsules, $2-3$ times $(940 \mathrm{mg}$ ) \\
\hline 13 & Nutmeg herbal supplement & $\begin{array}{l}\text { Nutmeg powder (Myristica fragrans). Capsule } \\
\text { content: } 400 \mathrm{mg}\end{array}$ & $1-2$ capsules $(400 \mathrm{mg})$ \\
\hline
\end{tabular}


determined using UPLC with photodiode array detection (UPLC/PDA) at a wavelength $201 \mathrm{~nm}$ for elemicin and methyleugenol, and a wavelength $210 \mathrm{~nm}$ for myristicin and safrole.

\section{Determination of EDI of alkenylbenzenes resulting from the use of nutmeg-based PFS}

The EDI of alkenylbenzenes resulting from the use of the nutmeg based PFS was determined based on the alkenylbenzene content as determined in the present study (see Results) and a body weight of $70 \mathrm{~kg}$, the default value for adult body weight proposed by EFSA (EFSA, 2012b). Daily consumption of nutmeg-based PFS was also based on the recommendation for daily intake provided by the manufacturer and the amount of the material stated on the label to be present in each capsule or drop (Table 1). First, the EDI was calculated for individual compounds for all the samples. As several samples were found to contain more than one alkenylbenzene, and the different alkenylbenzenes show similarity in structure, target organ, type of adverse effects and mode of action through formation of a DNA reactive 1'-sulfoxymetabolite contributing to formation of liver tumors, a combined exposure assessment and subsequent risk assessment were also performed for those samples. To this end two approaches were used; summing up the EDIs of the alkenylbenzenes assuming equal potency, and a so-called toxic equivalency (TEQ) approach calculating the EDI values of the alkenylbenzenes using their TEF relative to safrole (Alajlouni et al., 2016b). In this study, safrole was taken as the reference compound (TEF $=1.0$ ), enabling expression of the overall alkenylbenzene concentration and EDI in safrole equivalents. TEF values for the different alkenylbenzenes for the TEQ approach need to be defined, which was done by calculating an average of three endpoints. The first one was the slope of the doseresponse curve for DNA-adduct formation in female CD-1 mice liver upon exposure to different alkenylbenzenes (Randerath et al., 1984). The second one, was the in vivo level of formation of 
the hepatocarcinogenic 1'-sulfoxymetabolite of the different alkenylbenzenes predicted using human physiologically based kinetic (PBK) models at a dose level of $0.01 \mathrm{mg} \mathrm{kg}^{-1}$ bw (Punt et al., 2009; Al-Subeihi et al., 2012;Martati et al., 2012; van den Berg et al., 2012; Alajlouni et al., 2016a; Al-Malahmeh et al., 2017). A third value was defined based on the BMDL 10 values derived from in vivo tumor data for safrole, estragole and methyleugenol (Miller et al., 1983), and by read-across from safrole for myristicin and apiol (Alajlouni et al., 2016a; Al-Malahmeh et al., 2017), or by read-across from methyleugenol and estragole for elemicin (van den Berg et al., 2012). The TEF values for the different alkenylbenzenes defined by the three approaches relative to safrole were subsequently averaged to define the final TEF values (Alajlouni et al., 2016b). Using these TEF values, the EDI of alkenylbenzenes in the nutmeg-based PFS were expressed in $\mu \mathrm{g}$ safrole equivalents $\mathrm{kg}^{-1}$ bw per day.

\section{Calculation of the margin of exposure}

Risk assessment of consumption of the nutmeg-based PFS samples was performed using the MOE approach (EFSA, 2005). For the individual alkenylbenzene approach, the $\mathrm{BMDL}_{10}$ values of the individual compounds were used (van den Berg et al., 2012; Alajlouni et al., 2016a; AlMalahmeh et al., 2017), and then compared with the EDIs of the alkenylbenzenes resulting from the use of nutmeg-based PFS. For the equal potency assumption approach, the BMDL 10 value of myristicin, the major alkenylbenzene in most of the samples, was used and compared to the sum of the EDIs. And finally, for the TEQ approach, the BMDL 10 of the reference compound safrole was compared to the EDI expressed in safrole equivalents. 


\section{RESULTS}

Table 2 presents the level of the different alkenylbenzenes found in the PFS samples. In eight PFS samples, four different alkenylbenzenes were detected including elemicin, methyleugenol, myristicin and safrole. In PFS 6, elemicin and myristicin were detected. Elemicin, myristicin, and safrole were detected in PFS 10, and elemicin, methyleugenol, and safrole in PFS 12. PFS 7 and PFS 11 did not contain a detectable level of any of the alkenylbenzenes. Table 2 also presents the EDI of the individual alkenylbenzenes obtained for these samples when considering the recommended dose regimen. The values obtained varied from 0.3 to $312 \mu \mathrm{g} \mathrm{kg}^{-1}$ bw per day with myristicin being the major alkenylbenzene. Figure 2 presents the relative contribution of the different alkenylbenzenes to the total alkenylbenzene content of the different PFS and shows that myristicin makes up 18.5 to $85.1 \%$ of the sum of all alkenylbenzenes, followed by elemicin making up 3.7 to $81.5 \%$, then safrole making up 8.8 to $25.1 \%$, and finally methyleugenol being the minor alkenylbenzene making up 2.4 to $21.0 \%$. As several alkenylbenzenes were found in the samples, and because these alkenylbenzenes are known to display similarity in structure, target organ, type of adverse effects and mode of action through the formation of a DNA reactive 10-sulfoxymetabolite contributing to the formation of liver tumors, a combined exposure and risk assessment were also performed. To this end, the combined exposure was estimated in two ways, assuming either equal potency or using a so-called TEQ approach. When assuming equal potency of the different alkenylbenzenes the combined EDI can be calculated by adding up the EDIs of the different alkenylbenzenes. In a second approach, the combined exposure was calculated in safrole equivalents taking the relative potency of the different alkenylbenzenes into account. Using the equal potency approach, the combined EDI values obtained vary in the range 
of 1.5 to $631 \mu \mathrm{g} \mathrm{kg}^{-1}$ bw per day. Using TEF values and the TEQ the combined EDI values obtained vary in the range of 0.4 to $295 \mu \mathrm{g}$ safrole equivalents $\mathrm{kg}^{-1}$ bw per day (Table 3).

Using the EDI values thus obtained MOE values were calculated. To this end, different BMDL 10 values were used for different approaches to obtain the MOE values. The $\mathrm{BMDL}_{10}$ values for the individual alkenylbenzenes were taken from literature (van den Berg et al., 2012; Alajlouni et al., 2016a; Al-Malahmeh et al., 2017) and were used to calculate MOE values for intakes of each alkenylbenzene (Table 4). MOE values thus obtained were all below 10000 except for elemicin in samples 4 and 6, with MOE values amounting to 10729 and 25877, respectively. Assuming equal potency, the BMDL 10 of myristicin of $1.9 \mathrm{mg} \mathrm{kg}^{-1}$ bw per day (Al-Malahmeh et al., 2017), was compared with the combined EDI, because in most cases myristicin was the major alkenylbenzene detected in the samples. The MOE values thus obtained vary between 3 and 1309 (Table 4). For the TEQ approach, the BMDL 10 of safrole of $1.9 \mathrm{mg} \mathrm{kg}^{-1}$ bw per day (van den Berg et al., 2012) was compared with the EDI expressed in safrole equivalents to calculate the MOE. When using the TEQ approach, MOE values ranged from 6 to 5020 (Table 4). Comparison of the MOE values obtained when using the combined exposure reveals that the values tend to increase when using the TEF concept. This is because the TEF for myristicin, the major alkenylbenzene detected in the samples, is lower than 1.0 resulting in lower EDI and higher MOE values. In spite of these differences, the priority for risk management for the PFS does not vary because the MOE remains below 10000 (in most cases even below 1000). From the data thus obtained it is clear that the EDI resulting from the daily use of the nutmeg-based PFS would generally result in MOE values that indicate a priority for risk management, independent of the way in which the EDI and the MOE were calculated. 


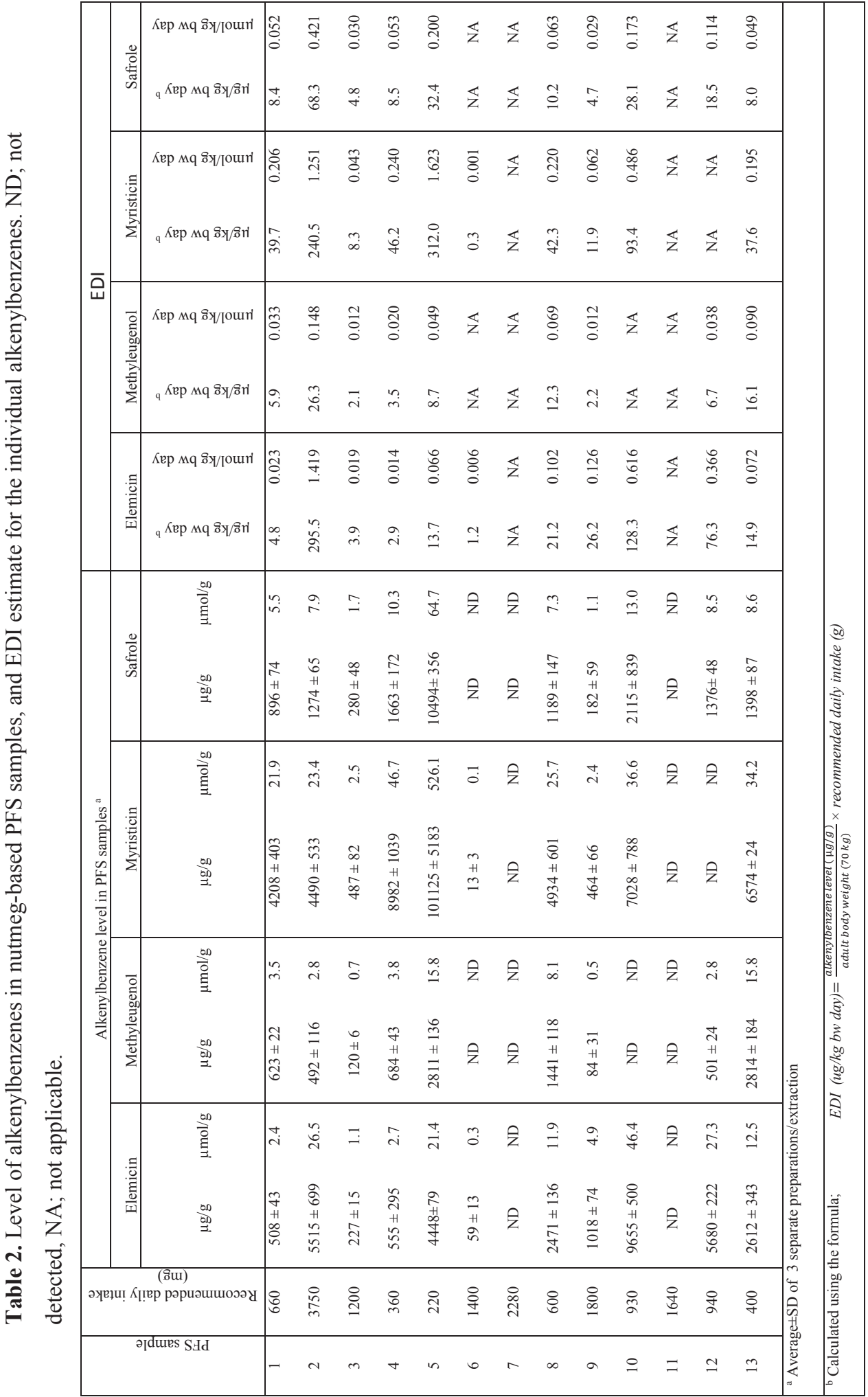




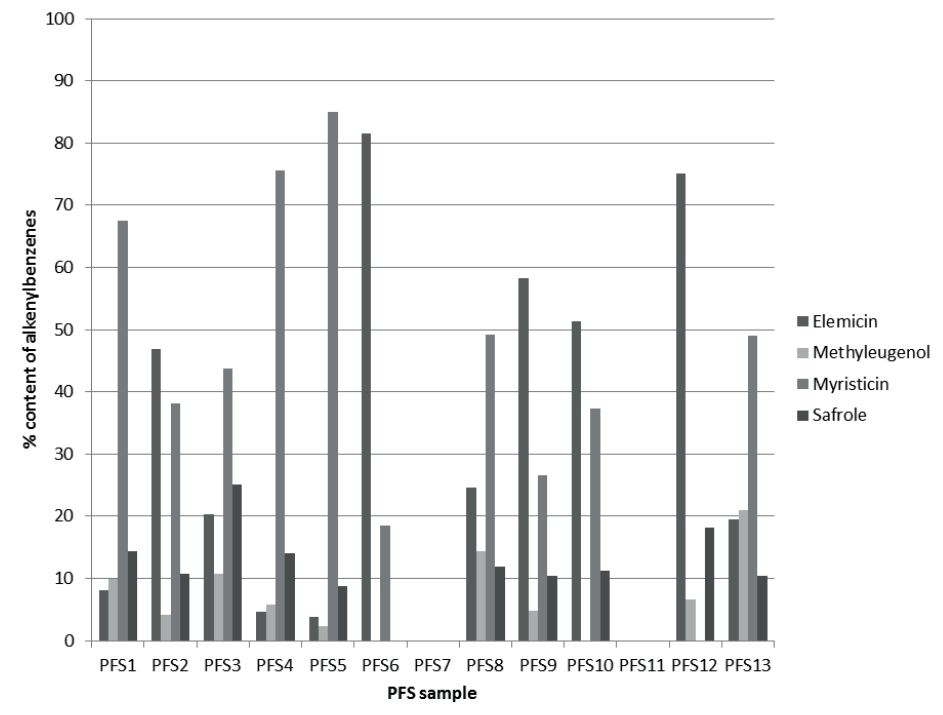

Figure 2. Level of the different alkenylbenzenes in the nutmeg-based plant food supplements (PFS) samples expressed as percentage of the total amount of alkenylbenzenes.

It is of importance; however, to consider that often use of PFS will not be for a lifetime but for shorter periods of time and how this may affect the risk assessment. There is no generally established method for taking a shorter than lifetime exposure into account, but one could consider using Haber's rule. Assuming that Haber's rule would apply, the toxic effect would vary linearly with the time of exposure and the concentration (i.e. $\mathrm{C} \times \mathrm{T}=\mathrm{k}$, where $\mathrm{C}$ is concentration or dose, $\mathrm{T}$ is time of exposure, and $\mathrm{k}$ is a constant toxic response for the specific substance) (Doull and Rozman, 2000). It is of interest to evaluate, using Haber's rule, what level of alkenylbenzenes, what amount of nutmeg-based PFS consumed and/or what exposure frequency would result in an MOE of 10000 and be of low priority for risk management. To this end, Figure 3 shows the relation between the total recommended daily intake of nutmeg-based PFS and the total level of alkenylbenzene in nutmeg-based PFS samples that would result in 
MOE values of 10000 assuming equal potency but different periods of use, including life time (estimated life expectancy of 75 years) (Felter et al., 2011), 4, 2, or 1week in a life time. The results presented indicate that the daily recommended consumption range of samples that contain 216 to $3750 \mathrm{mg}$ nutmeg-based PFS, the range of recommended daily intake (Table 1) would be of low priority for risk management at a total alkenylbenzene level of 61.6 to $3.6 \mu \mathrm{g} \mathrm{g}^{-1}$ for lifetime exposure. Intake of the recommended daily consumption of the nutmeg-based PFS, for limited periods of time, for example, 4, 2 and 1week, would be of low priority for risk management when the PFS would contain total alkenylbenzene levels of 60032 to 3458, 120069 to 6916 , and 240139 to $13832 \mu \mathrm{g} \mathrm{g}^{-1}$, respectively.

Table 3. Combined EDI values for PFS samples, tested positive for the presence of alkenylbenzenes, assuming equal potency and using a TEQ approach

\begin{tabular}{|c|c|c|}
\hline \multirow[b]{2}{*}{ PFS sample } & \multicolumn{2}{|c|}{ EDI } \\
\hline & Equal potency ${ }^{\text {a }}(\mu \mathrm{g} / \mathrm{kg}$ bw day $)$ & $\mathrm{TEQ}^{\mathrm{b}}(\mu \mathrm{g}$ safrole equivalents $/ \mathrm{kg}$ bw) \\
\hline 1 & 58.8 & 39.3 \\
\hline 2 & 631 & 295 \\
\hline 3 & 19.1 & 12.3 \\
\hline 4 & 61.1 & 41.8 \\
\hline 5 & 367 & 246 \\
\hline 6 & 1.5 & 0.4 \\
\hline 8 & 86.0 & 49.9 \\
\hline 9 & 45.0 & 18.5 \\
\hline 10 & 250 & 112 \\
\hline 12 & 102 & 36.0 \\
\hline 13 & 76.6 & 46.0 \\
\hline \multicolumn{3}{|c|}{${ }^{\text {a }}$ Calculated using the formula; $\quad E D I(u g / k g$ bw day $)=\sum_{i} E D I$} \\
\hline \multicolumn{3}{|c|}{$\begin{array}{l}\text { b Calculated using the formula; } \\
i \text {; different alkenylbenzene }\end{array}$} \\
\hline \multicolumn{3}{|c|}{ Average TEF values \pm SD (Alajlouni et al. 2016b) } \\
\hline Safrole & \multicolumn{2}{|l|}{1.00 (the reference compound) } \\
\hline Myristicin & \multicolumn{2}{|l|}{$0.66 \pm 0.39$} \\
\hline Methyleugenol & \multicolumn{2}{|l|}{$0.67 \pm 0.46$} \\
\hline Elemicin & \multicolumn{2}{|l|}{$0.17 \pm 0.16$} \\
\hline
\end{tabular}


The curves can also be used to derive that for the nutmeg-based PFS of the present study with total alkenylbenzene levels that vary from 73 to $118878 \mu \mathrm{g} \mathrm{g} \mathrm{g}^{-1}$ nutmeg-based PFS, daily consumption for a lifetime should be limited to 182 to $0.1 \mathrm{mg}$ of the nutmegbased PFS to be of low concern. For shorter periods of time for example 4, 2, and 1 week, the maximum allowance of consumption of the nutmeg-based PFS for the levels of alkenylbenzenes quantified in this study would be of low priority for risk management when the PFS would contain 177630 to 109 , 355274 to 218 , and 710548 to $436 \mathrm{mg}$ nutmeg-based material. This result also indicates that at the current levels of alkenylbenzenes in nutmeg-based PFS, their proposed uses would be of concern especially for people who use these PFS frequently during longer periods of time.

Table 4. MOE values for PFS, tested positive for presence of alkenylbenzenes, based on EDI values for individual alkenylbenzenes, and on combined EDI values calculated assuming equal potency and using a TEQ approach

\begin{tabular}{|c|c|c|c|c|c|c|}
\hline \multirow{3}{*}{$\begin{array}{c}\text { PFS } \\
\text { Sample }\end{array}$} & \multicolumn{6}{|c|}{ MOE } \\
\hline & \multicolumn{4}{|c|}{ Individual } & \multirow{2}{*}{ Equal potency ${ }^{a}$} & \multirow{2}{*}{$\mathrm{TEQ}^{\mathrm{b}}$} \\
\hline & Elemicin & Methyleugenol & Myristicin & Safrole & & \\
\hline 1 & 6386 & 2604 & 48 & 225 & 32 & 48 \\
\hline 2 & 104 & 581 & 8 & 28 & 3 & 6 \\
\hline 3 & 7870 & 7425 & 228 & 396 & 100 & 154 \\
\hline 4 & 10729 & 4349 & 41 & 222 & 31 & 45 \\
\hline 5 & 2229 & 1764 & 6 & 59 & 5 & 8 \\
\hline 6 & 25877 & NA & 7072 & NA & 1309 & 5020 \\
\hline 8 & 1445 & 1239 & 45 & 186 & 22 & 38 \\
\hline 9 & 1169 & 7062 & 159 & 406 & 42 & 103 \\
\hline 10 & 239 & NA & 20 & 68 & 8 & 17 \\
\hline 12 & 401 & 2272 & NA & 103 & 19 & 53 \\
\hline 13 & 2050 & 952 & 51 & 238 & 25 & 41 \\
\hline
\end{tabular}


To further illustrate how short-term exposure would affect F4 the MOE values, Figure 4 presents a comparison between MOE values obtained for combined exposure during lifetime and 4weeks. Figure 5 shows the number of weeks of daily consumption of nutmeg-based PFS samples analysed in this study that would result in a MOE of 10000 indicating a low priority for risk management.

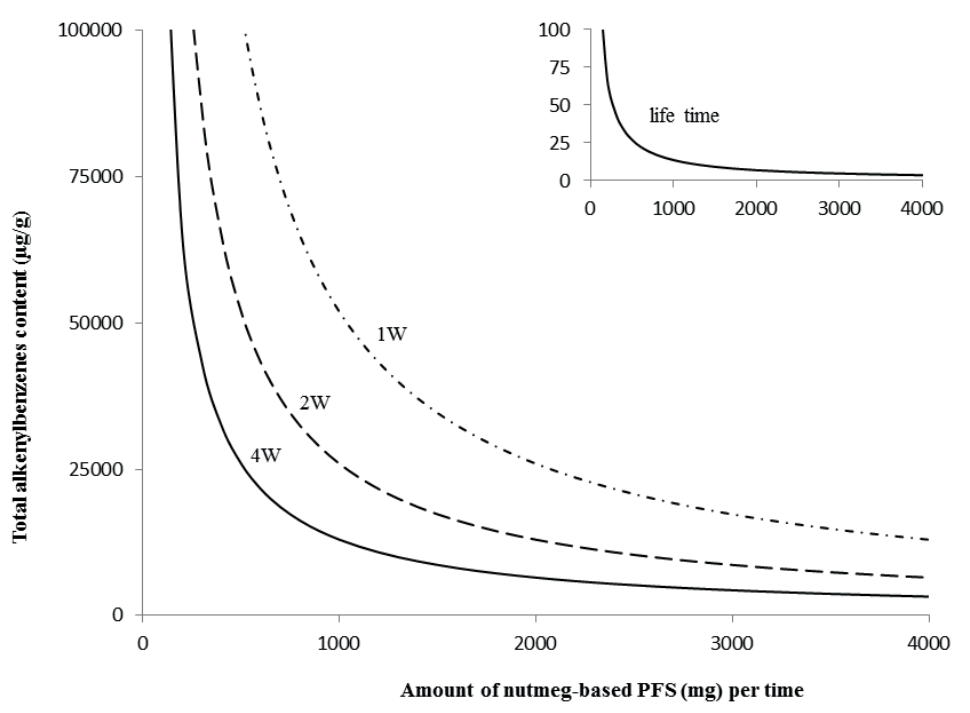

Figure 3. Relation between the total alkenylbenzene content $\left(\mu \mathrm{g} \mathrm{g}^{-1}\right)$ in a nutmeg-based PFS and the recommended daily intake of the PFS (mg), that would result in an MOE of 10000 upon daily consumption for a lifetime (insert), 1 (-•), 2 (--), and 4 weeks (-). The calculations assumed combined exposure and equal potency of the different alkenylbenzenes and uses the BMDL 10 of myristicin, the major alkenylbenzene detected in most PFS. Combinations of total alkenylbenzene levels and nutmeg-based PFS intake that result in values below the respective curves result in MOE values above 10000 and would be of low priority for risk management. W; week. 
Assuming both approaches, the equal potency and the TEQ, the longest time of daily combined exposure that would make the risk of low priority for risk management was for PFS 6 (the sample with the lowest EDI; $1.5 \mu \mathrm{g} \mathrm{kg}^{-1}$ bw day) and amounted to 511 and 1958 weeks, and the shortest time of daily combined exposure to make the risk of low priority was for PFS 2 (the sample with the highest EDI; $631 \mu \mathrm{g} \mathrm{kg}^{-1}$ bw day) amounting to 1 and 3 weeks, respectively.
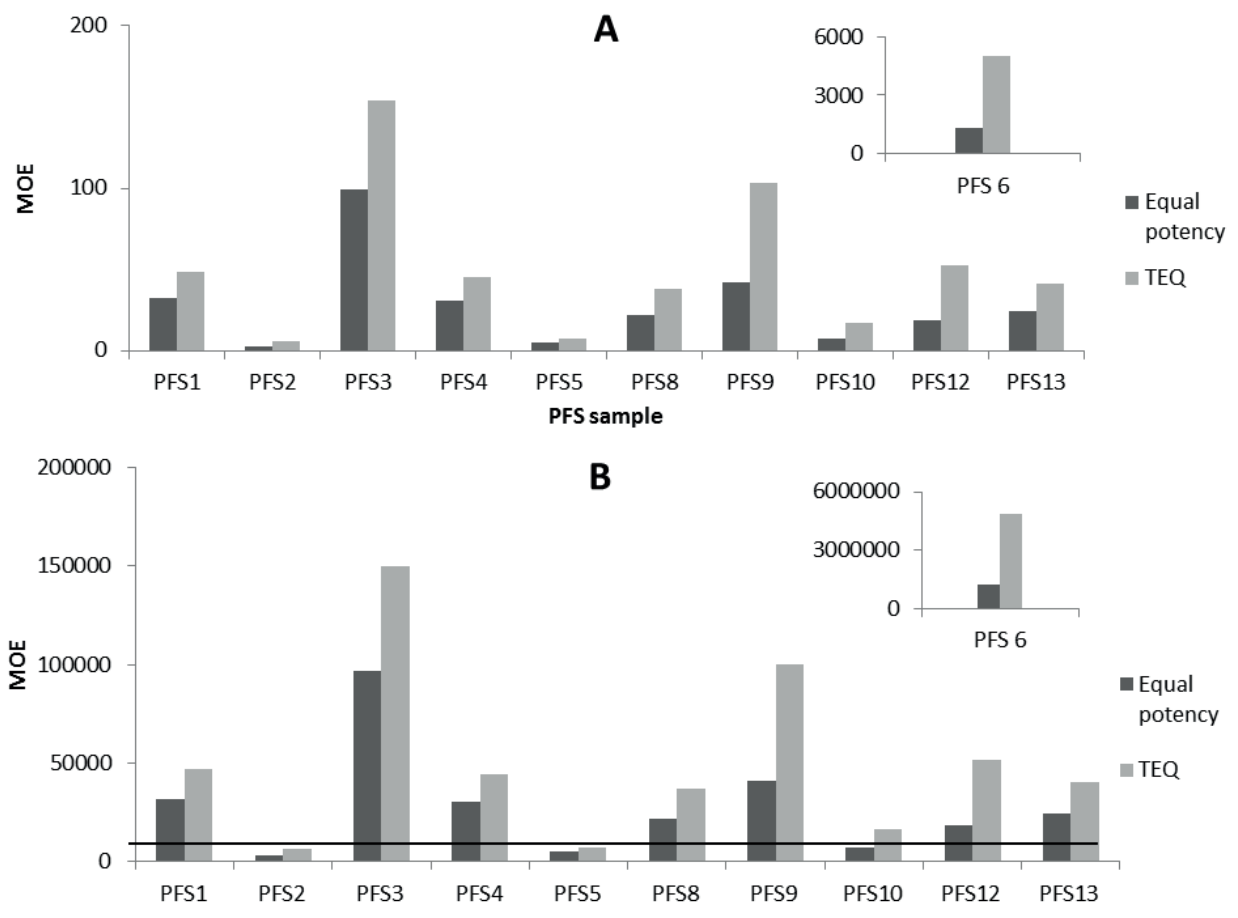

Figure 4. MOE values for the combined exposure assuming equal potency of the alkenylbenzenes and using the $\mathrm{BMDL}_{10}$ value of myristicin (black bars), and combined exposure using the TEQ approach based on safrole equivalents and using the BMDL 10 value of safrole (grey bars), assuming life time intake (A), and 4 weeks intake (B). The black horizontal line in Figure B presents the MOE of 10000. Note the difference in the Y axis of Figure A and B. The values for PFS 6 are presented in the insert at the right top of the graph. 


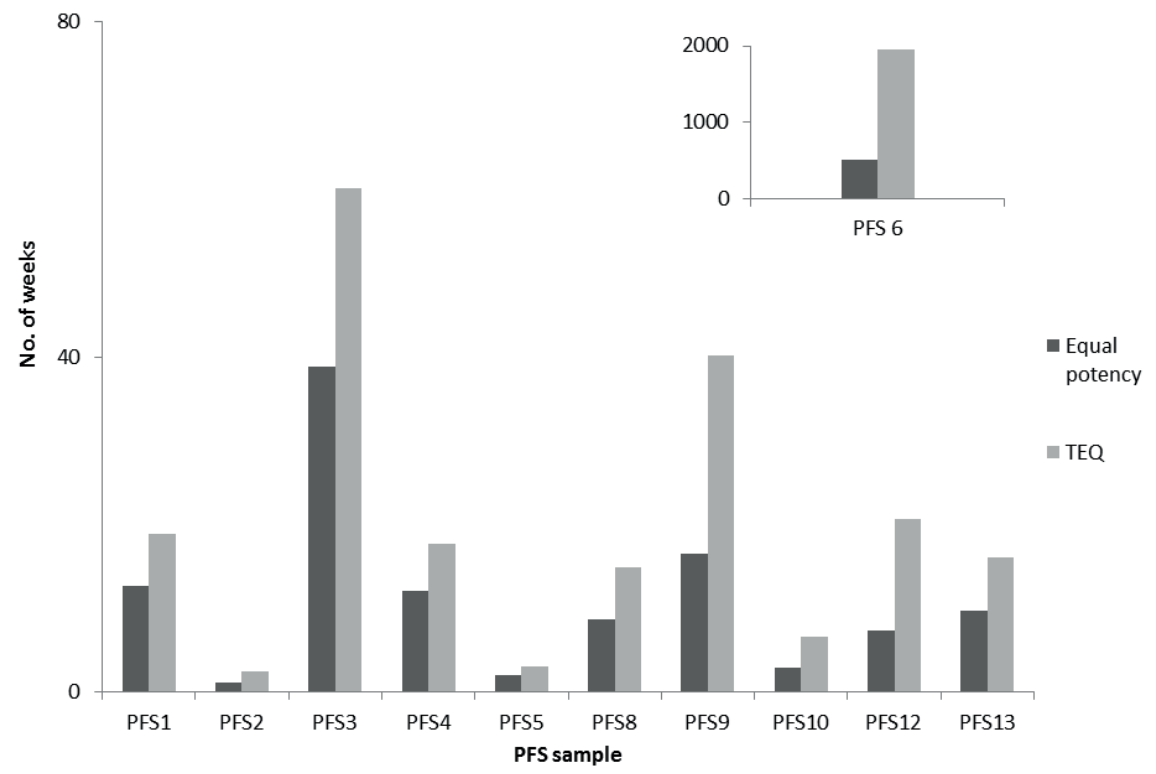

Figure 5. The number of weeks needed that would result in an MOE of 10000 upon daily consumption of nutmeg-based PFS samples analysed in the present study. The calculations assumed combined exposure and equal potency of the different alkenylbenzenes using the $\mathrm{BMDL}_{10}$ of myristicin, the major alkenylbenzene detected in most PFS (black bars), and combined exposure using the TEQ approach based on safrole equivalents and using the BMDL 10 value of safrole (grey bars), also taking into account the total alkenylbenzene content ( $\left.\mu \mathrm{g} \mathrm{g}^{-1}\right)$ of the nutmeg-based PFS obtained in the present study and the recommended daily intake of the PFS (mg) for the analysed samples. The values for PFS 6 are presented in the insert at the right top of the graph. 


\section{DISCUSSION}

The aim of the present study was to make a more detailed and extended analysis of the presence of different alkenylbenzenes in nutmeg-based PFS and perform an associated risk assessment based on the MOE approach, taking into consideration the possible combined exposure to different alkenylbenzenes. Given that the different alkenylbenzenes act by a similar mode of action, at a similar target organ causing liver carcinogenicity (EPA, 1986a, 1988, 2000), combined exposure can be evaluated by dose addition; predicting the response to the mixture by adding up the doses of the components considering equal potency, and/or after adjusting for the differences in potencies, using the TEQ approach (ATSDR, 2004). PFS samples analyzed were made of nutmeg powder alone or from nutmeg combined with material from other botanicals

(Table 1). Nutmeg is obtained from the nutmeg tree, Myristica frangans Houtt (Myristicaceae). The nutmeg seeds contain 5-15\% essential volatile oil and 24-40\% nutmeg butter (Forrest and Heacock, 1972). The relative percentages of the different components and the alkenylbenzenes vary depending on the geographical origin of the nutmeg and length of storage. The compounds that have been isolated and identified in the essential volatile oil were terpenes, monoterpene alcohol, a sesquiterpene, terpinic esters, acids, aromatic hydrocarbons, and our focus in this study; the aromatic ethers (myristicin, safrole, methyleugenol, and elemicin) (FAO, 1994). Levels of myristicin, elemicin, safrole, and methyleugenol detected in the nutmeg-based PFS samples analysed in the present study varied from 13 to 101124 , from 59 to 9655 , from 279 to 10494, and from 84 to $2813 \mu \mathrm{g} \mathrm{g}^{-1}$ nutmeg-based PFS, respectively, with levels of these alkenylbenzenes making up 26.5 to $85.1 \%, 3.7$ to $81.5 \%, 8.8$ to $25.1 \%, 2.4$ to $21.0 \%$ of the total alkenylbenzene content (Figure 2), with myristicin often being the major one detected, followed by elemicin and safrole, and methyleugenol. Literature data indicate that myristicin, 
safrole and elemicin may account for 3.86 to $12.7 \%, 0.53$ to $3.42 \%$ and 0.02 to $2.36 \%$, respectively of the nutmeg oil samples (IPCS, 1997). The wide variation in the alkenylbenzenes content of the different PFS may be caused by the variability between the quality (differences in composition) and quantity of nutmeg oil present in the various plants, depending on plant species, culture conditions, harvesting conditions and processing methods (Smith et al., 2002). Based on the alkenylbenzenes contents detected in the present study and the use levels of the respective PFS recommended on the labels, EDI values calculated for individual alkenylbenzenes ranged from 0.3 to $312 \mu \mathrm{g} \mathrm{kg} \mathrm{kg}^{-1}$ bw per day. Using the respective $\mathrm{BMDL}_{10}$ values these EDI values resulted in MOE values mostly below 10000 ranging from 6 to 7870 , except for sample 4 and 6 for which the MOE value for elemicin of 10729 and 25877 , respectively, exceeded the 10000 safety limit. A combined exposure assessment and subsequent risk assessment were performed for those PFS in which more than one alkenylbenzene was detected. Assuming equal potency of the alkenylbenzenes, combined EDI values obtained ranged from 1.5 to $631 \mu \mathrm{g} \mathrm{kg}^{-1}$ bw per day resulting in MOE values ranging from 3 to 1309 for the samples in which more than one alkenylbenzenes was detected. Using a TEQ concept with TEF values based on in vitro and in vivo data (Miller et al., 1983; Randerath et al., 1984; Punt et al., 2009; Al-Subeihi et al., 2012; Martati et al., 2012; van den Berg et al., 2012; Alajlouni et al., 2016a; Al-Malahmeh et al., 2017), combined EDI values ranged from 0.4 to $295 \mu \mathrm{g}$ safrole equivalents $\mathrm{kg}^{-1}$ bw leading to MOE values ranging from 6 to 5020. MOE values resulting from both these combined exposure assessments were up to 5-fold lower than the MOE values obtained when considering individual exposure to alkenylbenzenes. The MOE values obtained for the combined risk assessment based on the TEQ concept were higher than the ones obtained when assuming equal potency. This can be ascribed to the fact that the TEF values of the 
alkenylbenzenes present in the PFS, including myristicin, elemicin, and methyleugenol, are lower than that of safrole leading to lower EDI values when expressed in safrole equivalents and higher MOE values.

It is of interest to note that these MOE values refer to regular daily consumption of nutmeg-based PFS during a whole lifetime which may be an overestimation of realistic human consumption. Levels of alkenylbenzenes in nutmeg-based PFS samples and consumption frequency directly impact the EDI and the resulting MOE values. Using Haber's rule to correct for shorter than lifetime exposure it was also shown that limiting exposure to only one or two weeks could result in MOE values that would be, with the presently detected levels of alkenylbenzenes and proposed uses of the PFS, higher than 10000 and thus of low priority for risk management.

Use of Haber's Rule for products consumed for shorter periods of time may prevent overestimation of the actual risk to human health that may occur if MOE values are calculated assuming lifetime exposure. Applying Haber's Rule, however, is not a generally accepted approach when using the MOE for risk assessment of exposure to genotoxic carcinogens. Felter et al. (2011) was the first to propose use of Haber's Rule for assessing the risk from less-than lifetime exposure to carcinogens. It is important to acknowledge the assumptions underlying this methodology, which include the fact that chemical-specific carcinogenicity data should be available and that the data support a linear dose-response relationship (Felter et al., 2011). Whether such a linear dose-response relationship would apply to the dose-dependent induction of liver tumors by the alkenylbenzenes remains to be established and may depend on the mode of action underlying the carcinogenicity. This mode of action proceeds by cytochrome P450catalyzed hydroxylation to a 1'-hydroxymetabolite, followed by sulfotransferase (SULT)- 
mediated conversion to a 1'- sulfoxymetabolite (Phillips et al., 1981). This metabolite is unstable and reacts with DNA. Studies using PBK modelling revealed that the bioactivation of alkenylbenzenes to their ultimate carcinogenic 1'-sulfoxy metabolites is linear with the dose, from dose levels as low as levels of realistic human dietary intake up to dose levels as high as the $\mathrm{BMD}_{10}$ inducing liver tumors in rodent bioassays (Punt et al., 2009; Rietjens et al., 2010; Al-Subeihi et al., 2012; Martati et al., 2012). The mutagenic potential of alkenylbenzenes DNA adducts has not been extensively quantified so far. Herrmann et al. (2012) investigated the mutagenic potential of sulfate conjugates of 1'-hydroxymethyleugenol and showed that different isomeric hydroxylated metabolites of methyleugenol are mutagenic in an Ames test using Salmonella typhimurium TA100 strains expressing different sulfotransferase enzymes. This suggests that the formation of the 1'-sulfoxymetabolite and subsequently formed DNA adducts play an important role in the alkenylbenzene-induced carcinogenicity, and that knowledge of the levels of DNA adduct formation in human livers at relevant dietary intake levels would be of use to facilitate risk assessment for low-dose alkenylbenzenes intake. In this respect it is of interest to note that Herrmann et al. (2013) reported detection of methyleugenol DNA adducts in liver samples obtained from human subjects. Methyleugenol DNA adducts in the livers of these human subjects likely results from dietary intakes. The results of the present study imply that it would be of interest to look for also other alkenylbenzene DNA adducts in human liver samples. It would also be of use to extend the already-developed PBK models in humans to physiologically based dynamic (PBD) models that enable prediction of DNA adduct formation in human liver upon exposure to selected alkenylbenzenes. In a previous study by Paini et al. (2012) such a PBD model for liver DNA adduct formation was developed and validated in an in vivo study for estragole DNA adduct formation in the liver of rats. This study also revealed that 
not only bioactivatoin to the reactive 1'-sulfoxymetabolite but also DNA adduct formation in rat liver was linear with the dose of estragole (Paini et al., 2010, 2012). Development of such PBD models for liver DNA adduct formation in human could be achieved by combining the existing human PBK models with data on alkenylbenzene concentration-dependent DNA adduct formation in isolated human hepatocytes as done for rat hepatocytes exposed to estragole previously (Paini et al., 2010, Paini et al., 2012). Such studies in primary hepatocytes are likely to also account for possible repair and stability of the alkenylbenzene adducts and would thus provide insight in whether formation of adducts, even during a short period, could have irreversible effects and thus be deleterious, or whether they are likely to be repaired, thereby decreasing risk. Another issue to consider in this respect is whether it would be realistic that intake is not prolonged over time, especially in individuals who regard PFS as healthy and natural. A cross-sectional, 12 month retrospective survey that has been conducted in 24 cities in six European countries, by the PlantLIBRA consumer survey (2014), revealed that PFS product usage patterns are most often taken 'periodically' (37.3\%), when experiencing a 'worsening of a condition' (22.2\%), 'whenever/sporadically' (19.8\%), and on 'other non-specified occasions' (17.8\%). Periodically meaning 'once daily for at least 2 consecutive or non-consecutive weeks, more doses per week for at least 3 consecutive weeks, more doses per week for at least 4 consecutive or non-consecutive weeks, or 2 or more different PFS, in an appropriate dose form, at a minimum frequency of 1 or more doses per week, with the sum of the usage period of the 2 or more products being equal to at least 4 weeks (Garcia-Alvarez et al., 2014). This result indicates that some parts of the population may tend to use such products indeed for longer periods of time, whereas others may show more restricted periods of use. It is concluded that the 
results of the present paper reveal that daily nutmeg-based PFS consumption according to recommendations for daily intake for especially longer periods of time raise a concern.

\section{CONFLICT OF INTEREST}

Prof. IMCM Rietjens declares she is a member of the Expert Panel of the Flavour and Extract Manufacturers Association (FEMA). Other authors declare that no conflict of interest exists.

\section{ACKNOWLEDGEMENTS}

A.M.A. and A.J.A.M. acknowledge financial support from the SOIT foundation (The foundation for Stimulation of Innovation in Toxicology). 


\section{REFERENCES}

Al-Malahmeh, A. J., Alajlouni, A. M., Wesseling, S., Soffers, A. E., Al-Subeihi, A., Kiwamoto, R., Vervoort, J. and Rietjens, I. M. C. M. (2017a). "Physiologically based kinetic modeling of the bioactivation of myristicin." Archives of toxicology 91(2): 713-734. from http://www.ncbi.nlm.nih.gov/pubmed/27334372.

Al-Subeihi, A. A., Spenkelink, B., Punt, A., Boersma, M. G., van Bladeren, P. J. and Rietjens, I. M. C. M. (2012). "Physiologically based kinetic modeling of bioactivation and detoxification of the alkenylbenzene methyleugenol in human as compared with rat." Toxicology and applied pharmacology 260(3): 271-284. from http://www.ncbi.nlm.nih.gov/pubmed/22445790.

Alajlouni, A. M., Al-Malahmeh, A. J., Isnaeni, F. N., Wesseling, S., Vervoort, J. and Rietjens, I. M. C. M. (2016b). "Level of Alkenylbenzenes in Parsley and Dill Based Teas and Associated Risk Assessment Using the Margin of Exposure Approach." Journal of agricultural and food chemistry 64(45): 8640-8646. from http://www.ncbi.nlm.nih.gov/pubmed/27771948.

Alajlouni, A. M., Al Malahmeh, A. J., Kiwamoto, R., Wesseling, S., Soffers, A. E., Al-Subeihi, A. A., Vervoort, J. and Rietjens, I. M. C. M. (2016a). "Mode of action based risk assessment of the botanical food-borne alkenylbenzene apiol from parsley using physiologically based kinetic (PBK) modelling and read-across from safrole." Food and chemical toxicology : an international journal published for the British Industrial $\begin{array}{lllll}\text { Biological } & \text { Research } & \text { Association } & \text { 89-150. }\end{array}$ http://www.ncbi.nlm.nih.gov/pubmed/26826679.

ATSDR (2004). Guidance manual for the assessment of joint toxic actions of chemical mixtures. Agency_for_Toxic_Substances_and_Disease_Registry. Atlanta, GA, U.S. Department of Health and Human Services. Public Health Service.

Bradley, J. (2015). "The US supplement industry is $\$ 37$ billion, not $\$ 12$ billion." Nutrition Business Journal. from http://www.nutraingredients-usa.com/Markets/NBJ-The-USsupplement-industry-is-37-billion-not-12-billion.

Britannica, E. (2016). "Nutmeg." Encyclopædia Britannica, inc. from https://www.britannica.com/topic/nutmeg 
Doull, J. and Rozman, K. K. (2000). "Using Haber's law to define the margin of exposure." Toxicology 149(1): 1-2. from http://www.ncbi.nlm.nih.gov/pubmed/10963856.

EFSA (2004). "Botanicals and Botanical Preparations widely used as food supplements and related products: Coherent and Comprehensive Risk Assessment and Consumer Information Approaches." European Food Safety Authority: 6. from https://www.efsa.europa.eu/sites/default/files/assets/scdoc_advice03_botanicals_en.pdf

EFSA (2005). "Opinion of the scientific committee on a request from EFSA related to a harmonized approach for risk assessment of substances which are both genotoxic and carcinogenic." European Food Safety Authority 282: 1-31. from http://onlinelibrary.wiley.com/doi/10.2903/j.efsa.2005.282/epdf

EFSA (2009a). "Guidance on safety assessment of botanicals and botanical preparations intended for use as ingredients in food supplements." European Food Safety Authority $7(1249)$.

from https://www.pharmamedtechbi.com/ /media/Images/Publications/Archive/The\%20Tan\% 20Sheet/17/037/05170370014_b/090914_efsa_botanicals_guidance.pdf

EFSA (2009b). "Guidance of the Scientific Committee on Use of the benchmark dose approach in risk assessment." European Food Safety Authority 1150 1-72. from http://onlinelibrary.wiley.com/doi/10.2903/j.efsa.2009.1150/epdf

EFSA (2012a). "Compendium of botanicals reported to contain naturally occuring substances of possible concern for human health when used in food and food supplements." European Food Safety Authority 10(5): 60. from fhttps://www.efsa.europa.eu/en/efsajournal/pub/2663.

EFSA (2012b). "Guidance on selected default values to be used by the EFSA Scientific Committee, Scientific Panels and Units in the absence of actual measured data." $\begin{array}{lllll}\text { European } & \text { Food } & \text { Safety } & \text { Authority } & \text { from }\end{array}$ http://www.efsa.europa.eu/en/efsajournal/doc/2579.pdf.

EPA (1986a). Guidelines for the health risk assessment of chemical mixtures, United states Environmental Protection Agency. Fed Reg 51:34014-34025.

EPA (1988). Technical support document on health risk assessment of chemical mixtures. Office_of_Research_and_Development. Washington, D.C., United States Environmental Protection Agency. EPA/600/8-90/064. 
EPA (2000). Supplementary guidance for conducting health risk assessment of chemical mixtures. R. A. Forum. Washington, DC United States Environmental Protection Agency. EPA/630R-00/002.

European Commission (2008). Regulation (EC) No 1334/2008 of the European Parliament and of the Council of 16 December 2008 on flavourings and certain food ingredients with flavouring properties for use in and on foods and amending Council Regulation, Off $\mathrm{J}$ Eur. (EEC) No 1601/91, Regulations (EC) No 2232/96 and (EC) No 110/2008 and Directive 2000/13/EC.

FAO (1994). Nutmeg and derivatives. Rome, FOOD AND AGRICULTURE ORGANIZATION OF THE UNITED NATIONS.

Felter, S. P., Conolly, R. B., Bercu, J. P., Bolger, P. M., Boobis, A. R., Bos, P. M. J., Carthew, P., Doerrer, N. G., Goodman, J. I., Harrouk, W. A., Kirkland, D. J., Lau, S. S., Llewellyn, G. C., Julian Preston, R., Schoeny, R., Schnatter, A. R., Tritscher, A., van Velsen, F. and Williams, G. M. (2011). "A proposed framework for assessing risk from less-thanlifetime exposures to carcinogens." Critical Reviews in Toxicology 41(6): 507-544. from http://dx.doi.org/10.3109/10408444.2011.552063.

Forrest, E. and Heacock., J. a. R. A. (1972). "Nutmeg and Mace, the psychotropic spices from myristica fragrans." Lloydia 35(4): 440-449.

Garcia-Alvarez, A., Egan, B., de Klein, S., Dima, L., Maggi, F. and Isoniemi, M. (2014). "Usage of Plant Food Supplements across Six European Countries: Findings from the PlantLIBRA Consumer Survey." PLoS ONE 9(3): e92265. from https://doi.org/10.1371/journal.pone.0092265.

Gursale, A., Dighe, V. and Parekh, G. (2010). "Simultaneous quantitative determination of cinnamaldehyde and methyl eugenol from stem bark of Cinnamomum zeylanicum Blume using RP-HPLC." Journal of chromatographic science 48(1): 59-62. from http://www.ncbi.nlm.nih.gov/pubmed/20056038.

Herrmann, K., Engst, W., Appel, K. E., Monien, B. H. and Glatt, H. (2012). "Identification of human and murine sulfotransferases able to activate hydroxylated metabolites of methyleugenol to mutagens in Salmonella typhimurium and detection of associated DNA adducts using UPLC-MS/MS methods." Mutagenesis 27(4): 453-462. from http://www.ncbi.nlm.nih.gov/pubmed/22337896. 
Herrmann, K., Schumacher, F., Engst, W., Appel, K. E., Klein, K., Zanger, U. M. and Glatt, H. (2013). "Abundance of DNA adducts of methyleugenol, a rodent hepatocarcinogen, in human liver samples." Carcinogenesis 34(5): 1025-1030. from http://www.ncbi.nlm.nih.gov/pubmed/23334163.

IPCS. (1997). "Myristica fragrans $\quad$ Houtt.", from http://www.inchem.org/documents/pims/plant/pim355.htm.

Kobets, T., Duan, J., Brunnemann, K., Etter, S., Smith, B. and Williams, G. (2016). "Structure activity relationships for DNA damage by alkenylbenzenes in turkey egg fetal liver." Toxicological Sciences 150(2): 301-311.

Martati, E., Boersma, M. G., Spenkelink, A., Khadka, D. B., van Bladeren, P. J., Rietjens, I. M. C. M. and Punt, A. (2012). "Physiologically based biokinetic (PBBK) modeling of safrole bioactivation and detoxification in humans as compared with rats." Toxicological sciences : an official journal of the Society of Toxicology 128(2): 301-316. from http://www.ncbi.nlm.nih.gov/pubmed/22588462.

Miller, E. C., Swanson, A. B., Phillips, D. H., Fletcher, T. L., Liem, A. and Miller, J. A. (1983). "Structure-activity studies of the carcinogenicities in the mouse and rat of some naturally occurring and synthetic alkenylbenzene derivatives related to safrole and estragole." Cancer research 43(3): 1124-1134. from http://www.ncbi.nlm.nih.gov/pubmed/6825084.

NTP (2000). "Toxicology and Carcinogenesis Studies of Methyleugenol (CAS NO. 93-15-2) in F344/N Rats and B6C3F1 Mice (Gavage Studies)." National Toxicology Program technical report series 491: 1-412. from http://www.ncbi.nlm.nih.gov/pubmed/12563349.

Paini, A., Punt, A., Scholz, G., Gremaud, E., Spenkelink, B., Alink, G., Schilter, B., van Bladeren, P. J. and Rietjens, I. M. C. M. (2012). "In vivo validation of DNA adduct formation by estragole in rats predicted by physiologically based biodynamic modelling." Mutagenesis 27(6): 653-663. from http://www.ncbi.nlm.nih.gov/pubmed/22844077.

Paini, A., Punt, A., Viton, F., Scholz, G., Delatour, T., Marin-Kuan, M., Schilter, B., van Bladeren, P. J. and Rietjens, I. M. C. M. (2010). "A physiologically based biodynamic (PBBD) model for estragole DNA binding in rat liver based on in vitro kinetic data and estragole DNA adduct formation in primary hepatocytes." Toxicology and applied pharmacology 245(1): 57-66. from http://www.ncbi.nlm.nih.gov/pubmed/20144636. 
Phillips, D. H., Hanawalt, P. C., Miller, J. A. and Miller, E. C. (1981). "The in vivo formation and repair of DNA adducts from 1'-hydroxysafrole." Journal of supramolecular structure $\begin{array}{llll}\text { and } & \text { cellular } & \text { biochemistry } & \text { 83-90. }\end{array}$ http://www.ncbi.nlm.nih.gov/pubmed/7299840.

Punt, A., Paini, A., Boersma, M. G., Freidig, A. P., Delatour, T., Scholz, G., Schilter, B., van Bladeren, P. J. and Rietjens, I. M. C. M. (2009). "Use of physiologically based biokinetic (PBBK) modeling to study estragole bioactivation and detoxification in humans as compared with male rats." Toxicological sciences : an official journal of the Society of Toxicology 110(2): 255-269. from http://www.ncbi.nlm.nih.gov/pubmed/19447879.

Randerath, K., Haglund, R. E., Phillips, D. H. and Reddy, M. V. (1984). "32P-post-labelling analysis of DNA adducts formed in the livers of animals treated with safrole, estragole and other naturally-occurring alkenylbenzenes. I. Adult female CD-1 mice." Carcinogenesis 5(12): 1613-1622. from http://www.ncbi.nlm.nih.gov/pubmed/6499112.

Rietjens, I. M. C. M., Punt, A., Schilter, B., Scholz, G., Delatour, T. and van Bladeren, P. J. (2010). "In silico methods for physiologically based biokinetic models describing bioactivation and detoxification of coumarin and estragole: implications for risk assessment." Molecular nutrition \& food research 54(2): 195-207. from http://www.ncbi.nlm.nih.gov/pubmed/19943261.

Rietjens, I. M. C. M., Slob, W., Galli, C. and Silano, V. (2008). "Risk assessment of botanicals and botanical preparations intended for use in food and food supplements: emerging $\begin{array}{lllll}\text { issues." } & \text { Toxicology 131-136. } & \text { letters }\end{array}$ http://www.ncbi.nlm.nih.gov/pubmed/18602975.

SCF (2001a). "Opinion of the Scientific Committee on Food on Estragole (1-allyl-4methoxybenzene)." European Commission Health \& Consumer Protection DirectorateGeneral. from http://ec.europa.eu/food/fs/sc/scf/out104_en.pdf

SCF (2001b). "Opinion of the Scientific Committee on Food on Methyleugenol (1-allyl-1,2dimethoxybenzene)." European Commission Health \& Consumer Protection DirectorateGeneral. from http://ec.europa.eu/food/fs/sc/scf/out102_en.pdf

SCF (2002). "Opinion of the Scientific Committee on Food on the safety of the presence of safrole (1-allyl-3,4-methylene dioxybenzene) in flavourings and other food ingredients 
with flavouring properties." European Commission Health \& Consumer Protection Directorate-General. from http://ec.europa.eu/food/fs/sc/scf/out116_en.pdf

Smith, R. L., Adams, T. B., Doull, J., Feron, V. J., Goodman, J. I., Marnett, L. J., Portoghese, P. S., Waddell, W. J., Wagner, B. M., Rogers, A. E., Caldwell, J. and Sipes, I. G. (2002). "Safety assessment of allylalkoxybenzene derivatives used as flavouring substances methyl eugenol and estragole." Food and chemical toxicology : an international journal published for the British Industrial Biological Research Association 40(7): 851-870. from http://www.ncbi.nlm.nih.gov/pubmed/12065208.

Strategyr (2015). "The global herbal remedies and market trends, drivers and projections." Global Industry Analysts, Inc. from http://www.strategyr.com/MarketResearch/Herbal_Supplements_and_Remedies_Market -Trends.asp.

van den Berg, S. J. P. L., Punt, A., Soffers, A. E., Vervoort, J., Ngeleja, S., Spenkelink, B. and Rietjens, I. M. C. M. (2012). "Physiologically based kinetic models for the alkenylbenzene elemicin in rat and human and possible implications for risk assessment." Chemical research in toxicology 25(11): 2352-2367. from http://www.ncbi.nlm.nih.gov/pubmed/22992039.

van den Berg, S. J. P. L., Restani, P., Boersma, M., Delmulle, L. and Rietjens, I. M. C. M. (2011). "Levels of genotoxic and carcinogenic ingredients in plant food supplements and associated risk assessment." Food and Nutrition Sciences 2(9): 989-1010.

Vargas-Murga, L., Garcia-Alvarez, A., Roman-Vinas, B., Ngo, J., Ribas-Barba, L., van den Berg, S. J., Williamson, G. and Serra-Majem, L. (2011). "Plant food supplement (PFS) market structure in EC Member States, methods and techniques for the assessment of individual PFS intake." Food \& function 2(12): 731-739. from http://www.ncbi.nlm.nih.gov/pubmed/21879100.

Wiseman, R. W., Fennell, T. R., Miller, J. A. and Miller, E. C. (1985). "Further characterization of the DNA adducts formed by electrophilic esters of the hepatocarcinogens 1'hydroxysafrole and 1'-hydroxyestragole in vitro and in mouse liver in vivo, including new adducts at C-8 and N-7 of guanine residues." Cancer research 45(7): 3096-3105. from http://www.ncbi.nlm.nih.gov/pubmed/4005847. 
Zhou, G. D., Moorthy, B., Bi, J., Donnelly, K. C. and Randerath, K. (2007). "DNA adducts from alkoxyallylbenzene herb and spice constituents in cultured human (HepG2) cells." Environmental and molecular mutagenesis 48(9): 715-721. from http://www.ncbi.nlm.nih.gov/pubmed/17948277. 


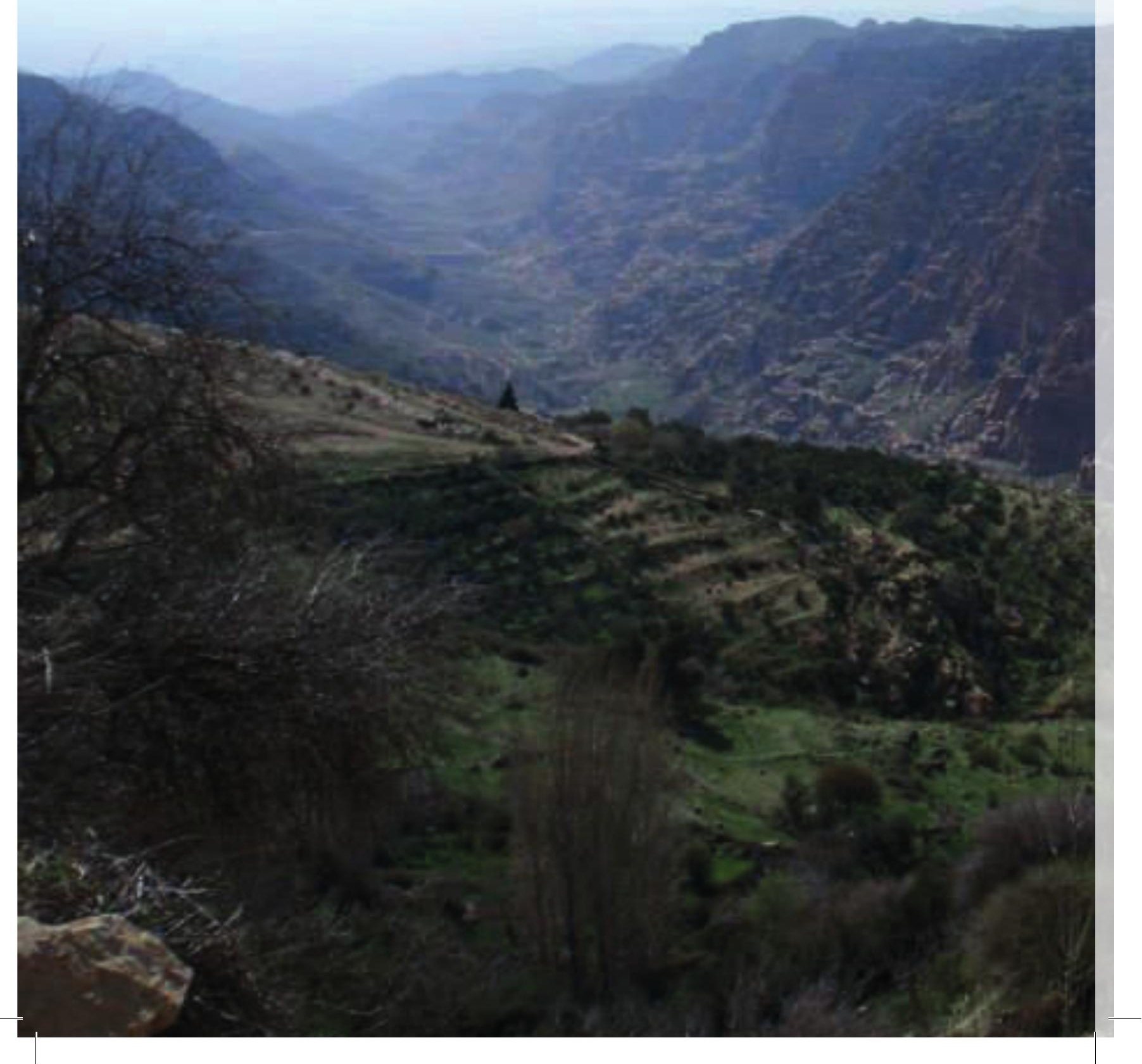




\section{Chapter 6}

General discussion and future perspectives 


\section{GENERAL DISCUSSION}

The present thesis focusses on the alkenylbenzenes myristicin, apiol, safrole, estragole, elemicin and methyleugenol. These alkenylbenzenes are naturally occurring in a variety of botanicals including anise, star anise, fennel, sweet fennel and parsley, belonging to the plant family Umbelliferae, nutmeg and mace, belonging to the plant family Myristicaceae, sweet and exotic basil, belonging to the family Labiatae, and tarragon, belonging to the plant family Compositeae. Exposure to myristicin, safrole, estragole, and methyleugenol via food occurs mostly from basil, nutmeg, and parsley. The range of estimated daily intakes (EDIs) of these alkenylbenzenes from the use of spices and spice oils ranges from 0.9 to $166 \mu \mathrm{g} / \mathrm{kg}$ bw per day, with the EDI of safrole being the lowest and that for estragole the highest (JECFA 2009). The EDIs of elemicin and apiol from all sources make a minor contribution to overall intake (Gavin et al. 2007). With respect to alkenylbenzene exposure, pesto paste eaters are considered the highest exposed group, with $20 \mathrm{mg}$ methyleugenol on average in each meal, making the EDI amount to $250 \mu \mathrm{g} / \mathrm{kg}$ bw per day of methyleugenol for a $70 \mathrm{~kg}$ person (Miele et al. 2001).

The alkenylbenzenes safrole, myristicin, apiol, estragole, methyleugenol, and elemicin are structurally related, and they may share similar metabolism, mode of action and biological effects (JECFA 2009; van den Berg et al. 2012). Botanicals and botanical preparation containing alkenylbenzenes may be of concern because these compounds may be genotoxic and carcinogenic displaying similar characteristics regarding tumor formation (Phillips et al. 1981; Miller et al. 1983; Randerath et al. 1984; Wiseman et al. 1985; NTP 2000; Zhou et al. 2007; Kobets et al. 2016). For myristicin and apiol, studies that show the ability to induce liver cancer are not available. The similarity of myristicin and apiol to safrole provides the basis for a mode 
of action based risk assessment using physiologically based kinetic (PBK) modelling based readacross from safrole for which adequate rodent tumor data are available.

PBK models, in general, are developed in order to study effects related to interspecies differences, intra-species differences, high to low dose extrapolations, route to route extrapolations, and exposure scenario extrapolations. PBK models integrate diverse sets of kinetic data, and can predict tissue dosimetry for situations relevant to human dietary intake of chemicals of interest.

For the assessment of the potential risks of human exposure to compounds that are both genotoxic and carcinogenic, the European Food Safety Authority (EFSA) recommended the Margin of Exposure (MOE) approach to evaluate the priority for risk management actions (EFSA 2005; EFSA 2009a). The MOE compares the exposure levels causing malignant tumors in experimental animals with dietary intake estimates (EDIs) in humans, considering differences in consumption patterns. To obtain the MOE, EFSA recommends the use of the $\mathrm{BMDL}_{10}$ (the lower confidence limit of the benchmark dose resulting in $10 \%$ extra cancer incidence) (EFSA 2009b). The BMDL 10 is a standardized reference point derived, by mathematical modelling, from the animal data, and falls within the observed range of experimental data (EFSA 2009a). In previous studies, the $\mathrm{BMDL}_{10}$ values for safrole, estragole, and methyleugenol could be derived from in vivo tumor data (van den Berg et al. 2011). However, not for all alkenylbenzenes tumor data enabling definition of a $\mathrm{BMDL}_{10}$ for risk assessment are available. Such data are not available for elemicin, myristicin and apiol. Previously, a BMDL 10 value for elemicin was derived by read-across from methyleugenol and estragole (van den Berg et al. 2012).

The aim of the present study was to develop a MOA and PBK modeling based approach for read-across in risk assessment from safrole for which in vivo toxicity studies are available to the 
related compounds myristicin and apiol for which tumor data are not reported, thus contributing to alternatives in animal testing, and to use the outcomes for risk assessment for the consumption of PFS and other botanical products containing myristicin and structurally related alkenylbenzenes considering individual and combined exposure.

In chapter 2 of this thesis, physiologically based kinetic (PBK) models were developed for myristicin by extension of the PBK models for the structurally related alkenylbenzene safrole in rat and human. The newly defined models provide a quantitative insight into the consequences of dose- and species- dependent effects on bioactivation of myristicin. The models were based on in vitro metabolic parameters determined using relevant tissue fractions, in silico derived partition coefficients, and physiological parameters derived from the literature. The models consist of six compartments including liver as metabolizing compartment, and separate compartments for fat, arterial blood, venous blood, richly perfused, and slowly perfused tissues. Following an exposure to dose levels of $0.05 \mathrm{mg} / \mathrm{kg}$ bw to $300 \mathrm{mg} / \mathrm{kg}$ bw myristicin, plasma and liver levels of myristicin and its proximate carcinogenic metabolite 1'-hydroxymyristicin were predicted showing myristicin to be almost completely metabolized within a 720 -hr period in rat and human. Comparing the predicted metabolite formation at 0.05 and $300 \mathrm{mg} / \mathrm{kg} \mathrm{bw}$, the percentage of the dose converted to the proximate carcinogenic metabolite 1'-hydroxymyristicin was predicted to increase in a dose-dependent manner. Comparison of the relative extent of bioactivation of myristicin by rat and human liver revealed that formation of 1'hydroxymyristicin (expressed as nmol/g liver) is comparable in rat and human liver at the low dose of $0.05 \mathrm{mg} / \mathrm{kg}$ bw and 1.8-fold higher in rat liver than in human liver at a dose of $300 \mathrm{mg} / \mathrm{kg}$ bw. Formation of the ultimate carcinogenic metabolite 1'-sulfoxymyristicin was predicted to be 
4-fold higher in human liver than in rat liver at a low dose of $0.05 \mathrm{mg} / \mathrm{kg}$ bw and 2.8 -fold higher in human liver than in rat liver at a dose of $300 \mathrm{mg} / \mathrm{kg}$ bw.

It was also shown that glucuronidation of 1'-hydroxymyristicin, representing a detoxification pathway, is the most important pathway in rat, while its oxidation is the most important pathway for conversion of 1'-hydroxymyristicin in human. Moreover, on the basis of the kinetic data obtained, bioactivation of 1'-hydroxymyristicin following sulfonation was found to represent only a minor pathway in both rat and human.

The PBK models for myristicin were comparable to the PBK models for estragole, methyleugenol, and safrole, for which more data allowing the evaluation of the models were available. The performance of the rat and human PBK models developed for estragole, methyleugenol, and safrole was reported before (Punt et al. 2008; Punt et al. 2009; Al-Subeihi et al. 2011; Martati et al. 2011; Al-Subeihi et al. 2012; Martati et al. 2012). Evaluation was done by comparing the predicted levels of a variety of metabolites in plasma or excreted in the urine of rats and the predicted blood concentrations in human to comparable data reported in the literature. These comparisons revealed that the predicted PBK model values and the levels of these metabolites derived from in vivo studies adequately matched. The performance of the newly developed PBK models for myristicin could not be evaluated against in vivo data because quantitative data on the formation or excretion of the different metabolites in rat or humans exposed to this compound are not available. The only data reported that were of use were the data by Beyer et al. (2006) reporting that for both rats and humans exposed to nutmeg, the corresponding $O$-demethylenation metabolite of myristicin was the predominant metabolite, exceeding other metabolites by at least a factor of 10 . In rat urine samples collected over a $24-\mathrm{hr}$ period after administration of a single oral dose of $100 \mathrm{mg} / \mathrm{kg}$ bw myristicin, urinary metabolites 
resulting from $O$-demethylenation amounted to $67 \%$ of the total dose (Beyer et al. 2006). In line with these results, the developed rat PBK model predicted the $O$-demethylenated myristicin metabolite 5-allyl-2,3-dihydroxyanisole to be the major metabolite formed at a dose of 100 $\mathrm{mg} / \mathrm{kg}$ bw myristicin in rat after $24-\mathrm{hr}$, with a percentage of $73 \%$ of the total dose. This predicted value of $73 \%$ of the dose matches well with the $67 \%$ observed in the in vivo rat study and it was concluded that the developed PBK models for myristicin will also adequately describe the in vivo levels of metabolites formed in rat and human after conversion of myristicin and 1'hydroxymyristicin at different oral dose levels of myristicin. Comparison of the PBK modelbased predictions of the bioactivation of myristicin by rat and human to that of its structurally related compound safrole, reveals that the formation of the DNA-reactive 1'-sulfoxy metabolite is comparable; in human formation of the 1'-sulfoxy metabolite is predicted to be 1.35 -fold higher for safrole than for myristicin at a low dose level $0.05 \mathrm{mg} / \mathrm{kg}$ bw, and 1.1-fold higher for myristicin at high dose level $100 \mathrm{mg} / \mathrm{kg}$ bw, in rat formation of the 1'-sulfoxy metabolite is predicted to be 1.5 -fold higher for myristicin than for safrole at low dose level $0.05 \mathrm{mg} / \mathrm{kg} \mathrm{bw}$, and 2.2-fold higher for myristicin at high dose level $100 \mathrm{mg} / \mathrm{kg}$ bw. This shows that the doseresponse function for myristicin is steeper (higher curve slope), and that the formation of the 1'sulfoxymetabolite is higher for safrole at lower doses, but that the order changes to have the formation of the 1'-sulfoxymetaboilte of myristicin being higher than that of safrole at higher doses. The PBK model outcomes obtained for the formation of reactive 1'-sulfoxy metabolites of myristicin and safrole can be compared to the relative bioactivation of these two alkenylbenzenes observed in other studies (Phillips et al. 1984; Randerath et al. 1984; Zhou et al. 2007). ${ }^{32} \mathrm{P}-$ postlabeling indicated that safrole and myristicin have the ability to produce DNA adducts in adult mouse liver upon intraperitoneal injections, amounting to levels of 17.5 and $7.8 \mathrm{pmol} / \mathrm{mg}$ 
DNA, respectively (Phillips et al. 1984). In another study the covalent binding to adult female mice CD-1 liver of safrole was 2.7 times higher than that of myristicin at low dose ( $2 \mathrm{mg} / \mathrm{mouse})$ and 4.0 times higher at higher dose (10 mg/mouse) (Randerath et al. 1984). Using human HepG2 cells exposed in vitro, the level of DNA adduct formation by safrole was 1.6 -fold higher than that for myristicin at low concentration $(50 \mu \mathrm{mol} / \mathrm{l})$, while at higher concentration $(450 \mu \mathrm{mol} / \mathrm{l})$, the level of adduct formation for myristicin was 1.6-fold higher than for safrole (Zhou et al. 2007).

Altogether, the results obtained support the possibility to perform the risk assessment for myristicin based on the MOE approach using the $\mathrm{BMDL}_{10}$ of safrole for tumor formation. Thus, risk assessment of myristicin may be based on the BMDL 10 derived for safrole of $1.9-5.1 \mathrm{mg} / \mathrm{kg}$ bw per day (van den Berg et al. 2011). Using an estimated daily intake of myristicin of 0.0019 $\mathrm{mg} / \mathrm{kg}$ bw per day (Gavin et al. 2007) resulting from the use of herbs and spices, this results in MOE values for myristicin that amount to 1000-2700, indicating a priority for risk management.

In chapter 3, a similar study was undertaken for apiol. To this end PBK models for apiol were developed in order to facilitate risk assessment based on read-across from the related alkenylbenzene safrole. The formation of the different microsomal metabolites of apiol in rat liver by the PBK model-based predictions was dose dependent with a relative increase in bioactivation of apiol at higher doses.

With the model obtained the relative extent of bioactivation and detoxification of apiol at different oral doses was examined. At low doses, formation of 4-allyl-3,6-dimethoxy benzene1,2-diol (ADD) and 2',3'-dihydroxyapiol (DHA) leading to detoxification appeared to represent the major metabolic pathways, occurring in the liver. At high doses, the rat model revealed a relative increase in the percentage of formation of the proximate carcinogenic metabolite 1'- 
hydroxyapiol; from $4 \%$ to about $7 \%$ of the dose at low and high dose levels respectively, occurring in the liver. By comparing the PBK model based predicted 1'-sulfoxy metabolite formation of apiol with that for safrole, it appeared that at similar dose levels the formation of the 1 '-sulfoxymetabolite for apiol is predicted to be about 3-fold lower than for safrole in rat liver and 2-fold lower in human liver. Based on these PBK modeling results, making a correction for the expected 3-fold lower formation of the ultimate carcinogenic 1'-sulfoxymetabolite at similar dose levels, the apiol $\mathrm{BMDL}_{10}$ value would be 3 times the $\mathrm{BMDL}_{10}$ for safrole. Based on an estimated $\mathrm{BMDL}_{10}$ for apiol of 5.7 to $15.3 \mathrm{mg} / \mathrm{kg}$ bw per day and an estimated daily intake of $4 \times 10^{-5} \mathrm{mg} / \mathrm{kg}$ bw per day, the margin of exposure (MOE) would amount to 140000 to 385000 , and this indicates a low priority for risk management.

In Chapter 4, a more detailed analysis of the risks of the presence of alkenylbenzenes in basilcontaining sauce of pesto was made using the MOE approach and taking into consideration the possible combined exposure to different alkenylbenzenes. The determination of the levels of alkenylbenzenes in basil-containing sauce of pesto revealed that all the samples analysed contained methyleugenol. In addition to methyleugenol, some samples contained estragole, myristicin, and/or apiol. Based on chemical analysis the EDI values could be determined assuming a body weight of $70 \mathrm{~kg}$ and intake of $10 \mathrm{~g}$ of basil (based on wet weight) per meal (Miele et al. 2001), provided by an amount of pesto sauce that could be calculated taking into account the basil content (\%) in the pesto sauce as indicated on the label. For samples containing only methyleugenol, the EDI values for methyleugenol ranged from $3.2-44.3 \mu \mathrm{g} / \mathrm{kg}$ bw per day. These EDI values resulted in MOE values of 345-4781. Since several alkenylbenzenes were found in some of the pesto samples, and these alkenylbenzenes show high similarity in structure, target organ, type of adverse effects and mode of action through formation of a DNA reactive 1'- 
sulfoxymetabolite contributing to formation of liver tumors, a combined exposure assessment and subsequent risk assessment were also performed. For this combined risk assessment, the EDIs were calculated assuming equal potency of the alkenylbenzenes and also based on use of the so-called Toxic Equivalency (TEQ) approach. The Toxic Equivalency Factors (TEFs) for the different alkenylbenzenes were defined using methyleugenol as the reference compound $(\mathrm{TEF}=1)$. The TEF values for the other compounds were defined using different sets of literature data, including data for in vivo DNA adduct formation in the liver (Randerath et al. 1984) and also the PBK model based predictions for formation of the ultimate carcinogenic 1'-sulfoxy metabolites and the $\mathrm{BMDL}_{10}$ values obtained by read-across from safrole as defined for myristicin and apiol in Chapter 2 and Chapter 3 of the thesis, as well as the previously derived $\mathrm{BMDL}_{10}$ values for methyleugenol and safrole (van den Berg et al. 2011). In samples containing multiple alkenylbenzenes, the MOE values resulting from combined exposure assessment were 1.5-5-fold lower than the MOE values obtained when considering the presence of only methyleugenol, and are all below 10000. Combined risk assessment based on equal potency did not vary much from results obtained using the TEQ approach. This can be ascribed to the minor variation in potencies of the different alkenylbenzenes detected in the pesto samples.

It is of interest to note that these MOE values refer to regular daily consumption of pesto which may be an overestimation of realistic human consumption. Levels of methyleugenol in pesto sauce samples and consumption frequency of pesto sauce directly impact the EDI and the resulting MOE values. There is no generally established method for taking a shorter than life time exposure into account but one could consider using Haber's rule. Assuming that Haber's rule would apply, the toxic effect would vary linearly with the time of exposure and the concentration (i.e. $\mathrm{C} \times \mathrm{T}=\mathrm{k}$, where $\mathrm{C}$ is concentration or dose, $\mathrm{T}$ is time of exposure, and $\mathrm{k}$ is a 
constant toxic response for the specific substance) (Doull and Rozman 2000). In Chapter 4 it was evaluated, using Haber's rule, what level of alkenylbenzenes, what amount of basil-based pesto sauce consumed and/or what exposure frequency would result in an MOE of 10000 or higher and be of low priority for risk management. Based on that analysis it was concluded that consumption of pesto sauces would especially be of concern if consumed on a daily basis over longer periods of time. The results of chapter 4 reveal that pesto consumption does not always represent a cancer risk and provide insight into when this might be the case and under which level and frequency of consumption pesto consumption would not raise a concern.

In Chapter 5, a risk assessment of nutmeg-based plant food supplements (PFS) containing different alkenylbenzenes was performed based on the alkenylbenzene levels quantified in a series of PFS collected via the online market. Based on the alkenylbenzene contents detected and the use levels of the respective PFS recommended on the labels, EDI values calculated for individual alkenylbenzenes ranged from 0.3 to $312 \mu \mathrm{g} / \mathrm{kg}$ bw per day. Using the respective $\mathrm{BMDL}_{10}$ values these EDI values resulted in MOE values that were generally below 10000 ranging from 6 to 7870. A combined exposure assessment and subsequent risk assessment were performed for those PFS in which more than one alkenylbenzene was detected. Assuming equal potency of the alkenylbenzenes, combined EDI values obtained ranged from 1.5 to $631 \mu \mathrm{g} / \mathrm{kg}$ bw per day resulting in MOE values ranging from 3 to 1309 for the samples in which more than one alkenylbenzene was detected. Using a TEQ concept and the Toxic Equivalency Factors (TEFs) for the different alkenylbenzenes defined as described in Abdul et al. (2016) using safrole as the reference compound $(\mathrm{TEF}=1)$ (Alajlouni et al. 2016b). Combined EDI values ranged from 0.4 to $295 \mu \mathrm{g}$ safrole equivalents $/ \mathrm{kg}$ bw leading to MOE values ranging from 6 to 5020 . MOE values resulting from both these combined exposure assessments were up to 5-fold lower than the MOE 
values obtained when considering individual exposure to alkenylbenzenes. The MOE values obtained for the combined risk assessment based on the TEQ concept were higher than the ones obtained when assuming equal potency. This can be ascribed to the fact that the TEF values of the alkenylbenzenes present in the PFS, including myristicin, elemicin, and methyleugenol, are lower than that of safrole leading to lower EDI values when expressed in safrole equivalents and higher MOE values.

It is of interest to note that these MOE values refer to regular daily consumption of nutmeg-based PFS during a whole lifetime which may be an overestimation of realistic human consumption. Levels of alkenylbenzenes in nutmeg-based PFS samples and consumption frequency directly impact the EDI and the resulting MOE values. Using Haber's rule to correct for shorter than life time exposure it was shown that limiting exposure to only one or two weeks could result in MOE values that would be, with the levels of alkenylbenzenes detected in the PFS in the study and the proposed uses of these PFS, higher than 10000 and thus of low priority for risk management. It is concluded that the results of the study reveal that daily nutmeg-based PFS consumption following recommendations for daily intake for especially longer periods of time raises a concern. 


\section{FUTURE PERSPECTIVES}

This thesis presents the use of physiologically based kinetic (PBK) modeling to facilitate readacross in risk assessment from a compound for which in vivo toxicity studies are available to a related compound for which tumor data are not reported, and risk assessment of individual and combined exposure to alkenylbenzenes present in basil-containing pesto and nutmeg-based plant food supplements (PFS). In the next sections some suggestions are given for steps to be taken in the near future for further improvement of risk and safety assessment of individual and combined exposure to alkenylbenzenes from botanical preparations. Such steps include (1) Further development of the PBK models and the read-across approach to predict toxicological reference points for risk assessment of genotoxic carcinogens, (2) incorporation of the dynamic characteristics of the active chemical substance(s) in the in silico models, (3) additional considerations for the MOE based risk assessment including the incorporation of Chemical Specific Adjustment Factors (CSAFs) for interspecies and interindividual variation in kinetics within the human population, (4) long to short-term exposure adjustment, (5) further improvement of the TEF approach, (6) banding of the MOE values and related conclusions for risk management, and (7) quality assurance of food supplements and botanical preparations.

\section{Further development of the PBK models and the read-across approach to predict toxicological reference points for risk assessment of genotoxic carcinogens}

The MOE approach needs carcinogenicity data to define the BMDL 10 . However, not for all alkenylbenzenes tumor data enabling definition of a $\mathrm{BMDL}_{10}$ for risk assessment are available. Such data are missing for myristicin and apiol. So, a mode of action based PBK model approach was developed in chapter 2 and chapter 3 to perform a read-across from a compound for which 
rodent tumor data are available (safrole) to these compounds for which such data are not available (myristicin and apiol). The read-across was based on the similarity in structure, metabolism, mechanism of toxicity, and ultimate adverse effect of the alkenylbenzenes. Previously, a BMDL 10 value for elemicin was derived by PBK model based read-across from methyleugenol and estragole (Van den Berg et al. 2012). The PBK models quantify the dosedependent formation of the ultimate carcinogenic 1'-sulfoxymetabolite thereby facilitating the read-across based on predictions of relative bioactivation. It is important to realise that the PBK models as developed for the read-across in the present thesis required a large number of parameters many of which needed to be defined for each individual compound. This makes the development of these models time and effort consuming. For that reason, for efficient future development of this PBK model based read-across approach priority should be given to the development of generic PBK models for groups of related compounds to facilitate an efficient and time-and-cost-saving risk assessment on genotoxic carcinogens for which rodent tumor data are not available (Bessems et al. 2014). The models developed for the alkenylbenzenes, and especially the results of the sensitivity analyses, could be of use since they define and evaluate the influence of the various input parameters on the output. This could be of great use in the development of generic models for other botanical-borne naturally occurring group of compounds, focusing on those aspects in the model that affect the predictions most. Another category of botanical ingredients of concern for which limited tumor data for their risk assessment are available and for which PBK model based read-across would facilitate risk assessment are the pyrrolizidine alkaloids (Chen et al. 2017).

Some efforts in development of generic PBK models have already been reported. Brightman et al. (2007) introduced a generic model PBK model that was parameterized for human physiology 
predicting the in vivo pharmacokinetics of compounds for which plasma levels in human have been determined following an intravenous dose, concluding that the generic PBK model can be a powerful, efficient, and cost-effective tool for toxicokinetic predictions and reduction of in vivo animal experimentation. Chemical-specific data required by the model are generated from in silico (QSAR) and/or in vitro procedures. For oral exposure; generic PBK models likely will require quantitative values for intestinal barrier permeability, a measure of lipophilicity, an estimate of the fraction of the compound bound to plasma proteins, and an estimate of intrinsic hepatic clearance (Brightman et al. 2005; Brightman et al. 2006; d'Yvoire et al. 2007). Depending on the group of chemicals under study a few compound specific parameters may have to be added but the PBK model development could start from the generic basic model and its evaluation before adding additional parameters. Focusing on a limited set of parameters and definition of validated generic models will facilitate future applications of the PBK model based read-across presented in the present thesis for the alkenylbenzenes.

\section{Incorporation of the dynamic characteristics of the active chemical substance(s) in the in}

\section{silico models}

For refinement of the read-across process in risk assessment of genotoxic carcinogens, dynamic processes including DNA-adduct formation, DNA repair, mutation modulation, gene and protein expression and tumor formation occurring at low realistic intake levels should be considered in addition to already predicted kinetics (bioactivation and detoxification) of myristicin and apiol (Chapter 2 and 3). The dynamic process could be described using Physiologically Based Dynamic (PBD) models. 
Extending the PBK models to model the possible levels of DNA adduct formation upon exposure to the alkenylbenzenes has been done before for estragole (Paini et al. 2010). To this end, the PBK model describing the formation of the proximate carcinogenic 1'-hydroxymetabolite, was extended by linking the area under the curve for 1'-hydroxyestragole formation predicted by the PBK model to the area under the curve for 1'-hydroxyestragole in the in vitro experiments on DNA adduct formation in rat primary hepatocytes exposed to 1'-hydroxyestragole.

In this model formation of 1'-sulfoxyestragole as well as DNA repair were implicitly included, since these reactions occur in the isolated hepatocytes and thus affect the ultimate levels of DNA adduct formation detected. The PBD model for liver DNA adduct formation thus developed for rats predicted the formation of E-3'- $\mathrm{N}^{2}-\mathrm{dGuo}$ in the liver of rat at $400 \mathrm{mg} / \mathrm{kg}$ bw per day, quantified by LC-ESI-MS/MS, at a level amounting to 4 adducts in 10000 nucleotides. This value was within the same order of magnitude as DNA adduct formation in the liver of mice exposed to estragole determined using ${ }^{32} \mathrm{P}$-postlabeling detecting 1 adduct in 10000 nucleotides (Randerath et al. 1984).

The results obtained revealed that DNA adduct formation was adequately predicted and also that not only bioactivation to the reactive 1'-sulfoxymetabolite but also DNA adduct formation in rat liver was linear with the dose of estragole (Paini et al. 2010). Such studies also account for possible repair and stability of the alkenylbenzene adducts and would thus provide insight in whether formation of adducts, even during a short period, could have irreversible effects and thus be deleterious, or whether they are likely to be efficiently repaired, thereby decreasing risk. Also prediction of DNA adduct formation is one step closer to the ultimate mutagenicity and carcinogenicity than the predicted 1'-sulfooxyestragole formation, thus providing an even better basis for read-across. 


\section{Additional considerations for the MOE based risk assessment including the incorporation} of Chemical Specific Adjustment Factors (CSAFs) for interspecies and interindividual variation in kinetics within the human population

Many qualitative and quantitative approaches can be used to assess the risk of genotoxic carcinogenic compounds. Data used in these approaches are mainly obtained from rodent bioassays performed at high dose levels. This implies that extrapolation to lower exposure levels is required in order to judge the risks at realistic human daily exposure levels. Such an extrapolation may be far outside the experimental data range and up to five orders of magnitude below the observable response in the animal bioassay. EFSA questioned if such an extrapolation is justified, and denies quantitative risk assessment based on high to low dose extrapolation as a scientifically acceptable approach (Barlow et al. 2006; O'Brien et al. 2006; Benford et al. 2010). EFSA considered, amongst other reasons, that this extrapolation depends too much on the model applied, that evidence for the frequently used linear extrapolation model is not available, and that this extrapolation of rodent tumor data to human risk levels does not take into account species differences. As an alternative EFSA proposed the Margin of Exposure (MOE), defined as the ratio between the $\mathrm{BMDL}_{10}$ and the estimated daily intake (EDI), that was also applied in the present thesis. The EFSA Scientific Committee considered that an MOE of 10000 or more, based on animal cancer bioassay data, "would be of low concern from a public health point of view and might reasonably be considered as a low priority for risk management actions" (EFSA 2005). The value of 10000 was considered to include all possible uncertainties that may be involved and affect the risk assessment. It includes a factor of 100 for kinetic and dynamic differences between species and within humans, a factor of 10 that presents the variability in cell cycle control and DNA repair within humans, and a factor of 10 that takes into account that the 
$\mathrm{BMDL}_{10}$ represents a $10 \%$ BMR (EFSA 2005; O'Brien et al. 2006). Subdivision of the interspecies uncertainty factor of 10 into toxicokinetics and toxicodynamic components would allow part of the default value to be replaced by chemical-specific data consistent with the weight of evidence for mode of action when they are available. The proposed default value of 10 for interspecies differences for example can be considered to consist of a factor of 4 and 2.5 for the toxicokinetics and toxicodynamic components, respectively. This implies that when relevant chemical-specific toxicokinetics and toxicodynamic data on species differences would be available, the default values could be replaced with CSAFs for interspecies differences in toxicokinetics and toxicodynamic (HealthCanada 1994; Renwick 1999; Gundert-Remy and Sonich-Mullin 2002; Meek et al. 2003; IPCS 2005). The default uncertainty factor for interspecies differences in toxicokinetics can be informed through the use of PBK models (Rowland 1985; Andersen et al. 1995; Jarabek 1995). The PBK model based predictions for the formation of the ultimate carcinogenic 1'-sulfoxymetabolite for myristicin and apiol in rat and human defined in the present thesis showed that at low dose in human the formation of the ultimate carcinogenic metabolite is 4 times higher than in rat, while for apiol the difference was 15-fold. These results of the present thesis suggest that a factor of 4 to take into account species differences in toxicokinetics may be sufficient for myristicin but not for apiol. For apiol, the default MOE value of 10000 may increase accordingly which would result in more samples to result in MOE values that might be of concern.

In future, Monte Carlo simulation on the variability in the formation of the 1'-sulfoxymetabolite can potentially be used to derive the CSAFs, which can be used to evaluate the appropriateness of the default factor of 3.16 generally assumed to reflect interindividual variation in kinetics within the human population (Barton et al. 1996; Dourson et al. 1996; Clewell et al. 1999; Price 
et al. 1999; Haber et al. 2002; Lipscomb and Ohanian 2007). The results of this thesis illustrate how these PBK models may assist the development of CASFs in risk assessment.

\section{Long to short-term exposure adjustment}

The risk assessments presented in this thesis were based on the MOE approach which defines an MOE based on BMDL 10 values from chronic carcinogenicity data as well as EDI values assuming daily exposure over a life time. Use of the PFS and of sauce of pesto however, may be less than daily and not over a whole life time. This raises the question how to accommodate these different exposure scenario's in the MOE based risk assessment. One way to extrapolate from longer durations to shorter durations of exposure is through the use of Haber's Law: $=c \times t$, where $\mathrm{c}$ is the dose, $t$ the exposure time and $k$ a constant. This implies a linear relationship between the dose and the exposure time. The use of linear time-to-dose extrapolation to assess the risk from less-than-life-time exposure to genotoxic substances has been discussed by various authors, i.e. if linearity is assumed, then it is important to determine if Haber's Rule $(\mathrm{C} \times \mathrm{T})$ is appropriate for the exposure scenario of concern, Haber's rule supports distributing the lifetime dose over the total number of exposure days during less-than-lifetime exposure, thereby allowing for a higher daily intake than would be the case for lifetime exposure. If the response is nonlinear, it should be critically evaluated whether application of Haber's law is appropriate in estimating a toxicological reference point, taking into account the MOA and TK/TD based considerations. If Haber's law applies, several approaches could be considered, i.e. using Haber's law strictly without adjustment, adjusted by application of a Dose-Response Correction Factor (DRCF), the magnitude of which could vary according to the exposure scenario and/or what is known about the MOA, or according to predefined exposure scenarios (acute for14 days 
or fewer, short-term $\geq 14$ days to 1 year, intermediate $\geq 1$ year to 7 years, chronic $\geq 7$ years to 70 years), and assign "default" adjustment factors (Bos et al. 2004; Callis et al. 2010; Felter et al. 2011).

Felter et al. (2011) indicated that it is important to acknowledge the assumptions underlying this methodology of linear time-to-dose extrapolation, which include the fact that chemical-specific carcinogenicity data should be available and that the data support a linear dose-response relationship (Felter et al. 2011). Whether such a linear dose-response relationship would apply to the dose dependent induction of liver tumors by the alkenylbenzenes remains to be established and may depend on the MOA underlying the carcinogenicity. This mode of action proceeds by cytochrome P450-catalyzed hydroxylation to a 1'-hydroxymetabolite, followed by sulfotransferase (SULT)-mediated conversion to a 1'- sulfoxymetabolite (Phillips et al. 1981). This metabolite is unstable and reacts with DNA. Studies using PBK modelling revealed that the bioactivation of alkenylbenzenes to their ultimate carcinogenic 1'-sulfoxy metabolites is linear with the dose, from dose levels as low as levels of realistic human dietary intake up to dose levels as high as the $\mathrm{BMDL}_{10}$ and $\mathrm{BMD}_{10}$ inducing liver tumors in rodent bioassays (Punt et al. 2009; Rietjens et al. 2010; Al-Subeihi et al. 2012; Martati et al. 2012). The mutagenic potential of the 1'-sulfoxy alkenylbenzene DNA adducts has not been extensively quantified so far. Herrmann et al. (2012) investigated the mutagenic potential of sulfate conjugates of 1'hydroxymethyleugenol and showed that different isomeric hydroxylated metabolites of methyleugenol are mutagenic in an Ames test using Salmonella typhimurium TA100 strains expressing different sulfotransferase enzymes (Herrmann et al. 2012). This suggests that the 1'sulfoxymetabolite and the subsequently formed DNA adducts play an important role in the alkenylbenzene-induced carcinogenicity, and that knowledge of the levels of DNA adduct 
formation in human livers at relevant dietary intake levels would be of use to facilitate risk assessment for low-dose alkenylbenzenes intake. In this respect it is of interest to note that Herrmann et al. (2013) reported detection of methyleugenol DNA adducts in liver samples obtained from human subjects (Herrmann et al. 2013). Methyleugenol DNA adducts in the livers of these human subjects likely results from dietary intakes. The results of the present study imply that it would be of interest to look for also other alkenylbenzene DNA adducts in human liver samples. It would also be of use to extend the already-developed PBK models in humans to physiologically based dynamic (PBD) models that enable prediction of DNA adduct formation in human liver upon exposure to selected alkenylbenzenes. As already outline above in a previous study by Paini et al. (2012) such a PBD model for liver DNA adduct formation was developed and validated in an in vivo study for estragole DNA adduct formation in the liver of rats. This study also revealed that not only bioactivatoin to the reactive 1'-sulfoxymetabolite but also DNA adduct formation in rat liver was linear with the dose of estragole (Paini et al. 2010; Paini et al. 2012). Development of such PBD models for liver DNA adduct formation in human could be achieved by combining the existing human PBK models with data on 1'-hydroxyalkenylbenzene concentration-dependent DNA adduct formation in isolated human hepatocytes as done for rat hepatocytes exposed to 1'-hydroxyestragole previously (Paini et al. 2010; Paini et al. 2012). Thus the available data on bioactivation and DNA adduct formation of alkenylbenzenes show linearity and thereby provide kinetic and some dynamic data to support use of Haber's rule.

Another issue to consider when evaluating short term exposure scenarios is whether it would be realistic that intake is not prolonged over time, especially in individuals who regard PFS as healthy and natural. A cross-sectional, 12-month retrospective survey that has been conducted in 24 cities in six European countries, by the PlantLIBRA consumer survey (2014), revealed that 
PFS product usage patterns are most often taken "periodically" (37.3\%), when experiencing a "worsening of a condition" (22.2\%), "whenever/sporadically" (19.8\%), and on "other nonspecified occasions" (17.8\%). Periodically meaning "once daily for at least 2 consecutive or nonconsecutive weeks, more doses per week for at least 3 consecutive weeks, more doses per week for at least 4 consecutive or non-consecutive weeks, or 2 or more different PFS, in an appropriate dose form, at a minimum frequency of 1 or more doses per week, with the sum of the usage period of the 2 or more products being equal to at least 4 weeks" (Garcia-Alvarez et al. 2014). This result indicates that some parts of the population may tend to use such products indeed for longer periods of time, while others may show more restricted periods of use. The results of the present thesis illustrated how, using Haber's rule, the risks of different exposure scenario's, including scenario's with restricted periods of intake, could be evaluated. The results of the present thesis reveal that based on the MOE approach without a correction from long to short term exposure, daily consumption of PFS following recommendations for daily intake raises a concern.

\section{Further improvement of the TEF approach}

When analysing alkenylbenzene containing foods including the sauce of pesto and nutmeg-based PFS it appeared that many preparations contain more than one alkenylbenene, pointing at combined exposure (Alajlouni et al. 2016b; Al-Malahmeh et al. 2017a). This was also reported before by other authors (Meek et al. 2011; EFSA 2013; Pose-Juan et al. 2016; Alajlouni et al. 2016b; Al-Malahmeh et al. 2017b). For this reason risk assessment of combined exposure to alkenylbenzenes was performed for nutmeg-based PFS and basil-based pesto sauce. 
For alkenylbenzenes, known to have similar chemical structures, metabolic pathways and a similar MOA underlying induction of a similar adverse effect, and for which it can be assumed that they will display similarly shaped dose-response curves, the combined toxicity of the individual components can be estimated by so-called dose-addition using the sum of their doses, equally or scaled for potency relative to that of another component of the mixture for which adequate dose-response information is available. Based on the dose addition concept, the TEF methodology applies. Application of this methodology in human health risk assessment has been described and reaffirmed for use by for example the guidance of the Environmental Protection Agency (EPA) entitled: "Supplementary Guidance for Conducting Health Risk Assessment of Chemical Mixtures"' (EPA 2000). In practice, the scaling factor for each chemical in the group is typically based on a comparison of its toxic potency to that of a designated index chemical. The index chemical is well-studied toxicologically and must have a dose-response function to apply the methodology to a mixture. Toxicological data considered for these comparisons of toxic potency can be derived from both in vitro and in vivo studies as well as from structure-activity relationships. The relative potencies can also be defined based on biochemical changes, toxicity, and/or carcinogenicity.

Application of the TEF approach to the human health risk assessment of chemicals carries with it some uncertainties, i.e. the assumption of parallel dose-response curves, which is difficult to show particularly in the low response region of interest, and the assumption that the estimate of relative potency (REP) from animal studies are predictive of REPs in humans. In the process and data used to derive TEF (or REP) values, even more uncertainties evolve i.e. variability in the kind of information available in many types of in vivo and in vitro studies for comparing the responses. Safrole and methyleugenol were both used as index compound in this thesis, 
depending on their presence in the mixture of the botanical preparation studied. Both, safrole and methyleugenol are well-studied toxicologically and have a well-defined dose-response function for various endpoints on which the TEF values could be based including data from carcinogenicity studies, data on in vivo DNA adduct formation and data on formation of the reactive 1'-sulfoxy meytabolites.

A number of different methods are employed to calculate REP (or TEF) values (Haws et al. 2006), with the uncertainty in Toxic Equivalence (TEQ) estimates and in the TEF methodology being highly dependent on the exposure estimates used in the TEQ calculations. The BMD approach is suitable for the definition of TEF as it enables the estimation of equipotent doses by interpolation between applied doses, and it has been used to provide relative potency estimates for different organophosphates (Bosgra et al. 2009), for estimating equipotent doses in in vivo and in vitro genotoxicity tests (Bemis et al. 2015; Wills et al. 2015; Soeteman-Hernandez et al. 2015a; Soeteman-Hernandez et al. 2015b), and for testing if dose addition applies in chemical mixtures (Kienhuis et al. 2015). In this thesis combined risk assessment, based on either equal potencies and also based on relative potency of the different alkenylbenzenes was considered, the latter using TEF values. In an ideal situation such TEF values should be based on the endpoint under consideration, i.e. tumor formation. The carcinogenic potency of alkenylbenzenes was shown in previous studies (Miller et al. 1983; Phillips et al. 1984; Randerath et al. 1984; Zhou et al. 2007), but these studies focused on only a few of the alkenylbenzenes under study and did not provide data for myristicin and apiol that could be compared to those of safrole, estragole and myristicin to set TEF values. Therefore in the present thesis TEF values were determined using $\mathrm{BMDL}_{10}$ values obtained via read-across from safrole, but also surrogate endpoints including relative formation of the ultimate carcinogenic 1'-sulfoxy metabolite and DNA adduct formation 
upon in vivo exposure. The MOE values obtained for the combined risk assessment based on the TEQ concept did not vary much from the ones obtained when assuming equal potency. This can be ascribed to the fact that the TEF values of the alkenylbenzenes present in botanical preparations analysed vary by less than 2 -fold. Therefore it can be concluded that for a first Tier risk assessment on combined exposure to mixtures of alkenylbenzens dose addition without correction of differences in relative potencies is adequate and that only in cases where the outcome indicates the need for a refined estimate, i.e. when MOE values are around the threshold value of 10000, a TEF based approach might be needed.

\section{Banding of the MOE values and related conclusions for risk management}

MOE values obtained in the present thesis showed wide variation with values above and values below 10000 and some values even being lower than 1000. Even though the MOE approach was introduced to avoid the misleading use of apparently precise risk numbers, the threshold value of 10000 proposed to be used in discriminating whether there is a concern or not introduces a sharp cutoff value. This implies that an MOE of 10 , or one of 9000 , values that are both $<10000$ are both of concern, and one of 11000 or 100000 (both > 10000) are both of no concern, although they may indicate different levels of concern. When using an MOE approach based on the $\mathrm{BMDL}_{10}$ from an animal study, some banding systems have been proposed to aid risk communication. The Committee on Carcinogenicity of Chemicals in Food, Consumer Products and the Environment (COC) has proposed a banding system (i.e. $<10000$, may be a concern; 10000-1000000, unlikely to be a concern; and $>1000000$, highly unlikely to be a concern). This suggests some banding of the MOE, but it does not yet proposes how to interpret different values $<10000$. 
One could consider further banding of MOE cut-off values that are $<10000$ as follows: MOE $<$ 1000: Very high concern: $\mathrm{MOE}=1000-5000$ : High concern $: \mathrm{MOE}=5000-10000$ : Moderate concern.

Banding was also proposed for the so-called exposure potency index (EPI) approach, an alternative to the MOE approach proposed by Health Canada, in their Human Health Risk Assessment for Priority Substances under the Canadian Environmental Protection Act (HealthCanada 1994). The EPI is calculated as the average exposure in the population divided by the dose in experimental animals that produces a $5 \%$ incidence of tumors. The EPI can be regarded as a reciprocal of the MOE and the reciprocals of the EPI values correspond to MOE values of $<5000$ (high priority), 5000-500000 (moderate priority) and $>500000$ (low priority) (HealthCanada 1994). The biological basis and derivation of the different banding systems were not explained.

In addition to banding the value of the MOE outcome, one could also consider a new approach for banding based on the frequency of consumption, the amount consumed, and/or the content of the chemical of interest. In such a system the considerations discussed above for time-dose extrapolations could be taken into account, to correct the critical MOE value used to make the risk management decision for deviating time or dose regimens.

All together it is concluded that an internationally scientific framework to assess and refine the MOE approach, taking into account shorter than life time exposure, and models for banding of MOE values would be of use, and would improve the potential of the MOE approach for risk assessment. 


\section{Quality assurance of food supplements and botanical preparations}

Results of the present thesis revealed that food supplements and botanical preparations containing alkenylbenzenes at levels that do raise a safety concern are still freely available on the Dutch market and via the internet. This raises the issue of quality control. The guidelines for Good Agricultural and Wild Collection Practice of Medicinal and Aromatic (Culinary) plants are suggested to be applied to the growing and primary processing practices of plants and their derivatives traded and used in the European Union. Hence they apply to the production of all plant materials utilized either in a direct or processed form. They also apply to all methods of production including organic production in accordance with the European regulations. Plant raw material should meet the demands of the consumer and the standards of the highest quality. The presence and concentration of physiologically active substances in a botanical species can vary considerably depending on growth, development and chemical profile, influenced by a number of external factors such as soil quality and water properties, temperature, sunlight, the season of cultivation and time of harvesting. It is equally important that the batches of the botanical raw material undergo appropriate testing before acceptance for further processing to ensure that the concentrations of substances with known physiological effects fall within predetermined limits and allow for the natural variability of the botanical material. Accurate identification of all botanical source material selected for further processing is crucial as well. Care should be taken with the identification to avoid renaming or reclassification or switching of varieties. All participants of the production process, primary producers to traders, are required to keep the traceability of the production process. The most important information about the batch should always follow the material by a batch documentation, and Integrity of botanical material (EUROPAM 2006; FoodSupplementsEurope 2016). 
Establishment, applying and assuring a good quality system during botanical product preparation, and practicing in-house, internationally harmonized, and/or transferred valid analytical methods to characterize and to identify the bioactive compounds within these products will facilitate risk assessment and help to guarantee the quality of the final product. Integrated plans and continuous improvement through auditing, correcting and preventing non-conformities should be applied from farming to marketing.

\section{CONCLUSION}

This thesis assessed the risks of nutmeg-based PFS and basil-containing pesto sauce products that contain alkenylbenzenes using read-across through building of PBK models for two alkenylbenzenes (myristicin and apiol). This facilitated the estimation of a BMDL 10 for myristicin and apiol without the need for a rodent bioassay. These $\mathrm{BMDL}_{10}$ values and the ones derived for structurally related alkenylbenzenes directly from bioassays or via read-across were subsequently used in the risk assessment of exposure to these alkenylbenzenes via nutmeg-based PFS and basil-containing pesto sauce. The overall conclusion of the risk assessment of consumption of basil-based pesto sauce and nutmeg-based PFS revealed that daily lifetime consumption of most of these products would be a priority for risk management. On the other hand, exposure to those products for shorter periods of time will increase the MOE values to levels $>10000$ indicating a low priority for risk management. Thus, it can be concluded that the risks associated with the use of these products would be limited, provided intake is for only a few weeks during a lifetime. The thesis also provided new proofs of principle of how PBK model based approaches can facilitate novel non-animal based strategies in risk assessment contributing to the development of alternatives for animal testing. 


\section{REFERENCES}

Al-Malahmeh, A., Al-ajlouni, A. M., Wesseling, S., Vervoort, J. and Rietjens, I. M. C. M. (2017b). "Determination and risk assessment of naturally occurring genotoxic and carcinogenic alkenylbenzenes in basil-containing sauce of pesto." Toxicology Reports 4: $1-8$.

Al-Subeihi, A. A., Spenkelink, B., Punt, A., Boersma, M. G., van Bladeren, P. J. and Rietjens, I. M. C. M. (2012). "Physiologically based kinetic modeling of bioactivation and detoxification of the alkenylbenzene methyleugenol in human as compared with rat." Toxicology and applied pharmacology 260(3): 271-284. From http://www.ncbi.nlm.nih.gov/pubmed/22445790.

Al-Subeihi, A. A., Spenkelink, B., Rachmawati, N., Boersma, M. G., Punt, A., Vervoort, J., van Bladeren, P. J. and Rietjens, I. M. C. M. (2011). "Physiologically based biokinetic model of bioactivation and detoxification of the alkenylbenzene methyleugenol in rat." Toxicology in vitro : an international journal published in association with BIBRA 25(1): 267-285. from http://www.ncbi.nlm.nih.gov/pubmed/20828604.

Alajlouni, A. M., Al-Malahmeh, A. J., Isnaeni, F. N., Wesseling, S., Vervoort, J. and Rietjens, I. M. C. M. (2016b). "Level of Alkenylbenzenes in Parsley and Dill Based Teas and Associated Risk Assessment Using the Margin of Exposure Approach." Journal of agricultural and food chemistry 64(45): 8640-8646. from http://www.ncbi.nlm.nih.gov/pubmed/27771948.

Andersen, M., Clewell, H. and Krishnan, K. (1995). "Tissue dosimetry, pharmacokinetic modeling, and interspecies scaling factors." Risk Analysis 15: 533-537.

Barlow, S., Renwick, A. G., Kleiner, J., Bridges, J. W., Busk, L., Dybing, E., Edler, L., Eisenbrand, G., Fink-Gremmels, J., Knaap, A., Kroes, R., Liem, D., Muller, D. J., Page, S., Rolland, V., Schlatter, J., Tritscher, A., Tueting, W. and Wurtzen, G. (2006). "Risk assessment of substances that are both genotoxic and carcinogenic report of an International Conference organized by EFSA and WHO with support of ILSI Europe." Food and chemical toxicology : an international journal published for the British Industrial Biological Research Association 44(10): 1636-1650. from http://www.ncbi.nlm.nih.gov/pubmed/16891049. 
Barton, H., Flemming, C. and Lipscomb, J. (1996). "Evaluating human variability in chemical risk assessment: hazard identification and dose-response assessment for noncancer oral toxicity of trichloroethylene." Toxicology and Applied Pharmacology 111: 271-287.

Bemis, J., Wills, J., Bryce, S., Torous, D., Dertinger, S. and Slob, W. (2015). "Comparison of In Vitro and In Vivo Clastogenic Potency Based on Benchmark Dose Analysis of Flow Cytometric Micronucleus Data." Mutagenesis 31: 277-285.

Benford, D., Bolger, P. M., Carthew, P., Coulet, M., DiNovi, M., Leblanc, J. C., Renwick, A. G., Setzer, W., Schlatter, J., Smith, B., Slob, W., Williams, G. and Wildemann, T. (2010). "Application of the Margin of Exposure (MOE) approach to substances in food that are genotoxic and carcinogenic." Food and chemical toxicology : an international journal published for the British Industrial Biological Research Association 48 Suppl 1: S2-24. from http://www.ncbi.nlm.nih.gov/pubmed/20113851.

Bessems, J. G., Loizou, G., Krishnan, K., Clewell, H. J., 3rd, Bernasconi, C., Bois, F., Coecke, S., Collnot, E. M., Diembeck, W., Farcal, L. R., Geraets, L., Gundert-Remy, U., Kramer, N., Kusters, G., Leite, S. B., Pelkonen, O. R., Schroder, K., Testai, E., Wilk-Zasadna, I. and Zaldivar-Comenges, J. M. (2014). "PBTK modelling platforms and parameter estimation tools to enable animal-free risk assessment: recommendations from a joint EPAA--EURL ECVAM ADME workshop." Regul Toxicol Pharmacol 68(1): 119-139. from http://www.ncbi.nlm.nih.gov/pubmed/24287156.

Beyer, J., Ehlers, D. and Maurer, H. H. (2006). "Abuse of nutmeg (Myristica fragrans Houtt.): studies on the metabolism and the toxicologic detection of its ingredients elemicin, myristicin, and safrole in rat and human urine using gas chromatography/mass spectrometry." Therapeutic drug monitoring 28(4): 568-575. from http://www.ncbi.nlm.nih.gov/pubmed/16885726.

Bos, P. M. J., Baars, B. J. and van Raaij, M. T. M. (2004). "Risk assessment of peak exposure to genotoxic carcinogens: a pragmatic approach." Toxicol. Lett. 151: 43-50.

Bosgra, S., van der Voet, H., Boon, P. E. and Slob, W. (2009). "An integrated probabilistic framework for cumulative risk assessment of common mechanism chemicals in food: an example with organophosphorus pesticides." Regulatory toxicology and pharmacology : RTP 54(2): 124-133. from http://www.ncbi.nlm.nih.gov/pubmed/19303907. 
Brightman, F. A., Leahy, D. E., Searle, G. E. and S., T. (2006). "Application of a generic physiologically based pharmacokinetic model to the estimation of xenobiotic levels in rat plasma." Drug metabolism and disposition 34(1).

Brightman, F. A., Leahy, D. E., Searle, G. E. and Thomas, S. (2005). "Application of a generic physiologically based pharmacokinetic model to the estimation of xenobiotic levels in human plasma." Drug metabolism and disposition 34(1).

Callis, C. M., Bercu, J. P., DeVries, K. M., Dow, L. K., Robbins, D. K. and Varie, D. L. (2010). "Risk assessment of genotoxic impurities in marketed compounds administered over a short-term duration: applications to oncology products and implications for impurity control limits." Org. Process Res. Dev. 14: 986-992.

Chen, L., Mulder, P. P. J., Louisse, J., Peijnenburg, A., Wesseling, S. and Rietjens, I. (2017). "Risk assessment for pyrrolizidine alkaloids detected in (herbal) teas and plant food supplements." Regul Toxicol Pharmacol. 86: 292-302.

Clewell, H., Gearhart, J., Gentry, P., Covington, T., VanLandingham, C., Crump, K. and Shipp, A. (1999). " Evaluation of the uncertainty in an oral reference dose for methylmercury due to interindividual variability in pharmacokinetics." Risk Analysis 19: 547-558.

d'Yvoire, M. B., Prieto, P., Blaauboer, B. J., Bois, F. Y., Boobis, A., Brochot, C., Coecke, S., Freidig, A., Gundert-Remy, U., Hartung, T., Jacobs, M. N., Lavé, T., Leahy, D. E., H., L., Loizou, G. D., Meek, B., Pease, C., Rowland, M., Spendiff, M., Yang, J. and M., Z. (2007). "Physiologically-based Kinetic Modelling (PBK Modelling): Meeting the 3Rs Agenda. The Report and Recommendations of ECVAM Workshop 63." ATLA 35: 661671.

Doull, J. and Rozman, K. K. (2000). "Using Haber's law to define the margin of exposure." Toxicology 149(1): 1-2. from http://www.ncbi.nlm.nih.gov/pubmed/10963856.

Dourson, M., Felter, S. and Robinson, D. (1996). "Evolution of science-based uncertainty factors in noncancer risk assessment. ." Regulatory Toxicology and Pharmacology 24: 108-120.

EFSA (2005). "Opinion of the scientific committee on a request from EFSA related to a harmonized approach for risk assessment of substances which are both genotoxic and carcinogenic." European Food Safety Authority 282: 1-31. from http://onlinelibrary.wiley.com/doi/10.2903/j.efsa.2005.282/epdf 
EFSA (2009a). "Guidance on safety assessment of botanicals and botanical preparations intended for use as ingredients in food supplements." European Food Safety Authority 7(1249). from

https://www.pharmamedtechbi.com/ /media/Images/Publications/Archive/The\%20Tan\% 20Sheet/17/037/05170370014_b/090914_efsa_botanicals_guidance.pdf

EFSA (2009b). "Guidance of the Scientific Committee on Use of the benchmark dose approach in risk assessment." European Food Safety Authority 1150 1-72. from http://onlinelibrary.wiley.com/doi/10.2903/j.efsa.2009.1150/epdf

EFSA (2013). "International frameworks dealing with human risk assessment of combined exposure to multiple chemicals." (11): 3313-3382.

EPA (2000). Supplementary guidance for conducting health risk assessment of chemical mixtures. R. A. Forum. Washington, DC United States Environmental Protection Agency. EPA/630R-00/002.

EUROPAM (2006). "Guidelines for Good Agricultural and Wild Collection Practice (GACP) of Medicinal and Aromatic Plants " European Herb Growers Association, GACP Subcommittee $7(3)$.

from http://www.europam.net/documents/gacp/EUROPAM_GACP_7.3.pdf.

Felter, S. P., Conolly, R. B., Bercu, J. P., Bolger, P. M., Boobis, A. R., Bos, P. M. J., Carthew, P., Doerrer, N. G., Goodman, J. I., Harrouk, W. A., Kirkland, D. J., Lau, S. S., Llewellyn, G. C., Julian Preston, R., Schoeny, R., Schnatter, A. R., Tritscher, A., van Velsen, F. and Williams, G. M. (2011). "A proposed framework for assessing risk from less-thanlifetime exposures to carcinogens." Critical Reviews in Toxicology 41(6): 507-544. from http://dx.doi.org/10.3109/10408444.2011.552063.

FoodSupplementsEurope ( 2016). "Quality of Botanical Preparations Specific Recommendations for the Manufacturing of Botanical Preparations, Including Extracts as Food Supplements." from http://www.foodsupplementseurope.org/sites/0023/uploads/content/publications/qualityof botanicalpreparations.pdf? 1418124068 .

Garcia-Alvarez, A., Egan, B., de Klein, S., Dima, L., Maggi, F. and Isoniemi, M. (2014). "Usage of Plant Food Supplements across Six European Countries: Findings from the PlantLIBRA Consumer Survey." PLoS ONE 9(3): e92265. from 
https://doi.org/10.1371/journal.pone.0092265.

Gavin, C. L., Williams, M. C. and Hallagan, J. B. (2007). "2005 FEMA poundage and technical effects update survey."

Gundert-Remy, U. and Sonich-Mullin, C. (2002). "The use of toxicokinetic and toxicodynamic data in risk assessment: an international perspective." Science of the Total Environment 288: 3-11.

Haber, L., Maier, A., Gentry, P., Clewell, H. and Dourson, M. (2002). "Genetic polymorphisms in assessing interindividual variability in delivered dose." Regulatory Toxicology and Pharmacology 35: 177-197.

Haws, L., Su, S. and Harris, M. (2006). "Development of a refined database of mammalian relative potency estimates for dioxin-like compounds." Toxicol Sci 89(1): 4-30.

HealthCanada (1994). "Human health risk assessment for priority substances." Health Canada, Environmental Health Directorate. from http://www.hcsc.gc.ca/ewhsemt/alt_formats/hecs-sesc/pdf/pubs/contaminants/approach/approacheng.pdf.

Herrmann, K., Engst, W., Appel, K. E., Monien, B. H. and Glatt, H. (2012). "Identification of human and murine sulfotransferases able to activate hydroxylated metabolites of methyleugenol to mutagens in Salmonella typhimurium and detection of associated DNA adducts using UPLC-MS/MS methods." Mutagenesis 27(4): 453-462. from http://www.ncbi.nlm.nih.gov/pubmed/22337896.

Herrmann, K., Schumacher, F., Engst, W., Appel, K. E., Klein, K., Zanger, U. M. and Glatt, H. (2013). "Abundance of DNA adducts of methyleugenol, a rodent hepatocarcinogen, in human liver samples." Carcinogenesis 34(5): 1025-1030. from

http://www.ncbi.nlm.nih.gov/pubmed/23334163.

IPCS (2005). "Chemical-specific adjustment factors for interspecies differences and human variability: guidance document for use of data in dose/concentration-response assessment." World Health Organization, International Programme on Chemical Safety. from http://whqlibdoc.who.int/publications/2005/9241546786_eng.pdf).

Jarabek, A. (1995). "The application of dosimetry models to identify key processes and parameters for default dose-response assessment approaches." Toxicology Letters 79: 171-184. 
JECFA (2009). Safety evaluation of certain food additives-Alkoxy-substituted allylbenzenes present in foods and essential oils and used as flavouring agents. I. I. P. o. C. Safety. Geneva, World Health Organization. 60: 351-481.

Kienhuis, A., Slob, W., Gremmer, E., Vermeulen, J. and Ezendam, J. (2015). "A dose-response modelling approach shows that effects from mixture exposure to the skin sensitizers are in line with dose addition and not with synergism." Toxicological Sciences 147: 68-74.

Kobets, T., Duan, J., Brunnemann, K., Etter, S., Smith, B. and Williams, G. (2016). "Structure activity relationships for DNA damage by alkenylbenzenes in turkey egg fetal liver." Toxicological Sciences 150(2): 301-311.

Lipscomb, J. and Ohanian, E. e. (2007). "Toxicokinetics and risk assessment." Informa Healthcare, NY, USA: 361.

Martati, E., Boersma, M. G., Spenkelink, A., Khadka, D. B., Punt, A., Vervoort, J., van Bladeren, P. J. and Rietjens, I. M. C. M. (2011). "Physiologically based biokinetic (PBBK) model for safrole bioactivation and detoxification in rats." Chemical research in toxicology 24(6): 818-834. from http://www.ncbi.nlm.nih.gov/pubmed/21446753.

Martati, E., Boersma, M. G., Spenkelink, A., Khadka, D. B., van Bladeren, P. J., Rietjens, I. M. C. M. and Punt, A. (2012). "Physiologically based biokinetic (PBBK) modeling of safrole bioactivation and detoxification in humans as compared with rats." Toxicological sciences : an official journal of the Society of Toxicology 128(2): 301-316. from http://www.ncbi.nlm.nih.gov/pubmed/22588462.

Meek, M. E., Boobis, A. R., Crofton, K. M., Heinemeyer, G., Van Raaij, M. and Vickers, C. (2011). "Risk assessment of combined exposure to multiple chemicals: A WHO/IPCS framework." Regulatory Toxicology and Pharmacology 60(2): S1-S14. from $<$ Go to ISI $>: / / W O S: 000292173200001$.

Meek, M. E., Bucher, J. R., Cohen, S. M., Dellarco, V., Hill, R. N., Lehman-McKeeman, L. D., Longfellow, D. G., Pastoor, T., Seed, J. and Patton, D. E. (2003). "A framework for human relevance analysis of information on carcinogenic modes of action." Crit. Rev. Toxicol. 33: 591-653.

Miele, M., Dondero, R., Ciarallo, G. and Mazzei, M. (2001). "Methyleugenol in Ocimum basilicum L. Cv. genovese gigante." Journal of agricultural and food chemistry 49(1): 517-521. from http://www.ncbi.nlm.nih.gov/pubmed/11170620. 
Miller, E. C., Swanson, A. B., Phillips, D. H., Fletcher, T. L., Liem, A. and Miller, J. A. (1983). "Structure-activity studies of the carcinogenicities in the mouse and rat of some naturally occurring and synthetic alkenylbenzene derivatives related to safrole and estragole." Cancer research 43(3): 1124-1134. from http://www.ncbi.nlm.nih.gov/pubmed/6825084.

NTP (2000). "Toxicology and Carcinogenesis Studies of Methyleugenol (CAS NO. 93-15-2) in F344/N Rats and B6C3F1 Mice (Gavage Studies)." National Toxicology Program technical report series 491: 1-412. from http://www.ncbi.nlm.nih.gov/pubmed/12563349.

O'Brien, J., Renwick, A., Constable, A., Dybing, E., Muller, D., Schlatter, J., Slob, W., Tueting, W., Van Benthem, J., Williams, G. and Wolfreys, A. (2006). "Approaches to the risk assessment of genotoxic carcinogens in food: A critical appraisal." Food and Chemical Toxicology 44: 1613-1635.

Paini, A., Punt, A., Scholz, G., Gremaud, E., Spenkelink, B., Alink, G., Schilter, B., van Bladeren, P. J. and Rietjens, I. M. C. M. (2012). "In vivo validation of DNA adduct formation by estragole in rats predicted by physiologically based biodynamic modelling." Mutagenesis 27(6): 653-663. from http://www.ncbi.nlm.nih.gov/pubmed/22844077.

Paini, A., Punt, A., Viton, F., Scholz, G., Delatour, T., Marin-Kuan, M., Schilter, B., van Bladeren, P. J. and Rietjens, I. M. C. M. (2010). "A physiologically based biodynamic (PBBD) model for estragole DNA binding in rat liver based on in vitro kinetic data and estragole DNA adduct formation in primary hepatocytes." Toxicology and applied pharmacology 245(1): 57-66. from http://www.ncbi.nlm.nih.gov/pubmed/20144636.

Phillips, D. H., Hanawalt, P. C., Miller, J. A. and Miller, E. C. (1981). "The in vivo formation and repair of DNA adducts from 1'-hydroxysafrole." Journal of supramolecular structure $\begin{array}{llll}\text { and } & \text { cellular } & \text { biochemistry } & \text { 83-90. }\end{array}$ http://www.ncbi.nlm.nih.gov/pubmed/7299840.

Phillips, D. H., Reddy, M. V. and Randerath, K. (1984). "32P-post-labelling analysis of DNA adducts formed in the livers of animals treated with safrole, estragole and other naturallyoccurring alkenylbenzenes. II. Newborn male B6C3F1 mice." Carcinogenesis 5(12): 1623-1628. from http://www.ncbi.nlm.nih.gov/pubmed/6499113.

Pose-Juan, E., Fernandez-Cruz, T. and Simal-Gandara, J. (2016). "State of the art on public risk assessment of combined human exposure to multiple chemical contaminants." Trends in Food Science \& Technology 55: 11-28. from < Go to ISI>://WOS:000382592400002. 
Price, P., Keenan, R. and Schwab, B. (1999). "Defining the interindividual (intraspecies) uncertainty factor. Human and Ecological Risk Assessment." 5(5): 1023-1035.

Punt, A., Freidig, A. P., Delatour, T., Scholz, G., Boersma, M. G., Schilter, B., van Bladeren, P. J. and Rietjens, I. M. C. M. (2008). "A physiologically based biokinetic (PBBK) model for estragole bioactivation and detoxification in rat." Toxicology and applied pharmacology 231(2): 248-259. from http://www.ncbi.nlm.nih.gov/pubmed/18539307.

Punt, A., Paini, A., Boersma, M. G., Freidig, A. P., Delatour, T., Scholz, G., Schilter, B., van Bladeren, P. J. and Rietjens, I. M. C. M. (2009). "Use of physiologically based biokinetic (PBBK) modeling to study estragole bioactivation and detoxification in humans as compared with male rats." Toxicological sciences : an official journal of the Society of Toxicology 110(2): 255-269. from http://www.ncbi.nlm.nih.gov/pubmed/19447879.

Randerath, K., Haglund, R. E., Phillips, D. H. and Reddy, M. V. (1984). "32P-post-labelling analysis of DNA adducts formed in the livers of animals treated with safrole, estragole and other naturally-occurring alkenylbenzenes. I. Adult female CD-1 mice." Carcinogenesis 5(12): 1613-1622. from http://www.ncbi.nlm.nih.gov/pubmed/6499112.

Renwick, A. (1999). "Subdivision of uncertainty factors to allow for toxicokinetics and toxicodynamics." Human and Ecological Risk Assessment 5(5): 1035-1050.

Rietjens, I. M. C. M., Punt, A., Schilter, B., Scholz, G., Delatour, T. and van Bladeren, P. J. (2010). "In silico methods for physiologically based biokinetic models describing bioactivation and detoxification of coumarin and estragole: implications for risk assessment." Molecular nutrition \& food research 54(2): 195-207. from http://www.ncbi.nlm.nih.gov/pubmed/19943261.

Rowland, M. (1985). "Physiologic pharmacokinetic models and interanimal species scaling." Pharmacology and Therapeutics 29: 49-68.

Soeteman-Hernandez, L., Fellows, M., Johnson, G. and Slob, W. (2015b). "Correlation of in vivo versus in vitro Benchmark doses (BMDs) derived from micronucleus test data: A proof of concept study." Toxicological Sciences 147: 355-367.

Soeteman-Hernandez, L., Johnson, G. and Slob, W. (2015a). "Estimating the carcinogenic potency of chemicals from the in vivo micronucleus test." Mutagenesis, 31: 347-358.

Van den Berg, S. J., Punt, A., Soffers, A. E., Vervoort, J., Ngeleja, S., Spenkelink, B. and Rietjens, I. M. C. M. (2012). "Physiologically based kinetic models for the 
alkenylbenzene elemicin in rat and human and possible implications for risk assessment." Chemical research in toxicology 25(11): 2352-2367. from http://www.ncbi.nlm.nih.gov/pubmed/22992039.

van den Berg, S. J. P. L., Punt, A., Soffers, A. E., Vervoort, J., Ngeleja, S., Spenkelink, B. and Rietjens, I. M. C. M. (2012). "Physiologically based kinetic models for the alkenylbenzene elemicin in rat and human and possible implications for risk assessment." Chemical research in toxicology 25(11): 2352-2367. from http://www.ncbi.nlm.nih.gov/pubmed/22992039.

van den Berg, S. J. P. L., Restani, P., Boersma, M., Delmulle, L. and Rietjens, I. M. C. M. (2011). "Levels of genotoxic and carcinogenic ingredients in plant food supplements and associated risk assessment." Food and Nutrition Sciences 2(9): 989-1010.

Wills, J., Johnson, G., Doak, S., Soeteman-Hernandez, L., Slob, W., White, P. and . (2015). "Empirical analysis of BMD metrics in genetic toxicology. Part I: In vitro analyses to provide robust potency rankings." Mutagenesis, 31: 255-263.

Wiseman, R. W., Fennell, T. R., Miller, J. A. and Miller, E. C. (1985). "Further characterization of the DNA adducts formed by electrophilic esters of the hepatocarcinogens 1'hydroxysafrole and 1'-hydroxyestragole in vitro and in mouse liver in vivo, including new adducts at C-8 and N-7 of guanine residues." Cancer research 45(7): 3096-3105. from http://www.ncbi.nlm.nih.gov/pubmed/4005847.

Zhou, G.-D., Moorthy, B., Bi, J., Donnelly, K. C. and Randerath, K. (2007). "DNA adducts from alkoxyallylbenzene herb and spice constituents in cultured human (HepG2) cells." Environmental and Molecular Mutagenesis 48(9): 715-721. From http://dx.doi.org/10.1002/em.20348. 


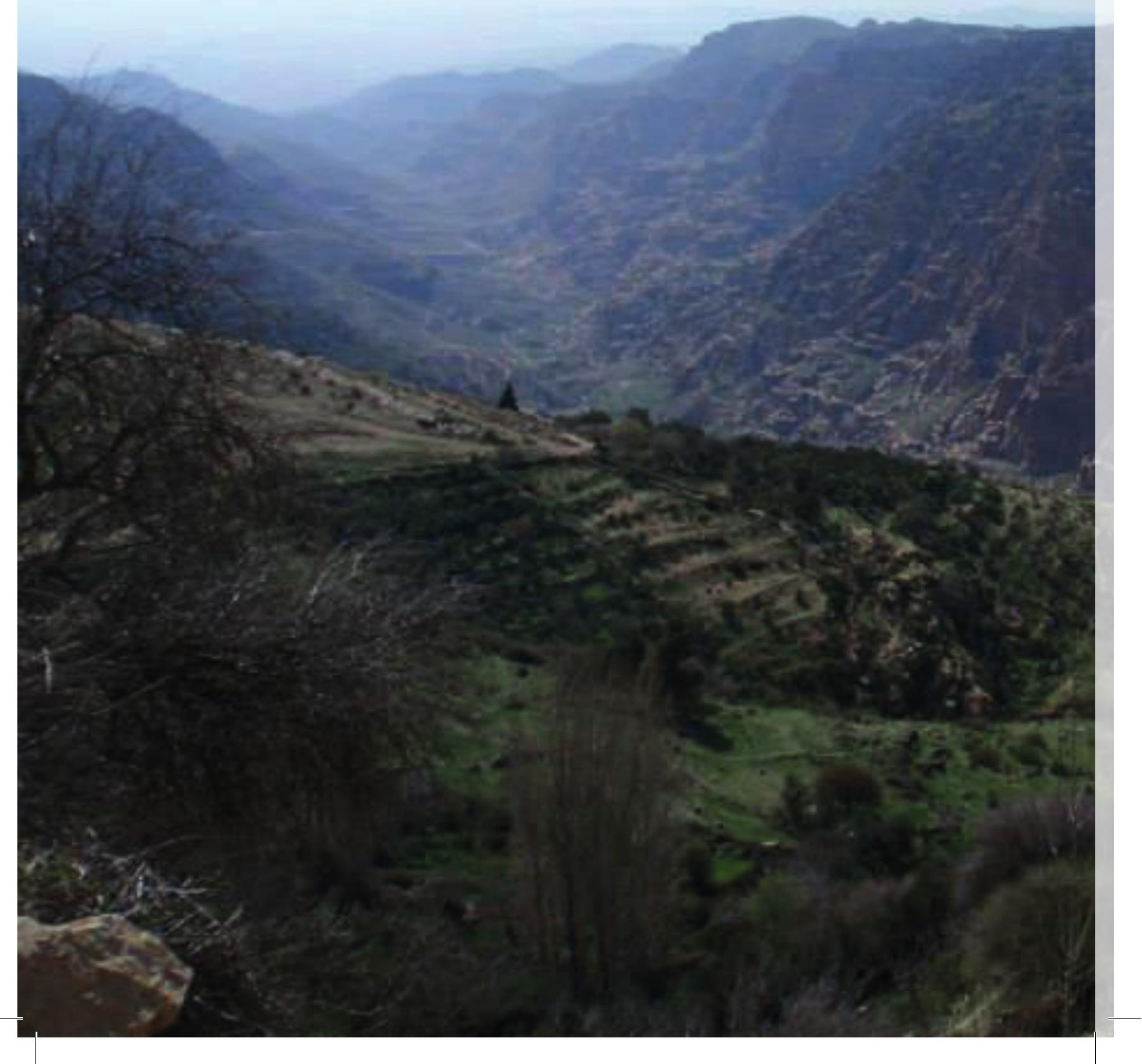




\section{Chapter 7}

Summary 
Botanicals and botanical preparations have become widely available on the market in the form of food supplements and other food preparations. In Europe the safety of botanicals and derived food products placed on the market has to comply with the general requirements set out in regulation (EC) No 178/2002. In spite of this regulation, the risks of botanicals and botanical preparations are generally not assessed before they enter the market.

The present thesis aimed to perform a risk assessment of some selected botanicals and derived preparations focusing on samples containing the so-called alkenylbenzenes, including myristicin, apiol, safrole, methyleugenol, elemicin, and estragole. Samples containing alkenylbenzenes may be of concern because these compounds may be genotoxic and carcinogenic displaying similar characteristics regarding mode of action (MOA) and tumor formation. The aim of the present study was to develop a MOA based approach for read-across in risk assessment from safrole, for which in vivo toxicity studies are available to myristicin and apiol for which tumor data are not reported, thus contributing to alternatives in animal testing. This was done using physiologically based kinetic (PBK) modelling. Botanical preparations included in the risk assessments performed in the present thesis were basil-containing pesto and nutmeg-based plant food supplements (PFS). Given that several of the preparations analyzed contained several alkenylbenzenes a risk assessment of combined exposure to these alkenylbenzenes was included as well, to give a better understanding of when risk management actions would be needed for botanicals and derived preparations containing these ingredients.

The introduction chapter starts with a short background and definition of the aim of the thesis, followed by a description of the physicochemical properties, natural occurrence and estimated daily intake (EDI) of the alkenylbenzenes, as well as of their ADME (absorption, distribution, metabolism and excretion) characteristics, carcinogenicity and MOA, the relevant risk assessment approach, and finally PBK modelling. 
Chapter 2 and 3 of the thesis describe the development of PBK models for myristicin and apiol in male rat and human, enabling the prediction of dose-dependent effects in bioactivation and detoxification of these alkenylbenzenes. This allows comparison of the PBK model-based prediction of bioactivation of myristicin or apiol to the PBK model-based predictions for bioactivation of the structurally related compound safrole, enabling estimation of a $\mathrm{BMDL}_{10}$ for myristicin and apiol from read-across to the $\mathrm{BMDL}_{10}$ available for safrole, thereby facilitating risk assessment of current dietary exposure to myristicin or apiol. The results from PBK analysis support that risk assessment of myristicin may be based on the $\mathrm{BMDL}_{10}$ derived for safrole, and that risk assessment of apiol may be performed using a $\mathrm{BMDL}_{10}$ value of 3 times the $\mathrm{BMDL}_{10}$ for safrole. These results enabled a preliminary risk assessment of current exposure to these alkenylbenzenes showing that the current exposure to myristicin results in MOE values indicating a priority for risk management (Chapter 2), while current exposure to apiol does not raise a concern (Chapter 3). The results obtained illustrate that PBK modeling can facilitate a read-across in risk assessment from a compound for which in vivo toxicity studies are available to a related compound for which tumor data are not reported, thus contributing to alternatives in animal testing.

Subsequently, in Chapter 4 the BMDL $_{10}$ values obtained were used to perform a risk assessment for alkenylbenzenes in basil-based pesto sauce. To this end the levels of methyleugenol and other alkenylbenzenes in basil-containing sauce of pesto were quantified enabling an associated risk assessment based on the MOE approach, taking into consideration the possible combined exposure to different alkenylbenzenes and the $\mathrm{BMDL}_{10}$ values as defined in literature and in chapter 2 and 3 of the thesis. The MOE values obtained generally indicated a priority for risk management when assuming daily consumption of basil-based pesto sauce. It was concluded that 
consumption of pesto sauces would be of concern if consumed on a daily basis over longer periods of time.

Chapter 5 evaluates the risk of exposure to myristicin and related alkenylbenzenes through human exposure to nutmeg-based PFS based on the MOE approach. Chemical analysis of various PFS samples was performed and the amount of alkenylbenzenes that would be consumed through consumption of these nutmeg-based PFS where quantified. MOE values where calculated for the individual alkenylbenzenes as well as taking into account the presence of more than one alkenylbenzenes within selected PFS samples. It was concluded that the results reveal that daily nutmeg-based PFS consumption following recommendations for daily intake for especially longer periods of time would raise a concern.

Chapter 6 summarizes the results obtained in the thesis, compiles the overall discussion and presents the future perspectives that follow from the results obtained. 


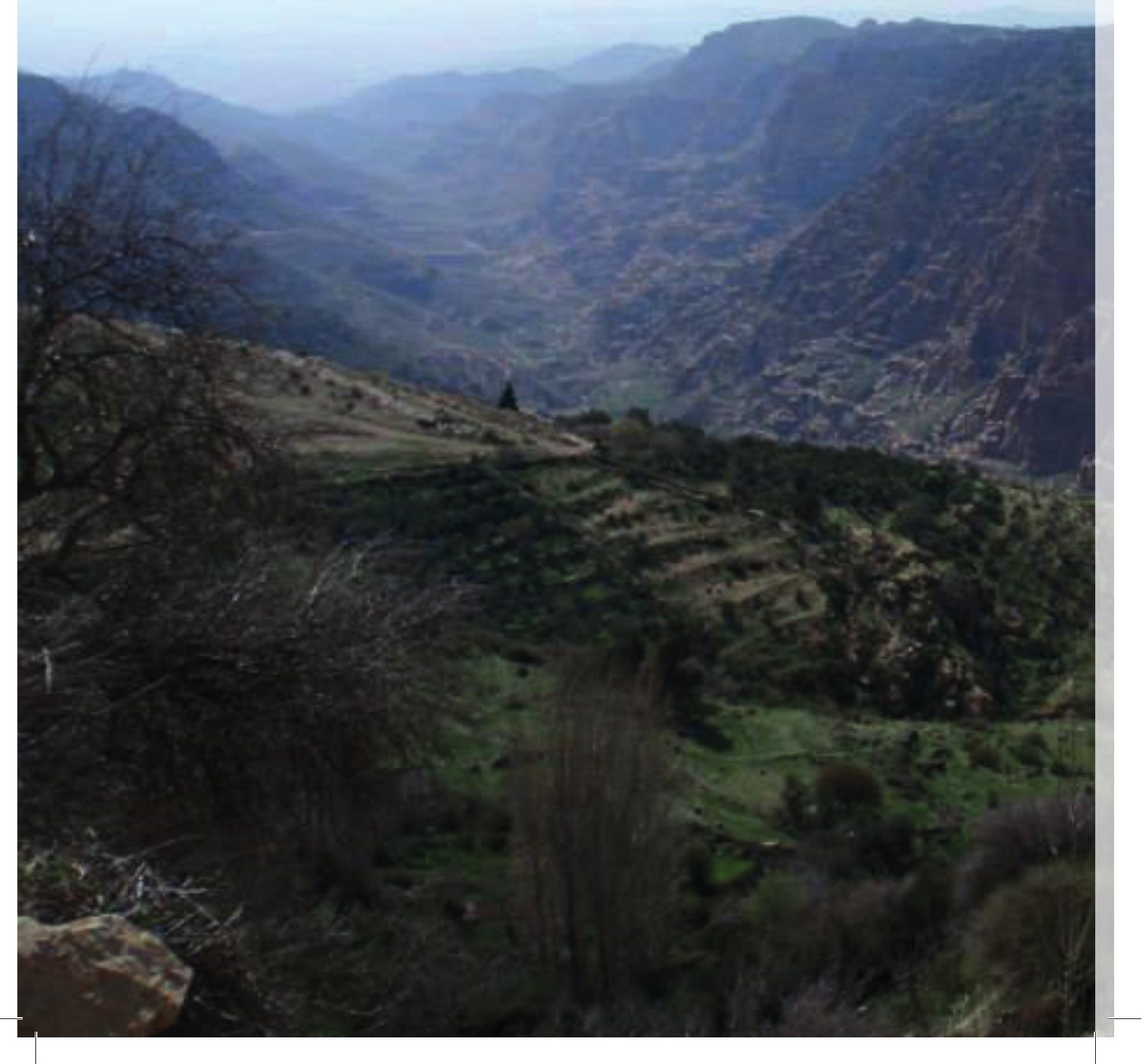




\section{Appendices}

Acknowledgements Curriculum vitae List of publications Overview of training activities 


\section{Acknowledgments}

I would like to acknowledge Dr. Ala' Al-Subeihi, Aqaba Special Economic Zone Authority (ASEZA)/BENHAYYAN, and the Jordanian government represented by the Civil Service Bureau for the initiation of the project of Botanicals Risk Assessment (BRAMA), under the umbrella of the European Neighbourhood and Partnership Instrument Cross Border Cooperation in the Mediterranean (ENPI-CBCMED).

Abdelmajeed Al-Ajlouni for being a good friend, a scientist, and a fun-to-be with person. Life simply became easier having him around.

Professor Jacques Vervoort: for his wisdom, diplomacy, providing logistics and technical advice and support, and for being a leader of the project having things done appropriately.

prof.dr.ir. IMCM (Ivonne) Rietjens, who I consider a great person in dusting potentials off, building capacities, and shaping the scientific and professional character by her leadership. Professor Ivonne has deep understanding and efficient and practical way of leading in academia; she keeps her students focused and motivated. Professor Ivonne manages approaches and measuring performances accurately, she takes care of every tiny detail, leaving no chance for mistakes. Thanks you for making a better person out of me.

WUR: Words don't come easy to describe Toxicology department of Wageningen University, I would like to thank every single person, without naming, starting with the administrative secretariat, research technicians, researchers and associate professors, $\mathrm{PhD}$ candidates and students, Master and Bachelor students, cleaning ladies, people providing coffee, WUR help desk, and utilities support people.

Financial support from the SOIT foundation (The foundation for Stimulation of Innovation in Toxicology). 
Georgia Papadi, Jia Jing, Aziza Hussein Bakheit Adam and Ignacio Miro Estruch for helping in graduation arrangement.

The University of Ioannina who gave a huge push for an efficient start of the project with the training courses they have provided at the University campus, and the un-forgettable memories the beautiful Mediterranean country and its friendly people.

My Parents, Jamil and Feryal, they were very patient and supportive while me being away. Being there for me whenever needed, thanks to you and to my brothers and sisters, Rania, Ghadeer, Nisreen, Mohammad, and Mustafa.

Joanna, Yahya, and Kinan, you have been very tolerant with me, I spent too much time away from you to complete my $\mathrm{PhD}$ tasks. Thank you for everything, Love you honey and the kids much.

Urve Liiv, my mother in law, thanks for making our stay in Estonia as easy and affordable as possible. Dear Urve, the differences between us have enriched and deepened our relationship and made it stronger.

I highly appreciate the Excellence in Analytical Chemistry (EACH) program represented by the University of Tartu, Estonia, more specifically professor Ivo Leito and Ms. Anu Teearu, for giving me the chance to challenge my knowledge in the $\mathrm{PhD}$ topic, teaching the course of Risk Assessment of Chemicals in Food at Chemicum, Tartu.

Highly appreciate as well, the university of Tartu and Technical University of Tallinn for facilitating a nice environment for me to do my $\mathrm{PhD}$ tasks at their nice libraries.

Thank you all! 


\section{Curriculum Vitae}

Amer Al-Malahmeh was born, raised, and grown up in Amman-Jordan. He has graduated from the Chemistry department at the University of Jordan holding a Bachelor Degree in Chemistry, he has been working in different industries, i.e. in utilities maintenance services, carbonated beverages, industrial research, Feed and Fertilizer industry, and Food and Environment Health, Safety, and Quality Laboratories. Meanwhile, he has attended many seminars, training courses, and Associate programs organized locally in Jordan, regionally, and internationally. Those building capacities events were mostly related to quality assurance and technical-oriented issues. 2011, he made a step up to a higher education in the field of measurement Science in Chemistry and earned his Euro-Master degree 2013 from the University of Tartu-Estonia. Afterward, he worked, as a freelancer, with Jordanian accreditation system and European Commission Joint Research Center (IRMM) as a technical Expert and Trainer on Chemistry Laboratories Fit-ForPurpose Quality Requirements, respectively. He has promoted and facilitated as well a technical support from the Organization for the Prohibition of Chemical Weapons to Aqaba Special Economic Zone Authority (ASEZA) to help in making world using chemistry in peace and having the world free of chemical weapons. He participated in many non-formal education and youth activities across the Mediterranean region bridging the gap between cultures and enhancing mutual understanding. Late 2013, Dr. Ala' Al-Subeihi, one of his colleagues at ASEZA, introduced him to the project of Botanicals Risk Assessment (BRAMA), under the umbrella of the European Neighborhood and Partnership Instrument Cross Border Cooperation in the Mediterranean (ENPI-CBCMED). The BRAMA project promotes for a $\mathrm{PhD}$ for a group of researchers regarding risk assessment of botanicals, and guide them to official recognition through the highest European standards (registration as European toxicologists). During his $\mathrm{PhD}$, 
he followed a number of postgraduate courses in toxicology required for registration as a toxicologist with the Netherlands Society of Toxicology and attended conference of 3R's Denmark Symposium.

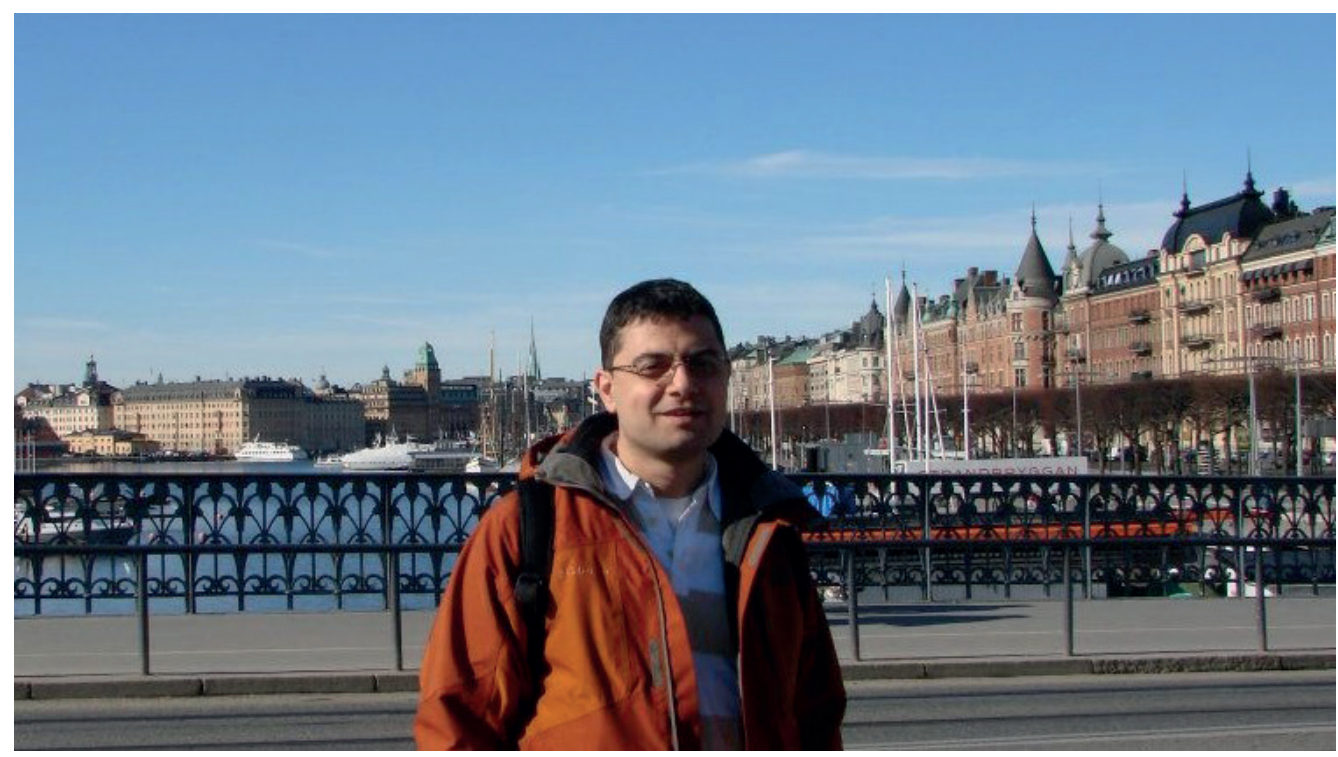




\section{List of publications}

Al-Malahmeh, A. J., A. M. Alajlouni, J. Ning, S. Wesseling, J. Vervoort and I. M. C. M. Ivonne (2017c). "Determination and risk assessment of naturally occurring genotoxic and carcinogenic alkenylbenzenes in nutmeg-based plant food supplements." J. Appl. Toxicol.

Al-Malahmeh, A., A. M. Al-ajlouni, S. Wesseling, J. Vervoort and I. M. C. M. Rietjens (2017b). "Determination and risk assessment of naturally occurring genotoxic and carcinogenic alkenylbenzenes in basil-containing sauce of pesto." Toxicology Reports 4: 1-8.

Al-Malahmeh, A. J., A. M. Alajlouni, S. Wesseling, A. E. Soffers, A. Al-Subeihi, R. Kiwamoto, J. Vervoort and I. M. C. M. Rietjens (2017a). "Physiologically based kinetic modeling of the bioactivation of myristicin." Archives of toxicology 91(2): 713-734. from http://www.ncbi.nlm.nih.gov/pubmed/27334372.

Alajlouni, A. M., A. J. Al-Malahmeh, M. Kallib, S. Wesseling, J. Vervoort and R. I. M.C.M. (2017). "Risk assessment of combined exposure to alkenylbenzenes through consumption of plant food supplements containing parsley and dill." Journal Food Additives \& Contaminants: Part A.

Alajlouni, A. M., A. J. Al-Malahmeh, F. N. Isnaeni, S. Wesseling, J. Vervoort and I. M. C. M. Rietjens (2016b). "Level of Alkenylbenzenes in Parsley and Dill Based Teas and Associated Risk Assessment Using the Margin of Exposure Approach." Journal of agricultural and food chemistry 64(45): 8640-8646. from http://www.ncbi.nlm.nih.gov/pubmed/27771948.

Alajlouni, A. M., A. J. Al Malahmeh, R. Kiwamoto, S. Wesseling, A. E. Soffers, A. A. AlSubeihi, J. Vervoort and I. M. C. M. Rietjens (2016a). "Mode of action based risk assessment of the botanical food-borne alkenylbenzene apiol from parsley using physiologically based kinetic (PBK) modelling and read-across from safrole." Food and chemical toxicology : an international journal published for the British Industrial Biological Research Association 89: 138-150. from http://www.ncbi.nlm.nih.gov/pubmed/26826679.

Suursoo, S., M. Kiisk, A. Al-Malahmeh, A. Jantsikene, K. Putk and L. Lumiste (2014). "226Ra measurement by LSC as a tool to assess the efficiency of a water treatment technology for removing radionuclides from groundwater." Appl Radiat Isot. 93: 57 - 63. 


\section{Overview of completed training activities}

Discipline specific activities:

International symposium (2015)

Molecular toxicology (2014)

Cell toxicology (2014)

Organ toxicology (2015)

Epidemiology (2014)

Ecotoxicology (2014)

Laboratory animal science (2014)

Pathobiology (2014)

Risk assessment (2014)

Immunotoxicology (2014)

Medical and Forensic (2014)

General Courses:

VLAG PhD week (2014)

PhD competence assessment (2014)

$\mathrm{PhD}$ symposium (2015)

Analytical chemistry skills (2014)

Measurement science and statistics (2014)

Optional:

Preparation of research proposal

General toxicology

Attending scientific presentation at toxicology

PBK modelling

Approved by the graduate school VLAG 


\section{Funding}

This publication has been produced with the financial assistance of the European Union under the ENPI CBC Mediterranean Sea Basin Programme. The contents of this document are the sole responsibility of ASEZA and can under no circumstances be regarded as reflecting the position of the European Union or of the programme's management structures. BRAMA (Botanicals Risk Assessment Training in the Mediterranean Area) project I.B/4.1/257. This report does not necessarily reflect the Commission views or its future policy on this area.

Financial support from Wageningen University for printing this thesis is gratefully acknowledged.

Printing: Digiforce Print \& Logistics

Amer Al-Malahmeh, 2017 